Portland State University

PDXScholar

Master of Environmental Management Project

Reports

Environmental Science and Management

Summer 2018

\title{
Waste Stream and Green Purchasing Analysis at Bonneville Lock and Dam
}

Alexander Bienko

Portland State University

Follow this and additional works at: https://pdxscholar.library.pdx.edu/mem_gradprojects

Part of the Environmental Health and Protection Commons, Environmental Studies Commons, and the Sustainability Commons

Let us know how access to this document benefits you.

\section{Recommended Citation}

Bienko, Alexander, "Waste Stream and Green Purchasing Analysis at Bonneville Lock and Dam" (2018).

Master of Environmental Management Project Reports. 30.

https://pdxscholar.library.pdx.edu/mem_gradprojects/30

https://doi.org/10.15760/mem.2

This Project is brought to you for free and open access. It has been accepted for inclusion in Master of Environmental Management Project Reports by an authorized administrator of PDXScholar. Please contact us if we can make this document more accessible: pdxscholar@pdx.edu. 
Waste Stream and Green Purchasing Analysis at Bonneville Lock and Dam

\author{
Project Lead: \\ Alexander Bienko \\ Portland State University \\ Environmental Science and Management \\ Professional Science Masters \\ Committee Members: \\ Joseph Maser \\ Eugene Foster \\ United States Army Corps of Engineers: \\ Kenneth Duncan \\ Melissa McBain
}

Date:

23 AUG 2018 


\section{Table of Contents}

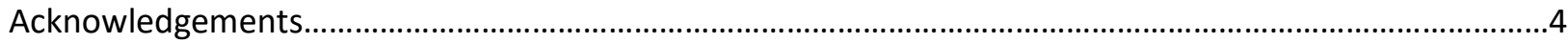

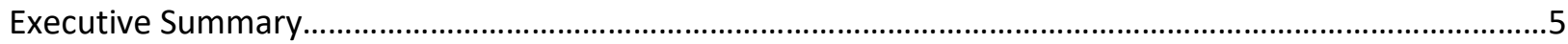

Introduction

Waste Stream Analysis

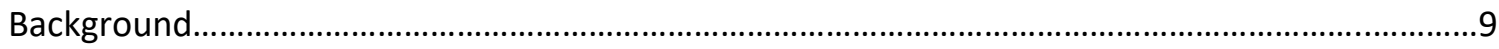

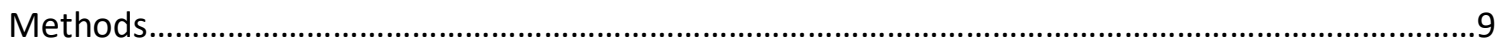

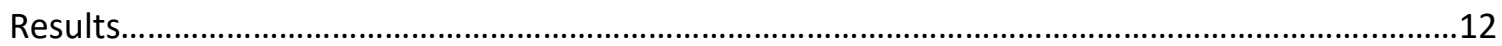

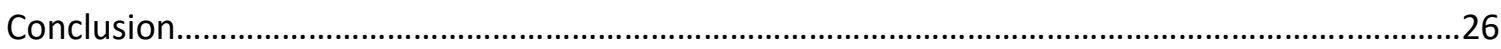

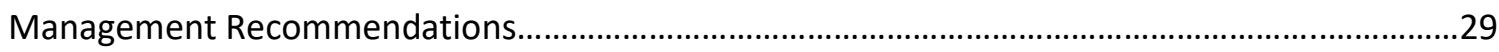

Recommendations for Future Waste Stream Audits.....................................................................31

Green Purchasing Analysis

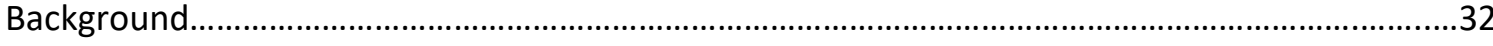

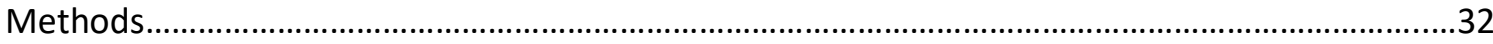

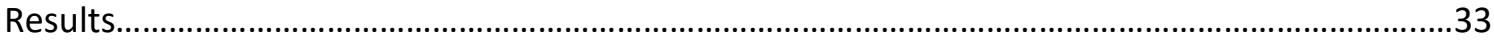

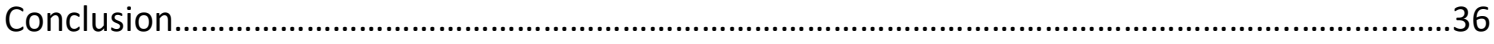

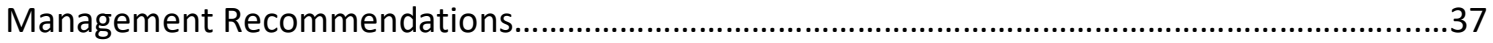

Study Conclusion

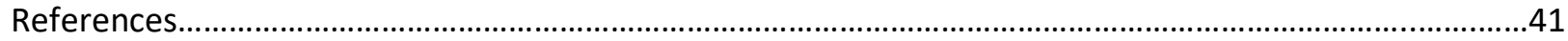

Appendices

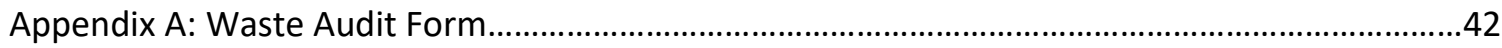

Appendix B: Kernel Density Maps for Recycling and Refuse Sort Categories

Distribution of Waste Material for Category Corrugated Cardboard..................................43

Distribution of Waste Material for Category Glass Bottles and Jars..................................44

Distribution of Waste Material for Category Milk Cartons and Juice Boxes......................45 
Distribution of Waste Material for Category Tin, Metal, and Aluminum Cans. .46

Distribution of Waste Material for Category Recyclable Mixed Paper and Newspaper..47

Distribution of Waste Material for Category Recyclable Plastic Bottles and Tubs.............48

Distribution of Waste Material for Category Recyclable Scrap Metal..................................49

Distribution of Waste Material for Category Soiled Cloth....................................................50

Distribution of Waste Material for Category Block Foam....................................................51

Distribution of Waste Material for Category Food Scraps...............................................52

Distribution of Waste Material for Category Food Soiled Paper........................................53

Distribution of Waste Material for Category Non-Recyclable Paper..................................54

Distribution of Waste Material for Category Non-Recyclable Plastic Bags, Film,

Containers, and Tubs. .55

Distribution of Waste Material for Category Wood, Yard, and Natural River Waste......56

Distribution of Waste Material for Category Other..........................................................57

Appendix C: Raw Data for Waste Stream Analysis......................................................................58

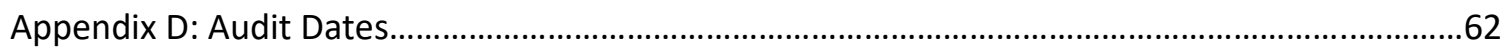

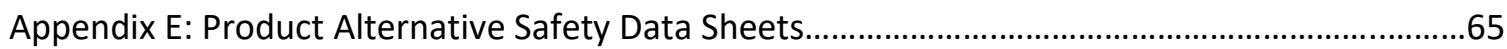




\section{Acknowledgements:}

I would like to thank my advisor Dr. Joseph Maser for his insight and support throughout this project. I would not have had the opportunity to work on this project without him.

I would like to thank my committee member Dr. Eugene Foster for his time to be on my committee and his comments in reviewing this report.

Special thanks to my supervisor at the Bonneville Project, Melissa McBain, for her support throughout the project. I could not have asked a better supervisor to work with.

I would also like to thank Kenneth Duncan who made this project possible and all the Bonneville project personnel who had to contend with me digging through their trash for the better part of the year.

A shout out to Amy, Britta, Bryn, and Dorothy for having me work in their office and the moral support they gave me to complete this project.

I would also like to thank my friends and family for all their support throughout this project. I would not have arrived at this point without them. 


\section{Executive Summary:}

The United States Army Corps of Engineers, Portland District, directed the Bonneville Lock and Dam to conduct a waste stream and green purchasing analysis of their operation. The results gained from the analyses is used to find reduction strategies of non-hazardous refuse waste heading to the landfill and incorporate strategies to increase the acquisition of sustainable products. In order to find the best nonhazardous refuse waste reduction strategies, a waste audit was conducted over a period of approximately eight months to characterize the type and amount of waste being generated. The results of the waste audit for the Bonneville Project are summarized in the following table:

Table 1: Describes the summary for non-hazardous waste type and container, the designated area for waste collection, the approximate annual sum weight total of recycling waste in recycling containers and refuse waste in refuse containers per designated area, the approximate annual sum weight total for recycling or refuse material found in refuse or recycling waste respectively, the approximate annual sum for recycling waste generation, the approximate annual sum for refuse waste generation, and the approximate annual sum of overall waste generation for the entire Bonneville Project. All weights are in pounds.

\begin{tabular}{|c|c|c|c|c|}
\hline $\begin{array}{c}\text { Waste/Container } \\
\text { Type }\end{array}$ & Designated Area & $\begin{array}{l}\text { Annual Waste } \\
\text { Weight Total }\end{array}$ & $\begin{array}{c}\text { Annual Recycling } \\
\text { Weight Total }\end{array}$ & $\begin{array}{c}\text { Annual Refuse } \\
\text { Weight Total }\end{array}$ \\
\hline Recycling & \multirow{2}{*}{ Auditorium } & 767.00 & 757.25 & 9.75 \\
\hline Refuse & & $2,475.20$ & 416.00 & $2,059.20$ \\
\hline Recycling & \multirow{2}{*}{ Warehouse } & $3,149.25$ & $2,955.33$ & 193.92 \\
\hline Refuse & & $13,609.38$ & $1,610.38$ & $11,999.00$ \\
\hline Recycling & \multirow{2}{*}{ Powerhouse 1} & $1,484.17$ & $1,432.17$ & 52.00 \\
\hline Refuse & & $12,119.25$ & $1,940.25$ & $10,179.00$ \\
\hline Recycling & \multirow{2}{*}{ Service Building } & $4,383.60$ & $4,243.20$ & 140.40 \\
\hline Refuse & & $20,084.26$ & 288.39 & $17,198.87$ \\
\hline Recycling & \multirow{2}{*}{ Powerhouse 2} & $1,029.00$ & 857.00 & 172.00 \\
\hline Refuse & & $2,755.24$ & 365.02 & $2,390.22$ \\
\hline Refuse & Adult Fish Facility & $1,187.33$ & 147.33 & $1,040.00$ \\
\hline Recycling & \multirow{2}{*}{$\begin{array}{c}\text { Juvenile Fish } \\
\text { Facility }\end{array}$} & 703.20 & 685.20 & 18.00 \\
\hline Refuse & & $1,476.80$ & 57.20 & $1,419.60$ \\
\hline Recycling Sum & \multirow{3}{*}{$\begin{array}{l}\text { Designated Areas } \\
\text { Combined }\end{array}$} & $11,516.22$ & & \\
\hline Refuse Sum & & $53,707.46$ & & \\
\hline Site Total Sum & & $65,223.68$ & & \\
\hline
\end{tabular}

This leads to the approximate waste generation at the Bonneville Project at 11,516 pounds and 53,707 pounds of non-hazardous recycling and non-hazardous refuse waste annually respectively for an approximate sum of all non-hazardous waste generation at 65,223 pounds as shown in Table 1 . For recycling waste in recycling containers, the sort category Corrugated Cardboard (CCB) was the largest, making up approximately $44 \%$ or 5,012 pounds across the Bonneville Project with the sort category Recyclable Mixed paper and Newspaper (RPa) the second largest, making up approximately 35\% or 
4,034 pounds. These two categories made up approximately $79 \%$ of recycling waste in recycling containers for the entire Bonneville Project over the audit period. For refuse waste in refuse containers, the sort category Other (O) was the largest, making up approximately $29 \%$ or 15,490 pounds with the sort category Wood, Yard, and Natural River Waste (W) the second largest, making up approximately $20 \%$ or 10,906 . These two categories made up approximately $49 \%$ of refuse waste in refuse containers for the entire Bonneville Project.

With a plan to reduce non-hazardous waste generation heading to the landfill by $50 \%{ }^{[4]}$, the Bonneville Project has an ambitious goal to meet. Recommendations to reach that goal such as, reducing single use non-recyclable paper products, looking into reuse or donation opportunities for wooden items and old tools, reducing the amount of non-hazardous recycling waste ending up in non-hazardous refuse waste, and investigate implementing composting services for food and grounds maintenance waste are just a few steps management can take for the Bonneville Project to reach their goal.

In an effort to increase the amount of sustainable acquisition at the Bonneville Project, there are a few opportunities that site personnel can do. With approximately 800 unique chemical products on site, the opportunity to incorporate green chemical products is potentially high. With green products becoming increasingly more common, there are ways for the Bonneville Project to incorporate ways to increase the use of such products on site. There are several ecolabels that companies can apply and certify their products for that incorporate standardized test methods and restrictions on chemical formulations such as USEPA Safer Choice, SCAQMD, GreenGuard, and USDA BioBased product. The organizations that certify green products also maintain a searchable database on the organization's website, which serves to be an efficient means to compile a list of green products by product type. Prioritizing products with these labels for purchase and use can potentially reduce the exposure of harmful chemicals on site. As a way to reduce waste and incorporate green chemical products, utilizing reusable application devices can aid in both waste reduction goals and increasing green product acquisition. Replacing conventional paints used on site with super-compliant type paints can be used to minimize VOC emissions. Some suitable green product alternatives investigated in this study were less expensive than the currently used conventional products. Many challenges lie ahead in further incorporating green products over conventional products already in use, such as resistance from Project personnel in adopting green products, but in doing so, can potentially reduce the risk of exposure of harmful chemicals to the environment and site personnel while also supporting a newer market of green goods.

The significance of the Bonneville Project lends it to be vigilant in its use of chemical products and reduction of non-hazardous waste. With the results and recommendations of this study, the Bonneville Project and the USACE will hopefully have gained significant insight into the waste stream to enable them to implement management strategies to reduce their contribution to local landfills, and to increase the use of green chemical products. 


\section{Introduction:}

The United States Army Corps of Engineers (USACE), Portland District, has jurisdiction on three locks and four dams in the Columbia River basin. These sites "contribute to a water resource management system that provides flood risk management, power generation, water quality improvement, fish and wildlife habitat and recreation on the Columbia River and some of its tributaries" [6]. The Bonneville Lock and Dam (Bonneville Project) site lies on the Columbia River approximately 40 miles east from Portland, Oregon (Figure 1 and Figure 2). Portions of the site have been declared a National Historic Landmark, from its origins in President Franklin D. Roosevelt's New Deal program from the Public Works Administration project. The spillway, first powerhouse, and navigation lock were completed in 1938 with the second powerhouse completed in 1981 and a larger navigation lock completed in 1993 (Figure 2). With its location on the Columbia River, the Bonneville Project also incorporates fish passages that allow Chinook salmon, Steelhead, and other fish species access to their historical habitat in the upper Columbia River Basin ${ }^{[6]}$. The important location of the Bonneville Project, due to its proximity to Portland, Oregon and being situated on the Columbia River, lends the site to be vigilant of its use of chemicals that could negatively impact the surrounding area and the lower Columbia River.

While hazardous waste is thoroughly documented and labeled according to Bonneville Project's Waste Management Program to ensure compliance with 40 CFR Parts 260 through 279 of the Resource Conservation and Recovery Act, characterization and approximate amount produced of non-hazardous waste is not known, and is one of the major focuses of this project. In the October 2016 to September 2017 fiscal year, USACE at Bonneville Project was directed to look into reducing their non-hazardous solid waste by $50 \%$, construction and demolition (C\&D) solid waste by $60 \%$, and expand their environmentally preferable purchasing program to increase sustainability ${ }^{[4]}$. With an emphasis on the Integrated Solid Waste Management program focusing on sustainable acquisition and incorporating a variety of diversion techniques to minimize the landfilling of solid waste, the need to understand the waste characterization and chemical use at Bonneville Project is needed. The characterization of nonhazardous waste is also needed to ensure compliance with USACE environmental compliance assessment program, which is incorporating compliance requirements from USACE Non-Hazardous Solid Waste Diversion and Materials Management Policy ${ }^{[4]}$. With the added focus on sustainable acquisition and the location of the Bonneville Project on an ecologically important area, considering and potentially incorporating chemical products that are less harmful to the surrounding environment take on an added importance.

This project has two main objectives. The first objective of this project is to analyze the waste stream of the Bonneville Project to enable management to look at possible ways to reduce their non-hazardous solid waste by $50 \%$ and to establish conformance to USACE Non-Hazardous Solid Waste Diversion and Materials Management Policy ${ }^{[4]}$. The second objective of this project is to conduct a green purchasing analysis with a focus on chemical products used at the Bonneville Project in order to potentially incorporate chemical products that are less harmful to the environment when used and to reduce the overall chemical count onsite. 


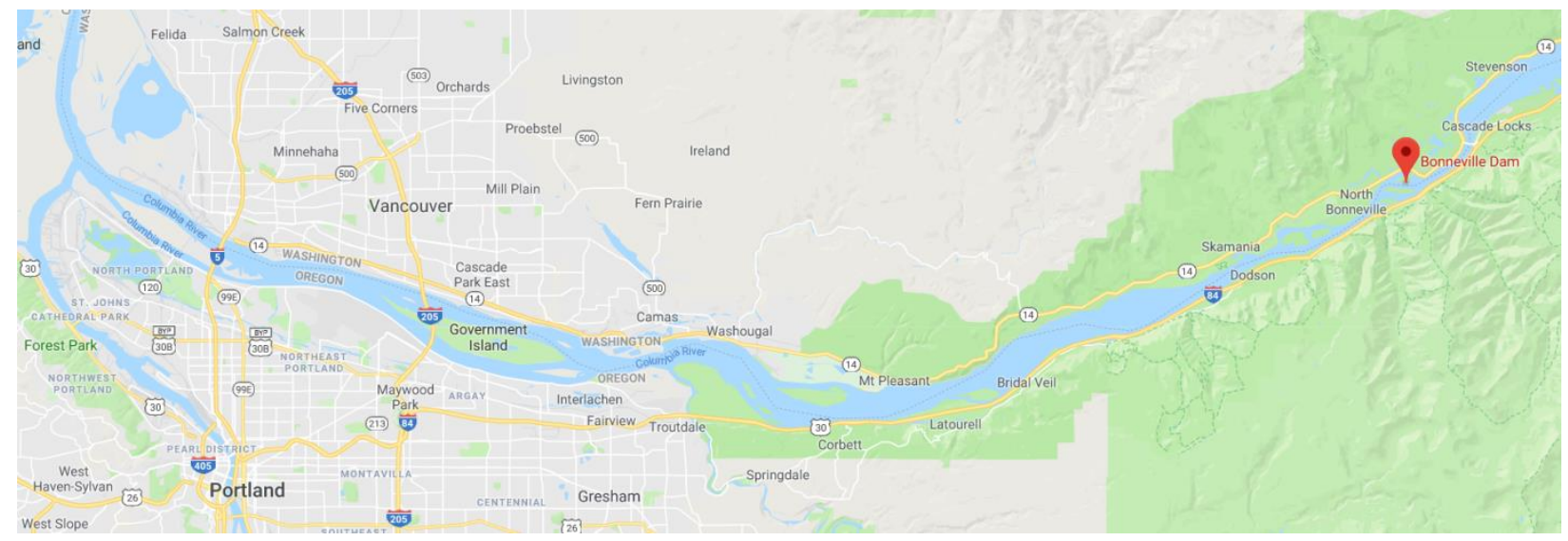

Figure 1: Map of northern Oregon with the locations of Portland, Oregon and USACE Bonneville Lock and Dam highlighted.

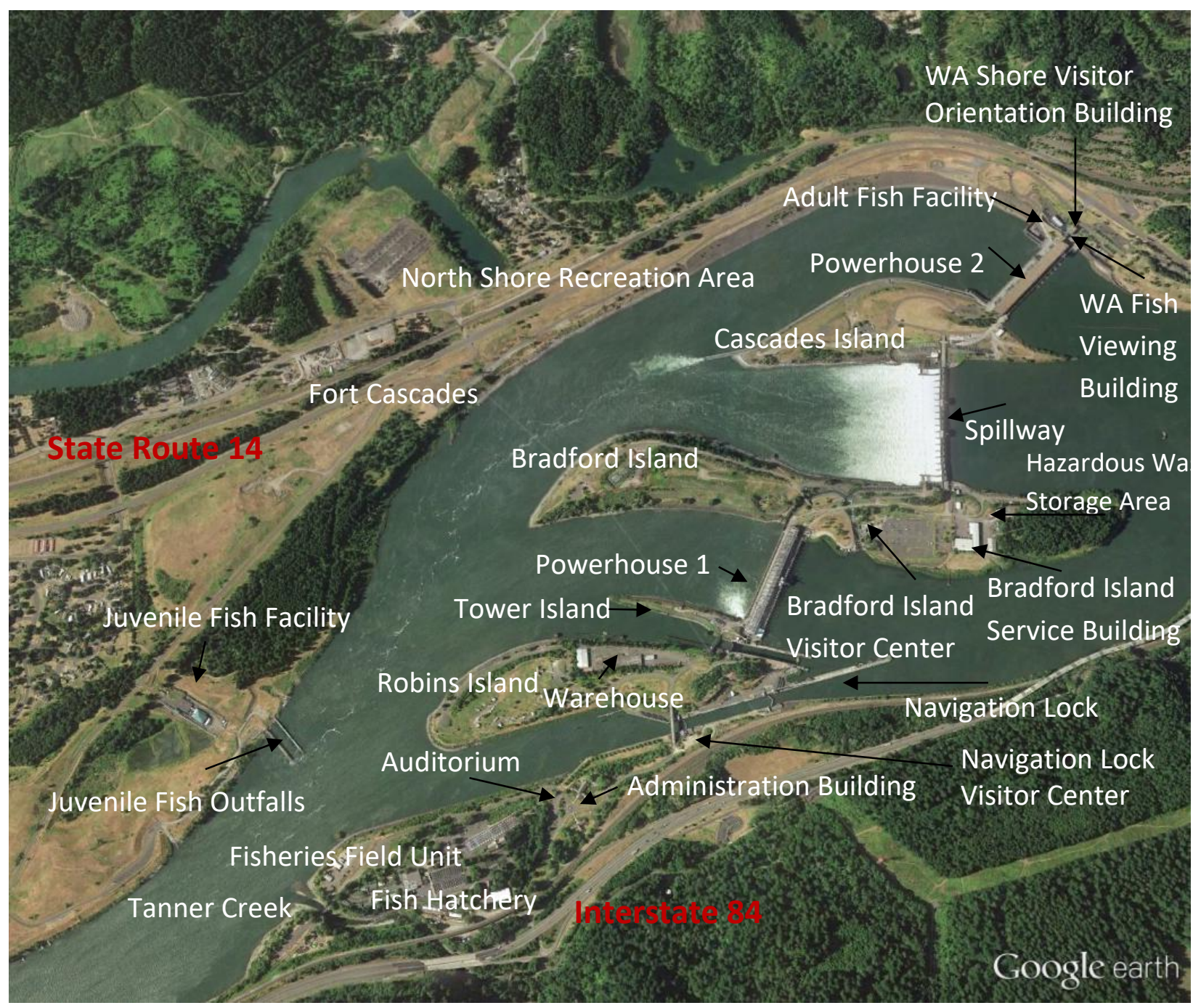

Figure 2: Map of the United States Army Corps of Engineers Bonneville Lock and Dam with labels of major facilities and points of interest. 


\section{Waste Stream Analysis}

\section{Background:}

Waste stream analysis, an understanding how much waste is generated and what it is composed of, is used to help make informed decisions in waste management and possible solid waste reduction strategies. Yu and Maclaren 1994 showed that a duel approach to waste stream analysis, looking at customer surveys and conducting a waste audit, produced the most accurate results for quantification and characterization of solid waste ${ }^{[14]}$. Having an understanding about a sites solid waste characterization and weight totals allows for the implementation of more refined practices for ensuring that recyclable and non-hazardous refuse materials are ending up in the appropriate locations, and coming up with processes to potentially reduce the amount of non-hazardous materials ending up in a landfill. For the purposes of this report, when referring to recycling and refuse waste in recycling and refuse containers, the waste being mentioned is non-hazardous unless noted otherwise. It should also be noted that when recycling and refuse waste are mentioned, there may or may not be refuse material or recycling material found within the recycling or refuse waste respectively.

\section{Methods:}

The work done for this project was carried out on the Bonneville Project, straddling the Columbia River and located in both Multnomah County, OR and Skamania County, WA. Guidelines to conducting the waste audit were drawn from the Metro and Washington County's Waste Assessment Guide ${ }^{[5]}$. The Bonneville Project has a total of 11 refuse and 6 recycling containers at the designated areas seen in Figure 3 and Table 2.

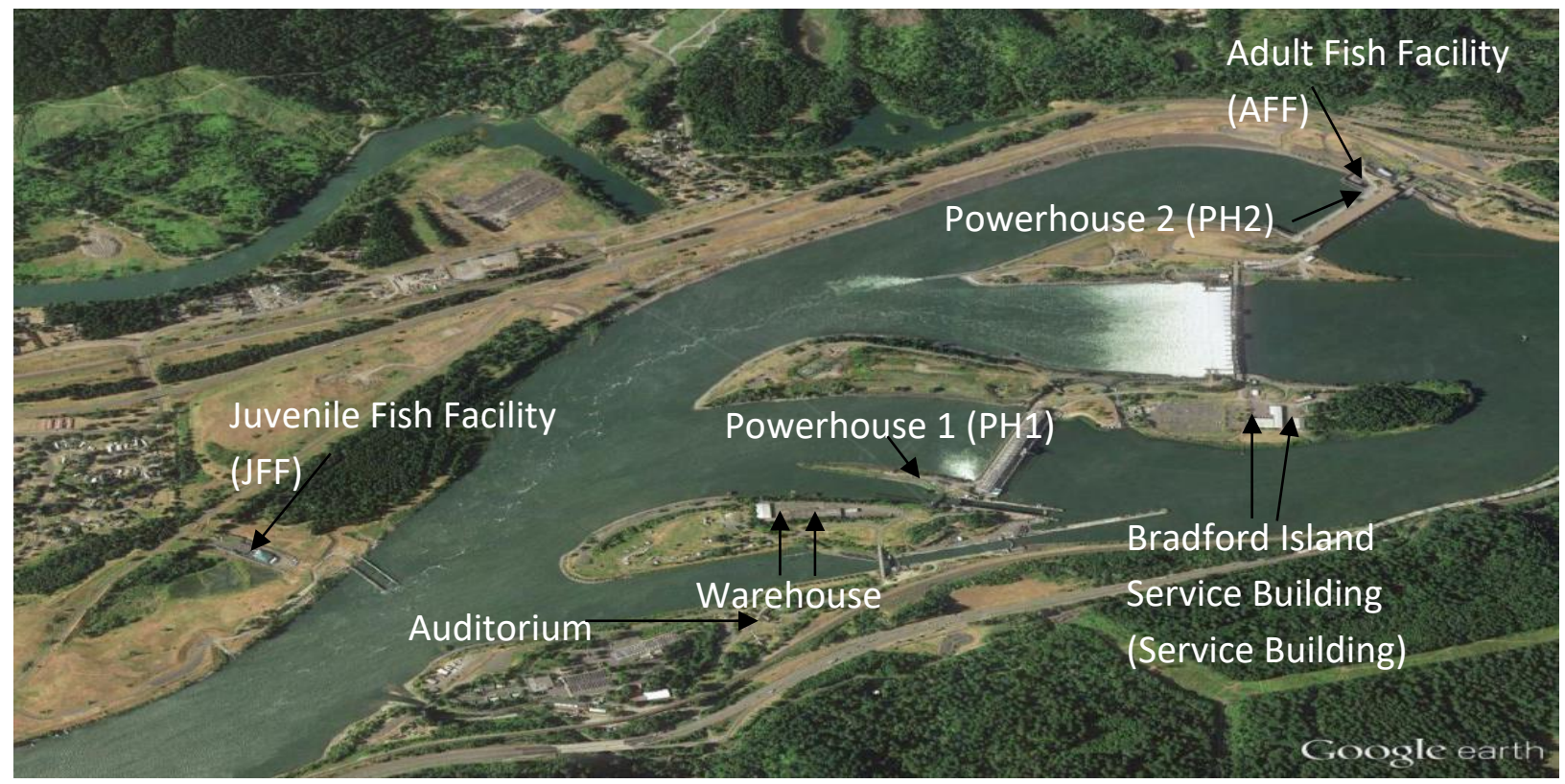

Figure 3: Map of the United States Army Corps of Engineers Bonneville Lock and Dam with the designated areas for waste collection labeled with approximate locations for recycling and refuse containers. 
Table 2: The number and size in volume capacity of recycling and refuse containers that were audited at each designated area at the Bonneville Project

\begin{tabular}{|l|l|l|}
\hline $\begin{array}{l}\text { Designated Area for Waste } \\
\text { Pickup }\end{array}$ & $\begin{array}{l}\text { Number of Recycling Containers } \\
\text { and Size (Volume Capacity) }\end{array}$ & $\begin{array}{l}\text { Number of Refuse Containers } \\
\text { and Size (Volume Capacity) }\end{array}$ \\
\hline Auditorium & 1 (1.5 yard) & 1 (1 yard) \\
\hline Warehouse & 2 (single 5 and single 6 yard) & 3 (4 yard) \\
\hline Powerhouse 1 (PH1) & 1 (5 yard) & 2 (single 2 and single 4 yard) \\
\hline Service Building & 1 (6 yard) & 1 (20 yard) \\
\hline Powerhouse 2 (PH2) & 1 (4 yard) & $2(2$ yard) \\
\hline Adult Fish Facility (AFF) & None & 1 (1 yard) \\
\hline Juvenile Fish Facility (JFF) & $1(4$ yard) & 1 (1 yard) \\
\hline
\end{tabular}

There are two waste haulers that serve the Bonneville Project. Crown Point Refuse and Recycling serves all of the Bonneville Project's recycling needs and collects waste from the refuse containers at the Auditorium, Warehouse, Powerhouse 1, and Service Building designated areas. Columbia River Disposal Inc. collects waste from the refuse containers at the Powerhouse 2, Adult Fish Facility, and Juvenile Fish Facility designated areas. Waste audits were conducted one to three days before pickup, which occurred on Thursday and Fridays. Material from all audited refuse containers are hauled away on a weekly basis (approximately 52 times annually) while material from recycling containers are hauled away biweekly (approximately 26 times annually) with the exception of PH2 and JFF as they are generally hauled away monthly (approximately 12 times annually). The Bonneville Project does have several large waste containers that were not included in this study as they were outside the scope of the project and are only serviced when requested by the Bonneville Project. These include a metals container located at the Service Building and Warehouse in which debris from construction activities and broken industrial equipment (such as generators) are discarded and a debris container located on Cascades Island between the Spillway and Powerhouse 2 (Figure 2) in which large river debris and construction waste are discarded.

Depending on the volume of solid waste contained within the designated area's drop box, either the whole unit or a representative sample was audited. The audit consisted of measuring or estimating the total weight of the contents of the containers. If the contents of the containers were deemed too vast to completely weigh, a representative sample (approximately $20 \%$ to $50 \%$ ) of the container was audited and weights were multiplied according to the representative sample percentage to arrive at the estimated weight of the entire container. For example, if a representative sample of approximately $20 \%$ is audited, the sample is then sorted and weighed, and then the weights would be multiplied by 5 to find the approximate total weight of contents found in the recycling or refuse container being audited. Due to the size and possible contents of the refuse container for the service building site, getting a representative sample was not always possible, and this was noted within the audit form. Each designated area was audited at least four times over the course of eight months. An initial view of the inside of each waste container was photographed before samples were pulled from the container. 
The waste audits were conducted adjacent to each drop box, with a ULINE H-104 portable analog scale used for weight measurement. Garbage bag lined plastic containers were used for auditing with each weighed before waste sorting. Waste categories were drawn from Metro and Washington County's Waste Assessment Guide and the Bonneville Lock and Dam Recycling Guide. In addition, the category Soiled Cloth (SC) was derived from category Other (O) after the final waste audit was conducted, and is therefore considered a conservative quantity since not all soiled cloth was separated and weighed from other waste material during auditing. Waste items, except for Soiled Cloth (SC), were sorted and placed in garbage bag lined plastic containers by category based on the following definitions:

- Corrugated Cardboard (CCB): Corrugated boxes used for shipping and packaging materials.

- Glass Bottles and Jars (G): Containers made of glass and exhibiting a neck or threaded top; excludes light bulbs.

- Recyclable Mixed Paper and Newspaper (RPa): Office paper, paperboard/soft cardboard, folders, scrap paper, sticky notes, shredded paper, paper bags, magazines, newspapers, and all other non-corrugated cardboard.

- Recyclable Plastic Bottles and Tubs (RPI): Plastic containers with a neck, including containers for beverages and other fluids and yogurt plastic tubs. No plastic lids, clamshells/trays, foodcontaminated plastics, non-recyclable plastic packaging, plastic wrappers, and residue-filled plastic containers.

- Tin, Metal, and Aluminum Cans (MC): Containers made of aluminum, steel, or tin, including for beverages and empty aerosol cans. Must not be food or residue contaminated.

- Recyclable Scrap Metal (SM): Metal that was not classified as a "container."

- Milk Cartons and Juice Boxes (C): Milk cartons and similar gable-top containers, and juice drink boxes.

- Food Soiled Paper (FSP): Paper fibers contaminated with food like coffee grinds and filters, soiled paper napkins, soiled paper bags, pizza boxes, and waxed corrugated cardboard.

- Non-Recyclable Paper (NRPa): Contaminated papers and non-recyclable types of paper such as tissues, paper plates, waxed papers, frozen food containers, paper packaging with metal or plastic parts. Paper based water/soda/coffee cups.

- Block Foam (F): Styrofoam, packing peanuts, and other foam-like materials.

- Wood, Yard, and Natural River Waste (W): Waste pulled from the river that includes, but not limited to, woody debris and aquatic plants. All wood-based materials like shipping pallets. Yard trimmings and plant debris.

- Food Scraps (FS): Vegetables, meats, dairy, grain-based, half-eaten plate scrapings, etc., and including the container the food is in if the container weight was not appreciable compared to the food inside.

- Non-Recyclable Plastic Bags, Films, Containers, and Tubs (NRPI): All bags (grocery, trash, and sandwich) also shrink wrap, plastic pallet wrap, and bubble wrap. Any contaminated plastic containers and tubs, such as plastic with dried paint, food wrappers, or soiled yogurt cups. All plastic trays, clamshells, utensils, lids, cups, etc. that is considered true waste (non-recyclable material). 
- Soiled Cloth (SC): Single use textiles contaminated with residuals such as oil, lubricants, or metal shavings.

- Other (0): Items sorted that do not fall into the above categories and considered true waste, such as textiles, light bulbs, rubber products, and unidentifiable items considered true waste (non-recyclable material).

Sorted waste items in the garbage bag lined plastic containers were then weighed on the ULINE H-104 scale with the weight of the plastic container subtracted from the total weight upon weight recording on the audit form. The plastic containers were not lined with a garbage bag when conducting a waste audit of the recycling containers unless refuse materials were found. The waste audit form can be found in Appendix A.

Analysis of the waste audit was comprised of calculating the sum and average weight for each designated area for refuse and recycling materials found in either the recycling or refuse containers. Designated area averages were done by grouping relevant audits together based on the designated area, container type, and season. The designated areas are as follows: Auditorium, Warehouse, Powerhouse 1 (PH1), Service Building, Powerhouse 2 (PH2), Adult Fish Facility (AFF), and Juvenile Fish Facility (JFF) (Table 2 and Figure 3). Apart from the Adult Fish Facility (AFF), all designated areas contained at least one recycling and refuse container. The fall season is represented by audits conducted in August, September, and October. The winter season is represented by audits conducted in November, December, January, and February. The spring season is represented by audits conducted in March and April. Utilizing ArcMap version 10.5.1 by ESRI, the Kernel Density algorithm from the Spatial Analyst function was utilized to visualize the total non-hazardous waste weight for the Bonneville Project based on the designated areas, recycling and refuse weight totals for each designated area, and audit category weight totals for each designated area. The approximate annual waste generation for the Bonneville Project is calculated utilizing data from Tables 1 and 3 by taking the average waste generation per designated area of either recycling waste in recycling containers or refuse waste in refuse containers and then multiply by either 26 or 12 for recycling container pickup on the Oregon side and Washington Side (Powerhouse 2 and Juvenile Fish Facility) respectively, or 52 for refuse container pickup throughout the Bonneville Project (Numbers based on hauler pickup schedule).

Results:

\section{Overall Bonneville Project Site}

The approximate annual weight in pounds for waste covering the entire Bonneville Project and the composition results of the waste are found in Figures 5 and 6 respectively. They represent the entirety of the Bonneville Project with Figures 5A and 5B representing the approximate annual weight in pounds for recycling waste in recycling containers and refuse waste in refuse containers respectively. Figures $6 \mathrm{~A}$ and $6 \mathrm{~B}$ represent the composition results for the approximate annual weight in pounds for the entire Bonneville Project for recycling waste in recycling containers and refuse waste in refuse containers respectively. Figures 4,7 , and 8 represent the kernel density maps for the Bonneville Project that represent the total waste found in recycling and refuse containers per designated area, the total 
recycling waste found in recycling container(s) per designated area, and the total refuse waste found in refuse container(s) per designated area respectively.
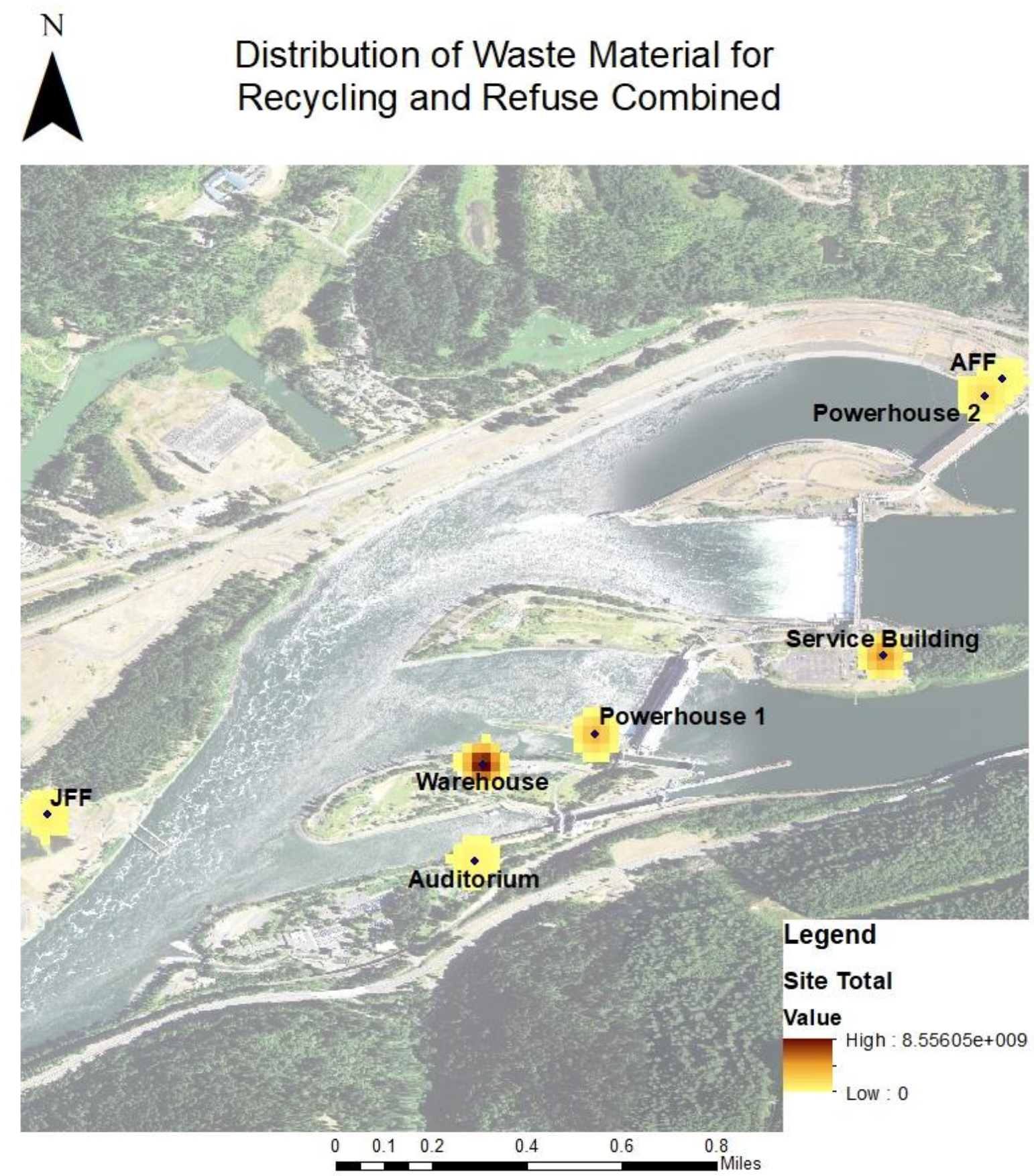

Figure 4: Kernel density map for category 'Recycling and Refuse Combined' at the Bonneville Project encompassing all designated areas. The darker the color scale is the higher amounts of weight found in all waste in recycling and refuse containers per designated area. JFF and AFF indicate Juvenile Fish Facility and Adult Fish Facility respectively. 
From Figure 5A, with an approximate annual weight of $11,516.22$ pounds for recycling waste in recycling containers, 586.07 pounds of refuse waste was found mixed with the recycling waste in the recycling containers. From Figure 5B, with an approximate annual weight of 53,707.46 pounds for refuse waste in refuse containers, $7,421.57$ pounds of recycling waste was found mixed with the refuse waste in the refuse containers.

\section{Project Wide Annual Weight for Recycling Containers}

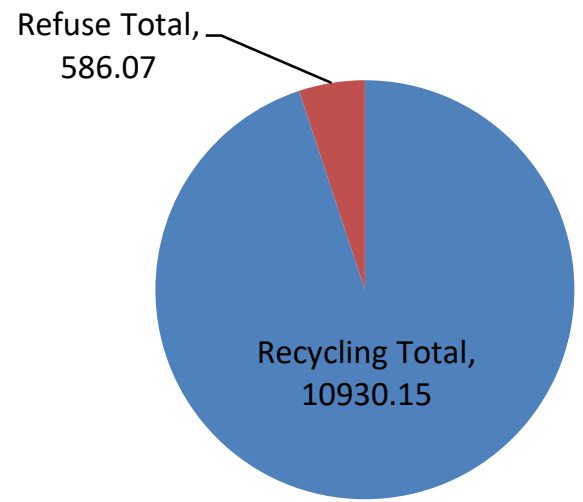

Figure 5A: The approximate annual weight in pounds for the entire Bonneville Project for recycling waste in recycling containers.

\section{Project Wide Annual Weight for Refuse Containers}

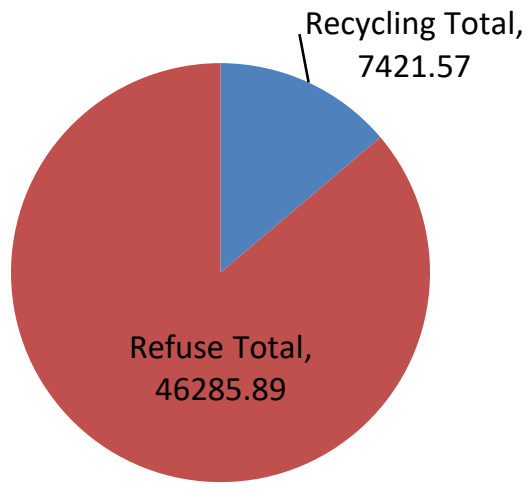

Figure 5B: The approximate annual weight in pounds for the entire Bonneville Project for refuse waste in refuse containers. 
From Figure 6A, the largest sort category at the Bonneville Project for recycling waste in recycling containers was Corrugated Cardboard (CCB) at 5,012.50 pounds followed by Recyclable Mixed Paper and Newspaper (RPa) at 4,034.38 pounds. From Figure 6B, the largest sort category at the Bonneville Project for refuse waste in refuse containers was Other $(0)$ at 15,490.05 pounds followed by Wood, Yard, and Natural River Waste (W) at 10,906.50 pounds.

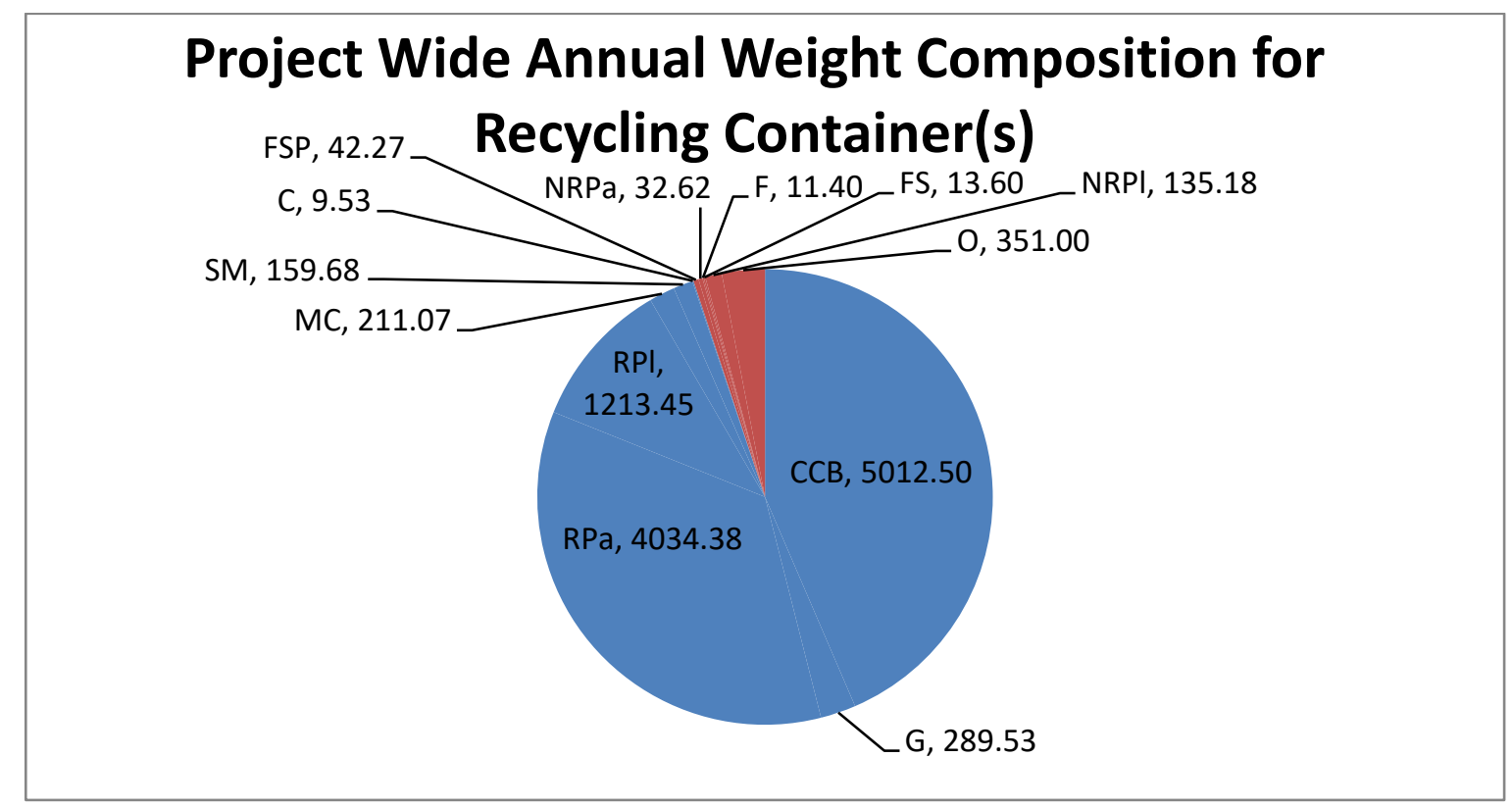

Figure 6A: The approximate annual weight in pounds for the entire Bonneville Project for recycling waste in recycling containers by composition. Blue shading is recycling, red shading is refuse.

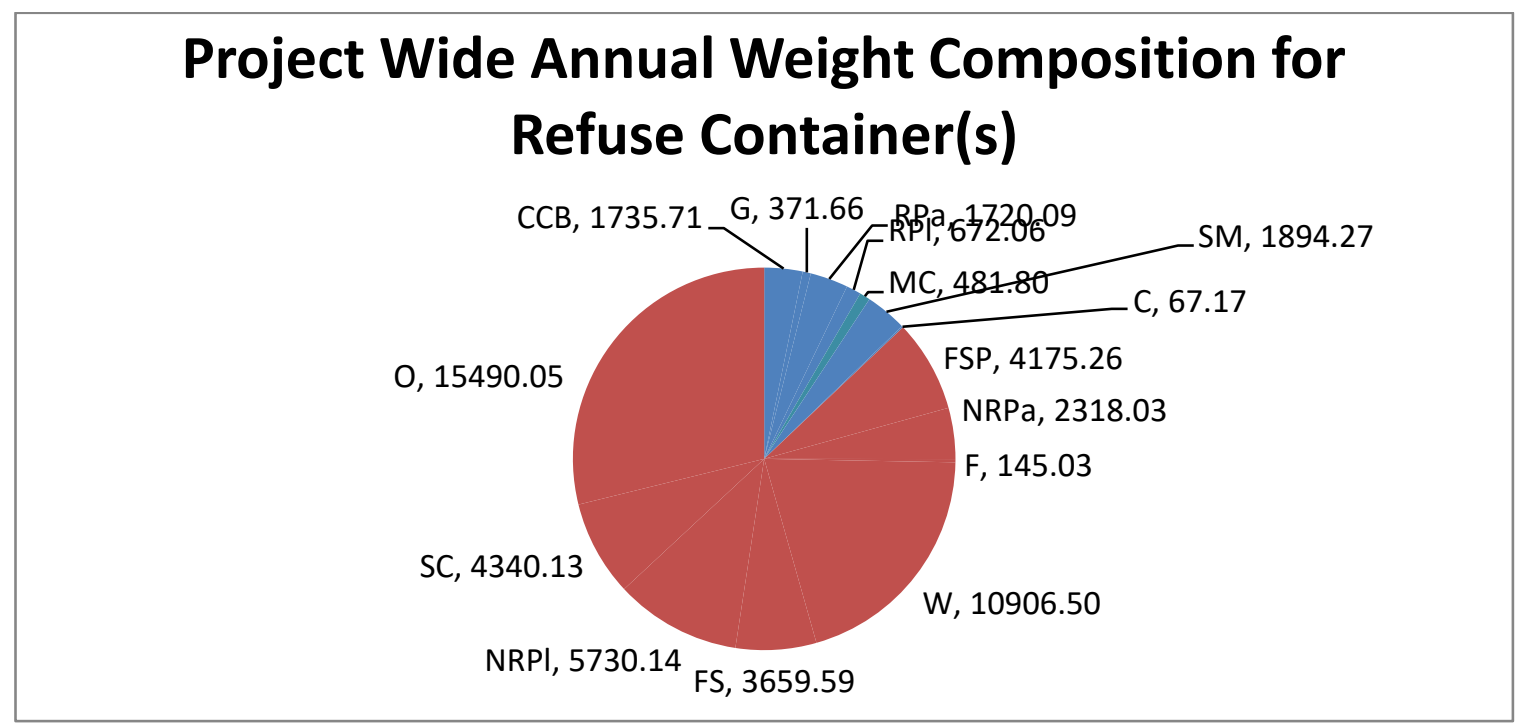

Figure 6B: The approximate annual weight in pounds for the entire Bonneville Project for refuse waste in refuse containers by composition. Blue shading is recycling, red shading is refuse. Corrugated Cardboard (CCB); Glass Bottles and Jars (G); Recyclable Mixed Paper and Newspaper (RPa); Recyclable Plastic Bottles and Tubs (RPI); Tin, Metal, and Aluminum Cans (MC); Recyclable Scrap Metal (SM); Milk Cartons and Juice Boxes (C); Food Soiled Paper (FSP); Non-Recyclable Paper (NRPa); Block Foam (F); Wood, Yard, and Natural River Waste (W); Food Scraps (FS); NonRecyclable Plastic Bags, Film, Containers, and Tubs (NRPI); Soiled Cloth (SC); Other (O). 


\section{Distribution of Waste Material for Recycling}

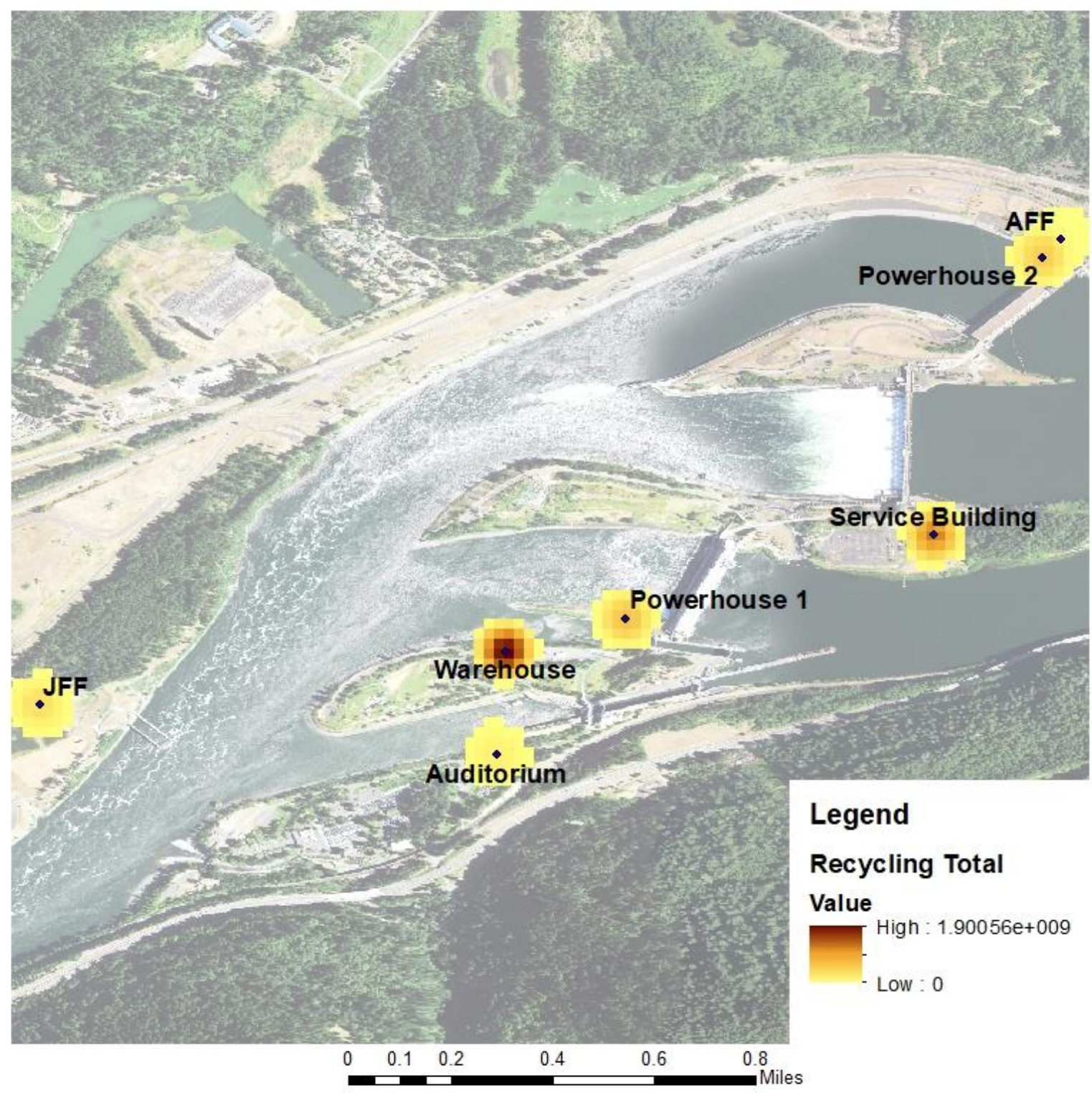

Figure 5: Kernel density map for category 'Recycling' at the Bonneville Project encompassing all designated areas. The darker the color scale is the higher amounts of weight found in all recycling waste in recycling containers per designated area. JFF and AFF indicate Juvenile Fish Facility and Adult Fish Facility respectively. 


\section{Distribution of Waste Material for Refuse}

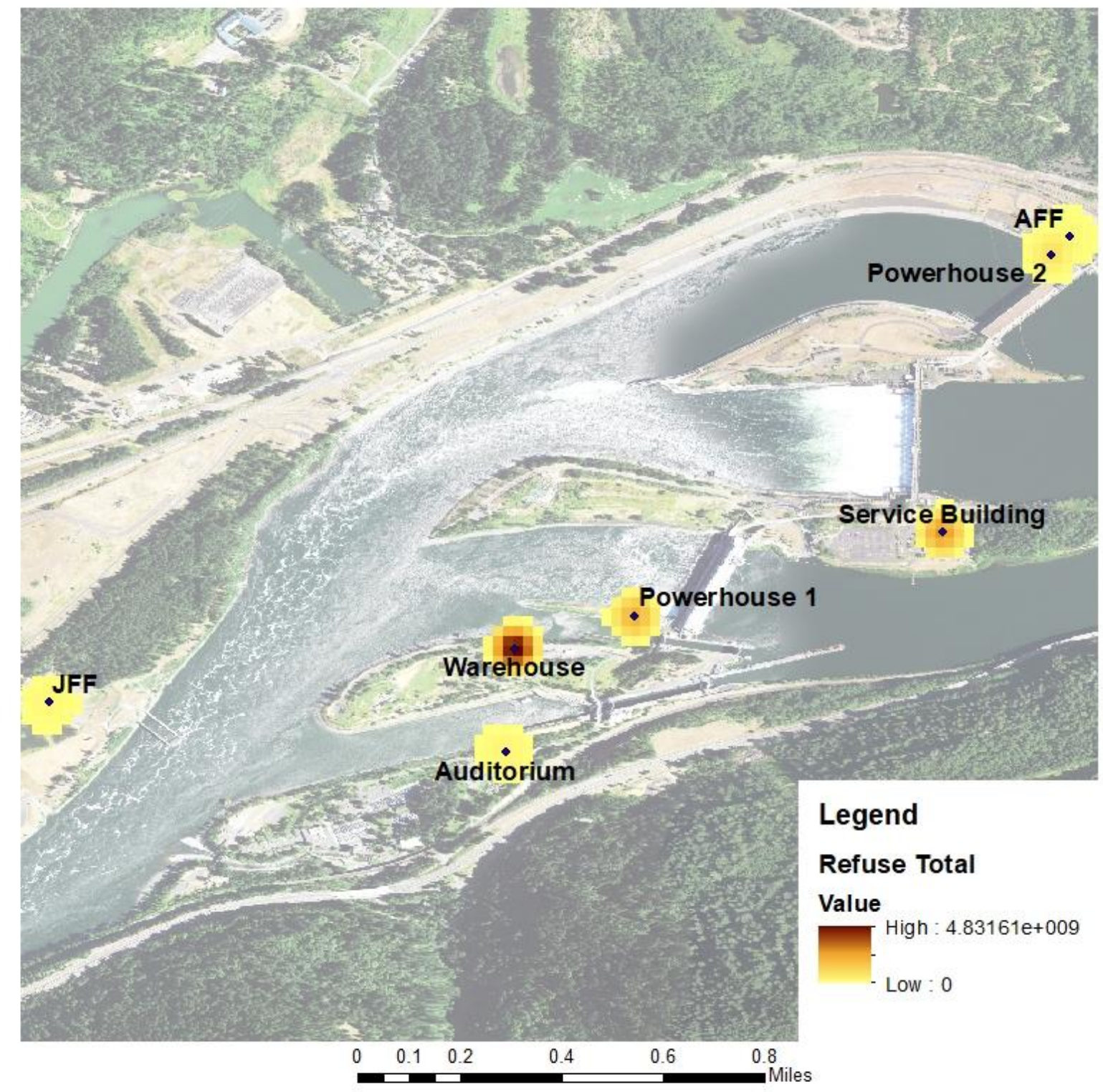

Figure 6: Kernel density map for category 'Refuse' at the Bonneville Project encompassing all designated areas. The darker the color scale is the higher amounts of weight found in all refuse waste in refuse containers per designated area. JFF and AFF indicate Juvenile Fish Facility and Adult Fish Facility respectively. 


\section{Designated Area:}

The seasonal average weight in pounds for recycling and refuse waste per designated area is found in Figure 9, which represents the entirety of the Bonneville Project during the audit period with Figures 9A and $9 \mathrm{~B}$ representing the average weight in pounds per designated area for recycling waste in recycling containers and refuse waste in refuse containers respectively per season.

From Figure 9A, the Fall seasonal average weights for the Auditorium, Warehouse, Powerhouse 1(PH1), Service Building, Powerhouse 2(PH2), and Juvenile Fish Facility (JFF) designated areas for recycling waste in recycling containers are $10.00,188.75,31.00,153.00,121.75$, and 83.75 pounds respectively. The Winter seasonal average weights for the Auditorium, Warehouse, Powerhouse 1(PH1), Service Building, Powerhouse 2(PH2), and Juvenile Fish Facility (JFF) designated areas for recycling waste in recycling containers are $29.25,96.50,63.83,179.00,67.75$, and 14.75 pounds respectively. The Spring seasonal average weights for the Auditorium, Warehouse, Powerhouse 1(PH1), and Juvenile Fish Facility (JFF) designated areas for recycling waste in recycling containers are 49.50, 78.13, 60.00, and 96.00 pounds respectively. Audits for designated areas Service Building and Powerhouse $2(\mathrm{PH} 2)$ were not conducted in the Spring season.

From Figure 9B, the Fall seasonal average weights for the Auditorium, Warehouse, Powerhouse 1(PH1), Service Building, Powerhouse 2(PH2), Adult Fish Facility (AFF), and Juvenile Fish Facility (JFF) designated areas for refuse waste in refuse containers are 42.00, 249.56, 236.75, 302.14, 18.17, 72.00, and 42.17 pounds respectively. The Winter seasonal average weights for the Auditorium, Warehouse, Powerhouse 1(PH1), Service Building, Powerhouse 2(PH2), Adult Fish Facility (AFF), and Juvenile Fish Facility (JFF) designated areas for refuse waste in refuse containers are 36.00, 344.58, 242.83, 611.00, 91.96, 3.83, and 8.00 pounds respectively. The Spring seasonal average weights for the Auditorium, Warehouse, Powerhouse 1(PH1), Service Building, Powerhouse 2(PH2), Adult Fish Facility (AFF), and Juvenile Fish Facility (JFF) designated areas for refuse waste in refuse containers are 88.00, 61.75, 189.00, 400, 48.83, 26.75 , and 7.50 pounds respectively. 


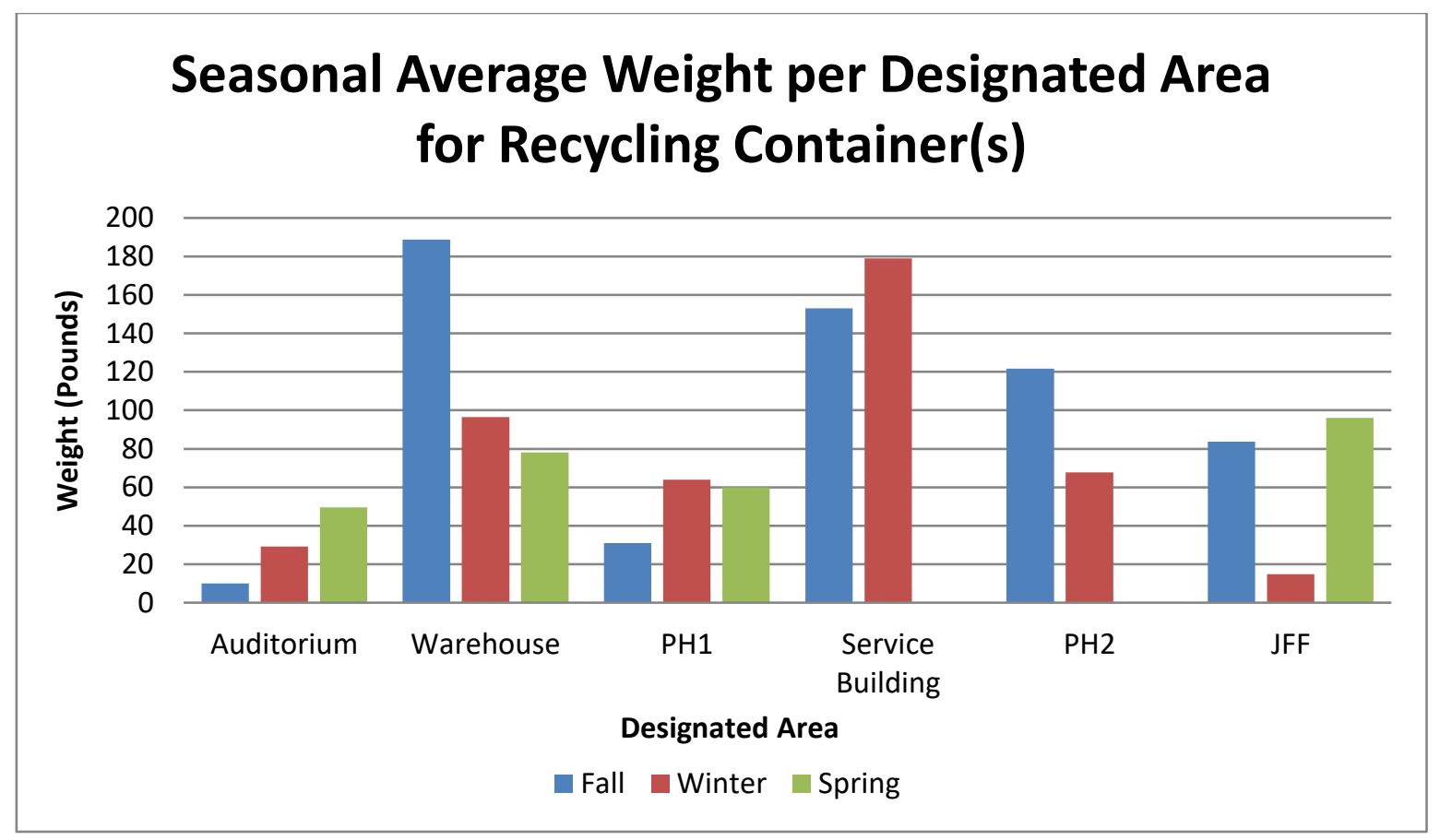

Figure 9A: The seasonal average weight in pounds per designated area at the Bonneville Project for recycling waste in recycling containers for the fall, winter, and spring seasons. $\mathrm{PH} 1, \mathrm{PH} 2$, and JFF indicate Powerhouse 1, Powerhouse 2, and the Juvenile Fish Facility respectively.

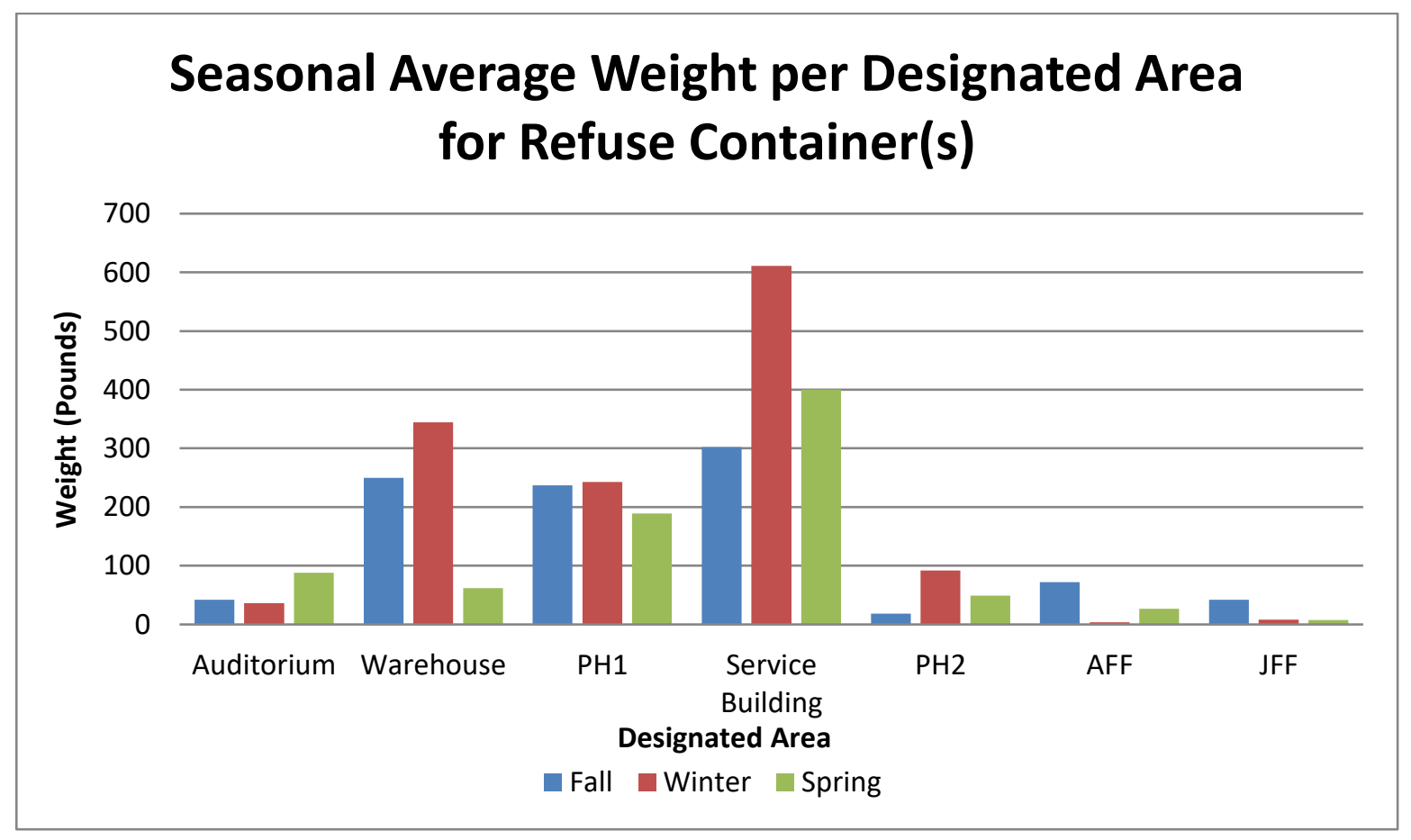

Figure 9B: The seasonal average weight in pounds per designated area at the Bonneville Project for refuse waste in refuse containers for the fall, winter, and spring seasons. PH1, PH2, AFF, and JFF indicate Powerhouse 1, Powerhouse 2, Adult Fish Facility, and the Juvenile Fish Facility respectively. 
Table 3: Depicts the average weight in pounds of recycling and refuse waste at the Bonneville Project. Table columns are as follows: Waste/Container Type, Designated Area, Weight Average in pounds of waste type with the total number of audits conducted at each designated area for each waste type in parenthesis, average weight totals for recycling waste in recycling containers (Rec. Total) and refuse waste in refuse containers (Ref. Total), and the composition of the waste. Waste composition categories are as follows: Corrugated Cardboard (CCB), Glass Bottles and Jars (G), Recyclable Mixed Paper and Newspaper (RPa), Recyclable Plastic Bottles and Tubs (RPI), Tin, Metal, and Aluminum Cans (MC), Recyclable Scrap Metal (SM), Milk Cartons and Juice Boxes (C), Food Soiled Paper (FSP), Non-Recyclable Paper (NRPa), Block Foam (F), Wood, Yard, and Natural River Waste (W), Food Scraps (FS), NonRecyclable Plastic Bags, Film, Containers, and Tubs (NRPI), Soiled Cloth (SC), and Other (O). The black bar is to divide the recyclable (top) and refuse (bottom) sort categories.

\begin{tabular}{|c|c|c|c|c|c|c|c|c|c|c|c|c|c|}
\hline 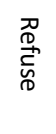 & 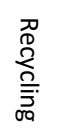 & $\begin{array}{l}\text { ग } \\
\stackrel{0}{0} \\
\stackrel{\vec{\omega}}{ \pm} \\
0\end{array}$ & 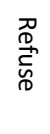 & 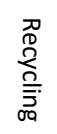 & 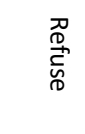 & 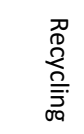 & 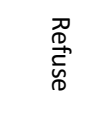 & 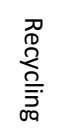 & 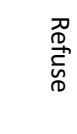 & 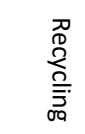 & 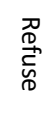 & 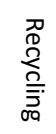 & 공 \\
\hline 留 & 氛 & 齐 & 꼿 & 모N & 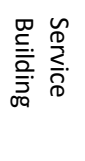 & 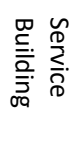 & 꿉 & 꿉 & 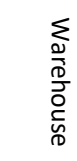 & 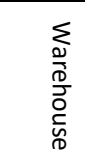 & 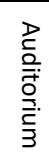 & 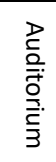 & 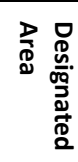 \\
\hline $\begin{array}{l}\tilde{N} \\
\dot{\infty} \\
\dot{0} \\
\underline{G}\end{array}$ & $\begin{array}{l}\text { ज } \\
\dot{0} \\
\dot{0} \\
\underline{G}\end{array}$ & $\begin{array}{l}\underset{N}{N} \\
\dot{\infty} \\
\stackrel{\omega}{\sigma} \\
\end{array}$ & $\begin{array}{l}\stackrel{\sim}{N} \\
\stackrel{0}{0} \\
\underline{\omega}\end{array}$ & 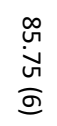 & 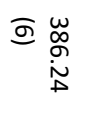 & 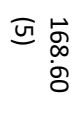 & వ $\underset{w}{\tilde{w}}$ & $\begin{array}{l}v \\
\dot{0} \\
\dot{\infty} \\
0\end{array}$ & 总 $\underset{\sim}{\sim}$ & 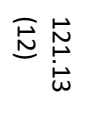 & $\begin{array}{l}\vec{v} \\
\dot{O} \\
\vec{G}\end{array}$ & $\begin{array}{l}\tilde{O} \\
\dot{0} \\
\stackrel{0}{E}\end{array}$ & 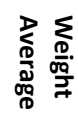 \\
\hline$\stackrel{\vec{b}}{\dot{b}}$ & 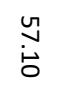 & $\stackrel{\sim}{\infty}$ & ì & $\stackrel{\vec{\sim}}{\stackrel{\sim}{\sim}}$ & $\begin{array}{l}\text { Un } \\
\dot{0}\end{array}$ & 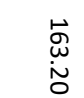 & $\underset{\omega}{\omega}$ & 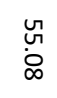 & $\begin{array}{l}\tilde{o} \\
\dot{\omega} \\
\dot{v}\end{array}$ & 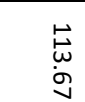 & $\stackrel{\infty}{8}$ & $\stackrel{\tilde{\omega}}{\tilde{\omega}}$ & 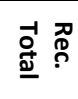 \\
\hline $\begin{array}{l}\dot{\delta} \\
\dot{\jmath}\end{array}$ & $\begin{array}{l}\tilde{+} \\
\dot{\theta}\end{array}$ & $\underset{\omega}{\stackrel{\omega}{\omega}}$ & 尤 & $\begin{array}{l}心 \\
\infty \\
\dot{\forall}\end{array}$ & $\begin{array}{l}\text { م. } \\
\text { Oे }\end{array}$ & 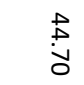 & $\begin{array}{l}\omega \\
\ddot{6} \\
0\end{array}$ & $\underset{\sim}{\sim} \underset{\omega}{\infty}$ & un & $\stackrel{\partial}{\dot{v}}$ & 영 & $\underset{i v}{i}$ & ลิ \\
\hline$\stackrel{\circ}{\dot{0}}$ & $\begin{array}{l}\circ \\
\dot{\infty}\end{array}$ & $\stackrel{P}{i}$ & 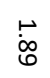 & 0 & $\stackrel{\stackrel{\circ}{\omega}}{\omega}$ & $\stackrel{\vec{b}}{\dot{b}}$ & $\tilde{\dot{8}}$ & $\underset{\omega}{\dot{w}}$ & $\underset{\infty}{\stackrel{\infty}{\infty}}$ & $\underset{\omega}{\tilde{\omega}}$ & $\stackrel{0}{\partial}$ & $\ddot{\ddot{8}}$ & ه \\
\hline 잉 & $\begin{array}{l}\dot{\tilde{O}} \\
\end{array}$ & $\dot{\circ}$ & 방 & $\begin{array}{l}\vec{o} \\
\stackrel{\tilde{u}}{u}\end{array}$ & ir & $\begin{array}{l}\stackrel{\infty}{0} \\
\stackrel{0}{0}\end{array}$ & $\begin{array}{l}\overrightarrow{\mathrm{c}} \\
\dot{b}\end{array}$ & $\stackrel{\overrightarrow{+}}{8}$ & $\dot{8}$ & $\begin{array}{l}\widetilde{\infty} \\
\stackrel{\infty}{\stackrel{N}{N}}\end{array}$ & $\tilde{\sigma}$ & $\stackrel{\infty}{w}_{v}^{\infty}$ & गु \\
\hline$\stackrel{\circ}{\dot{0}}$ & $\ddot{8}$ & $\stackrel{0}{\dot{v}}$ & 엉 & $\stackrel{\tilde{N}}{\infty}$ & $\stackrel{\vec{U}}{\tilde{u}}$ & $\begin{array}{l}\stackrel{\vec{\omega}}{\dot{\tilde{o}}} \\
\end{array}$ & $\underset{\tilde{u}}{\omega}$ & $\begin{array}{l}0 \\
\dot{g}\end{array}$ & $\stackrel{\sim}{\infty}$ & $\underset{\omega}{\stackrel{\leftrightarrow}{\omega}}$ & $\overrightarrow{\dot{\sigma}}$ & $\vec{i}_{\tilde{N}}^{N}$ & 㞧 \\
\hline $\begin{array}{l}\circ \\
\dot{0}\end{array}$ & $\begin{array}{l}u \\
\dot{0}\end{array}$ & $\begin{array}{l}0 \\
\stackrel{i}{N}\end{array}$ & 응 & $\stackrel{\circ}{\stackrel{D}{N}}$ & N & $\stackrel{N}{\circ}$ & 它 & $\stackrel{0}{\tilde{N}}$ & 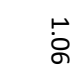 & $\underset{\omega}{\stackrel{\omega}{\omega}}$ & $\tilde{d}$ & $\stackrel{\overrightarrow{\tilde{N}}}{\mathrm{u}}$ & 3 \\
\hline 0 & $\begin{array}{l}v \\
\dot{0}\end{array}$ & 0 & i⿱ & 0 & $\begin{array}{l}\overrightarrow{\mathrm{c}} \\
\dot{8}\end{array}$ & 0 & iั & 0 & $\underset{\substack{\omega \\
\dot{w}}}{\vec{w}}$ & 욤 & 0 & $\tilde{\mathrm{in}}$ & $\tilde{\xi}$ \\
\hline$\stackrel{\circ}{\dot{0}}$ & 0 & 0 & $\stackrel{O}{\omega}_{\omega}$ & 0 & $\underset{\text { î }}{\circ}$ & $\begin{array}{l}\text { Oे } \\
\text { On }\end{array}$ & 0 & 0 & $\stackrel{\stackrel{\circ}{\omega}}{\sim}$ & 웅 & $\dot{\tilde{O}}$ & 莣 & n \\
\hline$\underset{\tilde{w}}{\tilde{w}}$ & ㅂ̆ㅇ & $\begin{array}{l}\tilde{O} \\
\dot{8}\end{array}$ & $\begin{array}{l}\vec{U} \\
\dot{\varphi}\end{array}$ & $\underset{\stackrel{\vec{w}}{\vec{w}}}{\vec{b}}$ & $\underset{\underset{u}{w}}{\stackrel{w}{u}}$ & $\underset{\Delta}{u}$ & $\begin{array}{l}\overrightarrow{0} \\
\stackrel{\omega}{v} \\
\dot{v}\end{array}$ & $\tilde{8}$ & $\underset{\sim}{\tilde{U}}$ & $\vec{a}$ & $\begin{array}{l}\omega \\
. \\
\delta\end{array}$ & $\stackrel{\circ}{\omega_{\infty}}$ & 䓃 \\
\hline
\end{tabular}




\begin{tabular}{|c|c|c|c|c|c|c|c|c|c|c|c|c|c|}
\hline $\begin{array}{l}\mathscr{0} \\
\dot{0}\end{array}$ & $\bullet$ & $\stackrel{\text { viv }}{ }$ & $\begin{array}{l}u \\
\dot{b} \\
\dot{p}\end{array}$ & 응 & $\underset{\substack{\infty \\
\omega}}{\tilde{\omega}}$ & 용 & $\underset{\dot{\omega}}{\vec{\omega}}$ & 0 & $\begin{array}{l}\vec{w} \\
\stackrel{u}{\sim}\end{array}$ & $\stackrel{\stackrel{\sim}{\sim}}{ }$ & $\begin{array}{l}\dot{8} \\
\dot{8}\end{array}$ & $\begin{array}{l}\stackrel{0}{\sim} \\
\stackrel{N}{N}\end{array}$ & गु \\
\hline in & $\dot{0}$ & 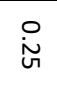 & $\begin{array}{l}\omega \\
\dot{\sigma}\end{array}$ & 0 & $\begin{array}{l}\overrightarrow{+} \\
\dot{8}\end{array}$ & $\stackrel{+}{\circ}$ & $\overrightarrow{\dot{b}}$ & 0 & $\stackrel{\stackrel{\vec{N}}{\omega}}{\stackrel{\omega}{\omega}}$ & : & 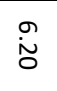 & $\begin{array}{l}\stackrel{O}{\sim} \\
\stackrel{\sim}{v}\end{array}$ & Zె刃 \\
\hline 0 & 0 & ○े & 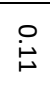 & ○ & $\stackrel{+}{\circ}$ & $\begin{array}{l}\circ \\
\text { Dे }\end{array}$ & $\stackrel{\stackrel{\circ}{\infty}}{\stackrel{\infty}{\varphi}}$ & 0 & in & 0 & $\begin{array}{l}\text { I } \\
\text { On }\end{array}$ & 0 & $\pi$ \\
\hline 0 & 0 & $\underset{\omega}{\stackrel{O}{\omega}}$ & $\underset{\omega}{\stackrel{O}{\omega}}$ & 0 & $\begin{array}{l}\stackrel{\circ}{ } \\
\dot{+}\end{array}$ & 0 & $\underset{\tilde{\omega}}{\tilde{\omega}}$ & 。 & $\begin{array}{l}\stackrel{\vec{N}}{\circ} \\
\stackrel{B}{*}\end{array}$ & 0 & 용 & 0 & $\varepsilon$ \\
\hline ب̃ & $\stackrel{\circ}{\dot{\delta}}$ & 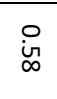 & $\stackrel{\dot{\tilde{\sigma}}}{ }$ & $\stackrel{\dot{i}}{v}$ & 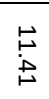 & $\begin{array}{l}\stackrel{\circ}{0} \\
\stackrel{0}{0}\end{array}$ & $\underset{w}{\tilde{w}}$ & 0 & $\begin{array}{l}\stackrel{b}{o} \\
\dot{v}\end{array}$ & 0 & $\begin{array}{l} \\
\dot{\infty} \\
\dot{0}\end{array}$ & 0 & $\pi$ \\
\hline $\begin{array}{l}\omega \\
\dot{g}\end{array}$ & 远 & $\stackrel{+}{g}$ & $\begin{array}{l}\omega \\
\dot{0} \\
0\end{array}$ & $\stackrel{\circ}{i}$ & 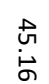 & $\stackrel{\omega}{\dot{\alpha}}$ & $\underset{\sim}{\tilde{v}}$ & $\dot{ }$ & $\begin{array}{l}\tilde{D} \\
\grave{\phi}\end{array}$ & $\dot{\dot{\omega}}$ & $\dot{\tilde{N}}$ & 0 & 超 \\
\hline 0 & 0 & 0 & $\begin{array}{l}\omega \\
\dot{\perp}\end{array}$ & 0 & $\begin{array}{l}D \\
0 \\
0 \\
0\end{array}$ & 0 & 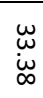 & 0 & $\stackrel{u}{u}$ & 0 & 0 & 0 & $\tilde{n}$ \\
\hline $\begin{array}{l}\infty \\
\infty \\
\infty \\
0\end{array}$ & 0 & $\underset{\stackrel{\vec{\omega}}{\dot{\omega}}}{\stackrel{\omega}{\omega}}$ & 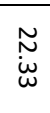 & $\begin{array}{l}\vec{w} \\
\dot{8}\end{array}$ & $\begin{array}{l}\stackrel{\omega}{\omega} \\
\stackrel{\infty}{\infty}\end{array}$ & 0 & సे & $\stackrel{+}{\omega}$ & $\stackrel{\omega}{\omega}_{\stackrel{\omega}{\omega}}$ & 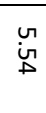 & $\begin{array}{l}\stackrel{b}{\circ} \\
\dot{8}\end{array}$ & $\stackrel{\stackrel{P}{\vec{N}}}{\text { in }}$ & 0 \\
\hline
\end{tabular}

The designated area average recycling waste in recycling container(s) by composition is shown in Figure 10A. All designated areas have a recycling container(s) except for Adult Fish Facility (AFF). The designated area average refuse waste in refuse container(s) by composition is shown in Figure $10 \mathrm{~B}$.

Average weight totals for recycling waste in recycling container(s) and refuse waste in refuse container(s) for each designated area are listed in Table 3. 


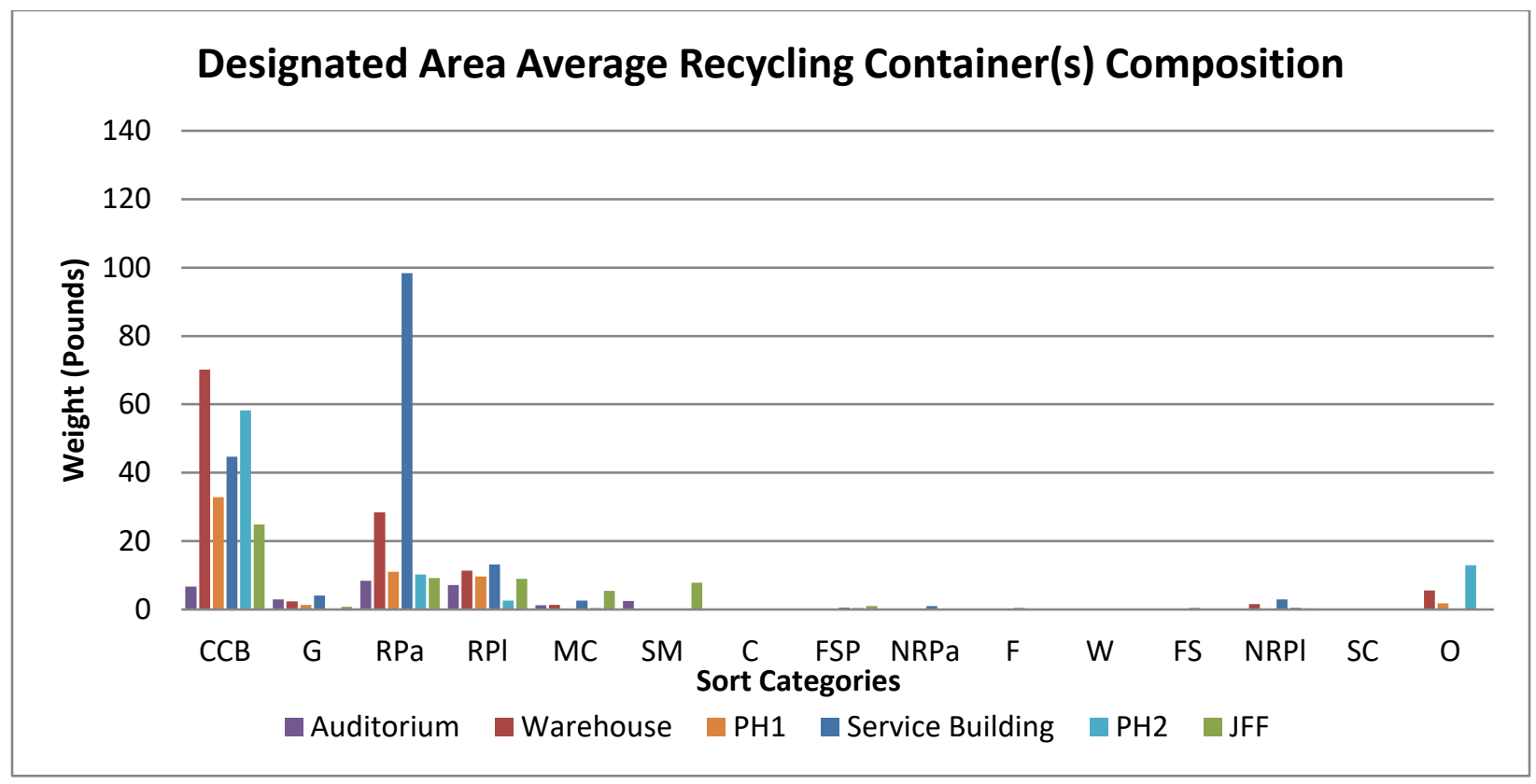

Figure 10A: The average weight in pounds per designated area for recycling waste in recycling container(s) by composition. PH1, PH2, and JFF represent Powerhouse 1, Powerhouse 2, and Juvenile Fish Facility respectively.

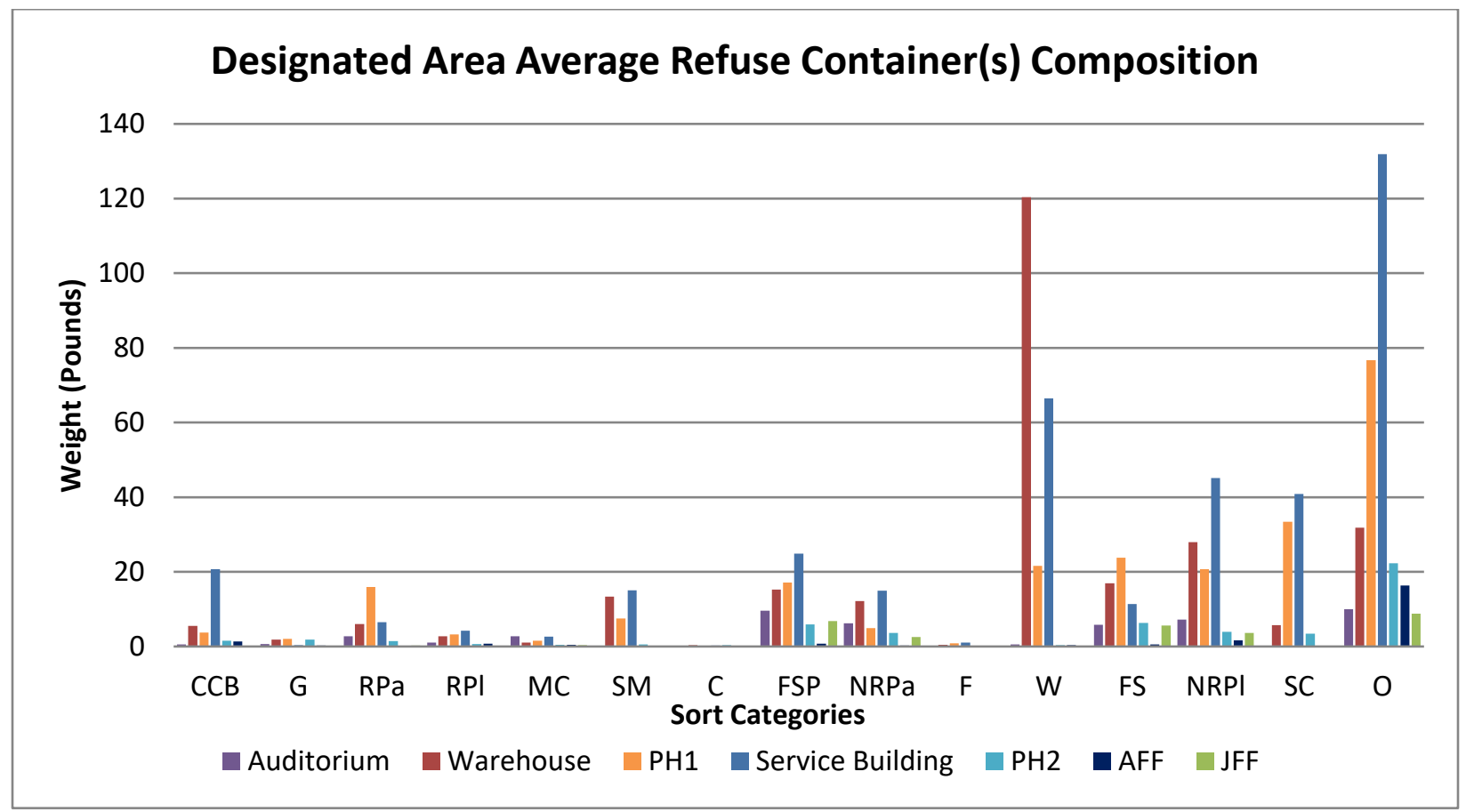

Figure 10B: The average weight in pounds per designated area for refuse waste in refuse container(s) by composition. PH1, PH2, AFF, and JFF represent Powerhouse 1, Powerhouse 2, Adult Fish Facility, and Juvenile Fish Facility respectively.

Corrugated Cardboard (CCB); Glass Bottles and Jars (G); Recyclable Mixed Paper and Newspaper (RPa); Recyclable Plastic Bottles and Tubs (RPI); Tin, Metal, and Aluminum Cans (MC); Recyclable Scrap Metal (SM); Milk Cartons and Juice Boxes (C); Food Soiled Paper (FSP); Non-Recyclable Paper (NRPa); Block Foam (F); Wood, Yard, and Natural River Waste (W); Food Scraps (FS); NonRecyclable Plastic Bags, Film, Containers, and Tubs (NRPI); Soiled Cloth (SC); Other (O). 
Auditorium:

From Table 3 and Figure 10A, with an average weight of 29.50 pounds for the recycling waste in the recycling container, 0.38 pounds of refuse materials were found on average. The largest sort category for the average recycling waste in the recycling container was Recyclable Mixed Paper and Newspaper (RPa) at 8.375 pounds followed by Recyclable Plastic Bottles and Tubs (RPI) at 7.125 pounds.

From Table 3 and Figure 10B, with an average weight of 47.60 pounds for the refuse waste in the refuse container, 8.0 pounds of recyclable materials were found on average. The largest sort category for the average refuse waste in the refuse container was Other $(0)$ at 10.0 pounds followed by Food Soiled Paper (FSP) at 9.60 pounds.

Warehouse:

From Table 3 and Figure 10A, with an average weight of 121.13 pounds for the recycling waste in the recycling containers, 7.46 pounds of refuse materials were found on average. The largest sort category for the average recycling waste in the recycling container was Corrugated Cardboard (CCB) at 70.17 pounds followed by Recyclable Mixed Paper and Newspaper (RPa) at 28.42 pounds.

From Table 3 and Figure 10B, with an average weight of 261.72 pounds for the refuse waste in the refuse containers, 30.97 pounds of recycling materials were found on average. The largest sort category for the average refuse waste in the refuse containers was Wood, Yard, and Natural River Waste (W) at 120.41 pounds followed by Other (O) at 31.81 pounds.

Powerhouse $1(\mathrm{PH} 1)$ :

From Table 3 and Figure 10A, with an average weight of 57.08 pounds for the recycling waste in the recycling container, 2.0 pounds of refuse materials were found on average. The largest sort category for the average recycling waste in the recycling container was Corrugated Cardboard (CCB) at 32.83 pounds followed by Recyclable Mixed Paper and Newspaper (RPa) at 11.0 pounds.

From Table 3 and Figure 10B, with an average weight of 233.06 pounds for the refuse waste in the refuse containers, 37.31 pounds of recycling materials were found on average. The largest sort category for the average refuse waste in the refuse containers was Other $(0)$ at 76.75 pounds followed by Soiled Cloth (SC) at 33.38 pounds.

Service Building:

From Table 3 and Figure 10A, with an average weight of 168.6 pounds for the recycling waste in the recycling container, 5.4 pounds of refuse materials were found on average. The largest sort category for the average recycling waste in the recycling container was Recyclable Mixed Paper and Newspaper (RPa) at 98.4 pounds followed by Corrugated Cardboard (CCB) at 44.7 pounds.

From Table 3 and Figure 10B, with an average weight of 386.24 pounds for the refuse waste in the refuse container, 55.49 pounds of recycling materials were found on average. The largest sort category 
for the average refuse waste in the refuse container was Other $(0)$ at 131.86 pounds followed by Wood, Yard, and Natural River Waste (W) at 66.44 pounds.

Powerhouse 2 (PH2):

From Table 3 and Figure 10A, with an average weight of 85.75 pounds for the recycling waste in the recycling container, 14.33 pounds of refuse materials were found on average. The largest sort category for the average recycling waste in the recycling container was Corrugated Cardboard (CCB) at 58.17 pounds followed by Other $(O)$ at 13.0 pounds.

From Table 3 and Figure 10B, with an average weight of 52.99 pounds for the refuse waste in the refuse containers, 7.02 pounds of recycling materials were found on average. The largest sort category for the average refuse waste in the refuse containers was Other $(0)$ at 22.33 pounds followed by Food Scraps (FS) at 6.26 pounds.

Adult Fish Facility (AFF):

From Table 3 and Figure 10B, with an average weight of 22.83 pounds for the refuse waste in the refuse container, 2.83 pounds of recycling materials were found on average for the refuse container. The largest sort category for the average refuse waste in the refuse container was Other $(0)$ at 16.33 pounds followed by Non-Recyclable Plastic Bags, Film, Containers, and Tubs (NRPI) at 1.67 pounds.

Juvenile Fish Facility (JFF):

From Table 3 and Figure 10A, with an average weight of 58.6 pounds for the recycling waste in the recycling container, 1.5 pounds of refuse materials were found on average. The largest sort category for the average recycling waste in the recycling container was Corrugated Cardboard (CCB) at 24.9 pounds followed by Recyclable Mixed Paper and Newspaper (RPa) at 9.2 pounds

From Table 3 and Figure 10B, with an average weight of 28.4 pounds for the refuse container, 1.1 pounds of recycling materials were found on average. The largest sort category for the average refuse waste in the refuse container was Other (O) at 8.8 pounds followed by Food Soiled Paper (FSP) at 6.8 pounds.

Figure 11 illustrates the amount of miss-placed waste in recycling and refuse containers per designated area. Figure $11 \mathrm{~A}$ shows the approximate average annual weight in percent of miss-placed refuse material found in recycling container(s) per designated area. Figure 11B shows the approximate average annual weight in percent of miss-placed recycling material found in refuse container(s) per designated area. Percentages are based on the approximate average annual weight in pounds per designated area. 


\section{Annual Weight in Percent of Miss-Placed Refuse Material in Recycling Container(s) per Designated Area}

Recycling Total $\square$ Refuse Total

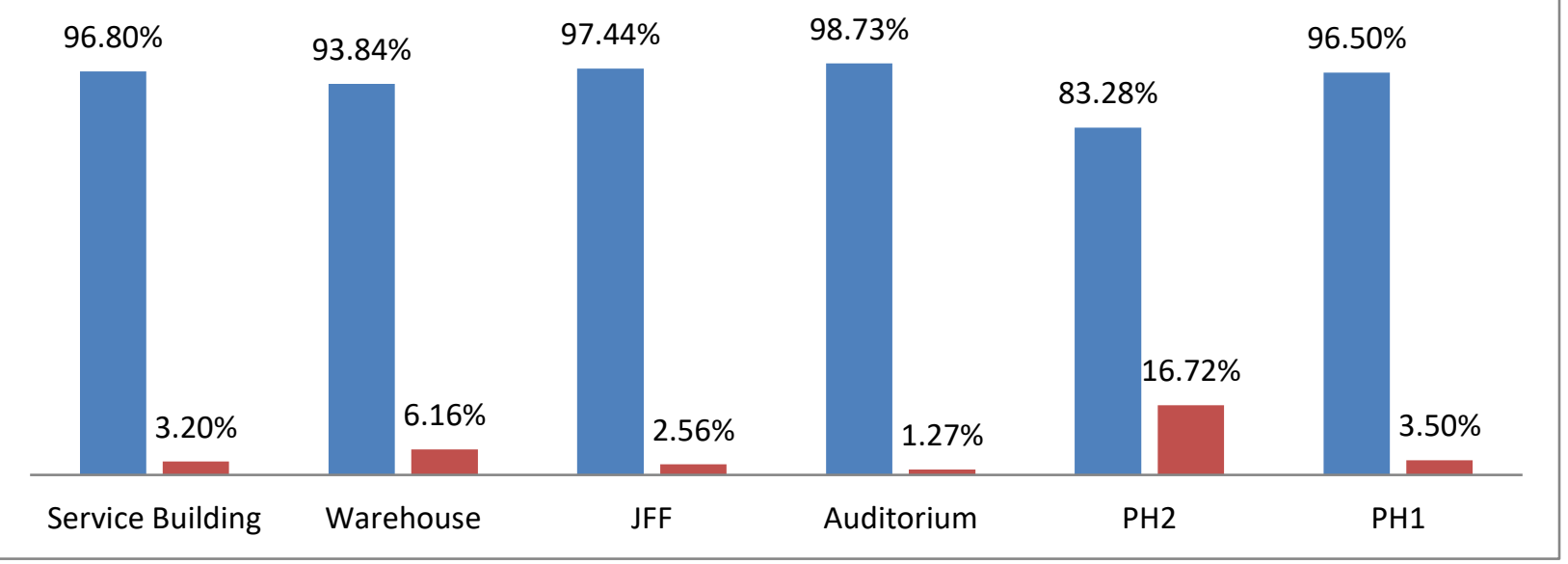

Figure 11A: The approximate average annual weight in pounds shown in percent of miss-placed refuse material found in recycling container(s) per designated area. PH1, PH2, and JFF represent Powerhouse 1, Powerhouse 2, and Juvenile Fish Facility respectively.

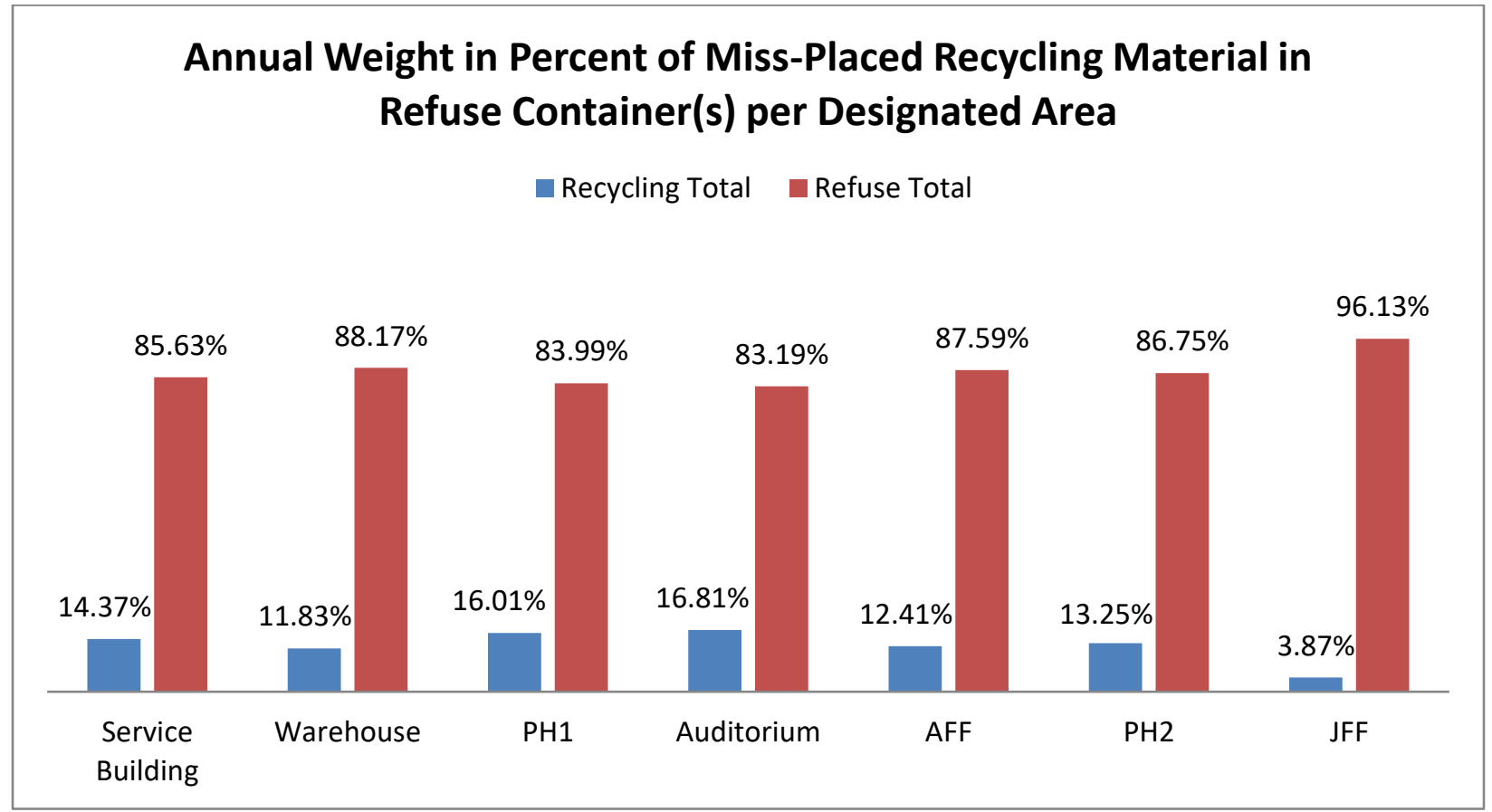

Figure 11B: The approximate average annual weight in pounds shown in percent of miss-placed recycling material found in refuse container(s) per designated area. PH1, PH2, AFF, and JFF represent Powerhouse 1, Powerhouse 2, Adult Fish Facility, and Juvenile Fish Facility respectively. 


\section{Conclusion:}

Looking at the approximate annual weight of waste generation for the Bonneville Project from Figure 5, the approximate annual weight in pounds for recycling waste in recycling containers (Figure $5 \mathrm{~A}$ ) is 11,516 pounds with $5 \%$ or 586 pounds of refuse waste found in recycling containers, and the approximate annual weight in pounds for refuse waste in refuse containers (Figure 5B) is 53,707 pounds with $14 \%$ or 7,421 pounds of recycling waste found in refuse containers. This leads to the approximate waste generation at the Bonneville Project at 65,233 pounds of recycling and refuse waste annually, with recycling waste being approximately $17 \%$ of total waste annually. Figure 6 illustrates the approximate annual weight of waste generation composition for the Bonneville Project. For recycling waste in recycling containers (Figure 6A), the sort category Corrugated Cardboard (CCB) was the largest, making up approximately 44\% or 5,012 pounds across the Bonneville Project with the sort category Recyclable Mixed paper and Newspaper (RPa) the second largest, making up approximately $35 \%$ or 4,034 pounds. These two categories made up approximately $79 \%$ of recycling waste in recycling containers for the entire Bonneville Project over the audit period. For refuse waste in refuse containers (Figure 6B), the sort category Other (O) was the largest, making up approximately $29 \%$ or 15,490 pounds with the sort category Wood, Yard, and Natural River Waste (W) the second largest, making up approximately $20 \%$ or 10,906 . These two categories made up approximately $49 \%$ of refuse waste in refuse containers for the entire Bonneville Project.

Figures 4, 7, and 8 show the highest occurrence of waste per designated area with the top two designated areas with the highest occurrence being the Warehouse and the Service Building. This was expected as the two areas have the highest capacity to handle waste, and according to Table 3 and Figure 10, are also the two highest generators of recycling and refuse waste.

An anomaly during an audit for the Warehouse refuse containers occurred on February 07, 2018 in which all three refuse containers were filled with leftover wood, most likely from construction (Table 5 in Appendix C and Table 6 in Appendix D). This caused the Warehouse approximate annual weight of refuse waste in refuse containers composition average, Table 3 and Figure 10B, to have a larger than expected value for the Wood, Yard, and Natural River Waste (W) sort category and thus slightly influenced the Bonneville Project wide approximate annual weight of refuse waste in refuse containers composition in figure 10B. However, removing the audit anomaly does not alter the Wood, Yard, and Natural River Waste (W) sort category from being the second largest.

A disruption in the audit collection for the month of September 2017, Table 6 in Appendix D, was due to the Bonneville Project being closed to all non-essential personnel and the general public caused by a wildfire in the Columbia Gorge on the Oregon side.

Looking at the average recycling waste in recycling container(s) per designated area seasonally, Figure $9 \mathrm{~A}$ shows that weight wise, the amount of recycling waste weighed increased at the Auditorium designated area while decreased at the Warehouse designated area based on the audits conducted during the seasons. For figure $9 \mathrm{~B}$, the average refuse waste in refuse container(s) per designated area seasonally, no trend is visible based on the audits that were conducted during the seasons. However, 
based on table 3, Figure 10B, and Table 5 in Appendix C, the anomaly audit for sort category Wood, Yard, and Natural River Waste (W) influenced the value for the Warehouse designated area for the Winter season.

Out of the designated areas, the Auditorium, Powerhouse 1 (PH1), Service Building, and Juvenile Fish Facility (JFF) (Figure 11A) had less than $4 \%$ of refuse waste found in their recycling waste in the recycling container(s). However, all designated areas, save the Juvenile Fish Facility (JFF) at 3.87\%, had at least $11 \%$ of recycling waste found in their refuse waste in the refuse container(s) (Figure 11B). The reason for the low percentage at the Juvenile Fish Facility (JFF) can be attributed to a few factors based on my observations and conversations with the personnel that work there. One of them being that the number of workers that are assigned there is low compared to the other designated areas and that they prioritize recycling their waste as much as possible. Another reason is that the personnel that work there are vigilant in what they discard to the refuse container, therefore preventing waste items that were meant for the recycling container ending up in the refuse container. From Figure $11 \mathrm{~A}$, Powerhouse 2 's (PH2) recycling waste in the recycling container had the highest percentage of refuse waste found, but this can be mainly attributed to finding a large amount of air filters during a single audit (Table 5 in Appendix $\mathrm{C}$ ). Removing this finding, Powerhouse $2(\mathrm{PH} 2)$ would have had less than $2 \%$ of refuse waste found in its recycling waste in the recycling container. The most common sort categories for refuse waste found in recycling waste in recycling containers based on the approximate annual waste generated by the Bonneville Project were Non-Recyclable Plastic Bags, Film, Containers, and Tubs (NRPI), Other (O), and Food Soiled Paper (FSP). The most common sort categories for recycling waste found in refuse waste in refuse containers based on the approximate annual waste generated by the Bonneville Project were Corrugated Cardboard (CCB), Recyclable Mixed Paper and Newspaper (RPa), and Recyclable Scrap Metal (SM).

As the sort category Other $(0)$ was for items that did not fit into the other categories neatly, the following are several examples of what was found that was put into the category: Wiring mixed with soiled cloth, air filters, light bulbs, soiled work gloves, used buckets with handles, varying kinds of rope and cable (steel and plastic), hard hats, laminated panels, soap dispensers, plastic cooler, PVC pipe, shotgun casings, quilting supplies, jump rope, playdough, carpet, types of circuit breakers, pet bed, flood lights, paint cans, face guard, rubber mats and parts, water samples, white board, rugs, absorbent pads for spills, various filters, chairs, used tools such as screwdrivers and hammers, tool cases, tool box, boots, life vests, half used sealant tubes, tarps, spare powder concrete, unknown valves and gauges, sun glasses, office supplies, gas can, tool bag, fishing gear, water hose, hair/animal feces, cat litter, biohazard box, brooms, whole fish, batteries, vacuum waste, toilet seat and cover, and light fixtures.

Overall, the approximate average annual weight in pounds and the relative percentage amount of refuse waste found in recycling waste in recycling containers is low. The refuse material items that were found can mainly be attributed to mistakenly discarding refuse waste into recycling containers. This can also be the cause for recycling waste found in refuse waste in refuse containers. However, even if a material is recyclable, further action may be required by the disposer before placing it in the recycling waste container. For example, a common item found in both the recycling and refuse containers was used yogurt cups. Some of the yogurt cups in the recycling containers were rinsed, while others were not. All 
yogurt cups in the refuse containers were not rinsed. The non-rinsed yogurt cups, while a recyclable material, is not recyclable if considerable food particles are left inside. This is counted as recyclable for the purpose of this audit, but is more in line with potentially recyclable. Non-rinsed yogurt cups should then be put in the refuse container, not the recycling container due to the non-recyclable nature of the food particles. It should be noted that under the guidelines for recycling at the Bonneville Project, it is stated that this type of cleaning is needed before placing the recyclable item in the recycling container.

This study was initiated in August 2017 and due to the wildfires near the Bonneville Project, data collection was suspended for four weeks. For this reason, waste audit data specific to visitors using the Bradford Island Visitor Center was limited to one audit period (highest number of visitors occurs during the summer season). Waste audits for the recycling and refuse container that occurred on August 23, 2017 and August 29, 2017, respectively, at the Service Building designated area (Table 5 in Appendix C) was mostly comparable to data collected at other time points throughout the study. It should be noted that there was a higher amount of sort category Recyclable Mixed paper and Newspaper (RPa) and Corrugated Cardboard (CCB) in the recycling container compared to other audits. However, an audit that occurred on January 24, 2018 had similar amount totals for the two recycling sort categories. The refuse container had no discernable differences in its waste composition when compared to other audits done throughout the study period besides sort category Food Soiled Paper (FSP) being approximately $40 \%$ higher from the waste audit that was conducted on August 29, 2017.

The sort categories that have the highest chance to be composted, Wood, Yard, and Natural River Waste (W) and Food Scraps (FS), make up to a quarter of refuse waste found in refuse containers Project wide during the audit period. Since the waste audit was limited to only one audit during the summer season, the values for compostable materials found in the aforementioned sort categories, especially Food Scraps (FS), may not reflect the most accurate representation when compared to the annual weight of waste generation at the Bonneville Project.

Compared to the national percent of waste generation in 2015, there are a few similarities with the results from the waste audit at the Bonneville Project. According to the Environmental Protection Agency (EPA), Municipal Solid Waste (MSW) is composed of $25.8 \%$ recycling, $8.9 \%$ composting, and $52.5 \%$ landfill and the remainder being combusted to product energy ${ }^{[15]}$. The Bonneville Project falls short with a recycling percentage of approximately $17 \%$, but is higher in the percent makeup of Corrugated Cardboard (CCB) and Recyclable Mixed paper and Newspaper (RPa) at 79\% compared to $66.9 \%$ nationwide. Nationwide, recyclable material found in waste heading to the landfill was approximately $30 \%$ compared to $14 \%$ at the Bonneville Project. Locally, Clark County, Washington had its refuse waste stream analyzed in 2012 . For commercial refuse waste, approximately $18 \%$ of recyclable material was found while in commercial compactor waste, approximately $14 \%$ of recyclable material was found ${ }^{[16]}$. The Bonneville Project, in comparison, has approximately $14 \%$ of recyclable material found in its refuse waste, which is similar to the overall commercial refuse waste generated in Clark County. Waste characterization data conducted by the Engineering, Research, and Development Center at the Construction Engineering Research Laboratory of the USACE has shown that approximately 30\% of recyclable material is found within refuse waste and food scraps were approximately $33 \%$ of refuse waste at three different site locations. While these sites are not considered industrial like the Bonneville 
Project, it does show that recyclable material found at the Bonneville Project is lower than at the three locations, but also has substantially lower sort category food scraps at $6 \%$. Portland General Electric had a waste stream analysis conducted at the One World Trade Center building in downtown Portland, Oregon. Their finding was that approximately $14 \%$ of recyclable material was found in waste heading to the landfill while approximately $5 \%$ of refuse waste was found in the recycling containers. The Bonneville Project's waste stream is similar with approximately $14 \%$ of recyclable material found in refuse waste and approximately $5 \%$ of misplaced refuse waste found in the recycling containers.

\section{Management Recommendations:}

With the in-depth investigation into the waste stream at the Bonneville Project of this study, the current overall recycling effort shows that the site recycles approximately a sixth of its total waste and does a good job of keeping refuse waste out of the recycling waste in recycling containers. However, for the facility to reduce refuse waste heading to the landfill by $50 \%{ }^{[4]}$, further work is needed. Looking at the waste composition project wide, there are a few recommendations that can be made to the Project in order for the site to reach their refuse waste reduction goal.

- Based on the approximate annual sum amount of Food Soiled Paper (FSP) throughout the Bonneville Project, 4,217.53 pounds, investigating reduction methods for single use, nonrecyclable paper products such as paper plates and paper coffee cups can help reduce up to approximately $8 \%$ of annual refuse waste.

- Based on the approximate annual sum amount of Non-Recyclable Paper (NRPa) throughout the Bonneville Project, 2,350.65 pounds, investigating options for employees to use air dryers in conjunction with paper towels in the restrooms can help reduce approximately up to $4.4 \%$ of annual refuse waste. Also, looking at revising policy to not discard partially used toilet paper rolls can aid in reducing this category of waste as well.

- Based on the approximate annual sum amount of Wood, Yard, and Natural River Waste (W) throughout the Bonneville Project, 10,906.50 pounds, investigating reduction methods such as reuse opportunities for wooden items such as scrap boards and broken pallets can help reduce up to approximately $20 \%$ of annual refuse waste.

- Based on the above recommendation and the approximate annual sum amount of Food Scraps (FS) throughout the Bonneville Project, 3,673.19 pounds, investigating the feasibility and cost of incorporating composting services for food scraps and grounds maintenance waste can help reduce up to approximately $6.8 \%$ food scraps and $20 \%$ wood waste of annual refuse waste.

- Based on the results and observations of the study, investigating ways to donate/give away items that could be reused such as old tools or office supplies can help in reduction of refuse waste efforts.

- Based on the approximate annual sum amount of recycling waste found in refuse waste in refuse containers throughout the Bonneville Project, 7,421.57 pounds, investigating reduction methods can help ensure that up to approximately $14 \%$ of annual refuse waste is reduced. For example, this can be done by ensuring that clear labeling for recycling bins are available, different bin sizes/color for refuse and recycling bins, and there are bins for recyclable metal in 
appropriate locations. In addition, better signage that indicates which items are recyclable may aid in reducing the amount of recyclable materials that is disposed of in refuse containers. Besides signage, investigating the possibility of visually distinguishing refuse and recycling containers by either specific color or paint pattern can, over time, enable project personnel to become accustomed to easily recognizing which containers refer to recycling or refuse if a standard is set across the Bonneville Project.

- Based on the results of the study, emphasizing during annual training to wash or rinse recyclable materials before placing them in recycling containers can help reduce up to 5,865 or $11 \%$ of annual refuse waste of category Non-Recyclable Plastic Bags, Film, Containers, and Tubs (NRPI) found in all designated areas combined.

- Based on the results and observations of the study, looking at incorporating a single refuse and recycling container, no larger than 4 yards, at the Robins Island camp grounds can reduce waste found at the Warehouse and lessen the chance that unauthorized personnel access the area.

- Based on the results and observations of the study, adding recycling and refuse containers to locations that visitors to the Bonneville Project use, specifically the Robins Island camp ground and Bradford Island Visitor Center, can aid in separating recycling and refuse waste generated by visitors from daily operations. This will be necessary if a future audit at the Bonneville Project aims to look at the amount and composition of waste visitors generate.

- Based on the results and observations of the study, removing the 2 yard refuse container at Powerhouse 1 and one of the 2 yard refuse containers at Powerhouse 2 is feasible as capacity was never reached for those containers at either location for refuse waste. If the Bonneville Project losses its ability to recycle at Powerhouse 2 and the Juvenile Fish Facility due to contract changes from hauler Crown Point Refuse and Recycling, then it will be necessary to have at least one 5 yard refuse container at Powerhouse 2 and at least a 2 yard refuse container at the Juvenile Fish Facility.

- Based on the results and observations of the study, investigating the methods employed by the employees assigned to the Juvenile Fish Facility (JFF) can aid in reducing the amount of recyclable materials that is disposed of in refuse containers.

- The USACE could conduct similar waste audits at different facilities by utilizing the methods employed by this study. This could aid in the USACE figuring out their waste streams and would be useful in comparing results and looking at waste reduction strategies that can be shared between USACE facilities.

If all the recommendations listed above are implemented and the Project personnel and visitors follow the recommendations, the Bonneville Project can expect up to approximately $64 \%$ reduction of refuse waste. This will enable the Bonneville Project to reach their refuse waste reduction goal of $50 \%$.

Particular, emphasizing during annual training recycling techniques and waste reduction strategies can help in ensuring continued refuse waste reduction.

However, there are challenging factors that may limit the ability of the Bonneville Project to reach their goal of reducing non-hazardous waste generation by $50 \%$. These factors include, but are not limited to, inability to fully realize management recommendations; ineffective refuse waste reduction training or 
reception; collecting various river waste that is removed from the Columbia River as the amount and type collected can vary annually; single use cloth that is used for various maintenance activities;

absorbent pads used in spills of substances that may pose a risk to the surrounding environment; broken and worn out tools and accessories; and old or outdated parts used in site operations that may have limited use outside the Bonneville Project. Tackling the challenging factors to waste reduction will be needed if the Bonneville Project aims to be a zero-waste facility.

\section{Recommendations for Future Waste Stream Audits}

With the conclusion of the waste stream audit at the Bonneville Project, any future audits that may be conducted there can be done more efficiently by incorporating the following recommendations:

- Increase the number of people conducting the waste audit. Having a team of at least three individuals would aid in the efficiency and speed at which waste audits are completed. In addition to increasing the number of audits conducted per day, full waste audits rather than representative sample audits can be done.

- In order to have comparable and complete seasonal data for a future Bonneville Project waste audit, waste audits should be conducted throughout the year with matching number of audits for each designated area's containers per season.

- Add additional sort categories for refuse waste from category Other $(0)$ such as used industrial equipment, used spill pads, textiles, and rubber based products. This would enable future waste audits conducted at the Bonneville Project to have more detailed refuse waste composition data.

- Use a canopy during audits to reduce the potential impact that rain may have on the weight of materials being audited.

With the recommendations above, future waste audits that may be conducted the Bonneville Project can aid management in identifying more accurately the composition of the waste stream, any changes to waste generation or composition seasonally, and reduce the chance the data collected are not compromised by factors such as rain. 


\section{Green Purchasing Analysis}

\section{Background:}

Environmentally preferable purchasing is an act of purchasing products that have been tested for their environmental impact and found to be less than similar conventional products. These types of products are, for simplicity, referred to as green products ${ }^{[12]}$. However, there are currently no national standards to what constitutes a green product. A few U.S. government and state agencies, such as the USEPA (United States Environmental Protection Agency) and SCAQMD (South Coast Air Quality Management District), have developed standards for certain products to qualify as green. The number of ecolabels has increased as consumer demand for green products has increased; leading to a 'greenwashing' of environmental claims ${ }^{[12]}$. This has led to a labeling push to call attention to certified ecolabels on products so that consumers can easily pick them out and for U.S. government and state agencies to advertise their efforts in ensuring compliance with their standards. Curran 2001 evaluated the framework of environmentally preferable purchasing and its impact on sustainability to improve the life cycle assessment and increase efficiency in green product procurement ${ }^{[9]}$. This approach helps reduce the amount of solid waste sent to landfills, and increases the amount of reuse and recycling done by an organization that implements green product procurement. The push by manufactures to certify their products to gain access to available ecolabels has increased the push into green chemistry which, by design, incorporates a reduced environmental impact upon product development and use ${ }^{[10,13]}$. However, without adequate research by the consumer on potential green products, this approach can be limited. The need for research leads to the other major focus of this project, which is to review chemical use at the Bonneville Project and look for environmentally friendly alternatives that can substitute for currently used chemicals while potentially reducing the overall chemical count on site.

\section{Methods:}

The Green Purchasing Analysis for the Bonneville Project is focused on the comprehensive list of currently used chemical products that are required by law to have a Material Safety Data Sheet (SDS). The emphasis on the currently used chemical product list is done since green purchasing is already done for items such as office supplies, and there was an opportunity to narrow the focus on chemical product use exclusively. A comprehensive chemical product list of over 800 unique chemicals was compiled by Melissa McBain, the environmental coordinator at the Bonneville Project, and several staff who thoroughly identified chemical products used and stored throughout the Project. The list has been kept up to date with any new products that are used on site and is maintained by a cloud based SDS database that is accessable to only Project personnel.

Since product use at the Bonneville Project is tracked by location within the Project, prioritizing which products to investigate was done by eliminating products that did not meet the following cirteria: listed in 3 or more areas, or found in Powerhouse 1 and Powerhouse 2; used on a regular basis (generally means that a product is used montly/seasonally and not just used once or twice a year); and is not considered a paint or motor oil product. Additional products were also investigated the request of Melissa McBain. Unless requested, paint and motor oil products were excluded to further narrow down 
the list and due to their potential to be utilized in a critical role at the Project. In addition, the USACE is currently conducting product testing on paints, oils, and lubricants considered to be environmentally friendly ${ }^{[11]}$. Products that may be affected by the outcome of the testing were avoided from being selected. Once the products to be investigated were selected from the comprehensive chemcial product list, the following information was collected:

- The quantity used for the past 3 years and cost per product unit were obtained from Melissa McBain. The cost per product unit was converted to cost per ounce.

- A general description and designated use was gathered from the manufacturer's website.

- The SDS sheet for the product was downloaded to and reviewed for any potential environmental risks the product may pose based on available active ingredients or product testing that was included.

Product alternatives were then investigated by conducting a Web based search. Alternative products that were considered have to generally meet one or both of the following criteria: certified by a program that is recognized by a reputiable $3^{\text {rd }}$ party, federal, or state entity (see below); or can be considered to be multi-use to reduce the overall chemical count found at the Bonneville Project. When available, the cost for the alternative products was recorded and the cost per ounce was calculated to compare with the currently used product.

The ecolabels with certifiable third party accreditation that were utilized in this study were USEPA Safer Choice, SCAQMD, GreenGuard, and the USDA (United States Department of Agriculture) BioBased products. USEPA Safer Choice is a voluntary effort that companies can apply for. For the product to be granted the label, it must be at least as good as conventional competitive products within its category, have undergone the required standardized testing from recognized third party associations such as AATCC (American Association of Textile Chemists and Colorists), follow the recommended life-cycle considerations, and adhere to component criteria ${ }^{[12]}$. The SCAQMD ecolabel ensures that solvent cleaning (Rule 1171) and solvent degreasing (Rule 1122) products with its label are VOC compliant with federal and state of California rules, doesn't contain compounds that are classified as ozone-depleting or global warming compounds, and its reactivity level is not higher than toluene ${ }^{[8]}$. GreenGuard is an ecolabel from UL, a global safety, consulting, and certification company. The company devises its testing standards from ASTM (American Society of Textile Manufactures) D1156 and D6670, California's Department of Public Health Services, and the ISO (International Organization for Standardization) 16000 environmental testing series. The GreenGuard label is most recognized by the United States Green Building Council's LEED (Leadership in Energy and Environmental Design) green building rating system ${ }^{[3]}$. Like the USEPA Safer Choice and SCAQMD ecolabels, the testing focuses on VOC emissions for air quality. The USDA BioBased ecolabel requires companies to establish at least a certain amount of biological products in their product which is done by utilizing the ASTM D6866 test method ${ }^{[2]}$.

Results:

The products selected for investigation and their suitable environmentally friendly alternative(s) are shown in Table 4. 
Table 4: Table incorporating product name, company, quantity used of current product, unit size availability, unit cost per ounce in United States dollars, and certifications.

\begin{tabular}{|c|c|c|c|c|c|c|c|c|c|c|c|c|c|c|c|}
\hline \multirow{2}{*}{$\begin{array}{l}\text { Currently } \\
\text { Used } \\
\text { Product } \\
\text { Name }\end{array}$} & \multirow[b]{2}{*}{ Company } & \multirow[b]{2}{*}{ Unit } & \multirow{2}{*}{$\begin{array}{c}\text { Current } \\
\text { Inventor } \\
y\end{array}$} & \multicolumn{4}{|c|}{ Quantity Used } & \multirow{2}{*}{$\begin{array}{l}\text { Cost } \\
\text { in } \\
\text { U.S. \$ }\end{array}$} & \multirow{2}{*}{$\begin{array}{c}\text { Cos } \\
t \\
\text { per } \\
\text { oz } \\
\text { in } \\
\text { U.S } \\
. \$ \\
\end{array}$} & \multirow[b]{2}{*}{ Product Alternative } & \multirow[b]{2}{*}{ Company } & \multirow[b]{2}{*}{ Unit } & \multirow{2}{*}{$\begin{array}{l}\text { Cost } \\
\text { in } \\
\text { U.S. } \\
\$\end{array}$} & \multirow{2}{*}{$\begin{array}{c}\text { Cost } \\
\text { per } \\
\text { oz } \\
\text { in } \\
\text { U.S. } \\
\$\end{array}$} & \multirow[b]{2}{*}{$\begin{array}{c}\text { Certificatio } \\
\text { ns }\end{array}$} \\
\hline & & & & $\begin{array}{c}r \text { red } \\
\text { Dat } \\
\text { Dat }\end{array}$ & $\begin{array}{c}201 \\
7\end{array}$ & $\begin{array}{c}201 \\
6\end{array}$ & $\begin{array}{c}201 \\
5\end{array}$ & & & & & & & & \\
\hline $\begin{array}{l}\text { 21A058 } \\
\text { Windshiel } \\
\text { d De-Icer }\end{array}$ & $\begin{array}{l}\text { Ashland } \\
\text { Chemical } \\
\text { Company }\end{array}$ & $16 \mathrm{oz}$ & 28 & 14 & 20 & 18 & 5 & 6.14 & $\begin{array}{r}0.3 \\
8\end{array}$ & \multicolumn{6}{|c|}{ No good alternatives for windshield de-icers } \\
\hline \multirow[t]{2}{*}{$\begin{array}{l}390 \\
\text { Cutting } \\
\text { Oil } \\
\text { (Aerosol) }\end{array}$} & $\begin{array}{l}\text { A. W. } \\
\text { Chesterto } \\
\mathrm{n} \\
\text { Company }\end{array}$ & $13 \mathrm{oz}$ & 5 & 10 & 8 & 5 & 23 & 20.74 & $\begin{array}{r}1.6 \\
0\end{array}$ & $\begin{array}{l}\text { LU208 Cutting Oil } \\
\text { (Aerosol) }\end{array}$ & Sprayon & $\begin{array}{l}14 \mathrm{fl} \\
\mathrm{oz}\end{array}$ & 6.75 & 0.48 & $\begin{array}{l}\text { Meets } \\
\text { SCAQMD } \\
\text { Requiremen } \\
\text { ts }\end{array}$ \\
\hline & & & & & & & & & & $\begin{array}{l}\text { Tap-Magic Eco-Oil } \\
\text { (Aerosol) }\end{array}$ & $\begin{array}{l}\text { The Steco } \\
\text { Corporation }\end{array}$ & $12 \mathrm{oz}$ & 12.61 & 1.05 & $\begin{array}{l}\text { NSF H1 } \\
\text { Food Grade }\end{array}$ \\
\hline \multirow[t]{2}{*}{$\begin{array}{l}8190 \mathrm{Hi}- \\
\text { Strength } \\
\text { Adhesive }\end{array}$} & $\begin{array}{l}\text { Aervoe } \\
\text { Industries } \\
\text { Inc. }\end{array}$ & $\begin{array}{l}12 \\
o z\end{array}$ & 8 & 18 & 0 & 30 & 13 & 8.55 & $\begin{array}{r}0.7 \\
1\end{array}$ & $\begin{array}{l}3 \mathrm{M}^{\mathrm{TM}} \text { Fast Tack } \\
\text { Water Based } \\
\text { Adhesive 1000NF, } \\
\text { Neutral }\end{array}$ & $3 \mathrm{M}$ & $1 \mathrm{gal}$ & $\begin{array}{l}78.87 \\
- \\
94.10\end{array}$ & $\begin{array}{l}0.62 \\
- \\
0.74\end{array}$ & $\begin{array}{l}\text { GreenGuard } \\
\text {, LEED }\end{array}$ \\
\hline & & & & & & & & & & $\begin{array}{l}\text { Super } 77 \text { Aerosol } \\
\text { Spray Low } 25 \% \text { VOC }\end{array}$ & $3 \mathrm{M}$ & $\begin{array}{l}24 \mathrm{fl} \\
\mathrm{oz}\end{array}$ & $\begin{array}{l}8.16- \\
9.14\end{array}$ & $\begin{array}{l}0.34 \\
- \\
0.38\end{array}$ & GreenGuard \\
\hline $\begin{array}{l}\text { Brakleen } \\
\text { Brake } \\
\text { Parts } \\
\text { Cleaner - } \\
\text { Non- } \\
\text { Chlorinat } \\
\text { ed }\end{array}$ & $\begin{array}{l}\text { CRC } \\
\text { Industries, } \\
\text { Inc. }\end{array}$ & $\begin{array}{l}14 \\
o z\end{array}$ & 103 & 94 & 106 & 183 & 392 & 7.88 & $\begin{array}{r}0.5 \\
6\end{array}$ & $\begin{array}{l}\text { Zero VOC Brake and } \\
\text { Parts Cleaner }\end{array}$ & $\begin{array}{l}\text { Wurth USA } \\
\text { Inc. }\end{array}$ & $14 \mathrm{oz}$ & 4.17 & 0.30 & SCAQMD \\
\hline $\begin{array}{l}\text { Citrasolve } \\
\text { K\&L } \\
\text { Supply }\end{array}$ & $\begin{array}{l}\text { Paige } \\
\text { Industries }\end{array}$ & $\begin{array}{l}5 \\
\text { gal }\end{array}$ & 4 & 0 & 4 & 9 & 6 & 150 & $\begin{array}{r}0.2 \\
3\end{array}$ & $\begin{array}{l}\text { GlobalTech }{ }^{\circledast} \text { Heavy } \\
\text { Duty } \\
\text { Degreaser/concentr } \\
\text { ate }\end{array}$ & JNJ Industries & $1 \mathrm{gal}$ & $\begin{array}{l}162- \\
192\end{array}$ & $\begin{array}{l}1.27 \\
- \\
1.50\end{array}$ & SCAQMD \\
\hline $\begin{array}{l}\text { Citrasolve } \\
\text { K\&L } \\
\text { Supply }\end{array}$ & $\begin{array}{l}\text { Paige } \\
\text { Industries }\end{array}$ & $\begin{array}{l}15 \\
\text { oz }\end{array}$ & 59 & 0 & 1 & 8 & 16 & 9.59 & $\begin{array}{r}0.6 \\
4\end{array}$ & $\begin{array}{l}\text { GlobalTech }{ }^{\circledast} \text { Heavy } \\
\text { Duty } \\
\text { Degreaser/concentr } \\
\text { ate }\end{array}$ & JNJ Industries & $16 \mathrm{oz}$ & $\begin{array}{l}9.75- \\
11.13\end{array}$ & $\begin{array}{l}0.61 \\
- \\
0.70\end{array}$ & SCAQMD \\
\hline $\begin{array}{l}\text { Contact } \\
\text { Cleaner } \\
2000 \\
\text { Precision } \\
\text { Cleaner } \\
\end{array}$ & $\begin{array}{l}\text { CRC } \\
\text { Industries, } \\
\text { Inc. }\end{array}$ & $\begin{array}{l}15 \\
o z\end{array}$ & 0 & 44 & 126 & 98 & 205 & 23.9 & $\begin{array}{r}1.5 \\
9\end{array}$ & ELECTRON Aerosol & EcoLink & $16 \mathrm{oz}$ & 22 & 1.38 & $\begin{array}{l}\text { Information } \\
\text { not found }\end{array}$ \\
\hline & & & & & & & & & & Positron Aerosol & EcoLink & $16 \mathrm{oz}$ & 22 & 1.38 & $\begin{array}{l}\text { Information } \\
\text { not found }\end{array}$ \\
\hline $\begin{array}{l}\text { WD-40 } \\
\text { Aerosol } \\
\text { by WD-40 } \\
\text { Company }\end{array}$ & $\begin{array}{l}\text { WD-40 } \\
\text { Company }\end{array}$ & $\begin{array}{l}12 \\
o z\end{array}$ & 8 & 33 & 118 & 81 & 182 & 9.48 & $\begin{array}{r}0.7 \\
9\end{array}$ & $\begin{array}{l}\text { Bio Penetrating } \\
\text { Lubricant Aerosol }\end{array}$ & $\begin{array}{l}\text { Renewable } \\
\text { Lubricants, } \\
\text { Inc. }\end{array}$ & $11 \mathrm{oz}$ & 16 & 1.45 & $\begin{array}{l}\text { EAL VGP } \\
\text { Compliant } \\
\text { (EPA) }\end{array}$ \\
\hline $\begin{array}{l}\text { Multi-Use } \\
\text { Product } \\
\text { Bulk } \\
\text { Liquid }\end{array}$ & $\begin{array}{l}\text { WD-40 } \\
\text { Company }\end{array}$ & $\begin{array}{l}1 \\
\text { Gal } \\
\text { lon }\end{array}$ & 6 & 19 & 14 & 18 & 20 & 23.59 & $\begin{array}{r}0.1 \\
8\end{array}$ & $\begin{array}{l}\text { Biodegradable } \\
\text { Penetrating Oil }\end{array}$ & Lubriplate & $12 \mathrm{oz}$ & 16.15 & 1.35 & $\begin{array}{l}\text { USDA } \\
\text { BioBased } \\
\text { Product }\end{array}$ \\
\hline $\begin{array}{l}\text { Smart } \\
\text { Straw } \\
\text { Aerosol } \\
\text { by WD-40 } \\
\text { Company }\end{array}$ & $\begin{array}{l}\text { WD-40 } \\
\text { Company }\end{array}$ & $\begin{array}{l}12 \\
o z\end{array}$ & 5 & 36 & 118 & 81 & 182 & 9.48 & $\begin{array}{r}0.7 \\
9\end{array}$ & $\begin{array}{l}\text { Biodegradable } \\
\text { Penetrating Oil }\end{array}$ & Lubriplate & $12 \mathrm{oz}$ & 16.15 & 1.35 & $\begin{array}{l}\text { USDA } \\
\text { BioBased } \\
\text { Product }\end{array}$ \\
\hline $\begin{array}{l}\text { Original } \\
\text { KRUD } \\
\text { KUTTER }\end{array}$ & $\begin{array}{l}\text { Krud Kutter, } \\
\text { Inc. }\end{array}$ & $\begin{array}{l}55 \\
\text { gal }\end{array}$ & 2 & 0 & 0 & 1 & 0 & 825 & $\begin{array}{r}0.1 \\
2\end{array}$ & & & & & & $\begin{array}{l}\text { EPA Safer } \\
\text { Choice }\end{array}$ \\
\hline $\begin{array}{l}\text { Bee } \\
\text { Bopper } \\
\text { Wasp } \\
\text { Killer }\end{array}$ & ARI & $\begin{array}{l}14 \\
o z\end{array}$ & 50 & 10 & 88 & 43 & 97 & 14.51 & $\begin{array}{r}1.0 \\
4\end{array}$ & $\begin{array}{l}\text { EcoSMART } \\
\text { Organic }{ }^{T M} \\
\text { Insecticide Wasp } \\
\text { and Hornet Killer } \\
\text { (DR-F-039) }\end{array}$ & $\begin{array}{l}\text { EcoSMART } \\
\text { Technologies } \\
\text {, Inc. }\end{array}$ & $14 \mathrm{oz}$ & 9.44 & 0.67 & $\begin{array}{l}\text { Information } \\
\text { not found }\end{array}$ \\
\hline
\end{tabular}




\begin{tabular}{|c|c|c|c|c|c|c|c|c|c|c|c|c|c|c|c|}
\hline $\begin{array}{l}\text { PB } \\
\text { B'laster } \\
\text { Lubricant }\end{array}$ & $\begin{array}{l}\text { The Blaster } \\
\text { Corporation }\end{array}$ & $\begin{array}{l}15 \\
o z\end{array}$ & 12 & 29 & 35 & 45 & 71 & 8.95 & $\begin{array}{r}0.6 \\
0\end{array}$ & $\begin{array}{l}\text { Bio Penetrating } \\
\text { Lubricant }\end{array}$ & $\begin{array}{l}\text { Renewable } \\
\text { Lubricants, } \\
\text { Inc. }\end{array}$ & $11 \mathrm{oz}$ & 16 & 1.45 & $\begin{array}{l}\text { EAL VGP } \\
\text { Compliant } \\
\text { (EPA) }\end{array}$ \\
\hline $\begin{array}{l}\text { LOCTITE } \\
592 \\
\text { MEDIUM } \\
\text { STRENGT } \\
\text { H THREAD } \\
\text { SEALANT } \\
\text { known as } \\
\text { LOCTITE } \\
592 \text { PST } \\
\text { PIPE } \\
\text { SEALAN } \\
\end{array}$ & $\begin{array}{l}\text { Henkel } \\
\text { Corporation }\end{array}$ & $\begin{array}{l}2 \\
o z\end{array}$ & 21 & 25 & 68 & 55 & 52 & 15.05 & $\begin{array}{r}7.5 \\
3\end{array}$ & Dripstop 927 & $\begin{array}{l}\text { Hernon } \\
\text { Manufacturin } \\
\mathrm{g}, \mathrm{Inc}\end{array}$ & Inform & ion not $f$ & & \\
\hline $\begin{array}{l}\text { Heavy } \\
\text { Duty } \\
\text { Degreaser } \\
\text { ii }\end{array}$ & $\begin{array}{l}\text { CRC } \\
\text { Industries } \\
\text { Inc. }\end{array}$ & $\begin{array}{l}15 \\
o z\end{array}$ & 11 & 4 & 4 & 4 & 28 & 18.59 & $\begin{array}{r}1.2 \\
4\end{array}$ & $\begin{array}{l}\text { WD-40 Specialist } \\
\text { Industrial-Strength } \\
\text { Cleaner and } \\
\text { Degreaser }\end{array}$ & $\begin{array}{l}\text { WD-40 } \\
\text { Company }\end{array}$ & $32 \mathrm{oz}$ & 8.39 & 0.26 & $\begin{array}{l}\text { EPA Safer } \\
\text { Choice }\end{array}$ \\
\hline $\begin{array}{l}\text { Huskey } \\
\text { Hydrolub } \\
\text { e Grease } \\
\text { (All NLGI } \\
\text { grades) } \\
\end{array}$ & $\begin{array}{l}\text { Huskey } \\
\text { Specialty } \\
\text { Lubricants }\end{array}$ & $\begin{array}{l}5 \\
\text { gal }\end{array}$ & 4 & 0 & 0 & 0 & 0 & $\begin{array}{r}126.6 \\
7\end{array}$ & $\begin{array}{r}0.2 \\
0\end{array}$ & & & & & & $\begin{array}{l}\text { Being } \\
\text { Tested by } \\
\text { USACE }\end{array}$ \\
\hline $\begin{array}{l}\text { Huskey } \\
\text { LVI-50 } \\
\text { Grease } \\
\text { (All NLGI } \\
\text { grades) }\end{array}$ & $\begin{array}{l}\text { Huskey } \\
\text { Specialty } \\
\text { Lubricants }\end{array}$ & $\begin{array}{l}5 \\
\text { gal }\end{array}$ & 5 & 6 & 2 & 4 & 4 & $\begin{array}{r}311.9 \\
1\end{array}$ & $\begin{array}{r}0.4 \\
9\end{array}$ & & & & & & $\begin{array}{l}\text { Being } \\
\text { Tested by } \\
\text { USACE }\end{array}$ \\
\hline $\begin{array}{l}\text { MIBK } \\
\text { Thinner }\end{array}$ & $\begin{array}{l}\text { Rodda Paint } \\
\text { Company }\end{array}$ & $\begin{array}{l}55 \\
\mathrm{gal}\end{array}$ & 3 & 2 & 3 & 4 & 4 & $\begin{array}{r}426.2 \\
5 \\
\end{array}$ & $\begin{array}{r}0.0 \\
6 \\
\end{array}$ & & & & & & \\
\hline $\begin{array}{l}\text { Methyl } \\
\text { Isobutyl } \\
\text { Ketone }\end{array}$ & $\begin{array}{l}\text { Sasol } \\
\text { Solvents a } \\
\text { division of } \\
\text { Sasol } \\
\text { Chemical } \\
\text { Industries }\end{array}$ & $\begin{array}{l}55 \\
\text { gal }\end{array}$ & 3 & 2 & 3 & 4 & 4 & 905.5 & $\begin{array}{r}0.1 \\
3\end{array}$ & $\begin{array}{c}\text { AcraStrip } 700 \\
\text { Recyclable Solvent } \\
\text { Replacement }\end{array}$ & Polychem & & Informa & on not & und \\
\hline $\begin{array}{l}\text { Techspray } \\
\text { Blue } \\
\text { Shower ii }\end{array}$ & Techspray & $\begin{array}{l}18 \\
\mathrm{oz}\end{array}$ & 20 & 0 & 0 & 1 & 10 & 29.05 & $\begin{array}{r}1.6 \\
1\end{array}$ & ELECTRON Aerosol & EcoLink & $16 \mathrm{oz}$ & 22 & 1.38 & $\begin{array}{l}\text { Information } \\
\text { not found }\end{array}$ \\
\hline $\begin{array}{l}\text { Windex } \\
\text { Original } \\
\text { Glass } \\
\text { Cleaner }\end{array}$ & $\begin{array}{l}\text { S.C. Johnson } \\
\text { and Son, } \\
\text { Inc. }\end{array}$ & $\begin{array}{l}32 \\
o z\end{array}$ & 15 & 16 & 33 & 48 & 41 & 9.23 & $\begin{array}{r}0.2 \\
9\end{array}$ & $\begin{array}{l}\text { ECOS Pro Glass } \\
\text { Cleaner / } \\
\text { Orangerine Window } \\
\text { Cleaner Rtu (9362) }\end{array}$ & $\begin{array}{l}\text { Venus } \\
\text { Laboratories }\end{array}$ & $32 \mathrm{oz}$ & 5.64 & 0.18 & $\begin{array}{l}\text { EPA Safer } \\
\text { Choice, } \\
\text { USDA } \\
\text { BioPreferre } \\
\text { d }\end{array}$ \\
\hline & & & & & & & & & & $\begin{array}{l}\text { Champion Sprayon } \\
\text { Green World N }{ }^{\oplus} \\
\text { Glass Cleaner }\end{array}$ & $\begin{array}{l}\text { Chase } \\
\text { Products Co. }\end{array}$ & $14 \mathrm{oz}$ & $\begin{array}{l}\text { Inform } \\
\text { not fou }\end{array}$ & & $\begin{array}{l}\text { EPA Safer } \\
\text { Choice, } \\
\text { SCAQMD }\end{array}$ \\
\hline Zep 40 & Zep Inc. & $\begin{array}{l}16 \\
\mathrm{oz}\end{array}$ & 28 & 14 & 20 & 18 & 5 & 6.14 & $\begin{array}{r}0.3 \\
8\end{array}$ & $\begin{array}{l}\text { ECOS Pro Glass } \\
\text { Cleaner / } \\
\text { Orangerine Window } \\
\text { Cleaner Rtu (9362) }\end{array}$ & $\begin{array}{l}\text { Venus } \\
\text { Laboratories }\end{array}$ & $32 \mathrm{oz}$ & 5.64 & 0.18 & $\begin{array}{l}\text { EPA Safer } \\
\text { Choice, } \\
\text { USDA } \\
\text { BioPreferre } \\
d\end{array}$ \\
\hline & & & & & & & & & & $\begin{array}{l}\text { Champion Sprayon } \\
\text { Green World N }{ }^{\circledast} \\
\text { Glass Cleaner }\end{array}$ & $\begin{array}{l}\text { Chase } \\
\text { Products Co. }\end{array}$ & $14 \mathrm{oz}$ & $\begin{array}{l}\text { Inform } \\
\text { not fou }\end{array}$ & & $\begin{array}{l}\text { EPA Safer } \\
\text { Choice, } \\
\text { SCAQMD }\end{array}$ \\
\hline $\begin{array}{l}\text { Zep Ice } \\
\text { Melt }\end{array}$ & Zep Inc. & $\begin{array}{l}50 \\
\text { lbs }\end{array}$ & 29 & 36 & 31 & 34 & 7 & 25.38 & $\begin{array}{r}0.0 \\
3 \\
\end{array}$ & \multicolumn{6}{|c|}{ No good alternatives for windshield de-icers } \\
\hline $\begin{array}{l}\text { Simple } \\
\text { Green } \\
\text { Industrial } \\
\text { Cleaner \& } \\
\text { Degreaser } \\
\end{array}$ & $\begin{array}{l}\text { Sunshine } \\
\text { Makers, Inc. }\end{array}$ & $\begin{array}{l}1 \\
\text { gall } \\
\text { on }\end{array}$ & 14 & 14 & 41 & 25 & 17 & 12.99 & $\begin{array}{r}0.1 \\
0\end{array}$ & & & & & & $\begin{array}{l}\text { EPA Safer } \\
\text { Choice }\end{array}$ \\
\hline $\begin{array}{l}\text { PB } \\
\text { Penetrati } \\
\text { ng } \\
\text { Catalyst }\end{array}$ & $\begin{array}{l}\text { The Blaster } \\
\text { Corporation }\end{array}$ & $\begin{array}{l}15 \\
o z\end{array}$ & 12 & 29 & 35 & 45 & 71 & 8.95 & $\begin{array}{r}0.6 \\
0\end{array}$ & $\begin{array}{l}\text { Biodegradable } \\
\text { Penetrating Oil }\end{array}$ & Lubriplate & $12 \mathrm{oz}$ & 16.15 & 1.35 & $\begin{array}{l}\text { USDA } \\
\text { BioBased } \\
\text { Product }\end{array}$ \\
\hline
\end{tabular}


Out of the products investigated in Table 4, currently used products Original KRUD KUTTER from Krud Kutter, Inc. and Simple Green ${ }^{\circledR}$ Industrial Cleaner \& Degreaser from Sunshine Makers, Inc. already had a certification. In addition, two products that were investigated, Huskey Hydrolube Grease (All NLGI grades) and Huskey LVI-50 Grease (All NLGI grades), turned out to be a part of a study by USACE and further information was not collected regarding these products ${ }^{[11]}$.

Green product alternatives, that upon investigating, had incomplete information available were: ELECTRON Aerosol and Positron Aerosol by EcoLink and EcoSMART Organic ${ }^{\mathrm{TM}}$ Insecticide Wasp and Hornet Killer (DR-F-039) by EcoSMART Technologies, Inc. for certifications; Dripstop 927 by Hernon Manufacturing, Inc. and AcraStrip 700 Recyclable Solvent Replacement by Polychem for unit size availability, unit cost per ounce, and certifications; and Champion Green ${ }^{\circledR}$ Industrial Cleaner \& Degreaser by Chase Products Co. for unit cost.

Zep Ice Melt by Zep Inc. and 21A058 Windshield De-Icer by Ashland Chemical Company did not have a suitable green product alternative when investigated.

Out of the suitable green product alternatives that were investigated, the following had a lower cost per ounce than comparable currently used products: LU208 Cutting Oil (Aerosol) by Sprayon; Tap-Magic Eco-Oil (Aerosol); 3M ${ }^{\mathrm{TM}}$ Fast Tack Water Based Adhesive 1000NF, Neutral by 3M; Super 77 Aerosol Spray Low $25 \%$ VOC by 3M; Zero VOC Brake and Parts Cleaner by Wurth USA Inc.; ELECTRON Aerosol and Positron Aerosol by EcoLink; WD-40 Specialist Industrial-Strength Cleaner and Degreaser by WD-40 Company; and ECOS Pro Glass Cleaner by Venus Laboratories.

\section{Conclusion:}

The Bonneville Project currently has approximately 800 unique chemical products on site at a given time, ranging from machine lubricants to paints. According to the comprehensive chemical product list and the number of unique chemical products used at each location, the main operations using chemicals within the Bonneville Project are Powerhouse 1, Powerhouse 2, and the Paint Shop. These locations have at least 250 unique chemical products on site, representing an opportunity to increase environmentally preferable purchasing to lessen the potential impact these operations could cause to the Bonneville Project and the surrounding area. The focus on products used at multiple operational sites is a step done to look at more widely used chemical products that can have the most impact to the environment based on multiple exposure zones and quantity used.

The green products in Table 4 represent results found after conducting a web based search for alternatives to the conventional products currently used on-site. The most common attribute for a product to be considered a green chemical product was for it to have a low or no VOCs (Volatile Organic Compounds).

For some conventional products, the search was inconclusive to find a suitable green product replacement. This can be mainly attributed to a lack of demand for a green product in the conventional product category with specific properties, such as an aerosol application feature, or minimal incentive for companies to develop new formulas and get them certified as a green product ${ }^{[10]}$. 
There were products investigated where their suitable green alternative was less expensive per ounce. For instance, the currently used product 390 Cutting Oil (Aerosol) by A.W. Chesterton Company is $\$ 1.60$ per ounce, while the two suitable green product alternatives, LU208 Cutting Oil (Aerosol) by Sprayon and Tap-Magic Eco-Oil (Aerosol), are $\$ 0.48$ and $\$ 1.05$ per ounce respectively. A current product, Brakeleen Brake Parts Cleaner - Non-Chlorinated by CRC Industries, Inc., goes through at least 100 units annually at a cost of $\$ 0.56$ per ounce. The green product alternative, Zero VOC Brake and Parts Cleaner by Wurth USA Inc. is less than Brakeleen at $\$ 0.30$ per ounce. This shows that while green product alternatives are usually associated with higher costs, this is not always the case.

A few products that were requested for product use, such as the Original KRUD KUTTER from Krud Kutter, Inc. already had an ecolabel. There were some products, such as Citrasolve, K\&L Supply by Paige Industries that had not been used in over a year and as such, a comparable green product to replace it would have minimal impact on the overall sustainable goals for the Bonneville Project. Conversely, high use products such as Brakleen Brake Parts Cleaner - Non-Chlorinated by CRC Industries, Inc. and WD-40 Aerosol by WD-40 Company have a potentially larger impact on the surrounding environment. The certified green product replacements for high use products categories can have a larger positive environmental impact when used compared to conventional products that contain chemical products that can have negative bio-accumulative effects or negatively impact the aquatic environment.

\section{Management Recommendations:}

With the large number of chemicals used at the Bonneville Project for various purposes, the opportunity to incorporate green chemicals is potentially high. The use of green chemical products has the potential to reduce the exposure of harmful chemicals to the environment and site personnel. While the Bonneville Project is still in the early stages of green product use, there may be ways to reduce conventional product use without reducing the efficiency of the Project's operations. The following are recommendations for the Bonneville Project to increase their green purchasing.

- Based on the observations made during this study, prioritizing products that have been certified green over conventional products may experience resistance from Project personnel. As such, incentivizing the use of green products, as well as trial testing them may be needed for these products to be accepted by Project personnel. A short survey should be conducted during testing to document the reactions and rating of product performance from Project personnel.

- Based on the findings for this study, the Bonneville Project can prioritize the replacement of some conventional products with their suitable green product alternatives without spending more.

- Based on the research done for this study, the Bonneville Project can conduct further searches for certified green products through a certification organization's website as an efficient means to compile a list of potential green product alternatives for a specific search category, such as cleaners and degreasers.

- Based on the research done for this study and observations done during the waste stream analysis, the USACE should encourage the use of reusable application devices for green 
products. Manufactures or distributers tend to sell green products in bulk and this is a way to reduce waste of single use application devices.

- Based on the research done for this study and the number of different paints used on site, prioritizing the procurement of super-compliant type paints is a good way to minimize VOC emissions. This type of product is formulated to be below limits for VOC emissions and must meet standards set by South Coast Air Quality Management District (SCAQMD).

Incorporating a larger percentage of green product use at the Bonneville Project is not without its challenges. One such challenge is the lack of suitable green product alternatives that are certified to replace conventional products ${ }^{[9]}$. The manufacturing sites for conventional products have their infrastructure setup in a way that makes changing chemical formulas to be green inherently difficult and not cost competitive. This is especially true if they do not deem there to not be enough market demand for a green chemical formula ${ }^{[1,9,10]}$. Also, companies that develop green chemical formulas might find it difficult to certify the products and or be able to scale up production in a sufficient time to meet demand as they tend to be smaller and not yet established ${ }^{[13]}$. Another challenge is convincing professionals and consumers to switch from a conventional product that works to a green product that is meant to compete with it ${ }^{[9,13]}$. This is especially more difficult if the green product is more expensive and/or the application method requires the user to adjust their habit of product use.

In conjunction with this study, USACE is also investigating several environmentally acceptable lubricants for in-water use structures and is primarily focused on greases ${ }^{[11]}$. The Bonneville Project is included in this USACE study with the final results to be released sometime in the future. As such, conventional type lubricants were excluded from being selected to prevent overlap with the USACE study unless otherwise requested. Limitations for green product alternatives also depended on the category of conventional products, such as oils or machine specific chemical products. For example, specialized equipment such as turbines, require specific products to be used for maintenance and if not used, could result in damage or voiding the warranty which is usually stated in the manufacture's maintenance and warranty manual. Other products, such as utilizing synthetic ester instead of mineral-oil for transformers, are highly specific and might require expensive retrofitting in order to utilize green alternatives. As such, The Bonneville Project's current design of transformers uses Exxon Mobile Corporation's UNIVOLT N 61 B transformer oil. If the Project decided to switch to synthetic ester instead of mineral oil, as is the case with the Siemen designed transformers that utilize synthetic ester instead of mineral-oil, then the current setup would most likely be incompatible ${ }^{[7]}$. Green product recommendations for specialized equipment will require USACE to conduct lengthy studies, such as the one for environmentally acceptable lubricants. Due to this constraint, those recommendations should be limited to applications that use conventional products that come into contact with sensitive environments regularly.

Incorporating green product alternatives across the Bonneville Project can help reduce the potential risk to the environment that conventional products can have. In addition, there is also a potential to reduce personnel exposure from potent chemical compounds when using green products. With the ubiquitous use and ease of use of conventional chemical products, there lie many challenges to adopting green chemical products ${ }^{[10,11,13]}$. However, introducing green products can potentially reduce risk for the 
Bonneville Project and its personnel while also being a showcase for their efficacy at a high profile location. 


\section{Study Conclusion}

The results gained from the waste stream and green purchasing analysis of the Bonneville Project can help the Project in reaching their goal of reducing refuse waste by $50 \%$ and increasing the procurement of green chemical products throughout their operations. With the Bonneville Project currently recycling a sixth of their total non-hazardous waste, there is room for increasing the rate of recycling. Focusing on reducing recycling waste found in refuse waste in refuse containers and reducing refuse waste in sort categories Wood, Yard, and Natural River Waste (W), Food Scraps (FS), Non-Recyclable Paper (NRPa), Non-Recyclable Plastic Bags, Film, Containers, and Tubs (NRPI), and Food Soiled Paper (FSP) will enable the Bonneville Project of reaching their refuse waste reduction goal. The extent of refuse waste reduction will depend on implementation and education practices. The designated area, Juvenile Fish Facility, has the lowest rate of refuse waste found in their recycling waste in the recycling container. The steps taken by the personnel that work at that designated area can be modeled to decrease the amount of refuse waste found in the recycling waste across the Bonneville Project. Also, tackling challenging waste factors that may limit the ability of the Bonneville Project to reach their goal will help their ultimate goal of becoming a zero-waste facility.

The benefits of increasing the procurement of green chemical products can potentially outweigh the time and cost of cleanup of conventional product spills. This is especially important for the Bonneville Project due to its location on the Columbia River and proximity to Portland, Oregon. With USACE currently looking at alternatives for greases and lubricants for in-water structures, there is a need within USACE to reduce the potential for toxic spills from conventional products. However, suitable green product alternatives can be difficult to find and verify that they work at the same level or better than conventional products while not costing more. This can be countered by replacing multiple conventional products that serve similar functions with one or more green product. In addition to reducing risk to the environment and Project personnel, the high profile location grants the Bonneville Project the chance to be a notable platform for their green purchasing program to highlight the program's efficacy.

The significance of the Bonneville Project on the Lower Columbia River and its surrounding human population adds importance to the facility's wide use of chemical products and reduction of nonhazardous waste. With the results and recommendations of this study, the USACE will hopefully have gained significant insight into the Bonneville Project's waste stream to enable them to implement management strategies to reduce their contribution to the landfill and to increase their use of green chemical products. 


\section{References:}

[1] Anastas, P., \& Eghbali, N. (2010). Green chemistry: principles and practice. Chemical Society Reviews, 39(1), 301-312.

[2] BioPreferred. (2018). Retrieved from https://biopreferred.gov/BioPreferred/faces/pages/AboutLabel.xhtml

[3] GreenGuard. (2018). Retrieved from http://www.greenguard.org/en/index.aspx

[4] DOD Instruction 4715.23. Integrated Recycling and Solid Waste Management. 24 October 2014. http://www.esd.whs.mil/Portals/54/Documents/DD/issuances/dodi/471523 dodi 2016.pdf

[5] http://www.co.washington.or.us/HHS/SWR/upload/Waste-Assessment-Guide-Final.pdf

[6] http://www.nwp.usace.army.mil/Locations/Columbia-River/Bonneville/

[7] https://www.siemens.com/global/en/home/products/energy/high-voltage/transformers/powertransformers.html

[8] Incentives and Programs, Business (2018). Retrieved from http://yourstory.aqmd.gov/home/programs/business

[9] Mary Ann Curran, (2001),"Developing a tool for environmentally preferable purchasing", Environmental Management and Health, Vol. 12 Iss 3 pp. $244-253$

[10] Matus, K. J., Clark, W. C., Anastas, P. T., \& Zimmerman, J. B. (2012). Barriers to the implementation of green chemistry in the United States. Environmental science \& technology, 46(20), 10892-10899.

[11] Medina, V. F. (2015). Evaluation of Environmentally Acceptable Lubricants (EALs) for dams managed by the U.S. Army Corps of Engineers. ERDC TN-WOTS-MS-9, Vicksburg, MS: U.S. Army Engineer Research and Development Center, [Environmental Laboratory].

[12] Safer Choice. (2018, May 23). Retrieved from http://www.epa.gov/saferchoice

[13] Tobiszewski, M., Mechlińska, A., \& Namieśnik, J. (2010). Green analytical chemistry-theory and practice. Chemical Society Reviews, 39(8), 2869-2878.

[14] Yu, C. C., \& Maclaren, V. (1995). A comparison of two waste stream quantification and characterization methodologies. Waste Management \& Research, 13(4), 343-361.

[15] USEPA. (2018, July). Advancing Sustainable Materials Management: 2015 Fact Sheet. Office of Land and Emergency Management (5306P), EPA530-F-18-004.

[16] Green Solutions (2012, December). 2012 Waste Stream Analysis for Clark County, Washington. Green Solutions Environmental Consulting. 


\section{Appendices:}

Appendix A: Audit Form

\begin{tabular}{|c|c|c|}
\hline \multicolumn{3}{|l|}{ Refuse/Recycling Container: } \\
\hline \multicolumn{3}{|l|}{ Date of Sort: } \\
\hline \multicolumn{3}{|l|}{ Individuals Involved: } \\
\hline Material Type: & Weight in lbs. & Notes \\
\hline \multicolumn{3}{|l|}{ Recycling: } \\
\hline \multicolumn{3}{|l|}{ Corrugated Cardboard } \\
\hline \multicolumn{3}{|l|}{ Glass Bottles/Jars } \\
\hline \multicolumn{3}{|l|}{ Mixed Paper/Newspaper } \\
\hline \multicolumn{3}{|l|}{ Plastic Bottles/Tubs } \\
\hline \multicolumn{3}{|l|}{ Tin/Metal/Aluminum/Cans } \\
\hline \multicolumn{3}{|l|}{ Scrap Metal } \\
\hline \multicolumn{3}{|l|}{ Milk Cartons/Juice Boxes } \\
\hline \multicolumn{3}{|l|}{ Refuse: } \\
\hline \multicolumn{3}{|l|}{ Food-Soiled Paper } \\
\hline \multicolumn{3}{|l|}{ Non-Recyclable Paper } \\
\hline \multicolumn{3}{|l|}{ Block Foam } \\
\hline \multicolumn{3}{|l|}{$\begin{array}{r}\text { Wood/Yard/Natural River } \\
\text { Waste }\end{array}$} \\
\hline \multicolumn{3}{|l|}{ Food Scraps } \\
\hline \multicolumn{3}{|l|}{$\begin{array}{r}\text { Plastic } \\
\text { Bags/Film/Containers/Tubs }\end{array}$} \\
\hline Other & & \\
\hline
\end{tabular}




\section{$\mathrm{N}$ Distribution of Waste Material for Category Corrugated Cardboard}

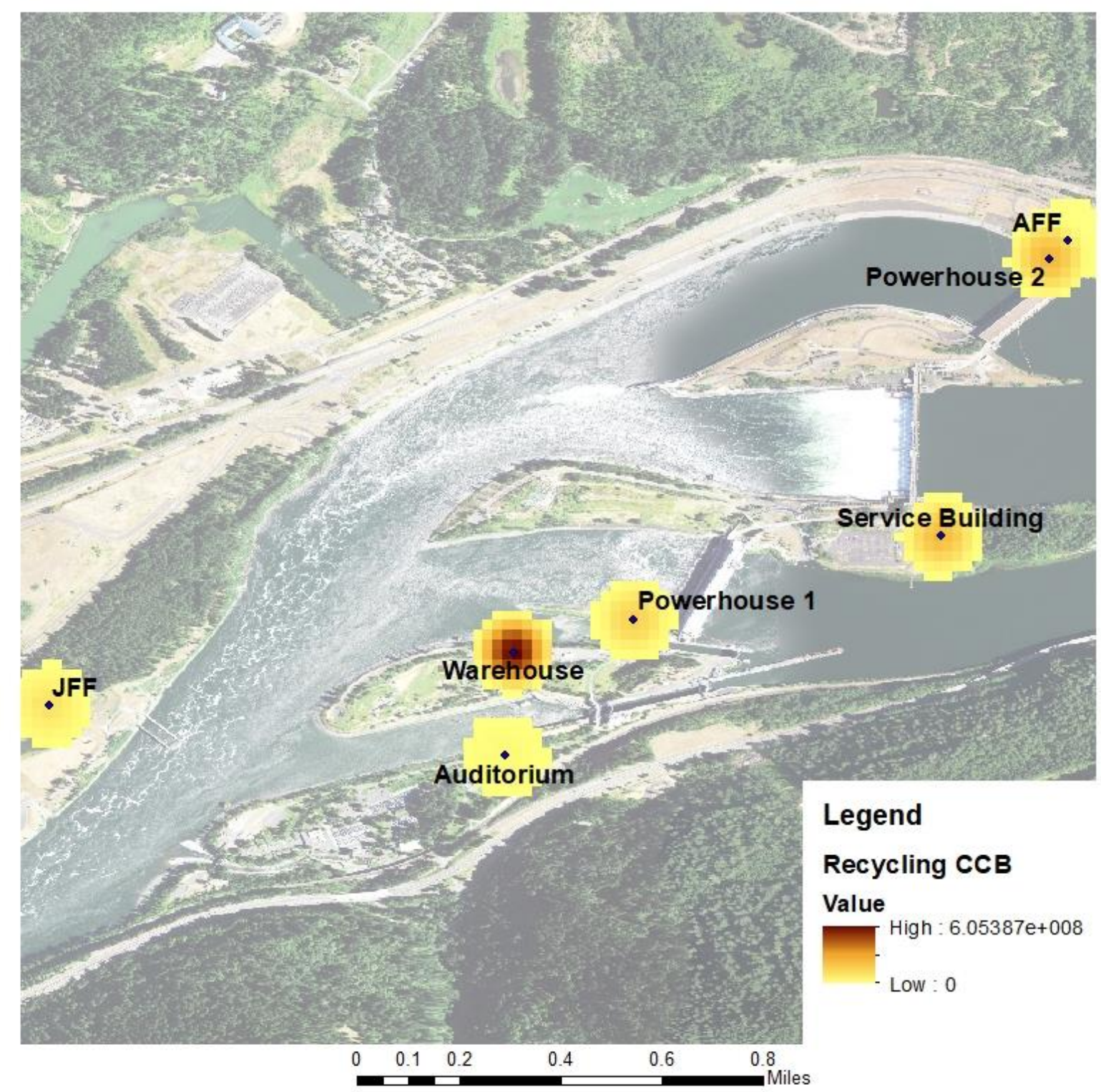

Figure 12: Kernel density map for category 'Corrugated Cardboard' at the Bonneville Project encompassing all designated areas. The darker the color scale, the higher amount of weight for the category represented per designated area. JFF and AFF indicate Juvenile Fish Facility and Adult Fish Facility respectively. 


\section{N Distribution of Waste Material for Category Glass Bottles and Jars}

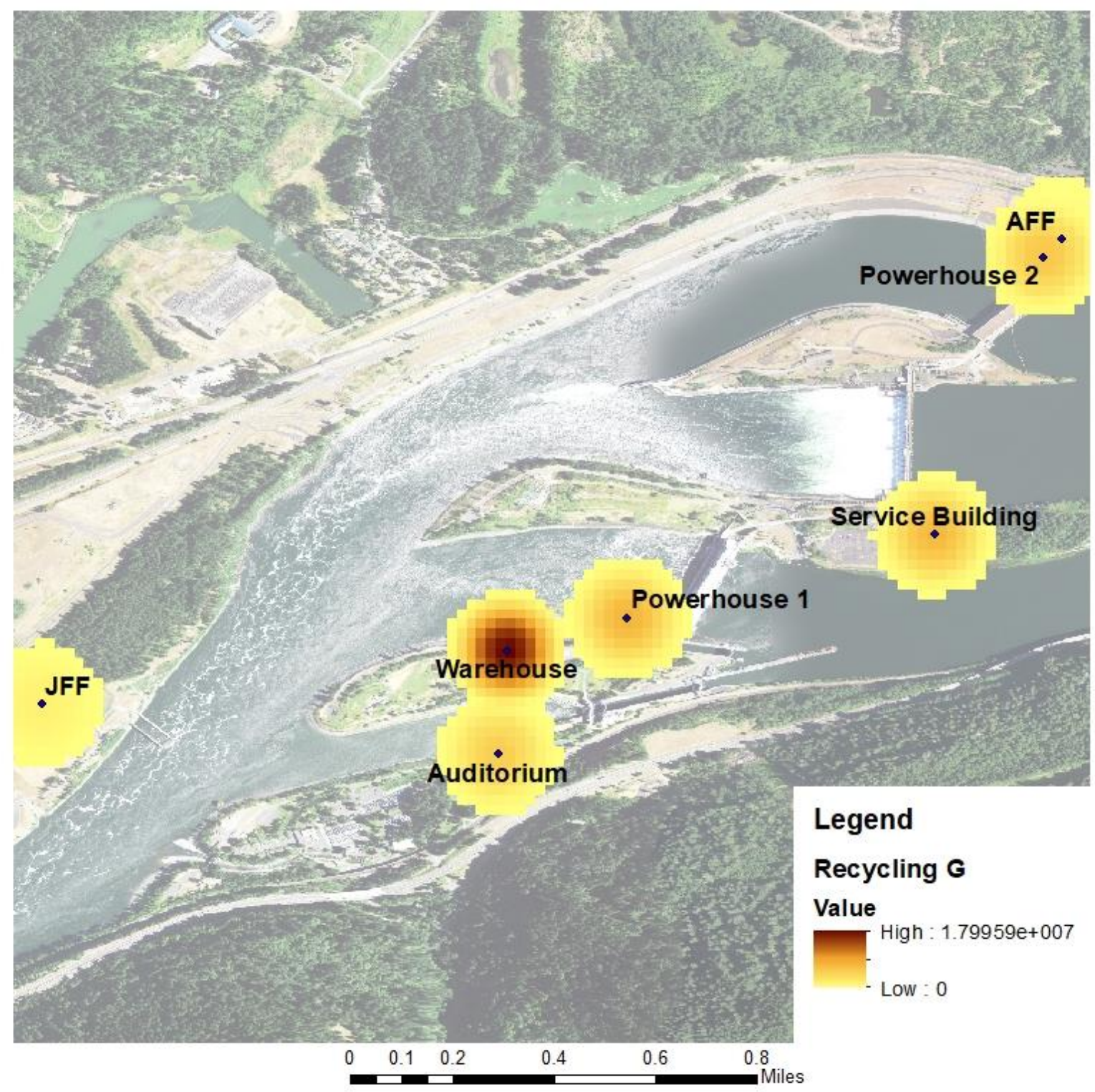

Figure 13: Kernel density map for category 'Glass Bottles and Jars' at the Bonneville Project encompassing all designated areas. The darker the color scale, the higher amount of weight for the category represented per designated area. JFF and AFF indicate Juvenile Fish Facility and Adult Fish Facility respectively. 


\section{N Distribution of Waste Material for Category Milk Cartons and Juice Boxes}

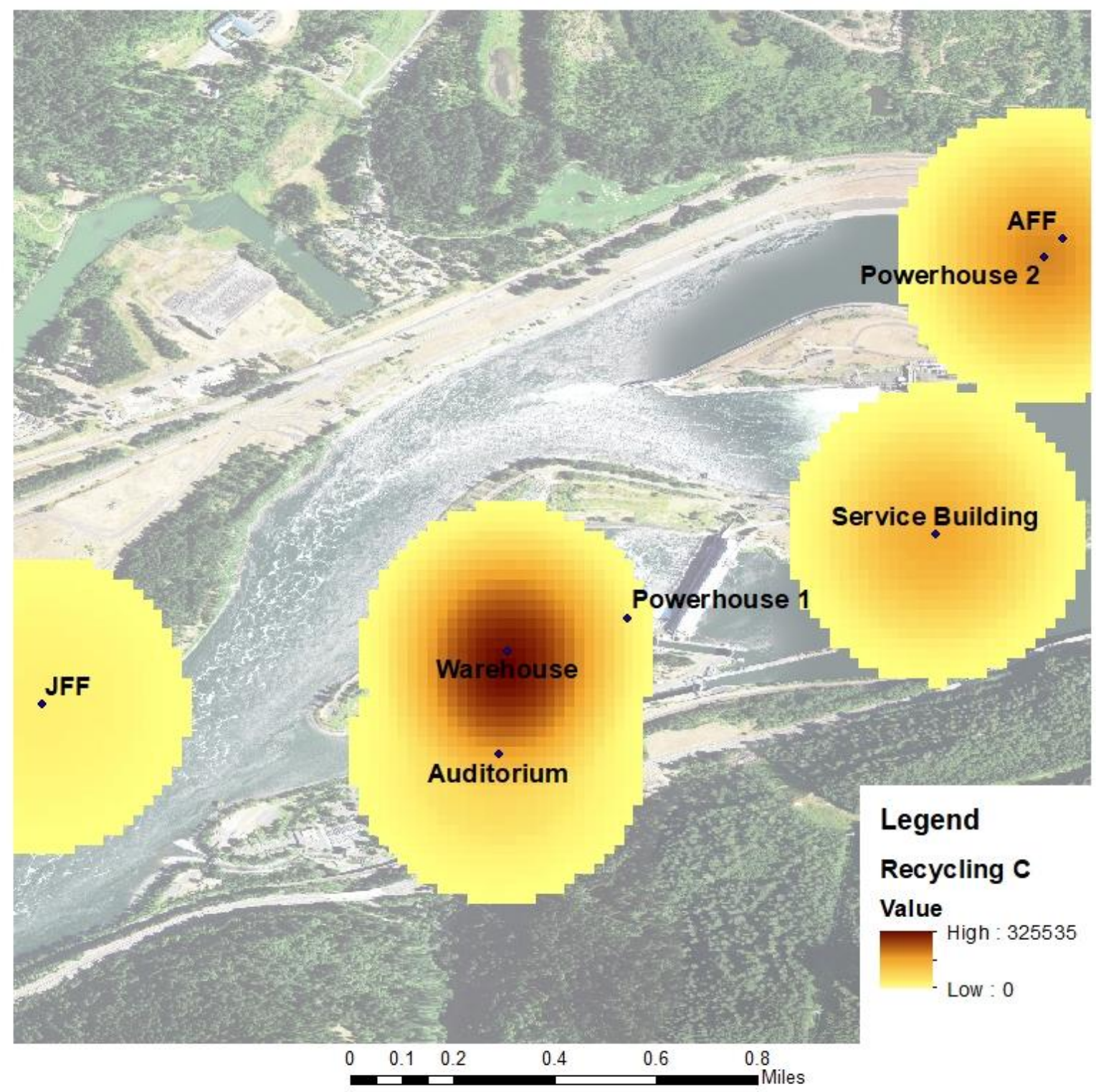

Figure 14: Kernel density map for category 'Milk Cartons and Juice Boxes' at the Bonneville Project encompassing all designated areas. The darker the color scale, the higher amount of weight for the category represented per designated area. JFF and AFF indicate Juvenile Fish Facility and Adult Fish Facility respectively. 


\section{Distribution of Waste Material for Category Tin, Metal, and Aluminum Cans}

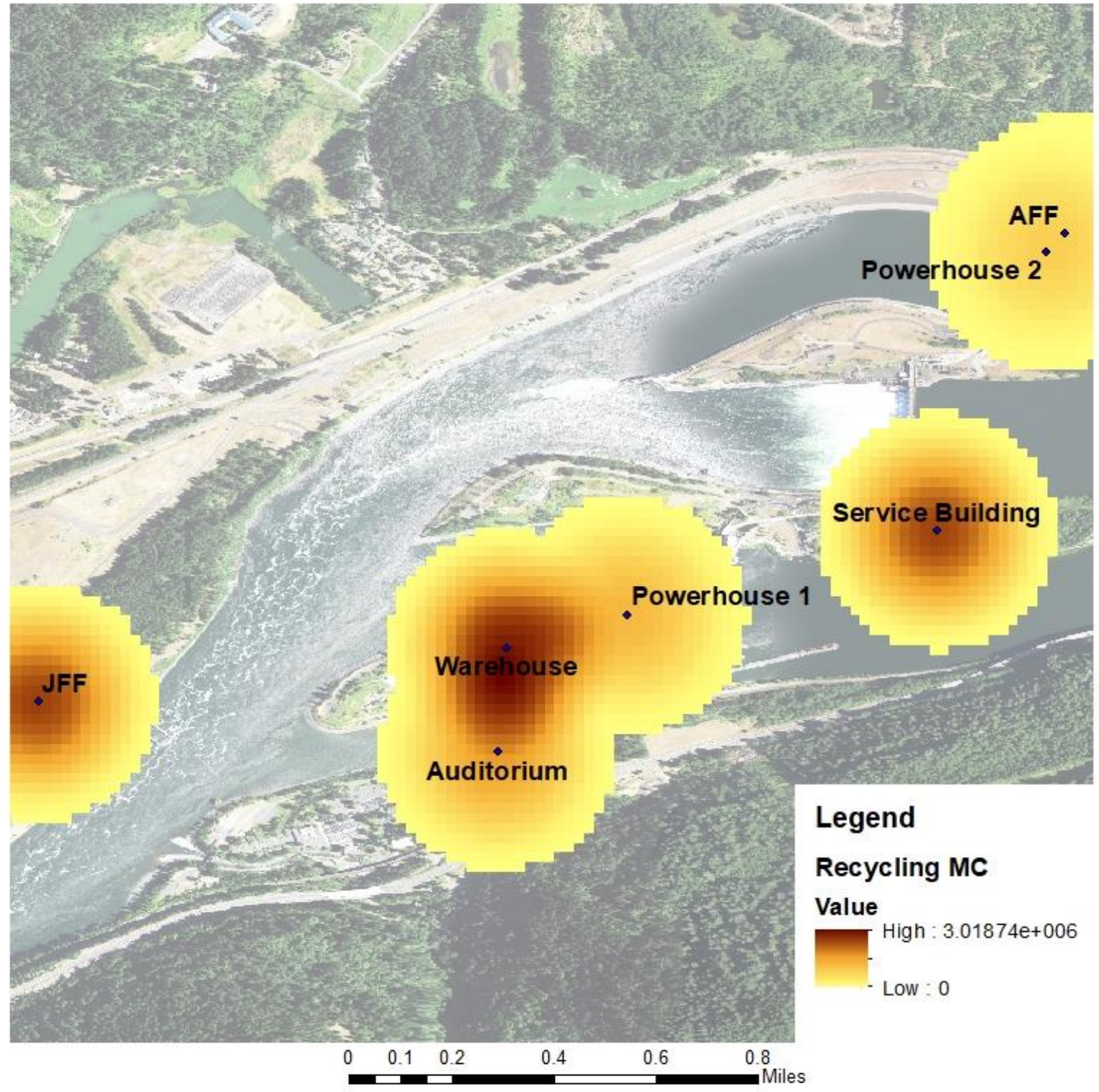

Figure 15: Kernel density map for category 'Tin, Metal, and Aluminum Cans' at the Bonneville Project encompassing all designated areas. The darker the color scale, the higher amount of weight for the category represented per designated area. JFF and AFF indicate Juvenile Fish Facility and Adult Fish Facility respectively. 


\section{N Distribution of Waste Material for Category Recyclable Mixed Paper and Newspaper}

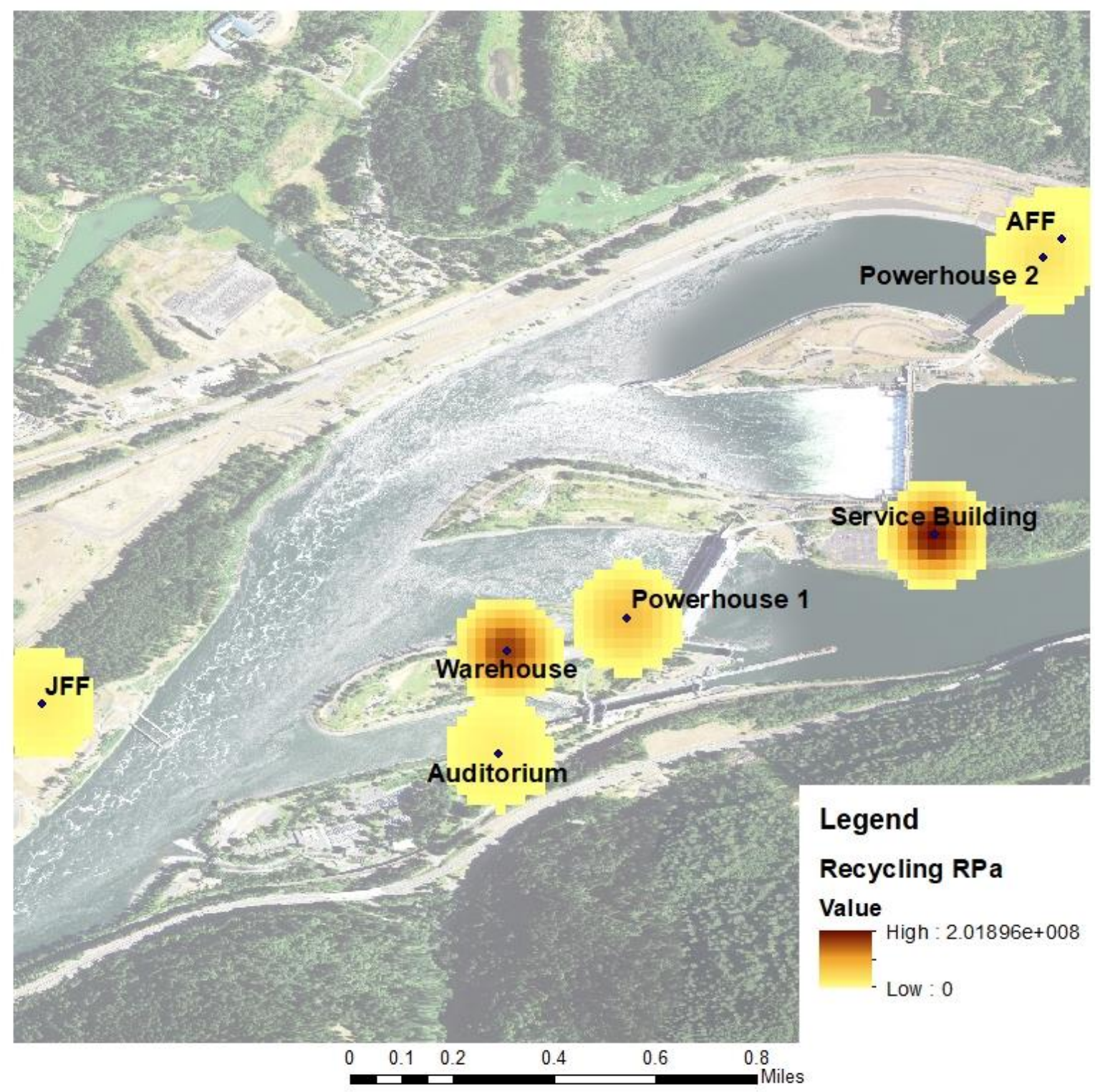

Figure 16: Kernel density map for category 'Recyclable Mixed Paper and Newspaper' at the Bonneville Project encompassing all designated areas. The darker the color scale, the higher amount of weight for the category represented per designated area. JFF and AFF indicate Juvenile Fish Facility and Adult Fish Facility respectively. 


\section{N Distribution of Waste Material for Category Recyclable Plastic Bottles and Tubs}

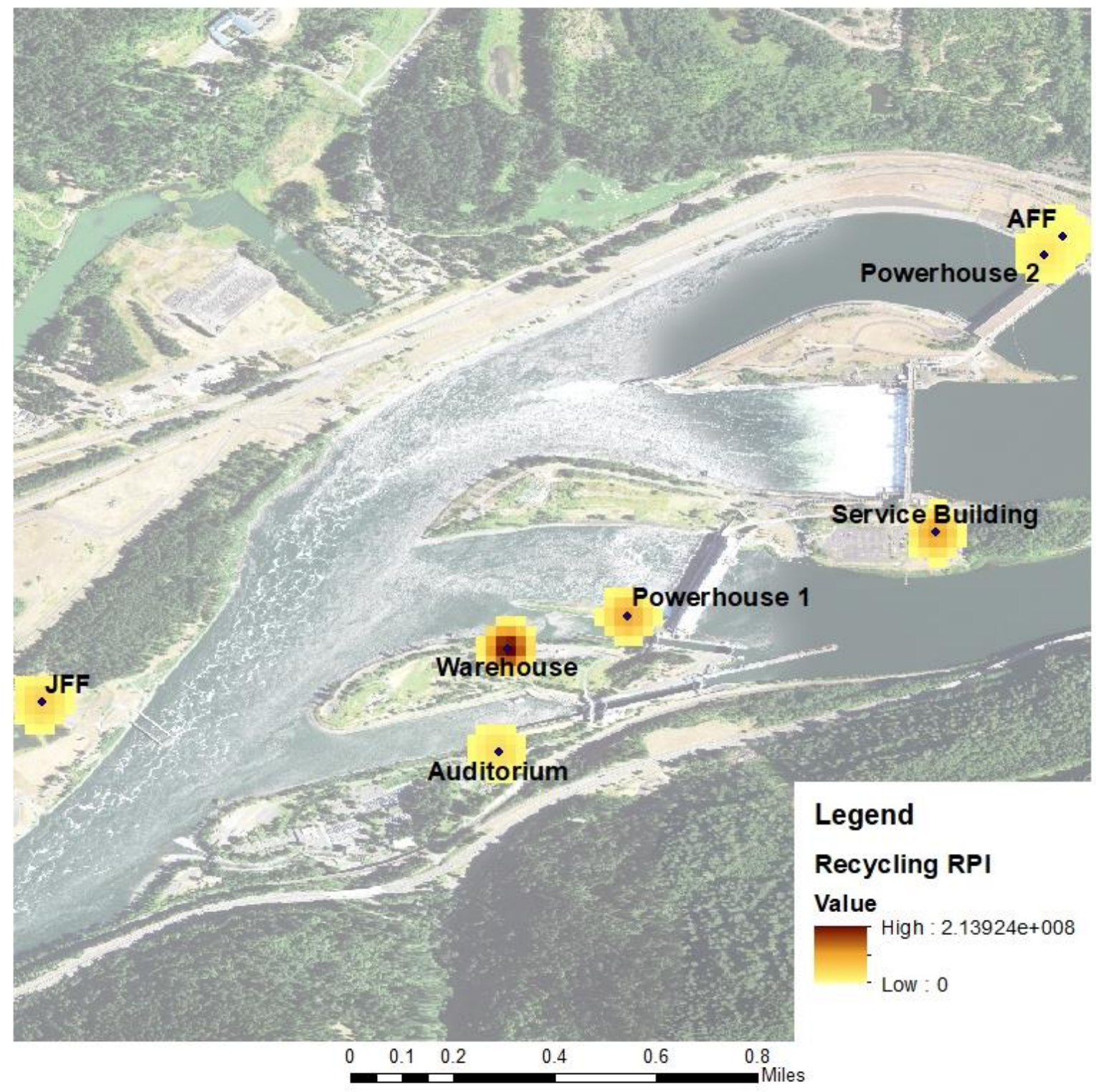

Figure 17: Kernel density map for category 'Recyclable Plastic Bottles and Tubs' at the Bonneville Project encompassing all designated areas. The darker the color scale, the higher amount of weight for the category represented per designated area. JFF and AFF indicate Juvenile Fish Facility and Adult Fish Facility respectively. 


\section{N Distribution of Waste Material for Category Recyclable Scrap Metal}

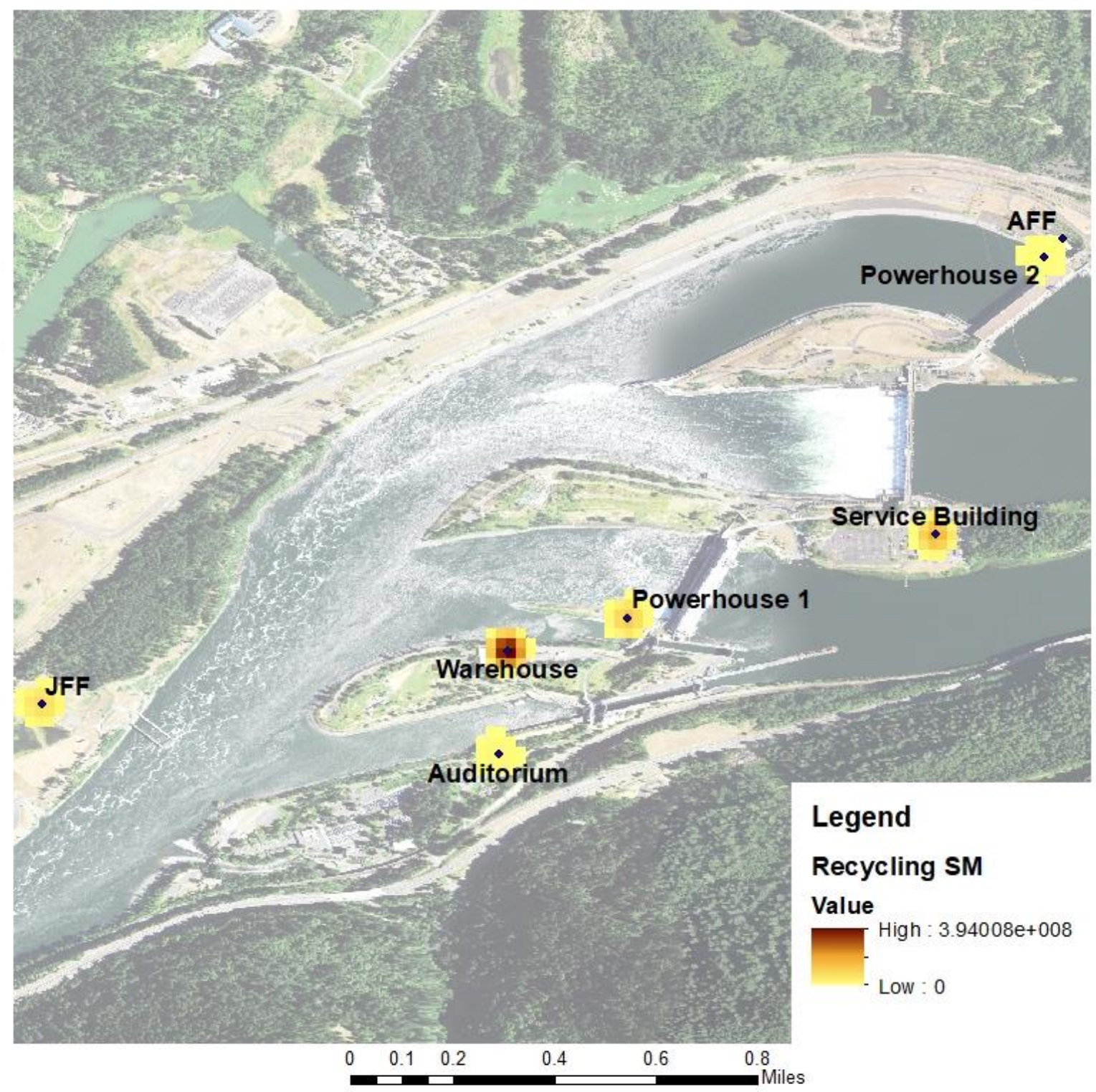

Figure 18: Kernel density map for category 'Recyclable Scrap Metal' at the Bonneville Project encompassing all designated areas. The darker the color scale, the higher amount of weight for the category represented per designated area. JFF and AFF indicate Juvenile Fish Facility and Adult Fish Facility respectively. 


\section{Distribution of Waste Material for Category
Soiled Cloth}

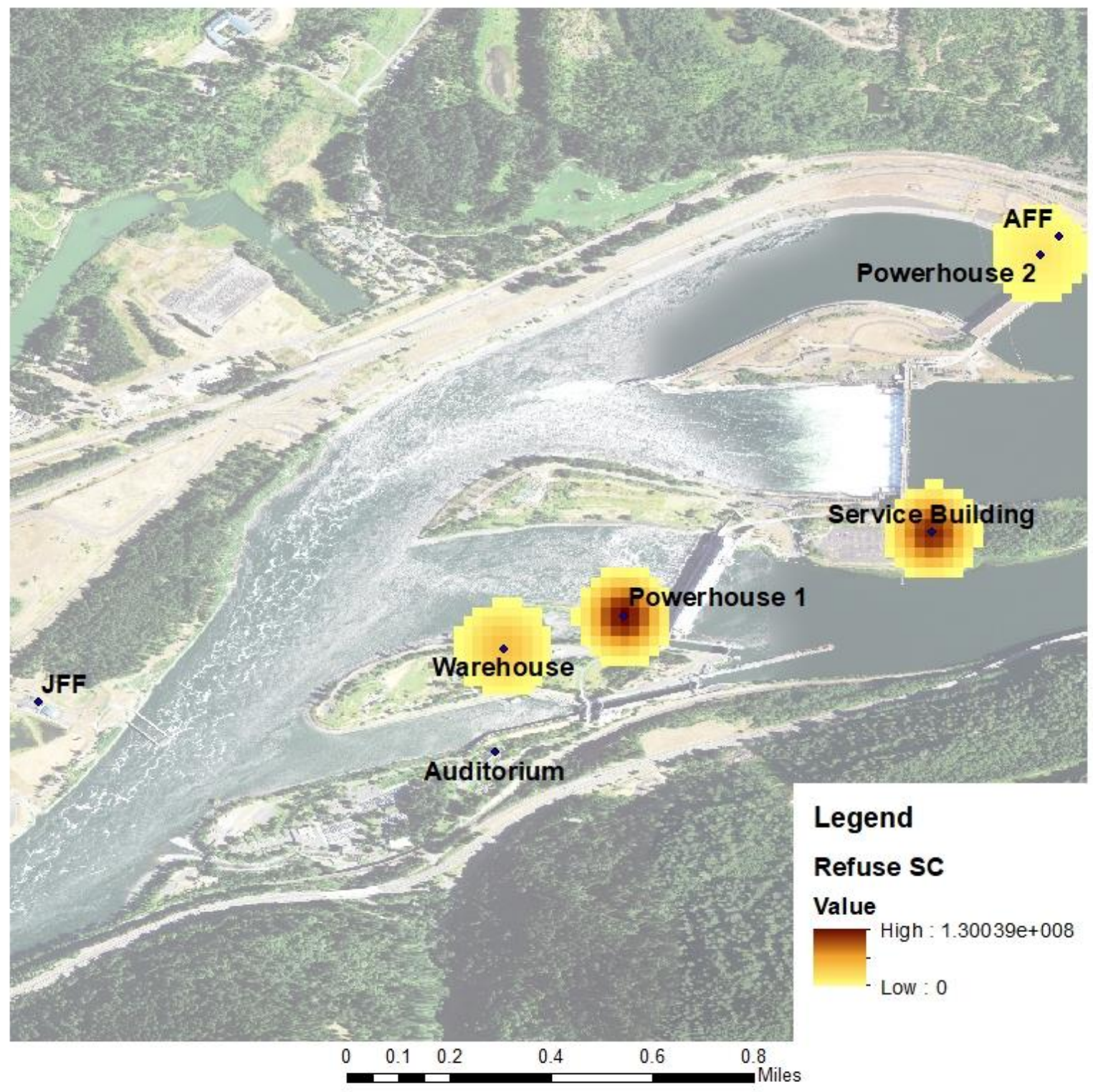

Figure 19: Kernel density map for category 'Soiled Cloth' at the Bonneville Project encompassing all designated areas. The darker the color scale, the higher amount of weight for the category represented per designated area. JFF and AFF indicate Juvenile Fish Facility and Adult Fish Facility respectively. 


\section{N Distribution of Waste Material for Category Block Foam}

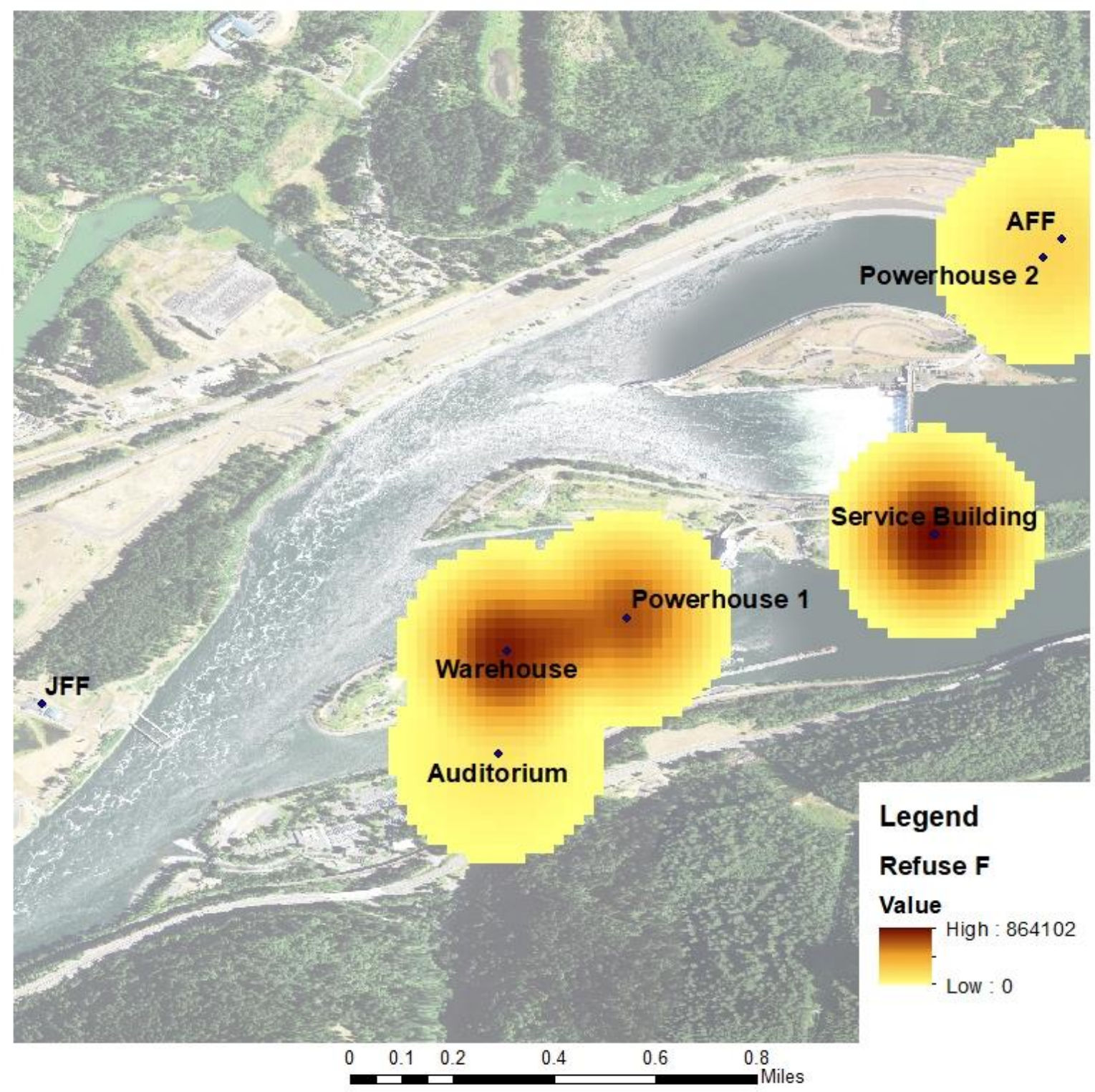

Figure 20: Kernel density map for category 'Block Foam' at the Bonneville Project encompassing all designated areas. The darker the color scale, the higher amount of weight for the category represented per designated area. JFF and AFF indicate Juvenile Fish Facility and Adult Fish Facility respectively. 


\section{N Distribution of Waste Material for Category Food Scraps}

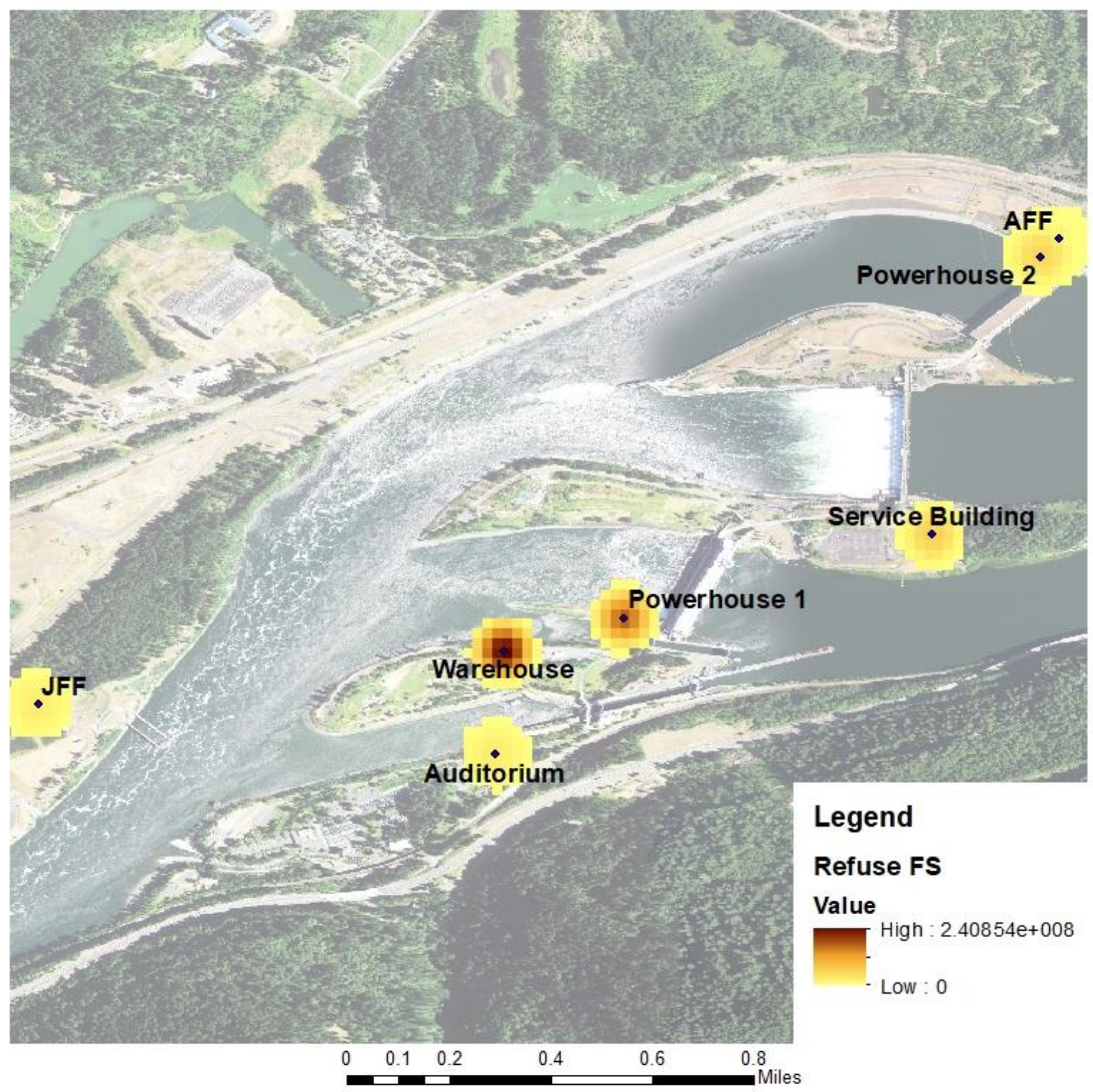

Figure 21: Kernel density map for category 'Food Scraps' at the Bonneville Project encompassing all designated areas. The darker the color scale, the higher amount of weight for the category represented per designated area. JFF and AFF indicate Juvenile Fish Facility and Adult Fish Facility respectively. 


\section{Distribution of Waste Material for Category
Food Soiled Paper}

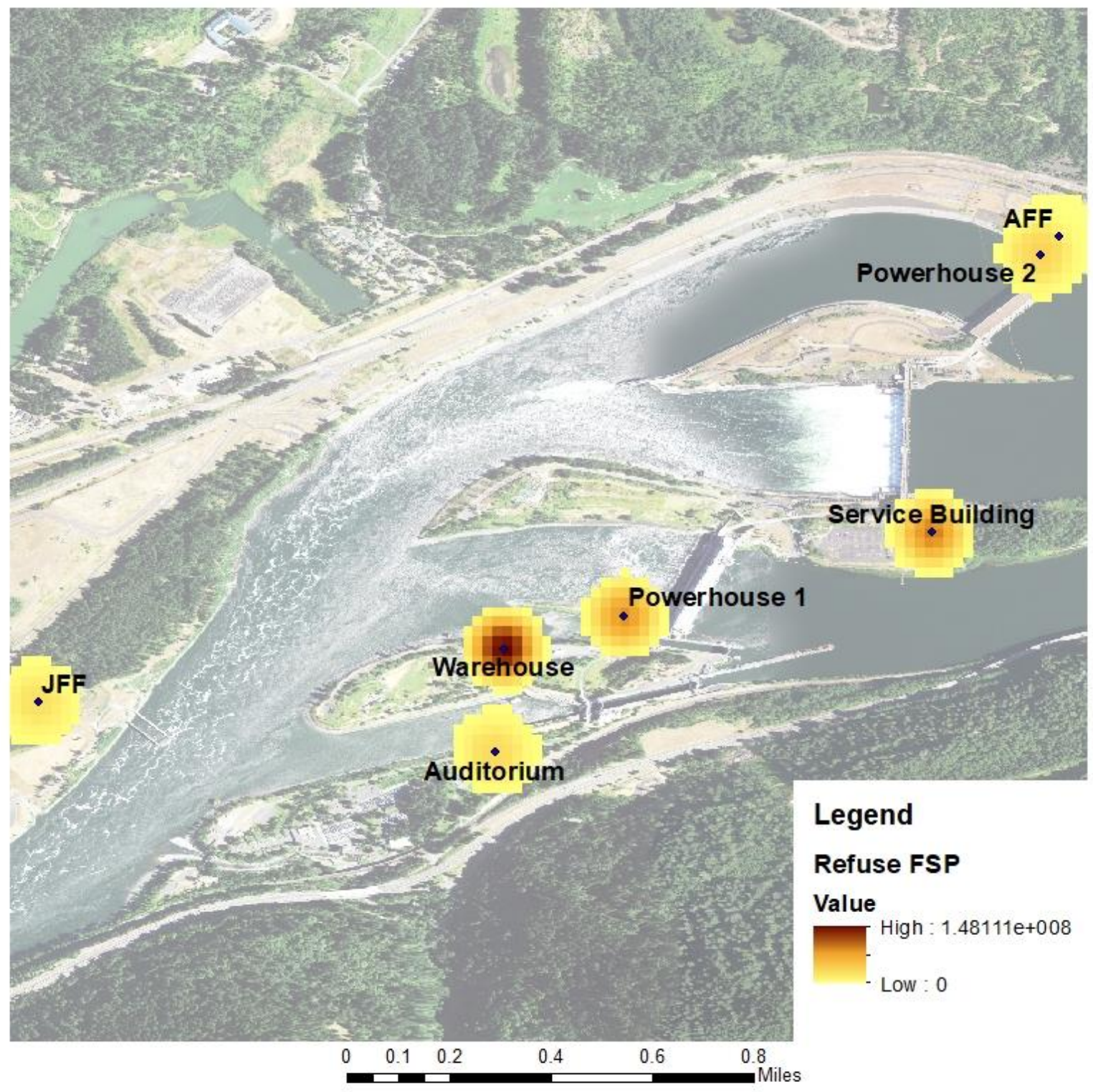

Figure 22: Kernel density map for category 'Food Soiled Paper' at the Bonneville Project encompassing all designated areas. The darker the color scale, the higher amount of weight for the category represented per designated area. JFF and AFF indicate Juvenile Fish Facility and Adult Fish Facility respectively. 


\section{Distribution of Waste Material for Category
Non-Recyclable Paper}

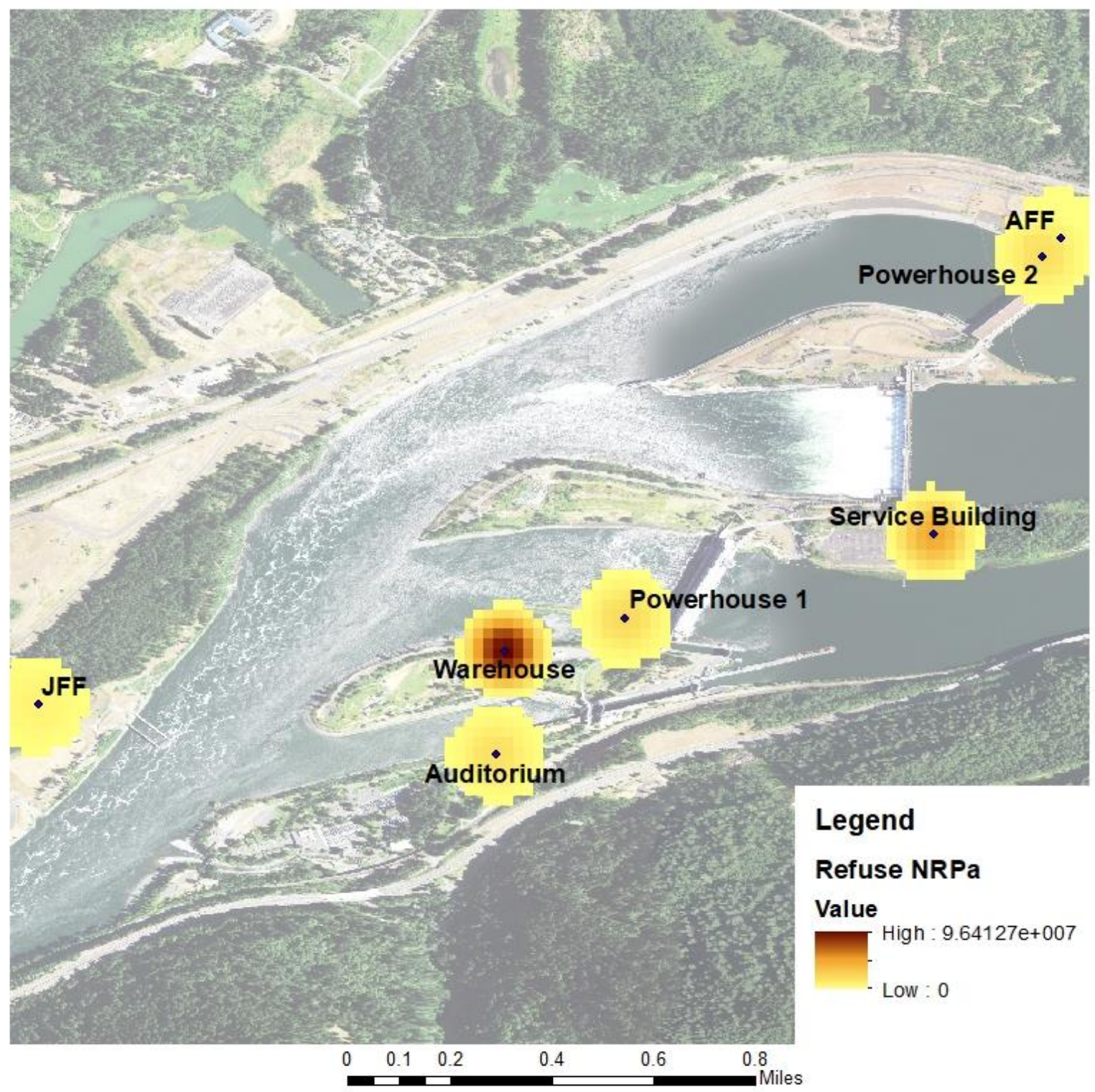

Figure 23: Kernel density map for category 'Non-Recyclable Paper' at the Bonneville Project encompassing all designated areas. The darker the color scale, the higher amount of weight for the category represented per designated area. JFF and AFF indicate Juvenile Fish Facility and Adult Fish Facility respectively. 


\section{N Distribution of Waste Material for Category Non-Recyclable Plastic Bags, Film, Containers, and Tubs}

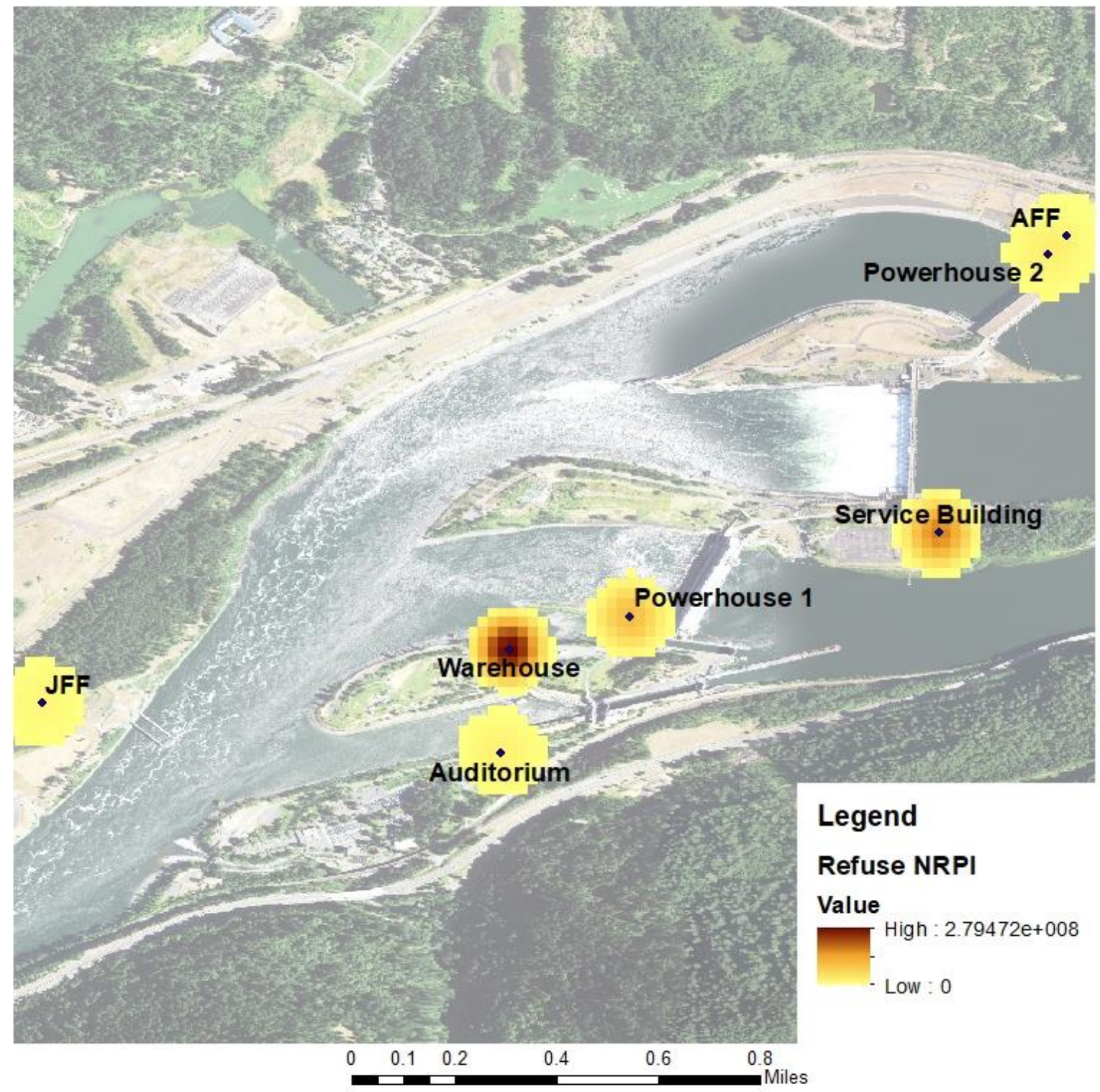

Figure 24: Kernel density map for category 'Non-Recyclable Plastic Bags, Film, Containers, and Tubs' at the Bonneville Project encompassing all designated areas. The darker the color scale, the higher amount of weight for the category represented per designated area. JFF and AFF indicate Juvenile Fish Facility and Adult Fish Facility respectively. 


\section{N Distribution of Waste Material for Category Wood, Yard, and Natural River Waste}

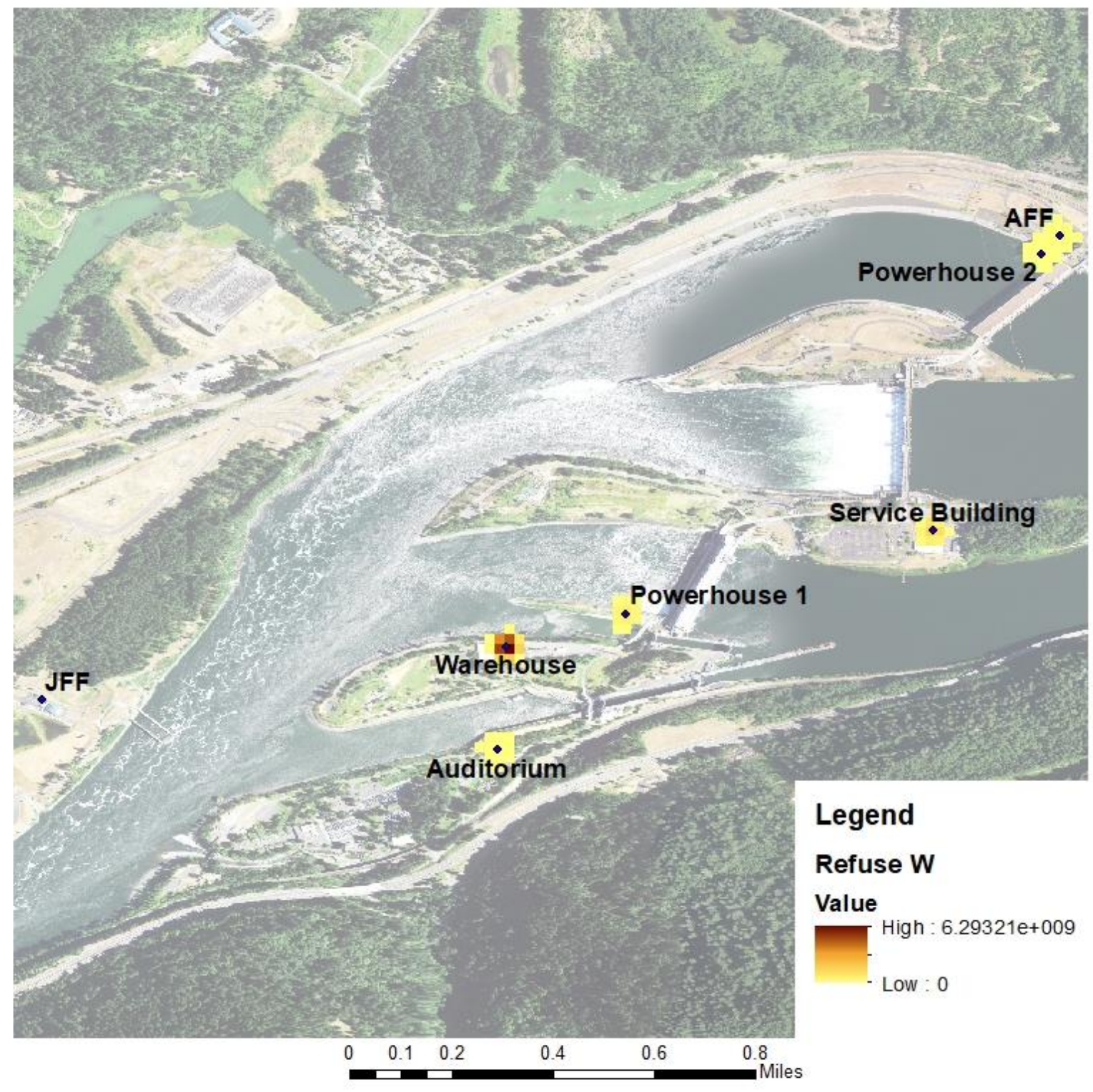

Figure 25: Kernel density map for category 'Wood, Yard, and Natural River Waste' at the Bonneville Project encompassing all designated areas. The darker the color scale, the higher amount of weight for the category represented per designated area. JFF and AFF indicate Juvenile Fish Facility and Adult Fish Facility respectively. 


\section{N Distribution of Waste Material for Category Other}

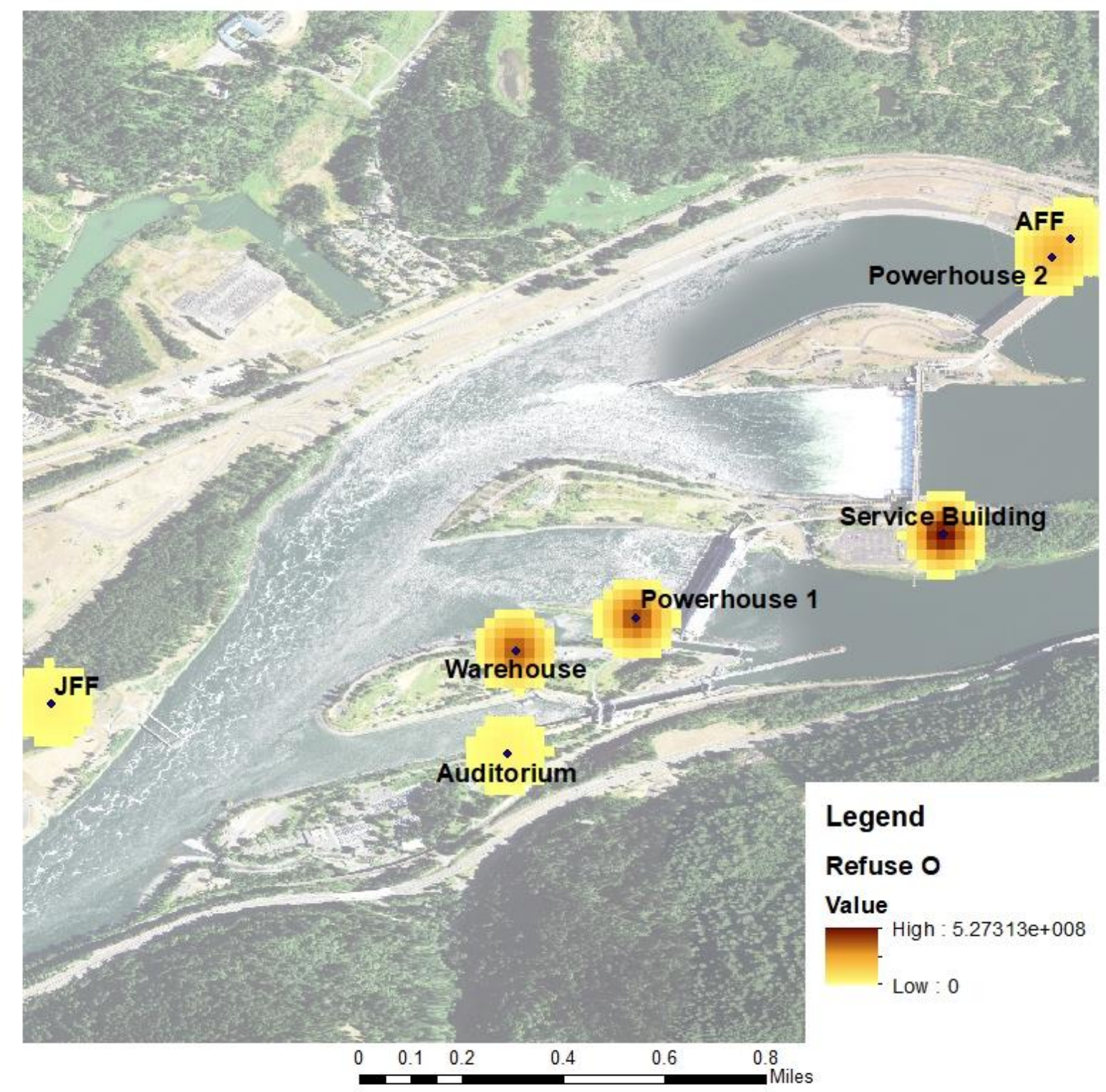

Figure 26: Kernel density map for category 'Other' at the Bonneville Project encompassing all designated areas. The darker the color scale, the higher amount of weight for the category represented per designated area. JFF and AFF indicate Juvenile Fish Facility and Adult Fish Facility respectively. 


\section{Appendix C: Raw Data for Waste Stream Analysis}

Table 5: Raw data for waste stream analysis covering waste type, the waste total, recycling waste total in recycling container(s), refuse waste total in refuse container(s), and waste composition categories in the following order: Corrugated Cardboard (CCB), Glass Bottles and Jars (G), Recyclable Mixed Paper and Newspaper (RPa), Recyclable Plastic Bottles and Tubs (RPI), Tin, Metal, and Aluminum Cans (MC), Recyclable Scrap Metal (SM), Milk Cartons and Juice Boxes (C), Food Soiled Paper (FSP), Non-Recyclable Paper (NRPa), Block Foam (F), Wood, Yard, and Natural River Waste (W), Food Scraps (FS), NonRecyclable Plastic Bags, Film, Containers, and Tubs (NRPI), Soiled Cloth (SC), and Other (O). All weight is in pounds. This table runs parallel to Table 6 in Appendix D.

\begin{tabular}{|c|c|c|c|c|c|c|c|c|c|c|c|c|c|c|c|c|c|c|}
\hline $\begin{array}{l}\text { Waste } \\
\text { Type }\end{array}$ & $\begin{array}{l}\text { Waste } \\
\text { Total }\end{array}$ & $\begin{array}{l}\text { Recycling } \\
\text { Total }\end{array}$ & $\begin{array}{l}\text { Refuse } \\
\text { Total }\end{array}$ & CCB & G & $\mathrm{RPa}$ & $\mathrm{RPI}$ & $\mathrm{MC}$ & SM & c & FSP & NRPa & $\mathrm{F}$ & w & FS & NRPI & sc & 0 \\
\hline $\begin{array}{l}\text { Service } \\
\text { Building } \\
\text { Recycling } \\
\end{array}$ & 207.00 & 204.50 & 2.50 & 94.50 & 1.50 & 106.00 & 2.00 & 0.50 & 0.00 & 0.00 & 0.00 & 0.00 & 1.00 & 0.00 & 0.00 & 1.50 & 0.00 & 0.00 \\
\hline $\begin{array}{l}\text { Service } \\
\text { Building } \\
\text { Refuse } \\
\end{array}$ & 200.00 & 6.00 & 194.00 & 0.00 & 2.00 & 0.00 & 1.00 & 1.00 & 2.00 & 0.00 & 49.00 & 5.00 & 1.00 & 89.00 & 2.00 & 17.00 & 0.00 & 31.00 \\
\hline PH1 Refuse & 186.00 & 18.00 & 168.00 & 1.50 & 4.50 & 3.00 & 7.50 & 1.50 & 0.00 & 0.00 & 63.00 & 9.00 & 0.00 & 30.00 & 12.00 & 9.00 & 45.00 & 0.00 \\
\hline $\begin{array}{l}\text { Warehouse } \\
\text { Recycling }\end{array}$ & 390.00 & 390.00 & 0.00 & 390.00 & 0.00 & 0.00 & 0.00 & 0.00 & 0.00 & 0.00 & 0.00 & 0.00 & 0.00 & 0.00 & 0.00 & 0.00 & 0.00 & 0.00 \\
\hline $\begin{array}{l}\text { Warehouse } \\
\text { Recycling }\end{array}$ & 295.00 & 295.00 & 0.00 & 12.00 & 11.00 & 222.00 & 43.00 & 6.00 & 0.50 & 0.50 & 0.00 & 0.00 & 0.00 & 0.00 & 0.00 & 0.00 & 0.00 & 0.00 \\
\hline $\begin{array}{l}\text { Warehouse } \\
\text { Refuse }\end{array}$ & 73.00 & 9.00 & 64.00 & 3.00 & 0.00 & 3.00 & 1.00 & 2.00 & 0.00 & 0.00 & 8.00 & 5.00 & 0.00 & 20.00 & 17.00 & 7.00 & 0.00 & 7.00 \\
\hline $\begin{array}{l}\text { Warehouse } \\
\text { Refuse }\end{array}$ & 680.00 & 30.00 & 650.00 & 5.00 & 0.00 & 10.00 & 5.00 & 5.00 & 0.00 & 5.00 & 90.00 & 40.00 & 0.00 & 240.00 & 170.00 & 110.00 & 0.00 & 0.00 \\
\hline $\begin{array}{l}\text { Warehouse } \\
\text { Refuse }\end{array}$ & 900.00 & 330.00 & 570.00 & 20.00 & 20.00 & 80.00 & 0.00 & 0.00 & 210.00 & 0.00 & 50.00 & 80.00 & 0.00 & 40.00 & 20.00 & 160.00 & 70.00 & 150.00 \\
\hline PH1 Refuse & 482.00 & 44.00 & 438.00 & 8.00 & 4.00 & 0.00 & 4.00 & 4.00 & 24.00 & 0.00 & 8.00 & 8.00 & 2.00 & 124.00 & 124.00 & 8.00 & 116.00 & 48.00 \\
\hline $\begin{array}{l}\text { Service } \\
\text { Building } \\
\text { Refuse } \\
\end{array}$ & 475.00 & 69.00 & 406.00 & 64.00 & 0.00 & 0.00 & 2.00 & 2.00 & 0.00 & 1.00 & 12.00 & 28.00 & 0.00 & 94.00 & 20.00 & 14.00 & 88.00 & 150.00 \\
\hline $\begin{array}{l}\text { SMF } \\
\text { Refuse }\end{array}$ & 40.00 & 0.00 & 40.00 & 0.00 & 0.00 & 0.00 & 0.00 & 0.00 & 0.00 & 0.00 & 2.00 & 3.00 & 0.00 & 0.00 & 8.00 & 4.00 & 0.00 & 23.00 \\
\hline $\begin{array}{l}\text { SMF } \\
\text { Recycling }\end{array}$ & 144.00 & 144.00 & 0.00 & 60.00 & 3.00 & 15.00 & 18.00 & 9.00 & 39.00 & 0.00 & 0.00 & 0.00 & 0.00 & 0.00 & 0.00 & 0.00 & 0.00 & 0.00 \\
\hline $\begin{array}{l}\text { PH2 } \\
\text { Recycling }\end{array}$ & 229.00 & 150.00 & 79.00 & 126.00 & 0.00 & 20.00 & 2.00 & 2.00 & 0.00 & 0.00 & 0.00 & 0.00 & 0.00 & 0.00 & 1.00 & 0.00 & 0.00 & 78.00 \\
\hline PH2 Refuse & 22.00 & 1.00 & 21.00 & 0.00 & 0.50 & 0.00 & 0.50 & 0.00 & 0.00 & 0.00 & 8.00 & 5.00 & 0.00 & 0.00 & 4.00 & 2.00 & 0.00 & 2.00 \\
\hline $\begin{array}{l}\text { Warehouse } \\
\text { Refuse }\end{array}$ & 103.00 & 3.00 & 100.00 & 1.00 & 0.00 & 0.00 & 1.00 & 1.00 & 0.00 & 0.00 & 22.00 & 4.00 & 0.00 & 28.00 & 12.00 & 22.00 & 0.00 & 12.00 \\
\hline $\begin{array}{l}\text { Warehouse } \\
\text { Refuse }\end{array}$ & 41.50 & 2.00 & 39.50 & 1.00 & 1.00 & 0.00 & 0.00 & 0.00 & 0.00 & 0.00 & 3.00 & 13.00 & 0.00 & 14.00 & 0.50 & 2.00 & 0.00 & 7.00 \\
\hline PH1 Refuse & 160.00 & 26.00 & 134.00 & 6.00 & 2.00 & 0.00 & 4.00 & 2.00 & 12.00 & 0.00 & 6.00 & 4.00 & 1.00 & 8.00 & 4.00 & 13.00 & 0.00 & 98.00 \\
\hline PH1 Refuse & 119.00 & 119.00 & 0.00 & 1.00 & 0.00 & 118.00 & 0.00 & 0.00 & 0.00 & 0.00 & 0.00 & 0.00 & 0.00 & 0.00 & 0.00 & 0.00 & 0.00 & 0.00 \\
\hline PH2 Refuse & 22.50 & 20.50 & 2.00 & 2.00 & 15.00 & 2.00 & 1.00 & 0.50 & 0.00 & 0.00 & 0.50 & 0.00 & 0.00 & 0.00 & 0.50 & 1.00 & 0.00 & 0.00 \\
\hline $\begin{array}{l}\text { SMF } \\
\text { Refuse }\end{array}$ & 33.50 & 1.50 & 32.00 & 0.00 & 0.00 & 0.00 & 0.00 & 1.00 & 0.00 & 0.50 & 10.00 & 2.00 & 0.00 & 0.00 & 8.00 & 8.00 & 0.00 & 4.00 \\
\hline
\end{tabular}




\begin{tabular}{|c|c|c|c|c|c|c|c|c|c|c|c|c|c|c|c|c|c|c|}
\hline $\begin{array}{l}\text { Warehouse } \\
\text { Recycling }\end{array}$ & 42.00 & 39.50 & 2.50 & 12.00 & 12.00 & 12.00 & 3.00 & 0.50 & 0.00 & 0.00 & 0.00 & 0.00 & 0.00 & 0.00 & 0.00 & 0.50 & 0.00 & 2.00 \\
\hline $\begin{array}{l}\text { Warehouse } \\
\text { Recycling }\end{array}$ & 28.00 & 28.00 & 0.00 & 28.00 & 0.00 & 0.00 & 0.00 & 0.00 & 0.00 & 0.00 & 0.00 & 0.00 & 0.00 & 0.00 & 0.00 & 0.00 & 0.00 & 0.00 \\
\hline $\begin{array}{l}\text { PH1 } \\
\text { Recycling }\end{array}$ & 31.00 & 31.00 & 0.00 & 24.00 & 0.00 & 4.00 & 2.00 & 1.00 & 0.00 & 0.00 & 0.00 & 0.00 & 0.00 & 0.00 & 0.00 & 0.00 & 0.00 & 0.00 \\
\hline $\begin{array}{l}\text { Auditorium } \\
\text { Refuse }\end{array}$ & 42.00 & 2.00 & 40.00 & 0.00 & 0.00 & 0.00 & 2.00 & 0.00 & 0.00 & 0.00 & 4.00 & 14.00 & 0.00 & 0.00 & 6.00 & 12.00 & 0.00 & 4.00 \\
\hline $\begin{array}{l}\text { Auditorium } \\
\text { Recycling }\end{array}$ & 10.00 & 10.00 & 0.00 & 3.00 & 0.00 & 4.00 & 2.00 & 1.00 & 0.00 & 0.00 & 0.00 & 0.00 & 0.00 & 0.00 & 0.00 & 0.00 & 0.00 & 0.00 \\
\hline $\begin{array}{l}\text { Service } \\
\text { Building } \\
\text { Recycling }\end{array}$ & 99.00 & 89.00 & 10.00 & 22.00 & 4.00 & 52.00 & 6.00 & 4.00 & 0.00 & 1.00 & 1.00 & 1.00 & 0.00 & 0.00 & 2.00 & 6.00 & 0.00 & 0.00 \\
\hline $\begin{array}{l}\text { SMF } \\
\text { Refuse }\end{array}$ & 53.00 & 2.00 & 51.00 & 0.00 & 0.00 & 1.00 & 0.50 & 0.50 & 0.00 & 0.00 & 17.00 & 7.00 & 0.00 & 0.00 & 9.00 & 3.00 & 0.00 & 15.00 \\
\hline $\begin{array}{l}\text { SMF } \\
\text { Recycling }\end{array}$ & 23.50 & 22.00 & 1.50 & 7.00 & 1.00 & 2.00 & 4.00 & 8.00 & 0.00 & 0.00 & 0.50 & 0.50 & 0.00 & 0.00 & 0.50 & 0.00 & 0.00 & 0.00 \\
\hline AFF Refuse & 72.00 & 8.00 & 64.00 & 5.00 & 0.00 & 0.00 & 3.00 & 0.00 & 0.00 & 0.00 & 0.00 & 0.00 & 0.00 & 2.00 & 0.00 & 5.00 & 0.00 & 57.00 \\
\hline PH2 Refuse & 10.00 & 1.00 & 9.00 & 0.00 & 0.00 & 0.00 & 1.00 & 0.00 & 0.00 & 0.00 & 2.00 & 5.00 & 0.00 & 0.00 & 1.00 & 1.00 & 0.00 & 0.00 \\
\hline $\begin{array}{l}\text { PH2 } \\
\text { Recycling }\end{array}$ & 14.50 & 14.50 & 0.00 & 12.00 & 0.00 & 1.00 & 1.00 & 0.50 & 0.00 & 0.00 & 0.00 & 0.00 & 0.00 & 0.00 & 0.00 & 0.00 & 0.00 & 0.00 \\
\hline $\begin{array}{l}\text { Service } \\
\text { Building } \\
\text { Refuse } \\
\end{array}$ & 231.42 & 14.93 & 216.49 & 8.96 & 0.00 & 2.99 & 1.49 & 0.75 & 0.00 & 0.75 & 5.97 & 19.41 & 1.49 & 71.66 & 7.47 & 14.93 & 28.37 & 67.19 \\
\hline $\begin{array}{l}\text { Warehouse } \\
\text { Refuse }\end{array}$ & 63.00 & 30.00 & 33.00 & 15.00 & 9.00 & 0.00 & 6.00 & 0.00 & 0.00 & 0.00 & 6.00 & 0.00 & 0.00 & 0.00 & 6.00 & 3.00 & 0.00 & 18.00 \\
\hline $\begin{array}{l}\text { Warehouse } \\
\text { Refuse }\end{array}$ & 38.00 & 8.00 & 30.00 & 0.00 & 0.00 & 0.00 & 2.00 & 2.00 & 4.00 & 0.00 & 6.00 & 6.00 & 0.00 & 0.00 & 2.00 & 4.00 & 12.00 & 0.00 \\
\hline $\begin{array}{l}\text { Warehouse } \\
\text { Refuse }\end{array}$ & 98.00 & 14.00 & 84.00 & 2.00 & 0.00 & 2.00 & 10.00 & 0.00 & 0.00 & 0.00 & 20.00 & 8.00 & 0.00 & 0.00 & 8.00 & 2.00 & 0.00 & 46.00 \\
\hline PH2 Refuse & 81.37 & 15.68 & 65.69 & 2.99 & 0.00 & 4.48 & 0.75 & 1.49 & 4.48 & 1.49 & 8.96 & 5.97 & 0.00 & 2.99 & 26.87 & 5.97 & 0.00 & 14.93 \\
\hline $\begin{array}{l}\text { Auditorium } \\
\text { Refuse }\end{array}$ & 17.50 & 2.50 & 15.00 & 0.00 & 0.50 & 0.50 & 0.50 & 1.00 & 0.00 & 0.00 & 5.00 & 2.00 & 1.00 & 2.00 & 2.00 & 3.00 & 0.00 & 0.00 \\
\hline PH1 Refuse & 190.00 & 30.00 & 160.00 & 2.00 & 2.00 & 2.00 & 1.00 & 1.00 & 22.00 & 0.00 & 10.00 & 4.00 & 2.00 & 8.00 & 10.00 & 20.00 & 20.00 & 86.00 \\
\hline $\begin{array}{l}\text { PH1 } \\
\text { Recycling }\end{array}$ & 57.00 & 46.00 & 11.00 & 40.00 & 5.00 & 0.00 & 1.00 & 0.00 & 0.00 & 0.00 & 0.00 & 0.00 & 0.00 & 0.00 & 0.00 & 0.00 & 0.00 & 11.00 \\
\hline $\begin{array}{l}\text { PH2 } \\
\text { Recycling }\end{array}$ & 35.00 & 35.00 & 0.00 & 33.00 & 0.00 & 1.00 & 1.00 & 0.00 & 0.00 & 0.00 & 0.00 & 0.00 & 0.00 & 0.00 & 0.00 & 0.00 & 0.00 & 0.00 \\
\hline $\begin{array}{l}\text { Service } \\
\text { Building } \\
\text { Recycling }\end{array}$ & 43.00 & 43.00 & 0.00 & 5.00 & 0.00 & 34.00 & 3.00 & 1.00 & 0.00 & 0.00 & 0.00 & 0.00 & 0.00 & 0.00 & 0.00 & 0.00 & 0.00 & 0.00 \\
\hline $\begin{array}{l}\text { Auditorium } \\
\text { Recycling }\end{array}$ & 32.50 & 32.50 & 0.00 & 2.00 & 8.00 & 6.00 & 3.00 & 3.00 & 10.00 & 0.50 & 0.00 & 0.00 & 0.00 & 0.00 & 0.00 & 0.00 & 0.00 & 0.00 \\
\hline $\begin{array}{l}\text { Auditorium } \\
\text { Refuse }\end{array}$ & 35.00 & 4.00 & 31.00 & 0.00 & 2.00 & 0.00 & 0.00 & 2.00 & 0.00 & 0.00 & 5.00 & 6.00 & 0.00 & 0.00 & 2.00 & 6.00 & 0.00 & 12.00 \\
\hline $\begin{array}{l}\text { Warehouse } \\
\text { Recycling }\end{array}$ & 34.50 & 26.00 & 8.50 & 7.00 & 5.00 & 5.00 & 7.00 & 2.00 & 0.00 & 0.00 & 0.00 & 1.00 & 0.00 & 0.00 & 0.00 & 4.00 & 0.00 & 3.50 \\
\hline $\begin{array}{l}\text { Warehouse } \\
\text { Recycling }\end{array}$ & 166.50 & 136.50 & 30.00 & 120.00 & 0.00 & 15.00 & 0.00 & 1.50 & 0.00 & 0.00 & 0.00 & 0.00 & 0.00 & 0.00 & 0.00 & 0.00 & 0.00 & 30.00 \\
\hline $\begin{array}{l}\text { Auditorium } \\
\text { Recycling }\end{array}$ & 26.00 & 25.00 & 1.00 & 6.00 & 0.00 & 0.50 & 18.50 & 0.00 & 0.00 & 0.00 & 0.00 & 0.50 & 0.00 & 0.00 & 0.00 & 0.00 & 0.00 & 0.50 \\
\hline $\begin{array}{l}\text { PH1 } \\
\text { Recycling }\end{array}$ & 78.00 & 78.00 & 0.00 & 21.00 & 0.00 & 3.00 & 54.00 & 0.00 & 0.00 & 0.00 & 0.00 & 0.00 & 0.00 & 0.00 & 0.00 & 0.00 & 0.00 & 0.00 \\
\hline
\end{tabular}




\begin{tabular}{|c|c|c|c|c|c|c|c|c|c|c|c|c|c|c|c|c|c|c|}
\hline $\begin{array}{l}\text { PH2 } \\
\text { Recycling }\end{array}$ & 44.50 & 44.00 & 0.50 & 43.00 & 0.00 & 0.50 & 0.50 & 0.00 & 0.00 & 0.00 & 0.00 & 0.00 & 0.00 & 0.00 & 0.00 & 0.50 & 0.00 & 0.00 \\
\hline AFF Refuse & 3.50 & 2.00 & 1.50 & 0.00 & 0.00 & 0.50 & 0.50 & 1.00 & 0.00 & 0.00 & 0.50 & 0.00 & 0.00 & 0.00 & 1.00 & 0.00 & 0.00 & 0.00 \\
\hline $\begin{array}{l}\text { PH1 } \\
\text { Recycling }\end{array}$ & 56.50 & 55.50 & 1.00 & 43.00 & 3.00 & 8.00 & 1.00 & 0.50 & 0.00 & 0.00 & 0.00 & 0.00 & 0.00 & 0.00 & 0.00 & 1.00 & 0.00 & 0.00 \\
\hline AFF Refuse & 4.00 & 1.00 & 3.00 & 0.00 & 0.50 & 0.00 & 0.50 & 0.00 & 0.00 & 0.00 & 1.00 & 0.50 & 0.00 & 0.00 & 0.50 & 1.00 & 0.00 & 0.00 \\
\hline $\begin{array}{l}\text { SMF } \\
\text { Recycling }\end{array}$ & 10.50 & 10.50 & 0.00 & 0.50 & 0.00 & 0.00 & 8.00 & 2.00 & 0.00 & 0.00 & 0.00 & 0.00 & 0.00 & 0.00 & 0.00 & 0.00 & 0.00 & 0.00 \\
\hline $\begin{array}{l}\text { PH2 } \\
\text { Recycling }\end{array}$ & 98.50 & 98.00 & 0.50 & 51.00 & 0.00 & 39.00 & 8.00 & 0.00 & 0.00 & 0.00 & 0.00 & 0.00 & 0.50 & 0.00 & 0.00 & 0.00 & 0.00 & 0.00 \\
\hline $\begin{array}{l}\text { Warehouse } \\
\text { Refuse }\end{array}$ & 96.00 & 6.00 & 90.00 & 2.00 & 0.00 & 0.00 & 4.00 & 0.00 & 0.00 & 0.00 & 8.00 & 4.00 & 0.00 & 0.00 & 4.00 & 10.00 & 0.00 & 64.00 \\
\hline $\begin{array}{l}\text { Warehouse } \\
\text { Refuse }\end{array}$ & 38.00 & 2.00 & 36.00 & 0.00 & 0.00 & 0.00 & 2.00 & 0.00 & 0.00 & 0.00 & 4.00 & 14.00 & 0.00 & 0.00 & 2.00 & 2.00 & 0.00 & 14.00 \\
\hline $\begin{array}{l}\text { Warehouse } \\
\text { Refuse }\end{array}$ & 73.00 & 5.00 & 68.00 & 4.00 & 0.00 & 0.00 & 0.00 & 1.00 & 0.00 & 0.00 & 9.00 & 0.00 & 0.00 & 10.00 & 2.00 & 5.00 & 10.00 & 32.00 \\
\hline PH1 Refuse & 373.50 & 16.50 & 357.00 & 6.00 & 0.00 & 3.00 & 6.00 & 1.50 & 0.00 & 0.00 & 9.00 & 1.50 & 1.50 & 0.00 & 6.00 & 72.00 & 42.00 & 225.00 \\
\hline $\begin{array}{l}\text { Warehouse } \\
\text { Recycling }\end{array}$ & 94.00 & 94.00 & 0.00 & 13.00 & 0.00 & 3.00 & 77.00 & 1.00 & 0.00 & 0.00 & 0.00 & 0.00 & 0.00 & 0.00 & 0.00 & 0.00 & 0.00 & 0.00 \\
\hline $\begin{array}{l}\text { Warehouse } \\
\text { Recycling }\end{array}$ & 91.00 & 91.00 & 0.00 & 91.00 & 0.00 & 0.00 & 0.00 & 0.00 & 0.00 & 0.00 & 0.00 & 0.00 & 0.00 & 0.00 & 0.00 & 0.00 & 0.00 & 0.00 \\
\hline $\begin{array}{l}\text { Service } \\
\text { Building } \\
\text { Recycling }\end{array}$ & 297.00 & 297.00 & 0.00 & 18.00 & 15.00 & 234.00 & 30.00 & 0.00 & 0.00 & 0.00 & 0.00 & 0.00 & 0.00 & 0.00 & 0.00 & 0.00 & 0.00 & 0.00 \\
\hline PH2 Refuse & 155.00 & 9.00 & 146.00 & 1.00 & 0.50 & 5.00 & 0.50 & 1.00 & 0.00 & 1.00 & 9.00 & 5.00 & 0.00 & 0.00 & 6.00 & 4.00 & 21.00 & 101.00 \\
\hline AFF Refuse & 4.00 & 1.50 & 2.50 & 0.00 & 0.50 & 0.00 & 0.50 & 0.50 & 0.00 & 0.00 & 1.00 & 0.00 & 0.00 & 0.00 & 0.50 & 1.00 & 0.00 & 0.00 \\
\hline $\begin{array}{l}\text { SMF } \\
\text { Refuse }\end{array}$ & 8.00 & 0.00 & 8.00 & 0.00 & 0.00 & 0.00 & 0.00 & 0.00 & 0.00 & 0.00 & 3.00 & 0.00 & 0.00 & 0.00 & 2.00 & 2.00 & 0.00 & 1.00 \\
\hline $\begin{array}{l}\text { Service } \\
\text { Building } \\
\text { Refuse }\end{array}$ & 611.00 & 129.00 & 482.00 & 10.00 & 0.00 & 24.00 & 7.00 & 5.00 & 48.00 & 0.00 & 35.00 & 10.00 & 2.00 & 60.00 & 25.00 & 65.00 & 15.00 & 305.00 \\
\hline $\begin{array}{l}\text { Auditorium } \\
\text { Refuse }\end{array}$ & 55.50 & 11.50 & 44.00 & 1.00 & 0.00 & 9.00 & 1.00 & 0.50 & 0.00 & 0.00 & 6.00 & 3.00 & 0.00 & 1.00 & 7.00 & 3.00 & 0.00 & 24.00 \\
\hline $\begin{array}{l}\text { Warehouse } \\
\text { Refuse }\end{array}$ & 164.00 & 9.00 & 155.00 & 6.00 & 0.00 & 1.00 & 1.00 & 1.00 & 0.00 & 0.00 & 1.00 & 8.00 & 2.00 & 68.00 & 0.00 & 8.00 & 0.00 & 68.00 \\
\hline $\begin{array}{l}\text { Warehouse } \\
\text { Refuse }\end{array}$ & 877.50 & 19.50 & 858.00 & 12.00 & 0.00 & 0.00 & 6.00 & 1.50 & 0.00 & 0.00 & 3.00 & 3.00 & 0.00 & 780.00 & 3.00 & 69.00 & 0.00 & 0.00 \\
\hline $\begin{array}{l}\text { Warehouse } \\
\text { Refuse }\end{array}$ & 819.00 & 12.00 & 807.00 & 6.00 & 0.00 & 0.00 & 4.00 & 2.00 & 0.00 & 0.00 & 4.00 & 2.00 & 2.00 & 721.00 & 6.00 & 24.00 & 0.00 & 48.00 \\
\hline PH2 Refuse & 39.50 & 2.00 & 37.50 & 0.50 & 0.00 & 0.00 & 0.50 & 0.50 & 0.50 & 0.00 & 7.00 & 2.00 & 0.50 & 0.00 & 9.00 & 5.00 & 0.00 & 14.00 \\
\hline PH1 Refuse & 165.00 & 9.00 & 156.00 & 2.00 & 2.00 & 0.00 & 2.00 & 1.00 & 2.00 & 0.00 & 14.00 & 4.00 & 0.00 & 0.00 & 22.00 & 26.00 & 44.00 & 46.00 \\
\hline $\begin{array}{l}\text { PH2 } \\
\text { Recycling }\end{array}$ & 93.00 & 87.00 & 6.00 & 84.00 & 0.00 & 0.00 & 3.00 & 0.00 & 0.00 & 0.00 & 3.00 & 0.00 & 0.00 & 0.00 & 0.00 & 3.00 & 0.00 & 0.00 \\
\hline $\begin{array}{l}\text { SMF } \\
\text { Recycling }\end{array}$ & 19.00 & 19.00 & 0.00 & 12.00 & 0.00 & 2.00 & 3.00 & 2.00 & 0.00 & 0.00 & 0.00 & 0.00 & 0.00 & 0.00 & 0.00 & 0.00 & 0.00 & 0.00 \\
\hline $\begin{array}{l}\text { Service } \\
\text { Building } \\
\text { Recycling } \\
\end{array}$ & 197.00 & 182.50 & 14.50 & 84.00 & 0.00 & 66.00 & 25.00 & 7.50 & 0.00 & 0.00 & 2.00 & 4.00 & 1.00 & 0.00 & 0.00 & 7.50 & 0.00 & 0.00 \\
\hline $\begin{array}{l}\text { Service } \\
\text { Building } \\
\text { Refuse } \\
\end{array}$ & 460.00 & 54.00 & 406.00 & 6.00 & 0.00 & 2.00 & 4.00 & 2.00 & 40.00 & 0.00 & 12.00 & 12.00 & 2.00 & 84.00 & 4.00 & 85.00 & 54.00 & 153.00 \\
\hline PH2 Refuse & 57.50 & 1.50 & 56.00 & 0.50 & 0.00 & 0.00 & 0.50 & 0.50 & 0.00 & 0.00 & 3.00 & 1.00 & 0.00 & 0.00 & 2.00 & 5.00 & 0.00 & 45.00 \\
\hline PH1 Refuse & 189.00 & 36.00 & 153.00 & 3.00 & 1.50 & 1.50 & 1.50 & 1.50 & 0.00 & 0.00 & 27.00 & 9.00 & 0.00 & 3.00 & 12.00 & 18.00 & 0.00 & 111.00 \\
\hline $\begin{array}{l}\text { SMF } \\
\text { Recycling }\end{array}$ & 96.00 & 90.00 & 6.00 & 45.00 & 0.00 & 27.00 & 12.00 & 6.00 & 0.00 & 0.00 & 4.50 & 0.00 & 0.00 & 0.00 & 0.00 & 1.50 & 0.00 & 0.00 \\
\hline
\end{tabular}




\begin{tabular}{|c|c|c|c|c|c|c|c|c|c|c|c|c|c|c|c|c|c|c|}
\hline $\begin{array}{l}\text { PH1 } \\
\text { Recycling }\end{array}$ & 55.00 & 55.00 & 0.00 & 55.00 & 0.00 & 0.00 & 0.00 & 0.00 & 0.00 & 0.00 & 0.00 & 0.00 & 0.00 & 0.00 & 0.00 & 0.00 & 0.00 & 0.00 \\
\hline $\begin{array}{l}\text { Warehouse } \\
\text { Recycling }\end{array}$ & 60.00 & 60.00 & 0.00 & 60.00 & 0.00 & 0.00 & 0.00 & 0.00 & 0.00 & 0.00 & 0.00 & 0.00 & 0.00 & 0.00 & 0.00 & 0.00 & 0.00 & 0.00 \\
\hline $\begin{array}{l}\text { Warehouse } \\
\text { Recycling }\end{array}$ & 151.50 & 119.00 & 32.50 & 35.00 & 0.00 & 74.00 & 5.00 & 5.00 & 0.00 & 0.00 & 2.50 & 0.00 & 0.00 & 0.00 & 0.00 & 10.00 & 0.00 & 20.00 \\
\hline $\begin{array}{l}\text { Auditorium } \\
\text { Recycling }\end{array}$ & 49.50 & 49.00 & 0.50 & 16.00 & 4.00 & 23.00 & 5.00 & 1.00 & 0.00 & 0.00 & 0.50 & 0.00 & 0.00 & 0.00 & 0.00 & 0.00 & 0.00 & 0.00 \\
\hline $\begin{array}{l}\text { SMF } \\
\text { Refuse }\end{array}$ & 7.50 & 2.00 & 5.50 & 0.50 & 0.50 & 0.50 & 0.00 & 0.50 & 0.00 & 0.00 & 2.00 & 0.50 & 0.00 & 0.00 & 1.00 & 1.00 & 0.00 & 1.00 \\
\hline $\begin{array}{l}\text { Warehouse } \\
\text { Refuse }\end{array}$ & 69.00 & 4.00 & 65.00 & 2.00 & 0.00 & 1.00 & 1.00 & 0.00 & 0.00 & 0.00 & 4.00 & 4.00 & 1.00 & 4.00 & 2.00 & 10.00 & 0.00 & 40.00 \\
\hline $\begin{array}{l}\text { Warehouse } \\
\text { Refuse }\end{array}$ & 54.50 & 12.00 & 42.50 & 9.00 & 0.00 & 0.00 & 1.50 & 1.50 & 0.00 & 0.00 & 6.00 & 3.00 & 3.00 & 1.50 & 17.00 & 9.00 & 0.00 & 3.00 \\
\hline AFF Refuse & 9.50 & 1.50 & 8.00 & 0.00 & 0.50 & 0.00 & 0.00 & 1.00 & 0.00 & 0.00 & 2.00 & 1.00 & 0.00 & 0.00 & 1.00 & 2.00 & 0.00 & 2.00 \\
\hline $\begin{array}{l}\text { Auditorium } \\
\text { Refuse }\end{array}$ & 88.00 & 20.00 & 68.00 & 2.00 & 1.00 & 4.00 & 2.00 & 10.00 & 0.00 & 1.00 & 28.00 & 6.00 & 0.00 & 0.00 & 12.00 & 12.00 & 0.00 & 10.00 \\
\hline PH2 Refuse & 51.50 & 9.00 & 42.50 & 6.00 & 0.00 & 1.00 & 1.00 & 0.00 & 0.00 & 1.00 & 7.00 & 2.00 & 0.50 & 0.00 & 3.00 & 6.00 & 10.00 & 14.00 \\
\hline $\begin{array}{l}\text { PH1 } \\
\text { Recycling }\end{array}$ & 65.00 & 65.00 & 0.00 & 14.00 & 0.00 & 51.00 & 0.00 & 0.00 & 0.00 & 0.00 & 0.00 & 0.00 & 0.00 & 0.00 & 0.00 & 0.00 & 0.00 & 0.00 \\
\hline $\begin{array}{l}\text { Warehouse } \\
\text { Recycling }\end{array}$ & 41.00 & 25.00 & 16.00 & 14.00 & 0.00 & 10.00 & 1.00 & 0.00 & 0.00 & 0.00 & 0.00 & 0.00 & 0.00 & 0.00 & 0.00 & 5.00 & 0.00 & 11.00 \\
\hline $\begin{array}{l}\text { Warehouse } \\
\text { Recycling }\end{array}$ & 60.00 & 60.00 & 0.00 & 60.00 & 0.00 & 0.00 & 0.00 & 0.00 & 0.00 & 0.00 & 0.00 & 0.00 & 0.00 & 0.00 & 0.00 & 0.00 & 0.00 & 0.00 \\
\hline $\begin{array}{l}\text { Service } \\
\text { Building } \\
\text { Refuse } \\
\end{array}$ & 340.00 & 60.00 & 280.00 & 35.00 & 0.00 & 10.00 & 10.00 & 5.00 & 0.00 & 0.00 & 35.00 & 15.00 & 0.00 & 0.00 & 10.00 & 75.00 & 60.00 & 85.00 \\
\hline PH2 Refuse & 37.50 & 3.50 & 34.00 & 0.50 & 1.00 & 1.00 & 0.50 & 0.50 & 0.00 & 0.00 & 8.00 & 7.00 & 0.00 & 0.00 & 4.00 & 5.00 & 0.00 & 10.00 \\
\hline AFF Refuse & 44.00 & 3.00 & 41.00 & 3.00 & 0.00 & 0.00 & 0.00 & 0.00 & 0.00 & 0.00 & 0.00 & 0.00 & 0.50 & 0.00 & 0.50 & 1.00 & 0.00 & 39.00 \\
\hline
\end{tabular}


Table 6: Table depicting the designated area, container type, audit date, and approximate collection date by the appropriate waste hauler of either recycling or refuse containers for the Bonneville Project during the study audit period. The symbol '*' indicates that the container audit was done with a representative sample.

\begin{tabular}{|c|c|c|c|}
\hline Designated Area & Container Type & Audit Date & Collection Date \\
\hline Service Building & Recycling & 23 August 2017 & 25 August 2017 \\
\hline Service Building & Refuse & 29 August 2017 & 01 September 2017 \\
\hline Powerhouse 1 & Refuse* & 30 August 2017 & 01 September 2017 \\
\hline Warehouse & Refuse* & 27 September 2017 & 29 September 2017 \\
\hline Warehouse & Refuse* & 27 September 2017 & 29 September 2017 \\
\hline Warehouse & Refuse & 27 September 2017 & 29 September 2017 \\
\hline Warehouse & Recycling & 27 September 2017 & 29 September 2017 \\
\hline Warehouse & Recycling* & 27 September 2017 & 29 September 2017 \\
\hline Service Building & Refuse* & 02 October 2017 & 06 October 2017 \\
\hline Powerhouse 1 & Refuse* & 02 October 2017 & 06 October 2017 \\
\hline Powerhouse 2 & Refuse & 04 October 2017 & 06 October 2017 \\
\hline Powerhouse 2 & Recycling* & 04 October 2017 & 06 October 2017 \\
\hline Juvenile Fish Facility & Recycling* & 04 October 2017 & 06 October 2017 \\
\hline Juvenile Fish Facility & Refuse & 04 October 2017 & 06 October 2017 \\
\hline Juvenile Fish Facility & Refuse & 16 October 2017 & 20 October 2017 \\
\hline Powerhouse 2 & Refuse* & 16 October 2017 & 20 October 2017 \\
\hline Powerhouse 1 & Refuse* & 16 October 2017 & 20 October 2017 \\
\hline Powerhouse 1 & Refuse* & 16 October 2017 & 20 October 2017 \\
\hline Warehouse & Refuse & 16 October 2017 & 20 October 2017 \\
\hline Warehouse & Refuse* & 16 October 2017 & 20 October 2017 \\
\hline Warehouse & Recycling & 23 October 2017 & 20 October 2017 \\
\hline Warehouse & Recycling & 23 October 2017 & 20 October 2017 \\
\hline Powerhouse 1 & Recycling & 23 October 2017 & 20 October 2017 \\
\hline Auditorium & Refuse* & 23 October 2017 & 20 October 2017 \\
\hline Auditorium & Recycling & 23 October 2017 & 20 October 2017 \\
\hline Service Building & Recycling* & 23 October 2017 & 20 October 2017 \\
\hline Juvenile Fish Facility & Refuse & 25 October 2017 & 27 October 2017 \\
\hline Juvenile Fish Facility & Recycling & 25 October 2017 & 27 October 2017 \\
\hline Adult Fish Facility & Refuse & 25 October 2017 & 27 October 2017 \\
\hline Powerhouse 2 & Refuse & 25 October 2017 & 27 October 2017 \\
\hline Powerhouse 2 & Recycling & 25 October 2017 & 27 October 2017 \\
\hline Warehouse & Refuse* & 30 October 2017 & 03 November 2017 \\
\hline Warehouse & Refuse* & 30 October 2017 & 03 November 2017 \\
\hline Warehouse & Refuse* & 30 October 2017 & 03 November 2017 \\
\hline Service Building & Refuse* & 30 October 2017 & 03 November 2017 \\
\hline Powerhouse 2 & Refuse* & 01 November 2017 & 03 November 2017 \\
\hline Auditorium & Refuse & 01 November 2017 & 03 November 2017 \\
\hline Powerhouse 1 & Refuse* & 01 November 2017 & 03 November 2017 \\
\hline
\end{tabular}




\begin{tabular}{|c|c|c|c|}
\hline Powerhouse 1 & Recycling & 06 November 2017 & 10 November 2017 \\
\hline Powerhouse 2 & Recycling & 13 November 2017 & 24 November 2017 \\
\hline Service Building & Recycling & 13 November 2017 & 17 November 2017 \\
\hline Auditorium & Recycling & 13 November 2017 & 17 November 2017 \\
\hline Auditorium & Refuse & 13 November 2017 & 17 November 2017 \\
\hline Warehouse & Recycling & 20 November 2017 & 24 November 2017 \\
\hline Warehouse & Recycling* & 20 November 2017 & 24 November 2017 \\
\hline Auditorium & Recycling & 06 December 2017 & 08 December 2017 \\
\hline Powerhouse 1 & Recycling & 06 December 2017 & 08 December 2017 \\
\hline Powerhouse 2 & Recycling & 06 December 2017 & 08 December 2017 \\
\hline Adult Fish Facility & Refuse & 06 December 2017 & 08 December 2017 \\
\hline Powerhouse 1 & Recycling & 10 January 2018 & 12 January 2018 \\
\hline Adult Fish Facility & Refuse & 10 January 2018 & 12 January 2018 \\
\hline Juvenile Fish Facility & Recycling & 10 January 2018 & 12 January 2018 \\
\hline Powerhouse 2 & Recycling* & 10 January 2018 & 12 January 2018 \\
\hline Powerhouse 1 & Refuse* & 17 January 2018 & 19 January 2018 \\
\hline Warehouse & Refuse & 17 January 2018 & 19 January 2018 \\
\hline Warehouse & Refuse* & 17 January 2018 & 19 January 2018 \\
\hline Warehouse & Refuse* & 17 January 2018 & 19 January 2018 \\
\hline Service Building & Recycling* & 24 January 2018 & 26 January 2018 \\
\hline Warehouse & Recycling & 24 January 2018 & 26 January 2018 \\
\hline Warehouse & Recycling & 24 January 2018 & 26 January 2018 \\
\hline Service Building & Refuse* & 31 January 2018 & 02 February 2018 \\
\hline Juvenile Fish Facility & Refuse & 31 January 2018 & 02 February 2018 \\
\hline Adult Fish Facility & Refuse & 31 January 2018 & 02 February 2018 \\
\hline Powerhouse 2 & Refuse & 31 January 2018 & 02 February 2018 \\
\hline Warehouse & Refuse* & 07 February 2018 & 09 February 2018 \\
\hline Warehouse & Refuse* & 07 February 2018 & 09 February 2018 \\
\hline Warehouse & Refuse* & 07 February 2018 & 09 February 2018 \\
\hline Auditorium & Refuse & 07 February 2018 & 09 February 2018 \\
\hline Powerhouse 2 & Refuse & 14 February 2018 & 16 February 2018 \\
\hline Powerhouse 1 & Refuse* & 14 February 2018 & 16 February 2018 \\
\hline Service Building & Recycling* & 28 February 2018 & 02 March 2018 \\
\hline Juvenile Fish Facility & Recycling & 28 February 2018 & 02 March 2018 \\
\hline Powerhouse 2 & Recycling* & 28 February 2018 & 02 March 2018 \\
\hline Service Building & Refuse* & 07 March 2018 & 09 March 2018 \\
\hline Powerhouse 2 & Refuse & 07 March 2018 & 09 March 2018 \\
\hline Powerhouse 1 & Refuse* & 07 March 2018 & 09 March 2018 \\
\hline Auditorium & Recycling & 20 March 2018 & 23 March 2018 \\
\hline Warehouse & Recycling* & 20 March 2018 & 23 March 2018 \\
\hline Warehouse & Recycling* & 20 March 2018 & 23 March 2018 \\
\hline Powerhouse 1 & Recycling* & 20 March 2018 & 23 March 2018 \\
\hline Juvenile Fish Facility & Recycling* & 20 March 2018 & 30 March 2018 \\
\hline Adult Fish Facility & Refuse & 28 March 2018 & 30 March 2018 \\
\hline Warehouse & Refuse* & 28 March 2018 & 30 March 2018 \\
\hline Warehouse & Refuse* & 28 March 2018 & 30 March 2018 \\
\hline
\end{tabular}




\begin{tabular}{|l|l|l|l|}
\hline Juvenile Fish Facility & Refuse & 28 March 2018 & 30 March 2018 \\
\hline Auditorium & Refuse* & 04 April 2018 & 06 April 2018 \\
\hline Powerhouse 2 & Refuse & 04 April 2018 & 06 April 2018 \\
\hline Warehouse & Recycling* & 11 April 2018 & 13 April 2018 \\
\hline Warehouse & Recycling & 11 April 2018 & 13 April 2018 \\
\hline Powerhouse 1 & Recycling & 11 April 2018 & 13 April 2018 \\
\hline Adult Fish Facility & Refuse & 18 April 2018 & 20 April 2018 \\
\hline Powerhouse 2 & Refuse & 18 April 2018 & 20 April 2018 \\
\hline Service Building & Refuse* & 18 April 2018 & 20 April 2018 \\
\hline
\end{tabular}


Appendix E: Product Alternative Safety Data Sheets:

3M ${ }^{\mathrm{TM}}$ Fast Tack Water Based Adhesive 1000NF, Neutral $05 / 08 / 15$

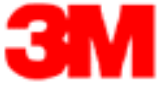

\section{Safety Data Sheet}

Copyright,2015,3M Company

All rights reserved. Copying and/or downloading of this information for the purpose of properly utilizing $3 \mathrm{M}$ products is allowed provided that: (1) the information is copied in full with no changes unless prior written agreement is obtained from $3 \mathrm{M}$, and (2) neither the copy nor the original is resold or otherwise distributed with the intention of eaming a profit thereon.

$\begin{array}{llll}\text { Document Group: } & 31-2738-8 & \text { Version Number: } & 5.00 \\ \text { Issue Date: } & 05 / 08 / 15 & \text { Supercedes Date: } & 07 / 17 / 13\end{array}$

\section{SECTION 1: Identification}

1.1. Product identifier

$3 \mathrm{M}^{\mathrm{TM}}$ Fast Tack Water Based Adhesive 1000NF, Neutral

Product Identification Numbers

$62-4226-7530-6,62-4226-7535-5,62-4226-8436-5,62-4226-8530-5,62-4226-9530-4,62-4226-9538-7,62-4226-9932-2$

1.2. Recommended use and restrictions on use

Recommended use

Adhesive, Industrial use

1.3. Supplier's details MANUFACTURER

DIVISION:

ADDRESS:

$3 \mathrm{M}$

Telephone:

Industrial Adhesives and Tapes Division

$3 \mathrm{M}$ Center, St. Paul, MN 55144-1000, USA

1-888-3M HELPS (1-888-364-3577)

1.4. Emergency telephone number $1-800-364-3577$ or (651) 737-6501 (24 hours)

\section{SECTION 2: Hazard identification}

2.1. Hazard classification

Not classified as hazardous according to OSHA Hazard Communication Standard, 29 CFR 1910.1200.

\subsection{Label elements}

Signal word

Not applicable.

Symbols

Not applicable.

Pictograms

Not applicable.

Precautionary Statements

Prevention: 
Wear eye/face protection.

Response:

IF IN EYES: Rinse cautiously with water for several minutes. Remove contact lenses, if present and easy to do.

Continue rinsing.

If eye irritation persists: Get medical advice/attention.

2.3. Hazards not otherwise classified

None.

\section{SECTION 3: Composition/information on ingredients}

\begin{tabular}{|l|l|l|}
\hline Ingredient & C.A.S. No. & $\%$ by Wt \\
\hline Acrylic Polymer & Trade Secret* & $45-55$ Trade Secret * \\
\hline Water & $7732-18-5$ & $40-50$ Trade Secret * \\
\hline Benzenesulfonic Acid, dodecyl-, branched, Sodium Salt & $69227-09-4$ & $<1$ Trade Secret * \\
\hline
\end{tabular}

*The specific chemical identity and/or exact percentage (concentration) of this composition has been withheld as a trade secret.

\section{SECTION 4: First aid measures}

\subsection{Description of first aid measures}

Inhalation:

No need for first aid is anticipated.

Skin Contact:

No need for first aid is anticipated.

Eye Contact:

Flush with large amounts of water. Remove contact lenses if easy to do. Continue rinsing. If signs/symptoms persist, get medical attention.

If Swallowed:

No need for first aid is anticipated.

4.2. Most important symptoms and effects, both acute and delayed See Section 11.1. Information on toxicological effects.

4.3. Indication of any immediate medical attention and special treatment required Not applicable

\section{SECTION 5: Fire-fighting measures}

5.1. Suitable extinguishing media

Material will not bum. Use a fire fighting agent suitable for the surrounding fire.

5.2. Special hazards arising from the substance or mixture

None inherent in this product.

Hazardous Decomposition or By-Products

Substance

Aldehydes

Condition

During Combustion 
Carbon monoxide

Carbon dioxide
During Combustion

During Combustion

5.3. Special protective actions for fire-fighters

No special protective actions for fire-fighters are anticipated.

\section{SECTION 6: Accidental release measures}

6.1. Personal precautions, protective equipment and emergency procedures

Ventilate the area with fresh air. For large spill, or spills in confined spaces, provide mechanical ventilation to disperse or exhaust vapors, in accordance with good industrial hygiene practice. Refer to other sections of this SDS for information regarding physical and health hazards, respiratory protection, ventilation, and personal protective equipment.

\subsection{Environmental precautions}

Avoid release to the environment. For larger spills, cover drains and build dikes to prevent entry into sewer systems or bodies of water.

\subsection{Methods and material for containment and cleaning up}

Contain spill. Working from around the edges of the spill inward, cover with bentonite, vermiculite, or commercially available inorganic absorbent material. Mix in sufficient absorbent until it appears dry. Remember, adding an absorbent material does not remove a physical, health, or environmental hazard. Collect as much of the spilled material as possible. Place in a closed container approved for transportation by appropriate authorities. Clean up residue with detergent and water. Seal the container. Dispose of collected material as soon as possible.

\section{SECTION 7: Handling and storage}

7.1. Precautions for safe handling

No specific handling precautions are necessary.

7.2. Conditions for safe storage including any incompatibilities

Store away from heat. Store away from strong bases.

\section{SECTION 8: Exposure controls/personal protection}

\subsection{Control parameters}

Occupational exposure limits

No occupational exposure limit values exist for any of the components listed in Section 3 of this SDS.

\subsection{Exposure controls}

\subsubsection{Engineering controls}

Use general dilution ventilation and/or local exhaust ventilation to control airbome exposures to below relevant Exposure Limits and/or control dust/fume/gas/mist/vapors/spray. If ventilation is not adequate, use respiratory protection equipment.

\subsubsection{Personal protective equipment (PPE)}

\section{Eye/face protection}

Select and use eye/face protection to prevent contact based on the results of an exposure assessment. The following eye/face protection(s) are recommended:

Safety Glasses with side shields 
Skin/hand protection

No chemical protective gloves are required.

Respiratory protection

None required.

\section{SECTION 9: Physical and chemical properties}

9.1. Information on basic physical and chemical properties

\begin{tabular}{|c|c|}
\hline $\begin{array}{l}\text { General Physical Form: } \\
\text { Odor, Color, Grade: }\end{array}$ & $\begin{array}{l}\text { Liquid } \\
\text { Slight acrylate white lavender }\end{array}$ \\
\hline Odor threshold & $\begin{array}{l}\text { Slight acrylate white lavender } \\
\text { No Data Available }\end{array}$ \\
\hline $\mathrm{pH}$ & $5-6$ \\
\hline Melting point & No Data Available \\
\hline Boiling Point & $212^{\circ} \mathrm{F}$ \\
\hline Flash Point & No flash point \\
\hline Evaporation rate & $1.00[\operatorname{Ref}$ Std: WATER=1] \\
\hline Flammability (solid, gas) & Not Applicable \\
\hline Flammable Limits(LEL) & Not Applicable \\
\hline Flammable Limits(UEL) & Not Applicable \\
\hline Vapor Pressure & No Data Available \\
\hline Vapor Density & No Data Available \\
\hline Density & $1 \mathrm{~g} / \mathrm{cm} 3$ \\
\hline Specific Gravity & $1[$ Ref Std: WATER=1] \\
\hline Solubility- non-water & No Data Available \\
\hline Partition coefficient: n-octanol/ water & No Data Available \\
\hline Autoignition temperature & No Data Available \\
\hline Decomposition temperature & No Data Available \\
\hline Viscosity & $400-1,100$ centipoise \\
\hline Hazardous Air Pollutants & $<=0 \%$ weight [Test Method: Calculated] \\
\hline VOC Less H2O \& Exempt Solvents & $0 \mathrm{~g} / 1$ [Test Method: calculated SCAQMD rule 443.1] \\
\hline Solids Content & $45-55 \%$ weight \\
\hline
\end{tabular}

\section{SECTION 10: Stability and reactivity}

10.1. Reactivity

This material may be reactive with certain agents under certain conditions - see the remaining headings in this section.

10.2. Chemical stability

Stable.

10.3. Possibility of hazardous reactions

Hazardous polymerization will not occur.

10.4. Conditions to aroid

Heat

10.5. Incompatible materials

Strong bases

10.6. Hazardous decomposition products Substance

Condition 
None known.

Refer to section 5.2 for hazardous decomposition products during combustion.

\section{SECTION 11: Toxicological information}

The information below may not be consistent with the material classification in Section $\mathbf{2}$ if specific ingredient classifications are mandated by a competent authority. In addition, toxicological data on ingredients may not be reflected in the material classification and/or the signs and symptoms of exposure, because an ingredient may be present below the threshold for labeling, an ingredient may not be available for exposure, or the data may not be relevant to the material as a whole.

\subsection{Information on Toxicological effects}

Signs and Symptoms of Exposure

Based on test data and/or information on the components, this material may produce the following health effects:

Inhalation:

No known health effects.

\section{Skin Contact:}

Contact with the skin during product use is not expected to result in significant irritation.

Eye Contact:

Contact with the eyes during product use is not expected to result in significant initation.

Ingestion:

No known health effects.

Toxicological Data

If a component is disclosed in section 3 but does not appear in a table below, either no data are available for that endpoint or the data are not sufficient for classification.

Acute Toxicity
\begin{tabular}{|l|l|l|l|}
\hline Name & Route & Species & Value \\
\hline Overall product & Ingestion & & No data available; calculated ATE $>5,000$ mg $/ \mathrm{kg}$ \\
\hline
\end{tabular}

ATE $=$ acute toxicity estimate

Skin Corrosion/Irritation

For the component/components, either no data are currently available or the data are not sufficient for classification.

Serious Eye Damage/Irritation

For the component/components, either no data are currently available or the data are not sufficient for classification.

Skin Sensitization

For the component/components, either no data are currently available or the data are not sufficient for classification.

Respiratory Sensitization

For the component/components, either no data are currently available or the data are not sufficient for classification.

Germ Cell Mutagenicity

For the component/components, either no data are currently available or the data are not sufficient for classification.

Carcinogenicity 
For the component/components, either no data are currently available or the data are not sufficient for classification.

Reproductive Toxicity

Reproductive and/or Developmental Effects

For the component/components, either no data are currently available or the data are not sufficient for classification.

Target Organ(s)

Specific Target Organ Toxicity - single exposure

For the component/components, either no data are currently available or the data are not sufficient for classification.

Specific Target Organ Toxicity - repeated exposure

For the component/components, either no data are currently available or the data are not sufficient for classification.

Aspiration Hazard

For the component/components, either no data are currently available or the data are not sufficient for classification.

Please contact the address or phone number listed on the first page of the SDS for additional toxicological information on this material and/or its components.

\section{SECTION 12: Ecological information}

\section{Ecotoxicological information}

Please contact the address or phone number listed on the first page of the SDS for additional ecotoxicological information on this material and/or its components.

\section{Chemical fate information}

Please contact the address or phone number listed on the first page of the SDS for additional chemical fate information on this material and/or its components.

\section{SECTION 13: Disposal considerations}

13.1. Disposal methods

Dispose of contents/ container in accordance with the local/regional/national/intemational regulations.

Prior to disposal, consult all applicable authorities and regulations to insure proper classification. Dispose of waste product in a permitted industrial waste facility. Empty and clean product containers may be disposed as non-hazardous waste. Consult your specific regulations and service providers to determine available options and requirements.

EPA Hazardous Waste Number (RCRA): Not regulated

$$
\text { SECTION 14: Transport Information }
$$

For Transport Information, please visit http://3M.com/Transportinfo or call 1-800-364-3577 or 651-737-6501.

\section{SECTION 15: Regulatory information}

\subsection{US Federal Regulations}

Contact $3 \mathrm{M}$ for more information. 
3M ${ }^{\mathrm{TM}}$ Fast Tack Water Based Adhesive 1000NF, Neutral $\quad 05 / 08 / 15$

\section{1/312 Hazard Categories:}

Fire Hazard - No Pressure Hazard - No Reactivity Hazard - No Immediate Hazard - Yes Delayed Hazard - No

\subsection{State Regulations}

Contact $3 \mathrm{M}$ for more information.

\subsection{Chemical Inventories}

The components of this product are in compliance with the chemical notification requirements of TSCA. One or more chemical components of this material have been commercialized under the TSCA polymer exemption at 40CFR723.250. Polymers subject to this exemption are not listed on the TSCA Inventory, but are in compliance with TSCA requirements.

Contact $3 \mathrm{M}$ for more information.

\subsection{International Regulations}

Contact $3 \mathrm{M}$ for more information.

This SDS has been prepared to meet the U.S. OSHA Hazard Communication Standard, 29 CFR 1910.1200.

\section{SECTION 16: Other information}

NFPA Hazard Classification

Health: 1 Flammability: 0 Instability: 0 Special Hazards: None

National Fire Protection Association (NFPA) hazard ratings are designed for use by emergency response personnel to address the hazards that are presented by short-term, acute exposure to a material under conditions of fire, spill, or similar emergencies. Hazard ratings are primarily based on the inherent physical and toxic properties of the material but also include the toxic properties of combustion or decomposition products that are known to be generated in significant quantities.

$\begin{array}{llll}\text { Document Group: } & 31-2738-8 & \text { Version Number: } & 5.00 \\ \text { Issue Date: } & 05 / 08 / 15 & \text { Supercedes Date: } & 07 / 17 / 13\end{array}$

DISCLAIMER: The information in this Safety Data Sheet (SDS) is believed to be correct as of the date issued. 3M MAKES NO WARRANTIES, EXPRESSED OR IMPLIED, INCLUDING, BUT NOT LIMITED TO, ANY IMPLIED WARRANTY OF MERCHANTABILITY OR FITNESS FOR A PARTICULAR PURPOSE OR COURSE OF PERFORMANCE OR USAGE OF TRADE. User is responsible for determining whether the $3 \mathrm{M}$ product is fit for a particular purpose and suitable for user's method of use or application. Given the variety of factors that can affect the use and application of a $3 \mathrm{M}$ product, some of which are uniquely within the user's knowledge and control, it is essential that the user evaluate the $3 \mathrm{M}$ product to determine whether it is fit for a particular purpose and suitable for user's method of use or application.

$3 \mathrm{M}$ provides information in electronic form as a service to its customers. Due to the remote possibility that electronic transfer may have resulted in errors, omissions or alterations in this information, $3 \mathrm{M}$ makes no representations as to its completeness or accuracy. In addition, information obtained from a database may not be as current as the information in the SDS available directly from $3 \mathrm{M}$

3M USA SDSs are available at www.3M.com 
अM

\section{Safety Data Sheet}

Copyright,2017,3M Company.

All rights reserved Copying and/or downloading of this information for the purpose of properly utilizing $3 \mathrm{M}$ products is allowed provided that: (1) the information is copied in full with no changes unless prior written agreement is obtained from $3 \mathrm{M}$, and (2) neither the copy nor the original is resold or otherwise distributed with the intention of eaming a profit thereon.

$\begin{array}{llll}\text { Document Group: } & 29-3109-5 & \text { Version Number: } & 4.00 \\ \text { Issue Date: } & 04 / 25 / 17 & \text { Supercedes Date: } & 03 / 03 / 15\end{array}$

\section{SECTION 1: Identification}

1.1. Product identifier

Super 77 Aerosol Spray Low $25 \%$ VOC

Product Identification Numbers

$62-4876-4930-3,62-4876-4935-2$

\subsection{Recommended use and restrictions on use}

\section{Recommended use}

Adhesive, Industrial use

\subsection{Supplier's details} MANUFACTURER: DIVTSION: ADDRESS:

Telephone:

$3 \mathrm{M}$

Industrial Adhesives and Tapes Division

$3 \mathrm{M}$ Center, St. Paul, MN 55144-1000, USA

1-888-3M HELPS (1-888-364-3577)

1.4. Emergency telephone number $1-800-364-3577$ or (651) 737-6501 (24 hours)

\section{SECTION 2: Hazard identification}

\subsection{Hazard classification}

Flammable Aerosol: Category 1.

Gas Under Pressure: Dissolved gas.

Serious Eye Damage/Iritation: Category 2A.

Specific Target Organ Toxicity (single exposure): Category 1.

Specific Target Organ Toxicity (single exposure): Category 3.

\subsection{Label elements}

Signal word

Danger

Symbols

Flame | Gas cylinder | Exclamation mark | Health Hazard | 


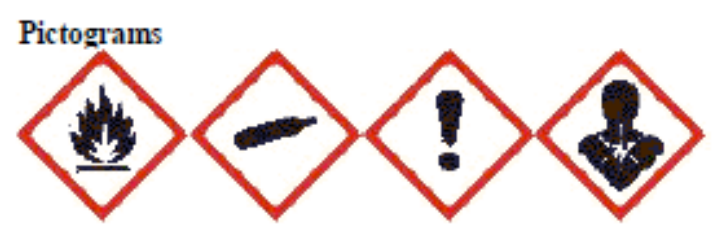

Hazard Statements

Extremely flammable aerosol.

Contains gas under pressure; may explode if heated.

Causes serious eye imitation.

May cause drowsiness or dizziness.

Causes damage to organs:

cardiovascular system

Precautionary Statements

General:

Keep out of reach of children.

Prevention:

Keep away from heat/sparks/open flames/hot surfaces. - No smoking.

Do not spray on an open flame or other ignition source.

Pressurized container: Do not pierce or bum, even after use.

Do not breathe dust/fume/gas/mist/vapors/spray.

Use only outdoors or in a well-ventilated area.

Wear eye/face protection.

Do not eat, drink or smoke when using this product.

Wash thoroughly after handling.

Response:

IF INHALED: Remove person to fresh air and keep comfortable for breathing.

IF IN EYES: Rinse cautiously with water for several minutes. Remove contact lenses, if present and easy to do.

Continue rinsing.

If eye initation persists: Get medical advice/attention.

IF exposed: Call a POISON CENTER or doctor/physician.

Specific treatment (see Notes to Physician on this label).

Storage:

Protect from sunlight. Do not expose to temperatures exceeding 50C/122F.

Store in a well-ventilated place. Keep container tightly closed.

Store locked up.

Disposal:

Dispose of contents/container in accordance with applicable local/regional/national/international regulations.

Notes to Physician:

Exposure may increase myocardial irritability. Do not administer sympathomimetic drugs unless absolutely necessary.

\subsection{Hazards not otherwise classified}

Supplemental Information:

Intentional misuse by deliberately concentrating and inhaling contents can be harmful or fatal. 


\section{SECTION 3: Composition/information on ingredients}

\begin{tabular}{|l|l|l|}
\hline Ingredient & C.A.S. No. & $\%$ by Wt \\
\hline Acetone & $67-64-1$ & $35-45$ Trade Secret * \\
\hline Non-hazardous components & Trade Secret* & $10-25$ Trade Secret * \\
\hline 1,1-Difluoroethane & $75-37-6$ & $10-15$ Trade Secret * \\
\hline Cyclohexane & $110-82-7$ & $5-15$ Trade Secret * \\
\hline Propane & $74-98-6$ & $10-15$ Trade Secret * \\
\hline
\end{tabular}

*The specific chemical identity and/or exact percentage (concentration) of this composition has been withheld as a trade secret.

\section{SECTION 4: First aid measures}

\subsection{Description of first aid measures}

Inhalation:

Remove person to fresh air. Get medical attention.

Skin Contact:

Wash with soap and water. If signs/symptoms develop, get medical attention.

Eve Contact:

Immediately flush with large amounts of water. Remove contact lenses if easy to do. Continue rinsing. Get medical attention.

If Swallowed:

Rinse mouth. If you feel unwell, get medical attention.

4.2. Most important symptoms and effects, both acute and delayed See Section 11.1. Information on toxicological effects.

4.3. Indication of any immediate medical attention and special treatment required Exposure may increase myocardial irritability. Do not administer sympathomimetic drugs unless absolutely necessary.

\section{SECTION 5: Fire-fighting measures}

5.1. Suitable extinguishing media

Use a fire fighting agent suitable for the surrounding fire.

5.2. Special hazards arising from the substance or mixture

Closed containers exposed to heat from fire may build pressure and explode.

Hazardous Decomposition or By-Products Substance Carbon monoxide

Condition

Carbon dioxide

5.3. Special protective actions for fire-fighters

Water may not effectively extinguish fire; however, it should be used to keep fire-exposed containers and surfaces cool and prevent explosive rupture. 


\section{SECTION 6: Accidental release measures}

6.1. Personal precautions, protective equipment and emergency procedures

Evacuate area. Keep away from heat/sparks/open flames/hot surfaces. - No smoking. Use only non-sparking tools. Ventilate the area with fresh air. For large spill, or spills in confined spaces, provide mechanical ventilation to disperse or exhaust vapors, in accordance with good industrial hygiene practice. Warning! A motor could be an ignition source and could cause flammable gases or vapors in the spill area to burn or explode. Refer to other sections of this SDS for information regarding physical and health hazards, respiratory protection, ventilation, and personal protective equipment.

\subsection{Environmental precautions}

Avoid release to the environment. For larger spills, cover drains and build dikes to prevent entry into sewer systems or bodies of water.

6.3. Methods and material for containment and cleaning up If possible, seal leaking container. Place leaking containers in a well-ventilated area, preferably an operating exhaust hood, or if necessary outdoors on an impermeable surface until appropriate packaging for the leaking container or its contents is available. Contain spill. Cover spill area with a fire-extinguishing foam. An appropriate aqueous film forming foam (AFFF) is recommended. Working from around the edges of the spill inward, cover with bentonite, vermiculite, or commercially available inorganic absorbent material. Mix in sufficient absorbent until it appears dry. Remember, adding an absorbent material does not remove a physical, health, or environmental hazard. Collect as much of the spilled material as possible using non-sparking tools. Place in a metal container approved for transportation by appropriate authorities. Clean up residue with an appropriate solvent selected by a qualified and authorized person. Ventilate the area with fresh air. Read and follow safety precautions on the solvent label and SDS. Seal the container. Dispose of collected material as soon as possible.

\section{SECTION 7: Handling and storage}

\subsection{Precautions for safe handling}

Keep out of reach of children. Keep away from heat/sparks/open flames/hot surfaces. - No smoking. Do not spray on an open flame or other ignition source. Do not pierce or burn, even after use. Do not breathe dust/fume/gas/mist/vapors/spray. Do not get in eyes, on skin, or on clothing. Do not eat, drink or smoke when using this product. Wash thoroughly after handling. Avoid release to the environment. Avoid contact with oxidizing agents (eg. chlorine, chromic acid etc.)

7.2. Conditions for safe storage including any incompatibilities

Store in a well-ventilated place. Keep container tightly closed. Protect from sunlight. Do not expose to temperatures exceeding $50 \mathrm{C} / 122 \mathrm{~F}$. Store away from heat. Store away from acids. Store away from oxidizing agents.

\section{SECTION 8: Exposure controls/personal protection}

\subsection{Control parameters}

Occupational exposure limits

If a component is disclosed in section 3 but does not appear in the table below, an occupational exposure limit is not available for the component.

\begin{tabular}{|l|l|l|l|l|}
\hline Ingredient & C.A.S. No. & Agency & Limit type & Additional Comments \\
\hline Cyclohexane & $110-82-7$ & ACGIH & TWA: $100 \mathrm{ppm}$ & \\
\hline Cyclohexane & $110-82-7$ & OSHA & TWA:1050 mg/m3(300 ppm) & \\
\hline Acetone & $67-64-1$ & OSHA & TWA:2400 mg/m3(1000 ppm) & \\
\hline Acetone & $67-64-1$ & ACGIH & TWA:250 ppm;STEL:500 ppm & $\begin{array}{l}\text { A4: Not class. as human } \\
\text { carcin }\end{array}$ \\
\hline Propane & & & & \\
\hline Propane & $74-98-6$ & ACGIH & Limit value not established: & \\
\hline
\end{tabular}




\begin{tabular}{|l|l|l|l|l|}
\hline 1,1-Difluoroethane & $75-37-6$ & AIHA & TWA:2700 mg/m3(1000 ppm) & \\
\hline
\end{tabular}

ACGIH : American Conference of Governmental Industrial Hygienists

AIHA : American Industrial Hygiene Association

CMRG : Chemical Mamufacturer's Recommended Guidelines

OSHA : United States Department of Labor - Occupational Safety and Health Administration

TWA: Time-Weighted-Average

STEL: Short Term Exposure Limit

CEIL: Ceiling

\subsection{Exposure controls}

\subsubsection{Engineering controls}

Use general dilution ventilation and/or local exhaust ventilation to control airbome exposures to below relevant Exposure

Limits and/or control dust/fume/gas/mist/vapors/spray. If ventilation is not adequate, use respiratory protection equipment.

\subsubsection{Personal protective equipment (PPE)}

\section{Eye/face protection}

Select and use eye/face protection to prevent contact based on the results of an exposure assessment. The following eye/face protection(s) are recommended:

Indirect Vented Goggles

\section{Skin/hand protection}

Select and use gloves and/or protective clothing approved to relevant local standards to prevent skin contact based on the results of an exposure assessment. Selection should be based on use factors such as exposure levels, concentration of the substance or mixture, frequency and duration, physical challenges such as temperature extremes, and other use conditions. Consult with your glove and/or protective clothing manufacturer for selection of appropriate compatible gloves/protective clothing.

Gloves made from the following material(s) are recommended: Fluoroelastomer

Nitrile Rubber

Polyvinyl Alcohol (PVA)

\section{Respiratory protection}

An exposure assessment may be needed to decide if a respirator is required If a respirator is needed, use respirators as part of a full respiratory protection program. Based on the results of the exposure assessment, select from the following respirator type(s) to reduce inhalation exposure:

Half facepiece or full facepiece air-purifying respirator suitable for organic vapors

For questions about suitability for a specific application, consult with your respirator manufacturer.

\section{SECTION 9: Physical and chemical properties}

9.1. Information on basic physical and chemical properties General Physical Form: Specific Physical Form:

Odor, Color, Grade:

Odor threshold

$\mathrm{pH}$

Melting point

Boiling Point

Flash Point

Evaporation rate

Flammability (solid, gas)

Flammable Limits(LEL)

Liquid

Aerosol

clear, solvent odor

No Data Available

Not Applicable

Not Applicable

$44{ }^{\circ} \mathrm{F}$ [Details:Acetone]

$-156^{\circ} \mathrm{F}$ [Test Method:Closed Cup]

$>1$ [Ref Std: $\mathrm{BUOAC}=1]$

Not Applicable

$1.3 \%$ volume 
Flammable Limits(UEL)

Vapor Pressure

Vapor Density

Density

Specific Gravity

Solubility in Water

Solubility- non-water

Partition coefficient: n-octanol/ water

Autoignition temperature

Decomposition temperature

Viscosity

Molecular weight

Percent volatile

VOC Less H2O \& Exempt Solvents
$12.8 \%$ volume

$c=4137 \mathrm{mmHg}\left[\right.$ @ $68^{\circ} \mathrm{F}$ ]

$>1$ [Ref Std: $A \mathbb{R}=1]$

$0.80 \mathrm{~g} / \mathrm{ml}$

0.80 [Ref Std:WATER $=1]$

Nil

No Data Available

No Data Available

No Data Available

No Data Available

$c=100$ centipoise [@ $73.4{ }^{\circ} \mathrm{F}$ ]

No Data Available

$c=80.6 \%$ weight

$\varsigma=25 \%$ [Test Method:calculated per CARB title 2]

\section{SECTION 10: Stability and reactivity}

10.1. Reactivity

This material may be reactive with certain agents under certain conditions - see the remaining headings in this section.

10.2. Chemical stability

Stable.

10.3. Possibility of hazardous reactions

Hazardous polymerization will not occur.

10.4. Conditions to avoid

Heat

Sparks and/or flames

10.5. Incompatible materials

Not determined

10.6. Hazardous decomposition products

Substance

Condition

None known.

Refer to section 5.2 for hazardous decomposition products during combustion

\section{SECTION 11: Toxicological information}

The information below may not be consistent with the material classification in Section $\mathbf{2}$ if specific ingredient classifications are mandated by a competent authority. In addition, toxicological data on ingredients may not be reflected in the material classification and/or the signs and symptoms of exposure, because an ingredient may be present below the threshold for labeling, an ingredient may not be available for exposure, or the data may not be relevant to the material as a whole.

\subsection{Information on Toxicological effects}

Signs and Symptoms of Exposure

Based on test data and/or information on the components, this material may produce the following health effects: 
Inhalation:

Intentional concentration and inhalation may be harmful or fatal.

Respiratory Tract Initation: Signs/symptoms may include cough, sneezing, nasal discharge, headache, hoarseness, and nose and throat pain.

May cause additional health effects (see below).

Slin Contact:

Prolonged or repeated exposure may cause:

Dermal Defatting: Signs/symptoms may include localized redness, itching, drying and cracking of skin.

Eye Contact:

Severe Eye Irritation: Signs/symptoms may include significant redness, swelling, pain, tearing, cloudy appearance of the comea, and impaired vision.

Ingestion:

Gastrointestinal Irritation: Signs/symptoms may include abdominal pain, stomach upset, nausea, vomiting and diarrhea.

May cause additional health effects (see below).

\section{Additional Health Effects:}

Single exposure may cause target organ effects:

Central Nervous System (CNS) Depression: Signs/symptoms may include headache, dizziness, drowsiness, incoordination, nausea, slowed reaction time, slurred speech, giddiness, and unconsciousness.

Single exposure, above recommended guidelines, may cause:

Cardiac Sensitization: Signs/symptoms may include irregular heartbeat (arrhythmia), faintness, chest pain, and may be fatal.

Toxicological Data

If a component is disclosed in section 3 but does not appear in a table below, either no data are available for that endpoint or the data are not sufficient for classification.

\begin{tabular}{|c|c|c|c|}
\hline Name & Route & Species & Value \\
\hline Overall product & Dermal & & No data available; calculated ATE $>5,000 \mathrm{mg} / \mathrm{kg}$ \\
\hline Overall product & $\begin{array}{l}\text { Inhalation- } \\
\operatorname{Vapor}(4 \mathrm{hr})\end{array}$ & & No data available; calculated ATE $>50 \mathrm{mg} / \mathrm{l}$ \\
\hline Overall product & Ingestion & & No data available; calculated ATE $>5,000 \mathrm{mg} / \mathrm{kg}$ \\
\hline Acetone & Denmal & Rabbit & LD50 $>15,688 \mathrm{mg} / \mathrm{kg}$ \\
\hline Acetone & $\begin{array}{l}\text { Inhalation- } \\
\text { Vapor (4 } \\
\text { hours) }\end{array}$ & Rat & LC50 $76 \mathrm{mg} / 1$ \\
\hline Acetone & Ingestion & Rat & LD50 $5,800 \mathrm{mg} / \mathrm{kg}$ \\
\hline Propane & $\begin{array}{l}\text { Inhalation- } \\
\text { Gas (4 } \\
\text { hours) }\end{array}$ & Rat & LC50 $>200,000 \mathrm{ppm}$ \\
\hline 1,1-Difhuoroethane & $\begin{array}{l}\text { Inhalation- } \\
\text { Gas (4 } \\
\text { hours) }\end{array}$ & Rat & LC50 $>437,000 \mathrm{ppm}$ \\
\hline 1,1-Difhuoroethane & Ingestion & Rat & LD50 $>1,500 \mathrm{mg} / \mathrm{kg}$ \\
\hline Cyclohexane & Dermal & Rat & $\mathrm{LD} 50>2,000 \mathrm{mg} / \mathrm{kg}$ \\
\hline Cyclohexane & $\begin{array}{l}\text { Inhalation- } \\
\text { Vapor (4 } \\
\text { hours) }\end{array}$ & Rat & $\mathrm{LC} 50>32.9 \mathrm{mg} /$ \\
\hline
\end{tabular}

Page 7 of 12 


\begin{tabular}{|l|l|l|ll|}
\hline Cyclohexane & Ingestion & Rat & LD50 $\quad 6,200$ mglkg \\
\hline
\end{tabular}

$\mathrm{ATE}=$ acute toxicity estimate

Slin Corrosion/Irritation

\begin{tabular}{|l|l|l|}
\hline Name & Species & Value \\
\hline Acetone & Mouse & Minimal initation \\
\hline Propane & Rabbit & Minimal initation \\
\hline Cyclohexane & Rabbit & Mild irritant \\
\hline
\end{tabular}

Serious Eye Damage/Irritation

\begin{tabular}{|l|l|l|}
\hline Name & Species & Value \\
\hline Acetone & Rabbit & Severe iritant \\
\hline Propane & Rabbit & Mild irritant \\
\hline Cyclohexane & Rabbit & Mild irritant \\
\hline
\end{tabular}

Slin Sensitization

For the component/components, either no data are currently available or the data are not sufficient for classification.

Respiratory Sensitization

For the component/components, either no data are currently available or the data are not sufficient for classification.

Germ Cell Mutagenicity

\begin{tabular}{|l|l|l|}
\hline Name & Route & Value \\
\hline Acetone & In vivo & Not mutagenic \\
\hline Acetone & In Vitro & $\begin{array}{l}\text { Some positive data exist, but the data are not } \\
\text { sufficient for classification }\end{array}$ \\
\hline Propane & In Vitro & Not mutagenic \\
\hline $1,1-$ Difhuoroethane & In Vitro & $\begin{array}{l}\text { Some positive data exist, but the data are not } \\
\text { sufficient for classification }\end{array}$ \\
\hline $1,1-$ Difhuoroethane & In vivo & $\begin{array}{l}\text { Some positive data exist, but the data are not } \\
\text { sufficient for classification }\end{array}$ \\
\hline Crclohexane & In Vitro & Not mutagenic \\
\hline Cyclohexane & In vivo & $\begin{array}{l}\text { Some positive data exist, but the data are not } \\
\text { sufficient for classification }\end{array}$ \\
\hline
\end{tabular}

Carcinogenicity

\begin{tabular}{|l|l|}
\hline Name & Route \\
\hline Acetone & $\begin{array}{l}\text { Not } \\
\text { Specified }\end{array}$ \\
\hline $1,1-$ Difhuoroethane & Inhalation \\
\hline
\end{tabular}

\begin{tabular}{|l|l|}
\hline Species & Value \\
\hline $\begin{array}{l}\text { Multiple } \\
\text { animal } \\
\text { species }\end{array}$ & Not carcinogenic \\
\hline Rat & $\begin{array}{l}\text { Some positive data exist, but the data are not } \\
\text { sufficient for classification }\end{array}$ \\
\hline
\end{tabular}

\section{Reproductive Toxicity}

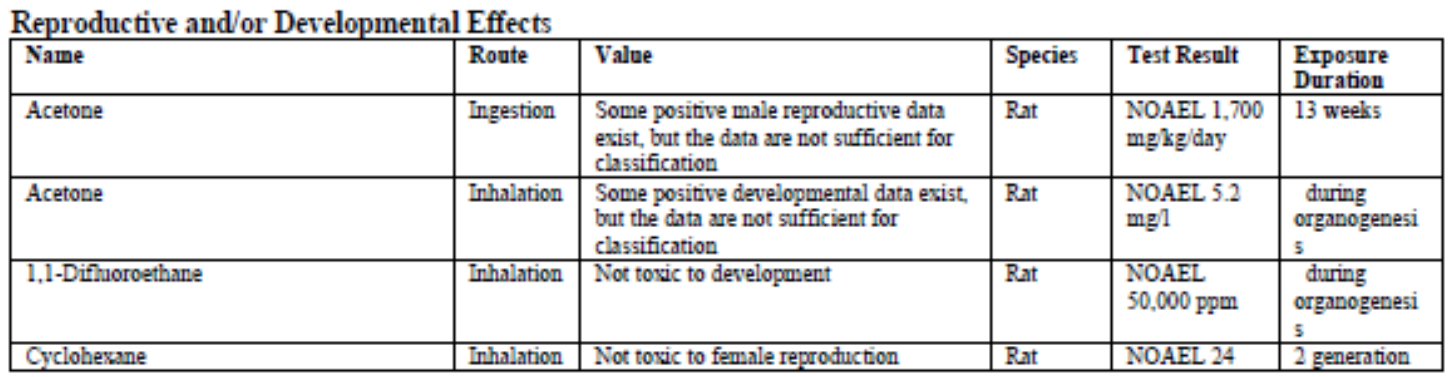

Page 8 of 12 


\begin{tabular}{|l|l|l|l|l|l|}
\hline & & & & mgl & \\
\hline Cyclohexane & Inhalation & Not toxic to male reproduction & Rat & $\begin{array}{l}\text { NoAEL 24 } \\
\text { mgl }\end{array}$ & 2 generation \\
\hline Cyclohexane & Inhalation & $\begin{array}{l}\text { Some positive developmental data exist, } \\
\text { but the data are not sufficient for } \\
\text { classification }\end{array}$ & $\begin{array}{l}\text { Rat } \\
\text { mg/1 }\end{array}$ & 2 generation \\
\hline
\end{tabular}

\section{Target Organ(s)}

Specific Target Organ Toxicity - single exposure

\begin{tabular}{|c|c|c|c|c|c|c|}
\hline Name & Route & Target Organ(s) & Value & Species & Test Result & $\begin{array}{l}\text { Erposure } \\
\text { Duration }\end{array}$ \\
\hline Acetone & Inhalation & $\begin{array}{l}\text { central nervous } \\
\text { system depression }\end{array}$ & $\begin{array}{l}\text { May cause drowsiness or } \\
\text { dizziness }\end{array}$ & Human & $\begin{array}{l}\text { NOAEL Not } \\
\text { available }\end{array}$ & \\
\hline Acetone & Inhalation & respiratory inritation & $\begin{array}{l}\text { Some positive data exist, but the } \\
\text { data are not sufficient for } \\
\text { classification }\end{array}$ & Human & $\begin{array}{l}\text { NOAEL Not } \\
\text { available }\end{array}$ & \\
\hline Acetone & Inhalation & immune system & $\begin{array}{l}\text { Some positive data exist, but the } \\
\text { data are not sufficient for } \\
\text { classification }\end{array}$ & Human & $\begin{array}{l}\text { NOAEL } 1.19 \\
\mathrm{mg} / 1\end{array}$ & 6 hours \\
\hline Acetone & Inhalation & liver & $\begin{array}{l}\text { Some positive data exist, but the } \\
\text { data are not sufficient for } \\
\text { classification }\end{array}$ & $\begin{array}{l}\text { Guinea } \\
\text { pig }\end{array}$ & $\begin{array}{l}\text { NOAEL Not } \\
\text { available }\end{array}$ & \\
\hline Acetone & Ingestion & $\begin{array}{l}\text { central nervous } \\
\text { system depression }\end{array}$ & $\begin{array}{l}\text { May cause drowsiness or } \\
\text { dizziness }\end{array}$ & Human & $\begin{array}{l}\text { NOAEL Not } \\
\text { available }\end{array}$ & $\begin{array}{l}\text { poisoning } \\
\text { and/or abuse }\end{array}$ \\
\hline Propane & Inhalation & cardiac sensitization & Causes damage to organs & Human & $\begin{array}{l}\text { NOAEL Not } \\
\text { available }\end{array}$ & \\
\hline Propane & Inhalation & $\begin{array}{l}\text { central nervous } \\
\text { system depression }\end{array}$ & $\begin{array}{l}\text { May cause drowsiness or } \\
\text { dizziness }\end{array}$ & Human & $\begin{array}{l}\text { NOAEL Not } \\
\text { available }\end{array}$ & \\
\hline Propane & Inhalation & respiratory intitation & All data are negative & Human & $\begin{array}{l}\text { NOAEL Not } \\
\text { available }\end{array}$ & \\
\hline 1,1-Diffuoroethane & Inhalation & cardiac sensitization & Causes damage to organs & $\begin{array}{l}\text { Human } \\
\text { and } \\
\text { animal }\end{array}$ & $\begin{array}{l}\text { NOAEL Not } \\
\text { available }\end{array}$ & $\begin{array}{l}\text { poisoning } \\
\text { and/or abuse }\end{array}$ \\
\hline 1,1-Diffuoroethane & Inhalation & $\begin{array}{l}\text { central nervous } \\
\text { system depression }\end{array}$ & $\begin{array}{l}\text { May cause drowsiness or } \\
\text { dizziness }\end{array}$ & $\begin{array}{l}\text { Human } \\
\text { and } \\
\text { animal }\end{array}$ & $\begin{array}{l}\text { NOAEL } \\
100,000 \mathrm{ppm}\end{array}$ & \\
\hline 1,1-Difhuoroethane & Inhalation & respiratory intitation & $\begin{array}{l}\text { Some positive data exist, but the } \\
\text { data are not sufficient for } \\
\text { classification }\end{array}$ & $\begin{array}{l}\text { Not } \\
\text { available }\end{array}$ & $\begin{array}{l}\text { NOAEL Not } \\
\text { available }\end{array}$ & not available \\
\hline Cyclohexane & Inhalation & $\begin{array}{l}\text { central nervous } \\
\text { system depression }\end{array}$ & $\begin{array}{l}\text { May cause drowsiness or } \\
\text { dizziness }\end{array}$ & $\begin{array}{l}\text { Human } \\
\text { and } \\
\text { animal }\end{array}$ & $\begin{array}{l}\text { NOAEL Not } \\
\text { available }\end{array}$ & \\
\hline Cyclohexane & Inhalation & respiratory intitation & $\begin{array}{l}\text { Some positive data exist, but the } \\
\text { data are not sufficient for } \\
\text { classification }\end{array}$ & $\begin{array}{l}\text { Human } \\
\text { and } \\
\text { animal }\end{array}$ & $\begin{array}{l}\text { NOAEL Not } \\
\text { available }\end{array}$ & \\
\hline Cyclohexane & Ingestion & $\begin{array}{l}\text { central nervous } \\
\text { system depression }\end{array}$ & $\begin{array}{l}\text { May cause drowsiness or } \\
\text { dizziness }\end{array}$ & $\begin{array}{l}\text { Professio } \\
\text { nal } \\
\text { judgeme } \\
\text { nt: }\end{array}$ & $\begin{array}{l}\text { NOAEL Not } \\
\text { available }\end{array}$ & \\
\hline
\end{tabular}

Specific Target Organ Toxicity - repeated exposure

\begin{tabular}{|l|l|l|l|l|l|l|}
\hline Name & Route & Target Organ(s) & Value & Species & Test Result & $\begin{array}{l}\text { Erposure } \\
\text { Duration }\end{array}$ \\
\hline Acetone & Dermal & eyes & $\begin{array}{l}\text { Some positive data exist, but the } \\
\text { data are not sufficient for } \\
\text { classification }\end{array}$ & $\begin{array}{l}\text { Guinea } \\
\text { pig }\end{array}$ & $\begin{array}{l}\text { NOAEL Not } \\
\text { available }\end{array}$ & 3 weeks \\
\hline Acetone & Inhalation & $\begin{array}{l}\text { hematopoietic } \\
\text { system }\end{array}$ & $\begin{array}{l}\text { Some positive data exist, but the } \\
\text { data are not sufficient for } \\
\text { classification }\end{array}$ & Human & $\begin{array}{l}\text { NOAEL } 3 \\
\text { mg1 }\end{array}$ & 6 weeks \\
\hline Acetone & Inhalation & immune system & $\begin{array}{l}\text { Some positive data exist, but the } \\
\text { data are not sufficient for } \\
\text { classification }\end{array}$ & Human & $\begin{array}{l}\text { NOAEL 1.19 } \\
\text { mg1 } 1\end{array}$ & 6 days \\
\hline Acetone & Inhalation & $\begin{array}{l}\text { kidney and/or } \\
\text { bladder }\end{array}$ & $\begin{array}{l}\text { Some positive data exist, but the } \\
\text { data are not sufficient for } \\
\text { classification }\end{array}$ & $\begin{array}{l}\text { Guinea } \\
\text { pig }\end{array}$ & $\begin{array}{l}\text { NOAEL 119 } \\
\text { mg1 } 1\end{array}$ & not available \\
\hline
\end{tabular}




\begin{tabular}{|c|c|c|c|c|c|c|}
\hline Acetone & Inhalation & heart | liver & All data are negative & Rat & \begin{tabular}{|l|}
$\begin{array}{l}\text { NOAEL } 45 \\
\mathrm{mgl}\end{array}$ \\
\end{tabular} & 8 weeks \\
\hline Acetone & Ingestion & $\begin{array}{l}\text { kidney and/or } \\
\text { bladder }\end{array}$ & $\begin{array}{l}\text { Some positive data exist, but the } \\
\text { data are not sufficient for } \\
\text { classification }\end{array}$ & Rat & $\begin{array}{l}\text { NOAEL } 900 \\
\mathrm{mg} / \mathrm{kg} / \mathrm{day}\end{array}$ & 13 weeks \\
\hline Acetone & Ingestion & heart & $\begin{array}{l}\text { Some positive data exist, but the } \\
\text { data are not sufficient for } \\
\text { classification }\end{array}$ & Rat & \begin{tabular}{|l|} 
NOAEL \\
2,500 \\
$\mathrm{mg} / \mathrm{kg} / \mathrm{day}$ \\
\end{tabular} & 13 weeks \\
\hline Acetone & Ingestion & $\begin{array}{l}\text { hematopoietic } \\
\text { system }\end{array}$ & $\begin{array}{l}\text { Some positive data exist, but the } \\
\text { data are not sufficient for } \\
\text { classification }\end{array}$ & Rat & $\begin{array}{l}\text { NOAEL } 200 \\
\mathrm{mg} / \mathrm{kg} / \mathrm{day}\end{array}$ & 13 weeks \\
\hline Acetone & Ingestion & liver & $\begin{array}{l}\text { Some positive data exist, but the } \\
\text { data are not sufficient for } \\
\text { classification }\end{array}$ & Mouse & \begin{tabular}{|l|} 
NOAEL \\
3,896 \\
$\mathrm{mglg} / \mathrm{day}$ \\
\end{tabular} & 14 days \\
\hline Acetone & Ingestion & eyes & All data are negative & Rat & $\begin{array}{l}\text { NOAEL } \\
3,400 \\
\mathrm{mg} / \mathrm{kg} / \mathrm{day}\end{array}$ & 13 weeks \\
\hline Acetone & Ingestion & respiratory system & All data are negative & Rat & \begin{tabular}{|l|} 
NOAEL \\
2,500 \\
$\mathrm{mg} / \mathrm{kg} / \mathrm{day}$ \\
\end{tabular} & 13 weeks \\
\hline Acetone & Ingestion & muscles & All data are negative & Rat & \begin{tabular}{|l|} 
NOAEL \\
$2,500 \mathrm{mg} \mathrm{kg}$
\end{tabular} & 13 weeks \\
\hline Acetone & Ingestion & $\begin{array}{l}\text { skin / bone, teeth, } \\
\text { nails, and/or hair }\end{array}$ & All data are negative & Mouse & \begin{tabular}{|l|} 
NOAEL \\
11.298 \\
$\mathrm{mg} / \mathrm{kg} / \mathrm{day}$ \\
\end{tabular} & 13 weeks \\
\hline 1,1-Difluoroethane & Inhalation & $\begin{array}{l}\text { hematopoietic } \\
\text { system | kidney } \\
\text { and/or bladder | } \\
\text { respiratory system }\end{array}$ & $\begin{array}{l}\text { Some positive data exist, but the } \\
\text { data are not sufficient for } \\
\text { classification }\end{array}$ & Rat & $\begin{array}{l}\text { NOAEL } \\
25,000 \mathrm{ppm}\end{array}$ & 2 years \\
\hline Cyclobexane & Inhalation & liver & $\begin{array}{l}\text { Some positive data exist, but the } \\
\text { data are not sufficient for } \\
\text { classification }\end{array}$ & Rat & \begin{tabular}{|l}
$\begin{array}{l}\text { NOAEL } 24 \\
\mathrm{mg} / 1\end{array}$ \\
\end{tabular} & 90 days \\
\hline Cyclohexane & Inhalation & auditory system & $\begin{array}{l}\text { Some positive data exist, but the } \\
\text { data are not sufficient for } \\
\text { classification }\end{array}$ & Rat & \begin{tabular}{|l|}
$\begin{array}{l}\text { NOAEL } 1.7 \\
\mathrm{mg} /\end{array}$ \\
\end{tabular} & 90 days \\
\hline Cyclohexane & Inhalation & $\begin{array}{l}\text { kidney and/or } \\
\text { bladder }\end{array}$ & $\begin{array}{l}\text { Some positive data exist, but the } \\
\text { data are not sufficient for } \\
\text { classification }\end{array}$ & Rabbit & \begin{tabular}{|l|} 
NOAEL 2.7 \\
$\mathrm{mg} / 1$
\end{tabular} & 10 weeks \\
\hline Cyclohexane & Inhalation & $\begin{array}{l}\text { hematopoietic } \\
\text { system }\end{array}$ & $\begin{array}{l}\text { Some positive data exist, but the } \\
\text { data are not sufficient for } \\
\text { classification } \\
\end{array}$ & Mouse & $\begin{array}{l}\text { NOAEL } 24 \\
\text { mgl }\end{array}$ & 14 weeks \\
\hline Cyclohexane & Inhalation & $\begin{array}{l}\text { peripheral nervous } \\
\text { system. }\end{array}$ & All data are negative & Rat & $\begin{array}{l}\text { NOAEL } 8.6 \\
\text { mel }\end{array}$ & 30 weeks \\
\hline
\end{tabular}

Aspiration Hazard

\begin{tabular}{|l|l|}
\hline Name & Value \\
\hline Cyclohexane & Aspiration hazard \\
\hline
\end{tabular}

Please contact the address or phone number listed on the first page of the SDS for additional toxicological information on this material and/or its components.

\section{SECTION 12: Ecological information}

\section{Ecotoxicological information}

Please contact the address or phone number listed on the first page of the SDS for additional ecotoxicological information on this material and/or its components.

\section{Chemical fate information}

Please contact the address or phone number listed on the first page of the SDS for additional chemical fate information on this material and/or its components.

\section{SECTION 13: Disposal considerations}

Page 10 of 12 
Super 77 Aerosol Spray Low 25\% VOC $\quad 04 / 25 / 17$

\subsection{Disposal methods}

Dispose of contents/ container in accordance with the local/regional/national/intemational regulations.

Incinerate in a permitted waste incineration facility. Facility must be capable of handling aerosol cans. Combustion products will include halogen acid $(\mathrm{HCl} / \mathrm{HF} / \mathrm{HBr})$. Facility must be capable of handling halogenated materials. As a disposal altemative, utilize an acceptable permitted waste disposal facility. Empty drums/barrels/containers used for transporting and handling hazardous chemicals (chemical substances/mixtures/preparations classified as Hazardous as per applicable regulations) shall be considered, stored, treated \& disposed of as hazardous wastes unless otherwise defined by applicable waste regulations. Consult with the respective regulating authorities to determine the available treatment and disposal facilities.

EPA Hazardous Waste Number (RCRA): D001 (Ignitable)

\section{SECTION 14: Transport Information}

For Transport Information, please visit http//3M.com/Transportinfo or call 1-800-364-3577 or 651-737-6501.

\section{SECTION 15: Regulatory information}

15.1. US Federal Regulations

Contact $3 \mathrm{M}$ for more information.

311/312 Hazard Categories:

Fire Hazard - Yes Pressure Hazard - Yes Reactivity Hazard - No Immediate Hazard - Yes Delayed

Hazard - No

EPCRA 311/312 Hazard Classifications (effective January 1, 2018):

Physical Hazards

Flammable (gases, aerosols, liquids, or solids)

Gas under pressure

\begin{tabular}{|l|}
\hline Health Hazards \\
\hline Serious eye damage or eye irritation \\
\hline Specific target organ toxicity (single or repeated exposure) \\
\hline
\end{tabular}

Section 313 Toxic Chemicals subject to the reporting requirements of that section and 40 CFR part 372 (EPCRA):

$\underline{\text { Ingredient }}$

Cyclohexane

\section{C.A.S. No $\quad \%$ by Wt \\ 110-82-7 Trade Secret 5- 15}

\subsection{State Regulations}

Contact $3 \mathrm{M}$ for more information.

15.3. Chemical Inventories

The components of this product are in compliance with the chemical notification requirements of TSCA.

Contact $3 \mathrm{M}$ for more information.

\subsection{International Regulations}


Contact $3 \mathrm{M}$ for more information

This SDS has been prepared to meet the U.S. OSHA Hazard Communication Standard, 29 CFR 1910.1200.

\section{SECTION 16: Other information}

NFPA Hazard Classification

Health: 2 Flammability: 4 Instability: 0 Special Hazards: None Aerosol Storage Code: 3

National Fire Protection Association (NFPA) hazard ratings are designed for use by emergency response personnel to address the hazards that are presented by short-term, acute exposure to a material under conditions of fire, spill, or similar emergencies. Hazard ratings are primarily based on the inherent physical and toxic properties of the material but also include the toxic properties of combustion or decomposition products that are known to be generated in significant quantities.
Document Group:
29-3109-5
Issue Date:
$04 / 25 / 17$
Version Number:
4.00
Supercedes Date:
$03 / 03 / 15$

DISCLAIMER: The information in this Safety Data Sheet (SDS) is believed to be correct as of the date issued 3MMAKES NO WARRANIIES, EXPRESSED OR IMPLIED, INCLUDING, BUT NOT LIMIIED TO, ANY IMPLIED WARRANTY OF MERCHANTABIITY OR FITNESS FOR A PARTICULAR PURPOSE OR COURSE OF PERFORMANCE OR USAGE OF TRADE. User is responsible for determining whether the 3 Mproduct is fit for a particular purpose and suitable for user's method of use or application Given the variety of factors that can affect the use and application of a3Mproduct, some of which are uniquely within the user's knowledge and control,it is essential that the user evaluate the3Mproduct to determine whether it is fit for a particular purpose and suitable for user's method of use or application.

3Mprovides information in electronic form as a service to its customers. Due to the remote possibility that electronic transfer may have resulted in errors, omissions or alterations in this information,3Mmakes no representations as to its completeness or accuracy. In addition, information obtained from a database may not be as current as the information in the SDS available directly from $3 \mathrm{M}$

3M USA SDSs are available at www.3M.com 


\section{Identification of the substance/mixture and of the company/undertaking}

1.1 Product identifier

- Trade name: ACRASTRIP 600 CRR

-1.2 Relevant identified uses of the substance or mixture and uses advised against

No further relevant information available.

-Application of the substance / the preparation: Cleaning agent/ Cleaner

1.3 Details of the supplier of the Safety Data Sheet

- Manufacturer/Supplier:

U.S. Polychemical Corp

584 Chestnut Ridge Road

Chestnut Ridge, NY 10977

Phone: 845-356-5530

Toll Free: $800-431-2072$

1.4 Emergency telephone number:

CHEMTREC

1-800-424-9300 (US/Canada)

+01 703-527-3887 (International)

\section{Hazards identification}

2.1 Classification of the substance or mixture

Classification according to Regulation (EC) No 1272/2008

The product is not classified according to GHS regulations.

The product is not classified according to the CLP regulation.

- Classification according to Directive 67/548/EEC or Directive 1999/45/EC Not applicable.

Information concerning particular hazards for human and environment:

The product does not have to be labelled due to the calculation procedure of the "General Classification guideline for preparations of the EU" in the latest valid version.

- Classification system:

The classification is according to the latest editions of the EU-lists, and extended by company and literature data.

The classification is in accordance with the latest editions of international substances lists, and is supplemented by information from technical literature and by information provided by the company.

-2.2 Label elements

- Labelling according to Regulation (EC) No 1272/2008 N/A

- Hazard pictograms N/A

- Signal word NA

- Hazard-determining components of labelling: None.

- Hazard statements: NA

- Hazard description:

WHMIS-symbols: Not hazardous under WHMIS. 
Safety Data Sheet

Trade Name: ACRASTRIP 600 CRR

NFPA ratings (scale $0-4$ )

(Contd. of page 1)

Health $=1$

Fire $=0$

Reactivity $=0$

HMIS-ratings (scale 0 - 4)

HEALTH 0 Health $=1$

FIRE $\square$ Fire $=0$

REACTMIYU Reactivity $=0$

-HMIS Long Term Health Hazard Substances

None of the ingredients is listed.

2.3 Other hazards

Results of PBT and vPvB assessment

PBT: Not applicable.

vPvB: Not applicable.

\section{Composition/information on ingredients}

\section{- 3.2 Mixtures}

Description: Mixture of substances listed below with nonhazardous additions.

Dangerous components: N/A

Additional information: For the wording of the listed risk phrases refer to section 16 .

\section{First aid measures}

4.1 Description of first aid measures

General information: No special measures required.

After inhalation: Supply fresh air; consult doctor in case of complaints.

After skin contact:

Immediately remove any clothing soiled by the product.

Rinse with warm water.

After eye contact:

Remove contact lenses if wom.

Rinse opened eye for several minutes under running water. Then consult a doctor.

After swallowing:

Rinse out mouth and then drink plenty of water.

Do not induce vomiting; call for medical help immediately.

4.2 Most important symptoms and effects, both acute and delayed

No further relevant information available.

Hazards No further relevant information available. 
Safety Data Sheet

Trade Name: ACRASTRIP 600 CRR

4.3 Indication of any immediate medical attention and special treatment needed No further relevant information available.

\section{Firefighting measures}

5.1 Extinguishing media

Suitable extinguishing agents:

$\mathrm{CO} 2$, powder or water spray. Fight larger fires with water spray or alcohol resistant foam.

For safety reasons unsuitable extinguishing agents: None.

-5.2 Special hazards arising from the substance or mixture: No further relevant information available.

5.3 Advice for firefighters

Protective equipment: No special measures required.

Additional information: Cool endangered receptacles with water spray.

\section{Accidental release measures}

6.1 Personal precautions, protective equipment and emergency procedures Not required.

6.2 Environmental precautions:

Dilute with plenty of water.

Do not allow to enter sewers/ surface or ground water.

6.3 Methods and material for containment and cleaning up:

Absorb with liquid-binding material (sand, diatomite, acid binders, universal binders, sawdust).

6.4 Reference to other sections

No dangerous substances are released.

See Section 7 for information on safe handling.

See Section 8 for information on personal protection equipment.

See Section 13 for disposal information.

\section{Handling and storage}

7.1 Precautions for safe handling No special measures required.

- Information about fire - and explosion protection: No special measures required.

- 7.2 Conditions for safe storage, including any incompatibilities

Storage:

- Requirements to be met by storerooms and receptacles: No special requirements.

Information about storage in one common storage facility: Store away from foodstuffs.

- Further information about storage conditions: Store in cool, dry conditions in well-sealed receptacles.

7.3 Specific end use(s) No further relevant information available.

\section{Exposure controls/personal protection}

Additional information about design of technical facilities: No further data; see item 7. 


\section{Safety Data Sheet \\ according to 1907/2006/EC (REACH), $1272 / 2008 / \mathrm{EC}$ (CLP), and GHS}

Trade Name: ACRASTRIP 600 CRR

(Contd. of page 3)

\subsection{Control parameters}

Ingredients with limit values that require monitoring at the workplace:

The product does not contain any relevant quantities of materials with critical values that have to be monitored at the workplace.

DNELs No further relevant information available.

PNECs No further relevant information available.

Additional information: The lists valid during the making were used as basis.

8.2 Exposure controls

Personal protective equipment:

General protective and hygienic measures:

The usual precautionary measures are to be adhered to when handling chemicals.

Wash hands before breaks and at the end of work.

Keep away from foodstuffs, beverages and feed.

Avoid contact with the eyes.

Avoid close or long term contact with the skin.

Respiratory protection:

Not necessary if room is well-ventilated.

Use suitable respiratory protective device when aerosol or mist is formed.

Protection of hands:

\section{(17) Protective gloves}

The glove material has to be impermeable and resistant to the product/ the substance/ the preparation. Selection of the glove material on consideration of the penetration times, rates of diffusion and the degradation

Material of gloves

Neoprene gloves

The selection of the suitable gloves does not only depend on the material, but also on further marks of quality and varies from manufacturer to manufacturer. As the product is a preparation of several substances, the resistance of the glove material cannot be calculated in advance and has therefore to be checked prior to the application.

Penetration time of glove material

The exact break through time has to be found out by the manufacturer of the protective gloves and has to be observed.

Eye protection: Gauze goggles

Body protection: Protective work clothing

Limitation and supervision of exposure into the environment No special requirements.

Risk management measures No special requirements. 
Safety Data Sheet

Trade Name: ACRASTRIP 600 CRR

(Contd. of page 4

\begin{tabular}{|c|c|}
\hline \multicolumn{2}{|c|}{9 Physical and chemical properties } \\
\hline $\begin{array}{l}\text { 9.1 Information on basic physic } \\
\text { General Information } \\
\text { Appearance: } \\
\text { Form: } \\
\text { Colour: } \\
\text { Odour: } \\
\text { Odour threshold: }\end{array}$ & $\begin{array}{l}\text { chemical properties } \\
\text { Solution } \\
\text { Clear } \\
\text { Mild } \\
\text { Not determined. }\end{array}$ \\
\hline pH-value at $20^{\circ} \mathrm{C}:$ & $6,5-7,5$ \\
\hline $\begin{array}{l}\text { Change in condition } \\
\text { Melting point/Melting range: } \\
\text { Boiling point/Boiling range: }\end{array}$ & $\begin{array}{l}\text { Undetermined. } \\
100^{\circ} \mathrm{C}\left(212^{\circ} \mathrm{F}\right)\end{array}$ \\
\hline Flash point: & Not applicable. \\
\hline Flammability (solid, gaseous): & Not applicable. \\
\hline Ignition temperature: & Not determined. \\
\hline - Decomposition temperature: & Not determined. \\
\hline Self-igniting: & Product is not self-igniting. \\
\hline Danger of explosion: & Product does not present an explosion hazard. \\
\hline $\begin{array}{l}\text { Explosion limits: } \\
\text { Lower: } \\
\text { Upper: } \\
\end{array}$ & $\begin{array}{l}\text { Not determined. } \\
\text { Not determined. }\end{array}$ \\
\hline - Vapour pressure at $20^{\circ} \mathrm{C}$ : & $23 \mathrm{hPa}$ \\
\hline $\begin{array}{l}\text { Density at } 20^{\circ} \mathrm{C}: \\
\text { Relative density } \\
\text { - Vapour density } \\
\text { Evaporation rate }\end{array}$ & $\begin{array}{l}1.03 \mathrm{~g} / \mathrm{cm}^{3} \\
\text { Not determined. } \\
\text { Not determined. } \\
\text { Not determined. }\end{array}$ \\
\hline $\begin{array}{l}\text { Solubility in / Miscibility with } \\
\text { water: }\end{array}$ & Soluble. \\
\hline - Partition coefficient (n-octanol & Not determined. \\
\hline $\begin{array}{l}\text { Viscosity: } \\
\text { Dynamic: } \\
\text { Kinematic: }\end{array}$ & $\begin{array}{l}\text { Not determined. } \\
\text { Not determined. }\end{array}$ \\
\hline $\begin{array}{l}\text { Solvent content: } \\
\text { Organic solvents: } \\
\text { VOC (EC) } \\
9.2 \text { Other information }\end{array}$ & $\begin{array}{l}0.0 \% \\
620 \mathrm{~g} / \mathrm{l} \\
\text { No further relevant information available. }\end{array}$ \\
\hline
\end{tabular}


Trade Name: ACRASTRIP 600 CRR

(Contd. of page 5)

\section{Stability and reactivity}

10.1 Reactivity

10.2 Chemical stability

- Thermal decomposition / conditions to be avoided:

No decomposition if used and stored according to specifications.

- 10.3 Possibility of hazardous reactions Reacts with strong oxidizing agents.

- 10.4 Conditions to avoid No further relevant information available.

- 10.5 Incompatible materials: No further relevant information available.

- 10.6 Hazardous decomposition products: Carbon monoxide and carbon dioxide

11 Toxicological information

-11.1 Information on toxicological effects

Acute toxicity:

- Primary irritant effect:

- on the skin: No inritant effect.

- on the eye: Slight irritant effect on eyes.

- Sensitization: No sensitizing effects known.

- Additional toxicological information:

The product is not subject to classification according to the calculation method of the General EU Classification Guidelines for Preparations as issued in the latest version.

When used and handled according to specifications, the product does not have any harmful effects to our experience and the information provided to us.

\section{Ecological information}

12.1 Toxicity

- Aquatic toxicity: No further relevant information available.

- 12.2 Persistence and degradability: No further relevant information available.

-12.3 Bioaccumulative potential: No further relevant information available.

12.4 Mobility in soil: No further relevant information available.

- Additional ecological information:

- General notes:

Water hazard class 1 (German Regulation) (Self-assessment): slightly hazardous for water

Do not allow undiluted product or large quantities of it to reach ground water, water course or sewage system.

-12.5 Results of PBT and vPvB assessment

- PBT: Not applicable.

- vPvB: Not applicable.

-12.6 Other adverse effects No further relevant information available.

(Contd. on page 7) 
Safety Data Sheet

Trade Name: ACRASTRIP 600 CRR

(Contd. of page 6)

\section{Disposal considerations}

-13.1 Waste treatment methods

- Recommendation: Smaller quantities can be disposed of with household waste.

- Uncleaned packaging:

- Recommendation: Disposal must be made according to official regulations.

- Recommended cleansing agents: Water, if necessary together with cleansing agents.

\section{Transport information}

\begin{tabular}{|c|c|}
\hline $\begin{array}{l}\text { 14.1 UN-Number } \\
\text { DOT, ADR, ADN, IMDG, IATA }\end{array}$ & N/A \\
\hline $\begin{array}{l}\text {-14.2 UN proper shipping name } \\
\text { - DOT, ADR, ADN, IMDG, IATA }\end{array}$ & N/A \\
\hline \multicolumn{2}{|l|}{-14.3 Transport hazard class(es) } \\
\hline $\begin{array}{l}\text { DOT, ADR, ADN, IMDG, IATA } \\
\text { Class }\end{array}$ & N/A \\
\hline $\begin{array}{l}\text { 14.4 Packing group } \\
\text { DOT, ADR, IMDG, IATA }\end{array}$ & N/A \\
\hline $\begin{array}{l}\text { 14.5 Environmental hazards: } \\
\text { Marine pollutant: }\end{array}$ & No \\
\hline 14.6 Special precautions for user & Not applicable. \\
\hline $\begin{array}{l}\text { 14.7 Transport in bulk according to Annex II of } \\
\text { MARPOL } 73 / 78 \text { and the IBC Code }\end{array}$ & Not applicable. \\
\hline UN "Model Regulation": & - \\
\hline
\end{tabular}

\section{Regulatory information}

- 15.1 Safety, health and environmental regulations/legislation specific for the substance or mixture - United States (USA)

SARA

- Section 355 (extremely hazardous substances):

None of the ingredients is listed.

Section 313 (Specific toxic chemical listings):

None of the ingredients is listed.

- TSCA (Toxic Substances Control Act):

All ingredients are listed. 
Safety Data Sheet

Trade Name: ACRASTRIP 600 CRR

Proposition 65 (California):

(Contd. of page 7)

Chemicals known to cause cancer:

None of the ingredients is listed.

Chemicals known to cause reproductive toxicity for females:

None of the ingredients is listed.

Chemicals known to cause reproductive toxicity for males:

None of the ingredients is listed.

Chemicals known to cause developmental toxicity:

None of the ingredients is listed.

- Carcinogenic Categories

- EPA (Environmental Protection Agency)

None of the ingredients is listed.

- IARC (International Agency for Research on Cancer)

None of the ingredients is listed.

TLV (Threshold Limit Value established by ACGIH)

None of the ingredients is listed.

NIOSH-Ca (National Institute for Occupational Safety and Health)

None of the ingredients is listed.

- OSHA-Ca (Occupational Safety \& Health Administration)

None of the ingredients is listed.

Canada

- Canadian Domestic Substances List (DSL)

All ingredients are listed.

Canadian Ingredient Disclosure list (limit $0.1 \%$ )

None of the ingredients is listed.

Canadian Ingredient Disclosure list (limit 1\%)

None of the ingredients is listed.

15.2 Chemical safety assessment: A Chemical Safety Assessment has not been carried out.

\section{Other information}

This information is based on our present knowledge. However, this shall not constitute a guarantee for any specific product features and shall not establish a legally valid contractual relationship.

Abbreviations and Acronyms:

ADR: Accord europeen sur le transport des marchandises dangereuses par Route (European Agreement concerning the International Carriage of Dangerous Goods by Road)

IMDG: Intemational Martime Code for Dangerous Goods

DOT: US Department of Transportation

IATA: Intemational Alr Transport Assoclation

GHS: Globally Harmonlzed System of Classincation and Labelling of Chemlcals

ACGIH: American Conference of Governmental Industrial Hyglenists

NFPA: National FIre Protection Assoclation (USA)

HMIS: Hazardous Materlals Identifcation System (USA)

(Contd. on page 9) 
Safety Data Sheet

according to 1907/2006/EC (REACH),

1272/2008/EC (CLP), and GHS

Printing date: 11.04 .2013

Revision: 11.04.2013

Trade Name: ACRASTRIP 600 CRR

WHMIS: Workolace Hazardous Materlals Information System (Canada)

Contd. of page 8)

DNEL: Dertved No-Effect Level (REACH)

PNEC: Predicted No-Efrect Concentration (REACH) 
SAFETY DATA SHEET

Issue Date 15 May 2015

Revision date: 1 June 2016

Version 1.1

\section{IDENTIFICATION OF THE SUBSTANCE/PREPARATION AND OF THE COMPANY/UNDERTAKTNG}

Product identifier

Product Name:

Other means of identification

Product code:

Synouyms

Bio-Penetrating Lubricant (BPL) (Food Grade) 11 oz Aerosol

87002

None

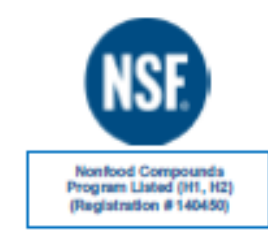

Recommended use of the chemical and restrictions on use

Food Grade Hl, Biobased Penetrating Lubricant, (Biodegradable), Coupliant with EPA. VGP, EAL

NSF Registered H1, H2 and is acceptable as a lubricant with incidental food contact (H1) for use in and around food processing areas.

Details of the supplier of the safety data sheet

Supplier and Manufacture

Renewable Lubricants, Inc.

476 Griggy RD NE, P.O. Box 474

Hartville, Oh 44632

Phone: (330) 877-9982

Fax: (330) $877-2266$

prow renewablelube com mww renewablelubricants.com

Emergency telephone number

Emergency Telephone

(CHEMTREC) 1-800-424-9300. Outside the U.S. (703) 527-3887

SECTION 2 Hazards Identification

Classification

OSHA Regulatory Status

This meets 2012 OSHA Hazard Communication Standard (29 CFR 1910.1200)

\begin{tabular}{|l|l}
\hline Gases under pressure & Compressed Gas \\
\hline
\end{tabular}

Label elements

Sigual word

WARNING:

Hazard statements

Contains gas under pressure; may explode if heated

\section{EMERGENCY OVERVIEW}

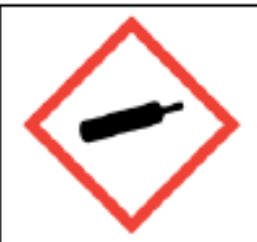

Appearance: Transparent white as sprayed Physical state Aerosol Odor No Odor

WARNING: Contains gas under pressure; may explode if heated

Storage and handling: Protect from sunlight. Store in a well-ventilated area.

Dispose of contents/container in accordance with local/regional regulations.

Hazards not otherwise classified (HNOC)

Other information

Material Name: Bio-Penetrating Lubricant (BPL) (Food Grade) $11 \propto z$. Aerosol Page 3 of 7

Issue Date: 15 May 2015 
SECTION 3 -COMPOSITION/INFORMATION on INGREDIENTS

This material is considered hazardous by the OSHA Hazard Communication Standard (29 CFR 1910.1200).

\begin{tabular}{|l|l|l|l|}
\hline Components & CAS-No & Weight \% & Trade Secret \\
\hline Carbon Dioxide & $124-38-9$ & $1-10 \%$ & \\
\hline Oil Mist & $5 \mathrm{mg} / \mathrm{m} \mathrm{3}$ & $5 \mathrm{mg} / \mathrm{m} \mathrm{3}$ & \\
\hline
\end{tabular}

SECTION 4 -FIRST AID MEASURES

Eye contact: $\quad$ Flush eye with water for 15 minutes. If symptoms persist, call a physician.

Slin contact: $\quad$ Wash off immediately with soap and plenty of water. Remove and wash contaminated clothing before re-use. If gkin irritation persists, call a physician.

Inhalation: $\quad$ Move to fresh air. If breathing is difficult, give oxygen If not breathing, give artificial respiration. If symptoms persist, call a physician.

Ingestion: $\quad$ Do not induce vomiting. Risk of product entering the lungs on vomiting after ingestion. If conscious, drink plenty of water. Obtain medical attention.

Most important symptoms and effects, both acute and delayed

Symptoms No information available.

$\underline{\text { Indication of any immediate medical attention and special treatment needed }}$

Notes to physician: Treat symptomatically.

\section{SECTION 5 - FIRE-FIGHTING MEASURES}

Suitable extinguishing media:

Use dry chemical, $\mathrm{CO} 2$, water spray or "alcohol" foam.

Unsuitable extinguishing media Do not use a solid water stream as it may scatter and spread fire

Specific hazards arising from the chemical

In the event of fire, cool tanks with water spray.

Erplosion data

Sensitivity to Mechanical Impact None.

Sensitivity to Static Discharge None.

Special protective equipment for firefighters:

In the event of fire, wear self-contained breathing apparatus.

\section{SECTION 6 -ACCIDENTAL RELEASE MEASURES}

Personal precautions, protective equipment and emergency procedures

Personal precautions: Use personal protective equipment.

Environmental precautions

Environmental precautions: $\quad$ Prevent product from entering drains. Do not contaminate surface water.

Methods and material for containment and cleaning up

Methods for containment:

Prevent further leakage or spillage if safe to do so.

Methods for cleaning up: Absorb spill with inert material (e.g. dry sand or earth), then place in a chemical waste

\section{SECTION 7 -HANDLING AND STORAGE}

Precautions for safe handling

Handling

Keep away from heat, sparks, open flames, hot surfaces etc. No smoking. Do not spray on an

open flame or other ignition source. Pressurized container: do not pierce or bum

Material Name: Bio-Penetrating Labricant (BPL) (Food Grade) $11 \propto z$. Aerosol Page 3 of 7

Issue Date: 15 May 2015 
Conditions for safe storage, including any incompatibilities

Control parameters

Exposure Guidelines

\begin{tabular}{|l|l|l|l|}
\hline Components & ACGIH TLV & OSHA (TWA mg/m 3): & IDLH \\
\hline Oil Mist & $5 \mathrm{mg} / \mathrm{m} \mathrm{3}$ & $5 \mathrm{mg} / \mathrm{m} 3$ & \\
\hline Carbon Dioxide & 9,000 (TWA) $\mathrm{mg} / \mathrm{m}^{3} 10 \mathrm{~h}$ & $9,000 \mathrm{mg} / \mathrm{m}^{3} \mathrm{hh}$ & \\
\hline
\end{tabular}

Appropriate engineering controls

Engineering measures to

reduce exposure: $\quad$ Use only in area provided with appropriate exhaust ventilation.

Individual protection measures, such as personal protective equipment

Respiratory protection:

Hand protection:

Eye protection:

Slin and body protection:

General Hygiene Consideration
No personal respiratory protective equipment normally required. In case of insufficient ventilation wear suitable respiratory equipment.

Nitrile rubber Neoprene gloves

Safety glasses

Impervious clothing

Avoid contact with skin, eyes and clothing

\begin{tabular}{|c|c|}
\hline \multicolumn{2}{|c|}{ SECTION 9--PHYSICAL AND CHEMICAL PROPERTIES } \\
\hline \multicolumn{2}{|c|}{ Trpical information on basic physical and chemical properties } \\
\hline Physical state & Aerosol \\
\hline Appearance & Oil stream to mist as sprayed \\
\hline Color & Transparent white \\
\hline Odor threshold & No odor \\
\hline Specific Gravity ( $\mathrm{H}: \mathrm{O}=1)$ : & $.88 @ 15.6^{\circ} \mathrm{C}$ \\
\hline Kinematic viscosity: & $13 \mathrm{cSt} @ 40^{\circ} \mathrm{C}$ \\
\hline Pour Point: & $-30^{\circ} \mathrm{C}\left(-22^{\circ} \mathrm{F}\right)$ \\
\hline Explosive properties: & Material does not have explosive properties. \\
\hline Oridizing properties: & See Section 2, No significant bazards. \\
\hline Volatile Organic Compound (VOC): & Components contain No VOC according to CARB \\
\hline Melting: point/freezing point: & Not Determined \\
\hline Percent Volatile: & Not Determined \\
\hline Boiling Point: & Not Determined \\
\hline Vapor Density $($ Air $=1)$ : & $<1$ \\
\hline Vapor pressure: & Not Determined \\
\hline Solubility in Water: & Insoluble \\
\hline Upper flammability limit: & Not Determined \\
\hline Lower flammability limit: & Not Determined \\
\hline Partition coefficient: & Not Determined \\
\hline Autoignition temperature: & Not Determined \\
\hline Decomposition temperature: & Not Determined \\
\hline \multicolumn{2}{|l|}{ Other information } \\
\hline Softening point & No information available \\
\hline \multicolumn{2}{|l|}{ Chemical stability } \\
\hline Stability & ader normal conditions \\
\hline
\end{tabular}




\section{Possibility of Hazardous Reactions}

Possibility of Hazardous Reactions None under normal processing.

Hazardous polymerization Hazardous polymerization does not occur.

Conditions to avoid

Conditions to avoid

Do not store at temperatures above $120^{\circ} \mathrm{F}$

Hazardous Decomposition Products

Hazardous Decomposition

Products

None under normal processing

Incompatible materials

Incompatible materials

Oxidizing agents

\section{SECTION 11 - TOXICOLOGICAL INFORMATION}

Information on likely routes of exposure

Product Information $\quad$ Product does not present an acute toxicity hazard based on known or supplied information

Eye contact

Slin contact

Inhalation

Contact with eyes may cause irritation.

Substance does not generally irritate and is only mildly irritating to the skin.

Avoid breathing vapors or mists.

Ingestion Ingestion may cause gastrointestinal irritation, nausea, vomiting and diarrboea.

Potential for aspiration if swallowed.

Aspiration may cause pulmonary edema and pneumonitis.

\begin{tabular}{|l|l|l|l|}
\hline Components & Oral LD50- & Dermal LD50 & Inhalation LC50 \\
\hline
\end{tabular}

Information on toricological effects

Delaved and immediate effects as well as chronic effects from short and long-term exposure

Sensitization

Mutagenic effects:

Carcinogenicity

Reproductive toricity

STOT - Single Exposure

STOT - Repeated Exposure

Aspiration hazard
No sensitization responses were observed.

Did not show mutagenic or teratogenic effects in animal experiments.

This product does not contain any carcinogens or potential carcinogens as listed by OSHA,

IARC or NTP.

This product does not contain any known or suspected reproductive hazards.

None under normal use conditions.

None under normal use conditions.

May be fatal if swallowed and enters airways.

Numerical measures of toxicity - Product Information

The following values are calculated based on chapter 3.1 of the GHS document

$\begin{array}{ll}\text { ATEmix (oral) } & 16516 \mathrm{mg} / \mathrm{kg} \\ \text { ATEmix (dermal) } & 6607 \mathrm{mg} / \mathrm{kg}\end{array}$

\section{SECTION 12 -ECOLOGICAI INFORMATION}

Ecotoricity: No known hazards to the aquatic environment

Biodegradation: Based on previous biodegradability studies, the products provide Ultimate Biodegradation Pw1 >60\% within 28 days in ASTM D-5864 Aerobic Aquatic Biodegradation of Lubricants.

Aquatic/Ecotoricity: Based on previous studies, (OECD 201, 202, and 203) LC50/EC50 >3,000 ppm (3000 mg L).

Bioaccumulation: No Potential to Bioconcentrate

Soil Mobility: Not Established

Persistence and degradability: Readily biodegradable $>60 \% \%$ after 28 days

Water Mobility: The product is insoluble and floats on water. WGK: 1

Material Name: Bio-Penetrating Lubricant (BPL) (Food Grade) 11 oz. Aerosol Page 3 of 7

Issue Date: 15 May 2015 


\section{Waste treatment methods}

Disposal of wastes Disposal should be in accordance with applicable regional, national and local laws and regulations.

Contaminated packaging Do not reuse container.

\section{SECTION 14 -TRANSPORTATION INFORMATION}

Aerosols (limited quantity),

Class 2.2, ERG 126, UN 1950

Air (LATA)

Aerosols (limited quantity),

Class 2.2, ERG 126, UN 1950

Vessel

Aerosol (limited quantity), Class 2.2, UN

1950

SECTION 15-REGULATORY INFORMATION

International Inventories

TSCA: Listed in TSCA

TSCA - $\quad$ United States Toric Substances Control Act Section 8(b) Inventory

Global Chemical Inventories:

USA All components of this material are on the US TSCA Inventory or are exempt.

EU All components are in compliance with the EC Seventh amendment Directive $92 / 32 / E E C$

Japan All components are in compliance with the Chemical Substances Control Law of Japan.

Australia All components are in compliance with chemical notification requirements in Australia.

Canada All components are in compliance with the Canadian Euvironmental Protection Act and are Canadian

DSL NDSL

Switzerland

China

All components are in compliance with the Euvironmentally Hazardous Substances Ordinance in Switzerland.

Korea All components of this product are listed on the Inventory of Existing Chemical Substances in China

All components are in compliance in Rorea.

Philippines All components are in compliance with the Philippines Toxic Substances and Hazardous and Nuclear Wastes Control Act of 1990 (R.A. 6969).

TSCA: All ingredients in this product are listed or exempt from listing on the TSCA Chemical inventory.

CEPA: $\quad$ All ingredients in this product are listed or exempt from listing on the Canadian DSLNDSL.

Proposition 65: This product contains no chemicals know to the state of California to cause cancer, birth defects of other reproductive harm.

\section{Federal Regulations}

SARA 313

Section 313 of Title III of the Superfund Amendments and Reauthorization Act of 1986 (SARA). This product does not contain any chemicals which are subject to the reporting requirements of the Act and Title 40 of the Code of Federal Regulations, Part 372

\section{SARA 311/312 Hazard Categories}

Acute Health Hasa

Chronic Health Hazard

Fire Hazard

Sudden release of pressure hazard

Reactive Hazard

Yes
No
No
Yes
No

CWA (Clean Water Act)

This product does not contain any substances regulated as pollutants pursuant to the Clean Water Act (40 CFR 122.21 and 40 CFR 122.42)

\section{CERCLA}

This material, as supplied, does not contain any substances regulated as hazardous substances under the Comprehensive Environmental Response Compensation and Liability Act (CERCLA) (40 CFR 302) or the Superfund Amendments and 
Reauthorization Act (SARA) (40 CFR 355). There may be specific reporting requirements at the local, regional, or state level pertaining to releases of this material

State Regulations (RTK):

California Proposition 65:

This product does not contain any Proposition 65 chemicals

U.S. State Right-to-Know Regulations:

\begin{tabular}{l|l|l|l} 
Components & NJRTK: & MARTK: & PARTK: \\
\hline
\end{tabular}

U.S. EPA Label Information

EPA Pesticide Registration Number Not applicable

\section{SECTION 16-OTHER INFORMATION}

Read and follow all label directions and precautions before using the product.

Nfpa:

Health: 1

Flammability: 1

Instability 0

NFPA/HMIS * for Carc, Muta, Tera, Specific Organ *

\section{HMIS health rating:}

Health: 1

Flammability: 1

Physical hazards 0

Personal protection B

Revision:

\begin{tabular}{l|l}
\hline Date & Revised Section \\
\hline 27 January 2015 & new \\
\hline 1 Jume 2016 & Section 9, Flash Point (PMCC) \\
\hline & \\
\hline
\end{tabular}

The information presented herein has been compiled from sources considered to be dependable and is accurate to the best of Renewable Lubricants, Inc. knowledge; however, Renewable Lubricants, Inc. makes no warranty whatsoever, expressed or implied, of MERCHANTABILITY OF FITNESS FOR THE PARTICULAR PURPOSE, regarding the accuracy of such data or the results to be obtained from the use thereof. Renewable Lubricants Inc. assumes no responsibility for injury to recipient or to third persons or for any damage to any property and recipient assumes all such risks.

Material Name: Bio-Penetrating Lubricant (BPL) (Food Grade) $11 \mathrm{oz}$. Aerosol Page 3 of 7 Issue Date: 15 May 2015 


\section{Safety Data Sheet}

Issue date 20 -Oct-2014

Version 1

\section{Identification of the Substance/Preparation and of the Company/Undertaking}

Product Identifier

Product name

Chemical name

CHAMPION SPRAYON GREEN WORLD N GLASS CLEANER

$7-8067$

Other means of identification

Product code

FG 438-5906-1

Synonyms

Glass Cleaner

Recommended use of the chemical and restrictions on use

Recommended Use

Uses advised against

Cleans and shines windows, mirrors, doors, windshields, TV screens, computer monitors,

and other glass, plastic and plexiglass surfaces.

DO NOT USE ON FLOORS

Details of the supplier of the safety data sheet

Supplier Address

Chase Products $\mathrm{Co}$

2727 Gardner Road

Broadview, IL 60155

708-273-1121

Manufacturer Address

Chase Products Co.

2727 Gardner Road

Broadview, IL 60155

708-273-1121

Emergency Telephone Number

Company Phone Number

24 Hour Emergency Phone Number 1-800-250

Emergency telephone ChemTel 1-800-255-3924

2. Hazards Identification

Classification

Gases Under Pressure Compressed Gas

Label Elements

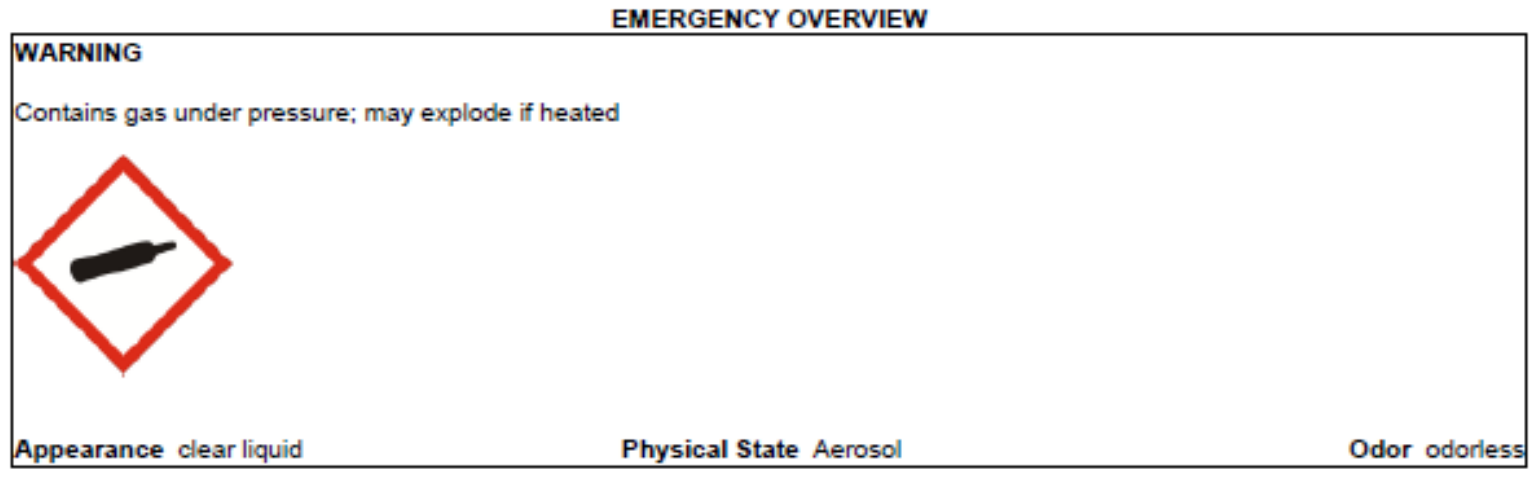

Precautionary Statements - Storage

Protect from sunlight. Store in a well-ventilated place

Page 1/7 
Hazards not otherwise classified (HNOC)

Other Information

\section{Composition/information on Ingredients}

Synonyms

Chemical Family

Formula

Chemical nature
Glass Cleaner.

MIXTURES.

$7-8067$

Aqueous solution of surfactants and cleaners.

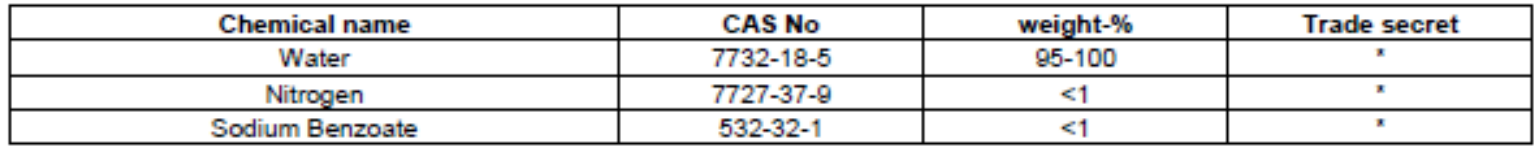

* The exact percentage (concentration) of composition has been withheld as a trade secret.

\section{First aid measures}

\section{FIRST AID MEASURES}

Eye Contact

Flush from eyes with plenty of water promptly.

Skin contact

Wash with soap and water.

inhalation

If overcome by vapor, move person to fresh air.

INGESTION

Ingestion from an aerosol product is unlikely to occur.

\section{Most important symptoms and effects, both acute and delayed}

Symptoms

Acute, Deliberate inhalation of concentrated vapor or mist may cause headaches.

Prolonged and repeated contact with the eyes may cause mild irritation.

Indication of any immediate medical attention and special treatment needed

Note to physicians

None needed.

\section{Fire-fighting measures}

Suitable extinguishing media

Dry chemical, $\mathrm{CO} 2$ or water spray.

Unsuitable extinguishing media Use water spray or fog: do not use straight streams.

Specific hazards arising from the chemical

Containers are under pressure. Temperatures above $120 \mathrm{~F}$ may cause cans to burst.

Hazardous combustion products Thermal decomposition may yield gases like nitrogen oxides, carbon monoxide and carbon dioxide.

Explosion data

Sensitivity to Mechanical Impact Contents under pressure, keep away from heat and open flame.

Sensitivity to Static Discharge Keep away from heat, sparks, flame, and other sources of ignition (i.e., pilot lights, electric motors and static electricity).

Protective equipment and precautions for firefighters

Use personal protective equipment as required.

Page $2 / 7$ 
FG 438-5906-1 CHAMPION SPRAYON GREEN WORLD N GLASS CLEANER

\section{Accidental release measures}

Personal precautions, protective equipment and emergency procedures

Personal precautions

Other Information

Environmental Precautions

Environmental Precautions

Methods and material for containment and cleaning up

Methods for Containment

Methods for cleaning up

Provide adequate ventilation to area being treated. Soak up spills with chemically inert, absorbent material.

Clean contaminated surface thoroughly.

\section{Handling and Storage}

Precautions for safe handling

Advice on safe handling

Avoid getting spray into eyes. Keep out of reach of children.

Conditions for safe storage, including any incompatibilities

Storage Conditions

Store in a cool, dry place away from heat and open flame. Avoid storing at below-freezing temperatures. AEROSOL STORAGE LEVEL I (NFPA-30B) .

Incompatible Materials

Temperatures above $120 \mathrm{~F}$.

8. Exposure Controls/Personal Protection

Control parameters

Exposure guidelines

Not applicable.

Appropriate engineering controls

Engineering controls

Use with adequate general or local exhaust ventilation.

Individual protection measures, such as personal protective equipment

Eye/face Protection

Conventional eyeglasses to guard against splashing.

Skin and Body Protection

Household type gloves, if desired.

Respiratory protection

None required if used in a well-ventilated area .

General hygiene considerations

Wash hands with water as a precaution.

\section{Physical and Chemical Properties}

Information on basic physical and chemical properties

Physical State

Appearance

Aerosol

clear liquid

Color

clear odorless

No information available

Page $3 / 7$ 


\begin{tabular}{|c|c|c|}
\hline $\begin{array}{l}\text { Property } \\
\mathrm{pH}\end{array}$ & $\frac{\text { Values }}{10.42+l-0.6}$ & $\begin{array}{l}\text { Remarks - Method } \\
\text { No information available }\end{array}$ \\
\hline Melting point/freezing point & NA & No information available \\
\hline Boiling point/boiling range & $212{ }^{\circ} \mathrm{F} / 100^{\circ} \mathrm{C}$ & No information available \\
\hline Flash Point & $\begin{array}{l}\text { Not Available. This is an aerosol } \\
\text { product for which Flame Projection is } 0 \\
\text { inches. Temperatures above } 120 \mathrm{~F} \\
\text { may cause cans to burst. }\end{array}$ & No information available \\
\hline $\begin{array}{l}\text { Evaporation Rate } \\
\text { Flammability (solid, gas) } \\
\text { Flammability Limits in Air }\end{array}$ & Faster than butyl acetate & $\begin{array}{l}\text { No information available } \\
\text { No information available } \\
\text { No information available }\end{array}$ \\
\hline Upper flammability limits & Not available & \\
\hline $\begin{array}{l}\text { Lower Flammability Limit } \\
\text { Vapor pressure } \\
\text { Vapor Density }\end{array}$ & $\begin{array}{l}\text { Not available } \\
\text { Not available }\end{array}$ & $\begin{array}{l}\text { No information available } \\
\text { No information available }\end{array}$ \\
\hline Specific gravity & $0.998+/-0.055$ concentrate & No information available \\
\hline $\begin{array}{l}\text { Water solubility } \\
\text { Solubility in other solvents }\end{array}$ & completely soluble & $\begin{array}{l}\text { No information available } \\
\text { No information available }\end{array}$ \\
\hline $\begin{array}{l}\text { Partition coefficient } \\
\text { Autoignition Temperature }\end{array}$ & & $\begin{array}{l}\text { No information available } \\
\text { No information available }\end{array}$ \\
\hline Decomposition temperature & & No information available \\
\hline Kinematic viscosity & & No information available \\
\hline $\begin{array}{l}\text { Dynamic viscosity } \\
\text { Explosive properties } \\
\text { Oxidizing properties }\end{array}$ & $\begin{array}{l}\text { No information available } \\
\text { No information available }\end{array}$ & No information available \\
\hline
\end{tabular}

\section{Other Information}

$\begin{array}{ll}\text { Softening point } & \text { No information available } \\ \text { Molecular weight } & \text { No information available } \\ \text { VOC content (\%) } & \text { None } \\ \text { Density } & \text { No information available } \\ \text { Bulk Density } & 8.31-8.77 \mathrm{lb} / g a l\end{array}$

\section{Stability and Reactivity}

Reactivity

Not applicable

no data available

Chemical stability

Stable.

Possibility of hazardous reactions

Temperatures above $120 \mathrm{~F}$ may cause cans to burst with force.

hazardous polymerization Hazardous polymerization does not occur.

Conditions to Avoid

Temperatures above $120 \mathrm{~F}$.

Incompatible Materials

Temperatures above $120 \mathrm{~F}$.

Hazardous decomposition products

Thermal decomposition may yield gases like nitrogen oxides, carbon monoxide and carbon dioxide.

11. Toxicological Information

Information on likely routes of exposure 


\begin{tabular}{|c|c|c|c|}
\hline inhalation & no data available. & & \\
\hline Eye Contact & no data available. & & \\
\hline Skin contact & no data available. & & \\
\hline INGESTION & no data available. & & \\
\hline Chemical name & Oral LD50 & dermal LD50 & Inhalation LC50 \\
\hline $\begin{array}{l}\text { Water } \\
7732-18-5\end{array}$ & $>90 \mathrm{~mL} / \mathrm{kg}$ ( Rat ) & - & - \\
\hline $\begin{array}{l}\text { Sodium Benzoate } \\
532-32-1\end{array}$ & $=2100 \mathrm{mg} / \mathrm{kg}$ (Rat) & - & - \\
\hline
\end{tabular}

Information on toxicological effects

Symptoms No information available.

Delayed and immediate effects as well as chronic effects from short and long-term exposure

sensitization

Germ Cell Mutagenicity

carcinogenicity
No information available.

No information available.

Not known chronic effects based on available data. None of the ingredients present in excess of $0.1 \%$ are listed as carcinogenic by NTP. IARC or OSHA.

No information available. $\begin{array}{ll}\text { STOT - single exposure } & \text { No information available. } \\ \text { STOT - repeated exposure } & \text { No information available. } \\ \text { Aspiration Hazard } & \text { No information available. }\end{array}$

$\begin{array}{ll}\text { STOT - single exposure } & \text { No information available. } \\ \text { STOT - repeated exposure } & \text { No information available. } \\ \text { Aspiration Hazard } & \text { No information available. }\end{array}$

$\begin{array}{ll}\text { STOT - single exposure } & \text { No information available. } \\ \text { STOT - repeated exposure } & \text { No information available. } \\ \text { Aspiration Hazard } & \text { No information available. }\end{array}$

Numerical measures of toxicity - Product Information

Unknown acute toxicity

The following values are calculated based on chapter 3.1 of the GHS document .

ATEmix (inhalation-gas) 10000000

ATEmix (inhalation-vapor) $\quad 16447.4 \mathrm{mg} /$

$\underline{\text { ecotoxicity }}$

$1 \%$ of the mixture consists of components(s) of unknown hazards to the aquatic environment

\begin{tabular}{|c|c|c|c|c|}
\hline Chemical name & Algaelaquatic plants & Fish & $\begin{array}{c}\text { Toxicity to } \\
\text { Microorganisms }\end{array}$ & Crustacea \\
\hline $\begin{array}{c}\text { Sodium Benzoate } \\
532-32-1\end{array}$ & & $\begin{array}{c}420-558: 96 \mathrm{~h} \text { Pimephales } \\
\text { promelas mg/L LC50 } \\
\text { fow-through } 100: 96 \mathrm{~h} \\
\text { Pimephales promelas mg/L } \\
\text { LC50 static }\end{array}$ & $\begin{array}{c}\text { mal Daphnia magna } \\
\text { mg/L E0 }\end{array}$ \\
\hline
\end{tabular}

Persistence and degradability

Made from biodegradable ingredients.

Bioaccumulation

No information available.

\begin{tabular}{|c|c|}
\hline Chemical name & Partition coefficient \\
\hline Sodium Benzoate \\
$532-32-1$ & -2.13 \\
\hline
\end{tabular}

Other adverse effects

No information available

Page $5 / 7$ 
FG 438-5906-1 CHAMPION SPRAYON GREEN WORLD N GLASS CLEANER

\section{Disposal Considerations}

\section{Waste treatment methods}

Disposal of wastes

Contaminated packaging

Do not puncture or incinerate container. If empty: Place in trash or offer for recycling if available. If partly filled: Call your local solid waste agency for disposal instructions.

Pressurized container: Do not pierce or burn, even after use.

\section{Transport Information}

$\begin{array}{cl}\underline{\text { DOT }} & \text { Limited quantity (LQ) } \\ \text { Proper Shipping Name } & \text { Glass Cleaner } \\ \text { Hazard Class } & 2.2\end{array}$

\section{Regulatory information}

International Inventories

TSCA

All ingredients of this product are listed or are excluded from listing under the U.S. Toxic Subtances Control Act (TSCA) Chemical Substance Inventory.

DSL All ingredients are listed or are excluded from listing on the DSL.

Legend:

TSCA - United States Toxic Substances Control Act Section 8(b) Inventory

DSL/NDSL - Canadian Domestic Substances List/Non-Domestic Substances List

$\underline{\text { US Federal Regulations }}$

SARA 313

This product does not contain toxic chemicals (above the de minimis level) subject to the reporting requirements of Section 313 of the Emergency Planning and Community Right-To-Know Act of 1986 and of 40 CFR 372.

\section{SARA 311/312 Hazard Categories}

$\begin{array}{ll}\text { Acute Health Hazard } & \text { yes } \\ \text { Chronic Health Hazard } & \text { No } \\ \text { Fire Hazard } & \text { No } \\ \text { Sudden release of pressure hazard } & \text { No } \\ \text { Reactive Hazard } & \text { No }\end{array}$

CWA (Clean Water Act)

This product does not contain any substances regulated as pollutants pursuant to the Clean Water Act (40 CFR 122.21 and 40 CFR 122.42)

\section{CERCLA}

This material, as supplied, does not contain any substances regulated as hazardous substances under the Comprehensive Environmental Response Compensation and Liability Act (CERCLA) (40 CFR 302) or the Superfund Amendments and Reauthorization Act (SARA) (40 CFR 355). There may be specific reporting requirements at the local, regional, or state level pertaining to releases of this material 
FG 438-5906-1 CHAMPION SPRAYON GREEN WORLD N GLASS CLEANER

\section{US State Regulations}

California Prepesition 65

This product does not contain any Proposition 65 chemicals

\section{U.S. State Right-to-Know Regulations}

\begin{tabular}{|c|c|c|c|}
\hline Chemical name & New Jersey & Massachusetts & Pennsylvania \\
\hline Water & & & $\mathrm{X}$ \\
$7732-18-5$ & $\mathrm{X}$ & $\mathrm{X}$ & $\mathrm{X}$ \\
\hline Nitrogen & & & \\
\hline
\end{tabular}

U.S. EPA Label information

EPA Pesticide registration number Not applicable

\section{Other information}

$\underline{\text { NFPA }}$

Health Hazards 1

Flammability 1

Instability 1

Physical and chemical properties Not

HMIS

Health Hazards 1

Flammability 1

Physical Hazards 1 applicable

Personal Protection A Eyes protection

Prepared by Regulatory Department

Issue date 20-Oct-2014

Revision note

This SDS supersedes a previous SDS dated April 17, 2014.

Disclaimer

The information provided in this Material Safety Data Sheet is correct to the best of our knowledge, information and belief at the date of its publication. The information given is designed only as a guidance for safe handling, use, processing, storage, transportation, disposal and release and is not to be considered a warranty or quality specification. The information relates only to the specific material designated and may not be valid for such material used in combination with any other materials or in any process, unless specified in the text.

End of Safety Data Sheet 


\section{SAFETY DATA SHEET}

The supplier loenthed below generated this SDS using the UL SDS template. UL dld not test, certify, or approve the substance described in this SDS, and all intormation in this SDS was provided by the suppller or was reproduced fom publically avalable regulatory data sources. UL makes no representations or warrantles regarding the completeness or accuracy of the informadion in this SDS and dlsclaims all llability in connection with the use of this information or the substance described in this SDS. The layout, appearance and format of this SDS is Q 2014 UL LLC. All inghts reserved.

\section{IDENTIFICATION OF THE SUBSTANCE/PREPARATION AND OF THE COMPANY/UNDERTAKING}

Product identifier

Product Name

Orangerine Window Cleaner Rtu (9362)

Other means of identification

Synonyms

None

Recommended use of the chemical and restrictions on use

Recommended Use $\quad$ Glass Cleaner - Non-Aerosol

Uses advised against No information available

Details of the supplier of the safety data sheet

Supplier Name

Supplier Address

Emergency telephone number
VENUSLABORATORIES

111 S ROHLWING ROAD

ADDISO

$\mathrm{N}$ IL

60101

US

Phone: 800-592-1900

Chemtrec: $800-424-9300$

\section{HAZARDSIDENTIFICATION}

\section{Classification}

This chemical is not considered hazardous by the 2012 OSHA Hazard Communication Standard (29 CFR 1910.1200)

GHS Label elements, including precautionary statements

Emergency Overview 
The product contains no substances which at their given concentration, are considered to be hazardous to health

Appearance Clear

Precautionary Statements - Prevention

Obtain special instructions before use

Precautionary Statements - Response

None

Precautionary Statements - Storage

None

Precautionary Statements - Disposal

None

Hazards not otherwise classified (HNOC)

Not applicable

Unknown Toxicity

$0.3288 \%$ of the mixture consists of ingredient(s) of unknown toxicity

Other information

May cause slight eye irritation

PROLONGED OR REPEATED CONTACT MAY DRY SKIN AND CAUSE IRRITATION

Interactions with Other Chemicals

No information available.

\section{COMPOSITION/INFORMATION ON INGREDIENTS}

\begin{tabular}{|l|c|c|c|}
\hline Chemical Name & CAS No. & Weight-\% & Trade Secret \\
\hline Ethyl alcohol & $64-17-5$ & $0.1-1$ & \\
\hline
\end{tabular}

"The exact percentage (concentration) of composition has been withheld as a trade secret

\section{FIRST AID MEASURES}

\section{First aid measures}

Eye Contact

Rinse thoroughly with plenty of water, also under the eyelids. If symptoms persist, call a physician.

Skin Contact

Wash skin with soap and water. In the case of skin irritation or allergic reactions see a physician.

Inhalation

Remove to fresh air. If symptoms persist, call a physician.

Ingestion

Do NOT induce vomiting. Drink plenty of water. If symptoms persist, call a physician.

Most important symptoms and effects, both acute and delayed 
Most Important Symptoms and No information available.

Effects

$\underline{\text { Indication of any immediate medical attention and special treatment needed }}$

Notes to Physician Treat symptomatically.

\section{FIRE-FIGHTING MEASURES}

Suitable Extinguishing Media

Use extinguishing measures that are appropriate to local circumstances and the surrounding environment.

Unsuitable Extinguishing Media

CAUTION: Use of water spray when fighting fire may be inefficient.

Specific Hazards Arising from the Chemical

No information available.

Uniform Fire Code

Sensitizer: Liquid

Hazardous Combustion Products

Carbon oxides.

Explosion Data

Sensitivity to Mechanical Impact No.

Sensitivity to Static Discharge No.

Protective equipment and precautions for firefighters

As in any fire, wear self-contained breathing apparatus pressure-demand, MSHA/NIOSH (approved or equivalent) and full

protective gear.

\section{ACCIDENTAL RELEASE MEASURES}

Personal precautions, protective equipment and emergency procedures

Personal Precautions

Avoid contact with eyes.

Environmental Precautions

Environmental Precautions

Refer to protective measures listed in Sections 7 and 8.

Methods and material for containment and cleaning up

Methods for Containment

Methods for cleaning up
Prevent further leakage or spillage if safe to do so.

Dam up. Soak up with inert absorbent material. Pick up and transfer to properly labeled containers. 


\section{HANDLING AND STORAGE}

\section{Precautions for safe handling}

Handling Handle in accordance with good industrial hygiene and safety practice. Avoid contact with eyes.

Conditions for safe storage, including any incompatibilities

Storag Keep container tightly closed.

e

Incompatible Products

None known based on information supplied.

\section{EXPOSURE CONTROLS/PERSONAL PROTECTION}

Control parameters

Exposure Guidelines

\begin{tabular}{|c|c|c|c|}
\hline Chemical Name & ACGIH TLV & OSHA PEL & NIOSH IDLH \\
\hline \begin{tabular}{c|c|c|} 
Ethyl alcohol \\
$64-17-5$
\end{tabular} & STEL: $1000 \mathrm{ppm}$ & TWA: $1000 \mathrm{ppm}$ & $\begin{array}{c}\text { IDLH: } 3300 \mathrm{ppm} \text { 10\% LEL } \\
\text { TWA: } 1000 \mathrm{ppm}\end{array}$ \\
& & $\begin{array}{c}\text { (vacated) TWA: } 1000 \mathrm{mpm} \\
\text { (vacated) TWA: } 1900 \mathrm{mg} / \mathrm{m}^{3}\end{array}$ & TWA: $1900 \mathrm{mg} / \mathrm{m}^{3}$ \\
& & \\
\hline
\end{tabular}

ACGIH TLV: American Conference of Govemmental Industrial Hygienists - Threshold Limit Value OSHA PEL: Occupational Safety and Health Administration - Permissible Exposure Limits NIOSH IDLH Immediately Dangerous to Life or Health

Other Exposure Guidelines

Vacated limits revoked by the Court of Appeals decision in AFL-CIO v. OSHA, 965 F.2d 962 (11th Cir., 1992)

Appropriate engineering controls

Engineering Measures

Showers

Eyewash stations

Ventilation systems

Individual protection measures, such as personal protective equipment

Eye/Face Protection

Skin and Body Protection

Respiratory Protection

Hygiene Measures
If splashes are likely to occur, wear safety glasses with side-shields.

No special protective equipment required.

No protective equipment is needed under normal use conditions. If exposure limits are exceeded or irritation is experienced, ventilation and evacuation may be required.

Handle in accordance with good industrial hygiene and safety practice.

\section{PHYSICAL AND CHEMICAL PROPERTIES}

Physical and Chemical Properties

Physical State

Appearance

Color
Liquid

Clear

No information available
Odor

Odor Threshold No information available 


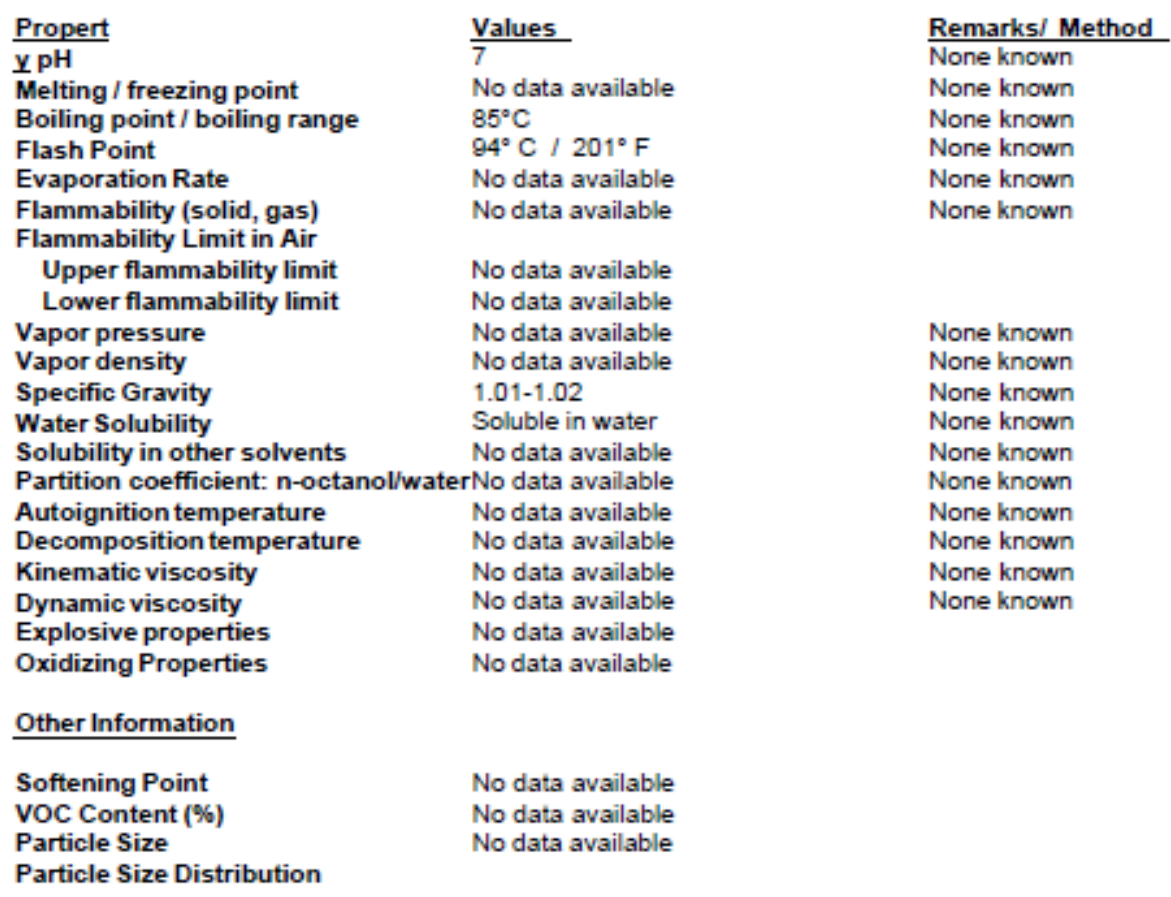

Reactivity

No data available.

Chemical stability

Stable under recommended storage conditions.

Possibility of Hazardous Reactions

None under normal processing.

Hazardous Polymerization

Hazardous polymerization does not occur.

Conditions to avoid

None known based on information supplied.

Incompatible materials

None known based on information supplied.

Hazardous Decomposition Products

Carbon oxides.

11. TOXICOLOGICALINFORMATION

Information on likely routes of exposure

(U) 


\begin{tabular}{|c|c|}
\hline Product Information & Product does not present an acute toxicity hazard based on $\mathrm{kr}$ \\
\hline Inhalation & Specific test data for the substance or mixture is not available. \\
\hline Eye Contact & Specific test data for the substance or mixture is not available. \\
\hline Skin Contact & Specific test data for the substance or mixture is not available. \\
\hline Ingestion & Specific test data for the substance or mixture is not availa \\
\hline
\end{tabular}

Component Information

\begin{tabular}{|l|c|c|c|}
\hline Chemical Name & Oral LD50 & Dermal LD50 & Inhalation LC50 \\
\hline $\begin{array}{l}\text { Ethyl alcohol } \\
64-17-5\end{array}$ & - & - & $=124.7 \mathrm{mg} / \mathrm{L}$ ( Rat ) $4 \mathrm{~h}$ \\
\hline
\end{tabular}

\section{$\underline{\text { Information on toxicological effects }}$}

Symptoms No information available.

Delayed and immediate effects as well as chronic effects from short and long-term exposure

\begin{tabular}{|c|c|c|c|c|}
\hline \multirow{2}{*}{$\begin{array}{l}\text { Sensitization } \\
\text { Mutagenic Effects }\end{array}$} & \multicolumn{4}{|c|}{ No information available. } \\
\hline & \multicolumn{4}{|c|}{ No information available. } \\
\hline Carcinogenicity & \multicolumn{4}{|c|}{$\begin{array}{l}\text { The table below indicates whether each agency has listed any ingredient as a carcinogen. } \\
\text { Ethanol has been shown to be carcinogenic in long-term studies only when consumed as } \\
\text { alcoholic beverage. }\end{array}$} \\
\hline Chemical Name & ACGIH & IARC & NTP & OSHA \\
\hline $\begin{array}{l}\text { Ethyl alcohol 64-17- } \\
5\end{array}$ & $\mathrm{~A} 3$ & Group 1 & Known & $\mathrm{x}$ \\
\hline \multicolumn{5}{|c|}{$\begin{array}{l}\text { ACGIH (American Conference of Governmental Industrial Hygienists) } \\
\text { A3 - Animal Carcinogen } \\
\text { IARC (Intermational Agency for Research on Cancer) } \\
\text { Group } 1 \text { - Carcinogenic to Humans } \\
\text { NTP (National Toxicology Program) } \\
\text { Known - Known Carcinogen } \\
\text { OSHA (Occupational Safety and Health Administration of the US Department of Labor) } \\
\text { X-Present }\end{array}$} \\
\hline Reproductive Toxicity & \multicolumn{4}{|c|}{ No information available. } \\
\hline STOT - single exposure & \multicolumn{4}{|c|}{ No information available. } \\
\hline STOT - repeated exposure & \multicolumn{4}{|c|}{ No information available. } \\
\hline Chronic Toxicity & \multicolumn{4}{|c|}{$\begin{array}{l}\text { Contains a known or suspected carcinogen. Ethanol has been shown to be a reproductive } \\
\text { toxin only when consumed as an alcoholic beverage. Ethanol has been shown to be } \\
\text { carcinogenic in long-term studies only when consumed as alcoholic beverage. }\end{array}$} \\
\hline Target Organ Effects & \multicolumn{4}{|c|}{ None known. } \\
\hline Aspiration Hazard & \multicolumn{4}{|c|}{ No information available. } \\
\hline
\end{tabular}


The following values are calculated based on chapter 3.1 of the GHS document Not applicable

\section{ECOLOGICAL INFORMATION}

Ecotoxicity

The environmental impact of this product has not been fully investigated.

Persistence and Degradability

No information available.

Bioaccumulation

No information available

\begin{tabular}{|c|c|}
\hline Chemical Name & Log Pow \\
\hline Ethyl alcohol 64-17- \\
5
\end{tabular}

Other adverse effects

No information available.

\section{DISPOSAL CONSIDERATIONS}

Waste treatment methods

Disposal methods

Contaminated Packaging

\begin{abstract}
This material, as supplied, is not a hazardous waste according to Federal regulations ( 40 CFR 261). This material could become a hazardous waste if it is mixed with or otherwise comes in contact with a hazardous waste, if chemical additions are made to this material, or if the material is processed or otherwise altered. Consult 40 CFR 261 to determine whether the altered material is a hazardous waste. Consult the appropriate state, regional, or local regulations for additional requirements.
\end{abstract}

Dispose of contents/containers in accordance with local regulations.

This product contains one or more substances that are listed with the State of California as a hazardous waste.

\begin{tabular}{|c|c|}
\hline Chemical Name & California Hazardous Waste \\
\hline Ethyl alcohol 64-17- & Toxic \\
5 & Ignitable \\
\hline
\end{tabular}

\section{TRANSPORTINFORMATION}

DOT

Proper Shipping Name

Hazard Class

$\underline{\text { TDG }}$

MEX

$\underline{\text { ICAO }}$

IATA

Proper Shipping Name
NOT REGULATED

NON REGULATED

N/A

Not regulated

Not regulated

Not regulated

Not regulated

NON REGULATED 


\begin{tabular}{ll}
\hline Hazard Class & N/A \\
$\frac{\text { IMDG/IMO }}{\text { Hazard Class }}$ & Not regulated \\
$\frac{\text { RID }}{\text { ADR }}$ & Not regulated \\
$\underline{\text { ADN }}$ & Not regulated \\
\hline
\end{tabular}

\section{REGULATORYINFORMATION}

International Inventories

TSCA

DSL

Complies

All components are listed either on the DSL or NDSL.

TSCA - United States Toxic Substances Control Act Section 8(b) Inventory

DSLNDSL - Canadian Domestic Substances List/Non-Domestic Substances List

\section{$\underline{\text { US Federal Regulations }}$}

\section{SARA 313}

Section 313 of Title III of the Superfund Amendments and Reauthorization Act of 1986 (SARA). This product does not contain any chemicals which are subject to the reporting requirements of the Act and Title 40 of the Code of Federal Regulations, Part 372

\begin{tabular}{ll} 
SARA 311/312 Hazard Categories & \\
\hline Acute Health Hazard & Yes \\
Chronic Health Hazard & No \\
Fire Hazard & No \\
Sudden release of pressure hazard & No \\
Reactive Hazard & No
\end{tabular}

CWA (Clean Water Act)

This product does not contain any substances regulated as pollutants pursuant to the Clean Water Act (40 CFR 122.21 and 40 CFR 122.42)

\section{CERCLA}

This material, as supplied, does not contain any substances regulated as hazardous substances under the Comprehensive Environmental Response Compensation and Liability Act (CERCLA) (40 CFR 302) or the Superfund Amendments and Reauthorization Act (SARA) (40 CFR 355). There may be specific reporting requirements at the local, regional, or state level pertaining to releases of this material

\section{$\underline{\text { US State Regulations }}$}

\section{California Proposition 65}

This product contains the following Proposition 65 chemicals. Ethyl alcohol is only a considered a Proposition 65 developmental hazard when it is ingested as an alcoholic beverage.

\begin{tabular}{|c|c|}
\hline Chemical Name & California Proposition 65 \\
\hline Ethyl alcohol - 64-17-5 & Carcinogen \\
& Developmental \\
\hline
\end{tabular}

\section{U.S. State Right-to-Know Regulations}

\begin{tabular}{|c|c|c|c|c|c|}
\hline Chemical Name & New Jersey & Massachusetts & Pennsylvania & Rhode Island & Illinois \\
\hline $\begin{array}{c}\text { Ethyl alcohol } \\
64-17-5\end{array}$ & & $X$ & & & \\
\hline
\end{tabular}




\begin{tabular}{|c|c|c|c|c|}
\hline $\begin{array}{c}\text { 2-phenoxyethanol } \\
122-99-6\end{array}$ & & & & $X$ \\
\hline
\end{tabular}

International Regulations

\begin{tabular}{|c|c|c|}
\hline Component & Carcinogen Status & Exposure Limits \\
\hline Ethyl alcohol & & Mexico: TWA 1000 ppm \\
$64-17-5(0.1-1)$ & & Mexico: TWA 1900 mg/m \\
\hline
\end{tabular}

\section{Canada}

WHMIS Hazard Class

D2A - Very toxic materials

D2B - Toxic materials

\section{OTHER INFORMATION}

$\begin{array}{lllll}\text { NFPA } & \text { Health Hazards } 1 & \text { Flammability } 0 & \text { Instability } 0 & \begin{array}{l}\text { Physical and } \\ \text { Chemical Hazards - }\end{array} \\ \text { HMIS } & \text { Health Hazards } 1 & \text { Flammability } 0 & \text { Physical Hazard } 0 & \begin{array}{l}\text { Personal Protection } \\ \text { X }\end{array}\end{array}$

\section{Revision Date}

02-Sep-2014

Revision Note

No information available

\section{Disclaimer}

The information provided in this Safety Data Sheet is correct to the best of our knowledge, information and belief at the date of its publication. The information given is designed only as a guidance for safe handling, use, processing, storage, transportation, disposal and release and is not to be considered a warranty or quality specification. The information relates only to the specific material designated and may not be valid for such material used in combination with any other materials or in any process, unless specified in the text

\section{End of Safety Data Sheet}




\section{MATERIAL SAFETY DATA SHEET}

This document has been prepared to meet the requirements of the U.S. OSHA Hazard Communication Standard 29 CFR 1910.1200, the EU Directive, 91/155/EEC and other regulatory requirements.

\section{Company and Product Identification}

\begin{tabular}{|c|c|c|c|c|}
\hline \multirow{2}{*}{$\begin{array}{l}\text { Product: } \\
\text { Manufacturer: }\end{array}$} & \multirow{2}{*}{\multicolumn{2}{|c|}{$\begin{array}{l}\text { EcoSMART Organic }{ }^{\mathrm{TM}} \text { Insecticide } \\
\text { Wasp \& Hornet Killer (DR-F-039) }\end{array}$}} & \multirow{2}{*}{\multicolumn{2}{|c|}{$\begin{array}{l}\text { Emergency Telephone Number: } \\
\text { Info Trac Chemical Response System } \\
(800) 535-5053 \text { ( } 24 \text { hours) } \\
\text { For General Information: } \\
\text { (888) } 326-\text { SAFE ( } 9 \text { am to } 5 \text { pm EST) }\end{array}$}} \\
\hline & & & & \\
\hline \multicolumn{5}{|c|}{ 2. Ingredients } \\
\hline \multicolumn{2}{|c|}{$\begin{array}{l}\text { Ingredient Name } \\
\text { Active Ingredients: }\end{array}$} & $\%$ by weight & $\underline{\mathrm{CAS}} \#$ & Exposure Limits \\
\hline \multicolumn{2}{|c|}{$\begin{array}{l}\text { Peppermint oil } \\
\text { 2-Phenethyl propionate }\end{array}$} & $\begin{array}{l}1.0 \% \\
0.5 \%\end{array}$ & $\begin{array}{l}8006-90-4 \\
122-70-3\end{array}$ & $\begin{array}{l}\text { None established } \\
\text { None established }\end{array}$ \\
\hline \multicolumn{5}{|l|}{ Inert Inqredients: } \\
\hline \multirow{2}{*}{\multicolumn{2}{|c|}{$\begin{array}{l}\text { Proprietary Solvent Blend } \\
\text { Carbon dioxide (Propellant) }\end{array}$}} & to $100 \%$ & Not Applicable & None established \\
\hline & & $3.5 \%$ & - & TWA: 5000ppm \\
\hline
\end{tabular}

\section{Hazards Identification}

Potential Health Effects:

Flammable:

May be harmful if swallowed or inhaled. May cause eye irritation. Avoid breathing spray mist. Avoid contact with skin, eyes or clothing.

... Contents under pressure. Do not use or store near heat or open flame. Do not puncture or incinerate container. Exposure to temperature above $130^{\circ} \mathrm{F}$ may cause bursting.

\section{First Aid Measures}

CAUTION:

IF IN EYES:

IF ON SKIN:

IF INHALED:

IF INGESTED:
Avoid contact with eyes.

Flush with plenty of water.

Wash with soap and water. If irritation persists, contact physician.

Move exposed person(s) to fresh air.

Rinse mouth out with water. Do not induce vomiting. Seek medical attention if necessary.

\section{Fire Fighting Measures}




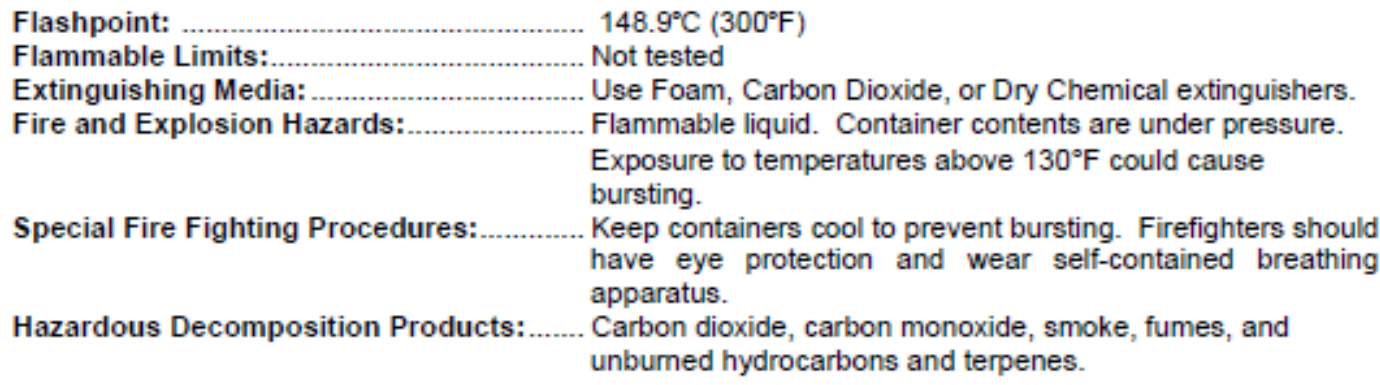

\section{Spill/Leak Procedures}

If spilled, eliminate sources of ignition, absorb liquid with an inert absorbent material and dispose of the empty container and absorbent material in accordance with local ordinances. Components of this product are not considered EPA hazardous wastes.

\section{Handling and Storage}

Store in a cool, dry area away from heat, sparks or open flame. Do not smoke while using product.

Disposal: When container is empty, recycle if available. If recycling is not available, wrap and place the empty container in a trash collector. Keep out of the reach of children and animals.

\section{Exposure Control/Personal Protection} Local exhaust ventilation is not required.

Ventilation: Not required with adequate ventilation.

Eye Protection: Not required. Safety glasses are recommended during volumetric treatments.

Gloves: Not required.

Other Protective equipment: Not required.

\section{Physical Properties}

\begin{tabular}{llll}
\hline $\begin{array}{l}\text { Appearance: } \\
\text { Odor: }\end{array}$ & $\begin{array}{l}\text { Colorless liquid } \\
\text { sweet citrus / minty scent }\end{array}$ & Specific Gravity (water =1): $0.86 \mathrm{~g} / \mathrm{ml}$ \\
\hline
\end{tabular}

\section{Stability and Reactivity}

Chemical Stability: Stable

Hazardous Polymerization: Will not occur

\section{Toxicological Information}




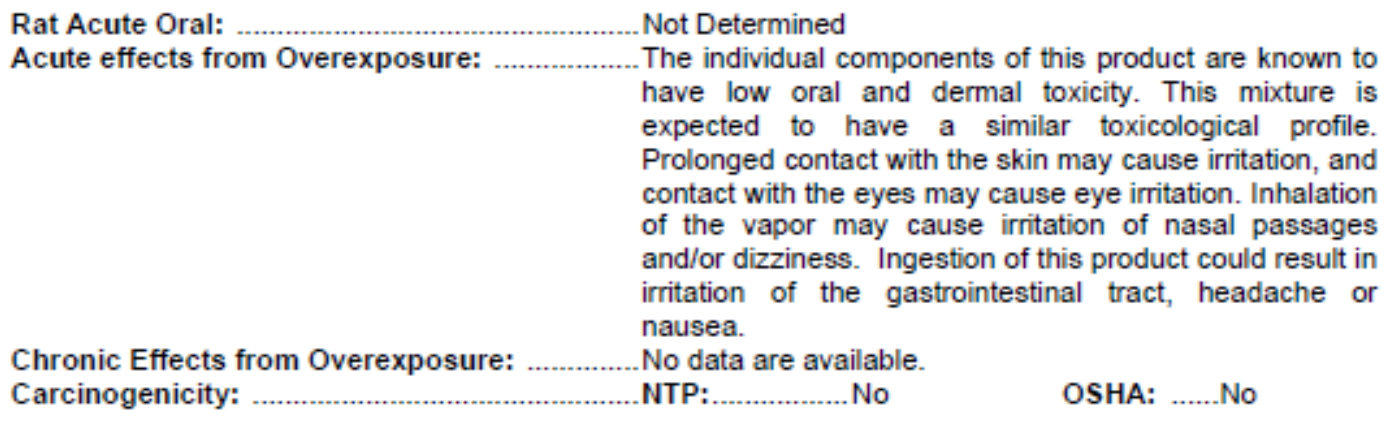

\section{Environmental Information}

While specific data regarding toxicity to fish or other aquatic organisms is not available for this product, care should always be taken to prevent insecticides from entering aquifers.

\section{Disposal}

The aerosol container is not refillable. When container is empty, recycle if available. If recycling is not possible, wrap the container and dispose of with ordinary trash.

\section{Transportation Information}

Proper Shipping Name: Consumer Commodity

DOT Hazard Class: ORM-D

\section{Regulatory Information}

\begin{tabular}{llll}
\hline NFPA Ratings: & Health $-1 \quad$ Fire $-2 \quad$ Reactivity $-0 \quad$ Special - none
\end{tabular}

TSCA: $\quad$ All ingredients in this product are either listed or excluded from the TSCA Inventory.

SARA Title III: $\quad$ This product does not contain any ingredients subject to Section 313 (40 CFR 372 ) reporting requirements.

\section{Other Information}

NFPA 30B Aerosol Classification: Class 3 


\section{Identification}

- Trade name: ELECTRON Aerosol

- Product description

Environmentally Preferred Dielectric Solvent

Product Name Part No. Packaging

ELECTRON (A) 365-1 $12 \times 16$ oz net Aerosol

- Details of the supplier of the safety data sheet

- Manufacturer/Supplier:

Ecolink

2177 Flintstone Dr., Ste. A

Tucker, GA 30084

www.ecolink.com

800-886-8240 or 770-621-8240 (8-5 EST)

- Emergency telephone number: Infotrac: 1-800-535-5053, 1-352-326-2510
National Stock No.

$6850-01-371-8048$

\section{Hazard(s) identification}

- Classification of the substance or mixture

4y) GHSO2 Flame

Flam. Aerosol 2 H223-229 Flammable aerosol. Pressurized container: May burst if heated.

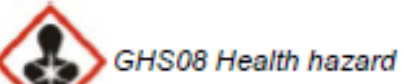

Asp. Tox. 1 . . H304_... May be fatal if swallowed and enters airways.

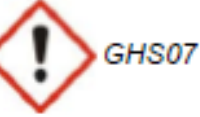

Skin Irnit. 2

H315 Causes skin irritation.

Skin Sens. 1

H317

May cause an allergic skin reaction.

\section{- Label elements}

- GHS label elements

The product is classified and labeled according to the Globally Harmonized System (GHS). 
Reviewed on $5 / 30 / 2015$

Trade name: ELECTRON Aerosol

- Hazard pictograms

(Contd. of page 1)

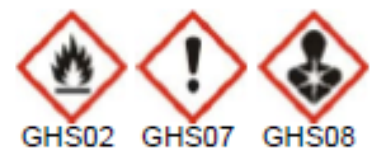

- Signal word Danger

Hazard-determining components of labeling:

Naphtha (petroleum), hydrotreated heavy

Citrus Terpene

- Hazard statements

H223+H229 Flammable aerosol. Pressurized container: May burst if heated.

H315 Causes skin irritation.

H317 May cause an allergic skin reaction.

H304 May be fatal if swallowed and enters airways.

Precautionary statements

Precautionary statements

P210 Keep away from heat/sparks/open flames/hot surfaces. - No smoking.

P251 Pressurized container: Do not pierce or burn, even after use. Do not spray on an open flame or other ignition sources.

P301+P310 IF SWALLOWED: Immediately call a POISON CENTER or doctor/physician.

P405 Store locked up.

$P 410+P 412$ Protect from sunlight. Do not expose to temperatures exceeding $50^{\circ} \mathrm{C} / 122{ }^{\circ} \mathrm{F}$.

P501 Dispose of contents/container in accordance with local/national/international regulations.

Classification system:

NFPA ratings (scale 0 - 4)

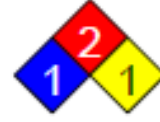

Health $=1$

Fire $=2$

Reactivity $=1$

- HMIS-ratings (scale 0 - 4)

HEALTH $\mathrm{I}$ Health $={ }^{*} 1$

FIRE 2 Fire $=2$

REACTIVITY Reactivity $=1$

- Other hazards

Results of PBT and $v P v B$ assessment

PBT: Not applicable.

- vPvB: Not applicable.

\section{Composition/information on ingredients}

- Chemical characterization: Mixtures

- Description: Mixture of the substances listed below with nonhazardous additions. 
Trade name: ELECTRON Aerosol

- Dangerous components:

(Contd. of page 2)

64742-48-9 Naphtha (petroleum), hydrotreated heavy

$60-90 \%$

Asp. Tox. 1, H304; H227

68647-72-3 Citrus Terpene

Flam. Liq. 3, H226; Asp. Tox. 1, H304; Aquatic Acute 1, H400

Aquatic Chronic 1, H410; Skin Irrit. 2, H315; Skin Sens. 1, H317

124-38-9 Carbon dioxide

Press. Gas, H280

\section{First-aid measures}

\section{- Description of first aid measures}

- After inhalation:

Supply fresh air and to be sure call for a doctor.

In case of unconsciousness, place patient securely in side position for transportation.

After skin contact: Immediately wash with water and soap and rinse thoroughly.

After eye contact: Rinse opened eye for several minutes under running water.

After swallowing: Give large amounts of water. If symptoms persist consult doctor.

Information for doctor:

Most important symptoms and effects, both acute and delayed

No further relevant information available.

Indication of any immediate medical attention and special treatment needed

No further relevant information available.

\section{Fire-fighting measures}

Extinguishing media

Suitable extinguishing agents: $\mathrm{CO} 2$, sand, extinguishing powder. Do not use water.

For safety reasons unsuitable extinguishing agents: Water with full jet

Special hazards arising from the substance or mixture No further relevant information available.

Advice for firefighters

Protective equipment: No special measures required.

\section{Accidental release measures}

Personal precautions, protective equipment and emergency procedures

Wear protective equipment. Keep unprotected persons away.

Environmental precautions:

Inform respective authorities in case of seepage into water course or sewage system.

Do not allow to enter sewers, surface or ground water.

Methods and material for containment and cleaning up:

Dispose contaminated material as waste according to section 13.

Ensure adequate ventilation.

Do not flush with water or aqueous cleansing agents

Reference to other sections

See Section 7 for information on safe handling. 
See Section 8 for information on personal protection equipment.

See Section 13 for disposal information.

\section{Handling and storage}

\section{Handling:}

Precautions for safe handling

Ensure good ventilation/exhaustion at the workplace.

Open and handle receptacle with care.

Information about protection against explosions and fires:

Do not spray on a naked flame or any incandescent material.

Keep ignition sources away - Do not smoke.

Protect from heat.

Protect against electrostatic charges.

Pressurized container: protect from sunlight and do not expose to temperatures exceeding $50^{\circ} \mathrm{C}$, i.e. electric lights. Do not pierce or burn, even after use.

Conditions for safe storage, including any incompatibilities

Storage:

Requirements to be met by storerooms and receptacles:

Store in a cool location.

Observe official regulations on storing packagings with pressurized containers.

Information about storage in one common storage facility: Not required.

Further information about storage conditions:

Keep receptacle tightly sealed.

Do not gas tight seal receptacle.

Store in cool, dry conditions in well sealed receptacles.

Protect from heat and direct sunlight.

Specific end use(s) No further relevant information available.

\section{Exposure controls/personal protection}

-Additional information about design of technical systems: No further data; see section 7 .

Control parameters

Components with limit values that require monitoring at the workplace:

124-38-9 Carbon dioxide

PEL Long-term value: $9,000 \mathrm{mg} / \mathrm{m} 3,5,000 \mathrm{ppm}$

REL Short-term value: $54,000 \mathrm{mg} / \mathrm{m} 3,30,000 \mathrm{ppm}$

Long-term value: $9,000 \mathrm{mg} / \mathrm{m} 3,5,000 \mathrm{ppm}$

TLV Short-term value: $54,000 \mathrm{mg} / \mathrm{m} 3,30,000 \mathrm{ppm}$ Long-term value: $9,000 \mathrm{mg} / \mathrm{m} 3,5,000 \mathrm{ppm}$

Additional information: The lists that were valid during the creation were used as basis.

\section{Exposure controls}

Personal protective equipment:

General protective and hygienic measures:

Keep away from foodstuffs, beverages and feed. 
Trade name: ELECTRON Aerosol

Immediately remove all soiled and contaminated clothing.

(Contd. of page 4)

Wash hands before breaks and at the end of work.

Avoid contact with the skin.

Avoid contact with the eyes and skin.

Breathing equipment:

In case of brief exposure or low pollution use respiratory filter device. In case of intensive or longer exposure, use respiratory protective device that is independent of circulating air.

Protection of hands:

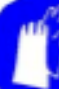

Protective gloves

The glove material has to be impermeable and resistant to the product. Due to missing tests no recommendation to the glove material can be given for the product.

Select glove material based on penetration times, rates of diffusion and degradation.

Material of gloves

The selection of the suitable gloves does not only depend on the material, but also on further marks of quality and varies from manufacturer to manufacturer. As the product is a preparation of several substances, the resistance of the glove material can not be calculated in advance and has therefore to be checked prior to the application.

Penetration time of glove material

The exact break-through time has to be determined and observed by the manufacturer of the protective gloves.

Eye protection: Tightly sealed goggles or safety glasses with side shields

\section{Physical and chemical properties}

Information on basic physical and chemical properties

General Information

Appearance:

Form:

Color:

Liquid

Colorless

Odor:

Odor threshold:

Mild citrus terpene

Not determined

pH-value:

Not determined.

- Change in condition

Melting point/Melting range:

Not determined.

Boiling point/Boiling range:

$160^{\circ} \mathrm{C}\left(320^{\circ} \mathrm{F}\right)$

Flash point:

$43^{\circ} \mathrm{C}\left(109^{\circ} \mathrm{F}\right)$

- Flammability (solid, gaseous):

Not applicable.

Ignition temperature:

$240^{\circ} \mathrm{C}\left(464^{\circ} \mathrm{F}\right)$

Decomposition temperature:

Not determined. 


\section{Safety Data Sheet (SDS)}

Page 6

OSHA Hazard Communication Standard 29 CFR 1910.1200. Prepared to GHS Rev03.

Reviewed on 5/30/2015

Trade name: ELECTRON Aerosol

\begin{tabular}{|c|c|}
\hline & (Contd. of page 5) \\
\hline Auto igniting: & Product is not self-igniting. \\
\hline Danger of explosion: & $\begin{array}{l}\text { Product is not explosive. However, formation of explosive air/ } \\
\text { vapor mixtures are possible. }\end{array}$ \\
\hline $\begin{array}{l}\text { Explosion limits: } \\
\text { Lower: } \\
\text { Upper: }\end{array}$ & $\begin{array}{l}0.6 \mathrm{Vol} \% \\
7.0 \mathrm{Vol} \%\end{array}$ \\
\hline -Vapor pressure@ $20^{\circ} \mathrm{C}\left(68^{\circ} \mathrm{F}\right):$ & $1 \mathrm{hPa}(1 \mathrm{~mm} \mathrm{Hg})$ \\
\hline $\begin{array}{l}\text { - Density @ } 20^{\circ} \mathrm{C}\left(68^{\circ} \mathrm{F}\right) \text { : } \\
\text { - Relative density @ } 20^{\circ} \mathrm{C}\left(68^{\circ} \mathrm{F}\right) \\
\text { - Vapor density } \\
\text { - Evaporation rate }\end{array}$ & $\begin{array}{l}0.784 \mathrm{~g} / \mathrm{cm} 3(6.542 \mathrm{lbs} / \mathrm{gal}) \\
6.54 \mathrm{lbs} / \mathrm{gal} \\
>1.0 \text { (air = 1). } \\
\text { Not applicable. }\end{array}$ \\
\hline $\begin{array}{l}\text { Solubility in / Miscibility with } \\
\text { Water: }\end{array}$ & Not miscible or difficult to mix. \\
\hline \multicolumn{2}{|c|}{ - Partition coefficient ( $n$-octanol/water): Not determined. } \\
\hline $\begin{array}{l}\text { Viscosity: } \\
\text { Dynamic: } \\
\text { Kinematic: }\end{array}$ & $\begin{array}{l}\text { Not determined. } \\
\text { Not determined. }\end{array}$ \\
\hline $\begin{array}{l}\text { Solvent content: } \\
\text { Organic solvents: } \\
\text { - Other information }\end{array}$ & $\begin{array}{l}95 \% \\
\text { No further relevant information available. }\end{array}$ \\
\hline
\end{tabular}

\section{Stability and reactivity}

- Reactivity No further relevant information available.

Chemical stability

- Thermal decomposition / conditions to be avoided:

No decomposition if used according to specifications.

- Possibility of hazardous reactions No dangerous reactions known.

- Conditions to avoid No further relevant information available.

- Incompatible materials: Strong oxidizing agents.

- Hazardous decomposition products: Oxides of carbon.

\section{Toxicological information}

- Information on toxicological effects

- Acute toxicity:

- $L D / L C 50$ values that are relevant for classification:

64742-48-9 Naphtha (petroleum), hydrotreated heavy

Oral $\quad L D 50>5,000 \mathrm{mg} / \mathrm{kg}$ (rat)

Dermal $L D 50>3,000 \mathrm{mg} / \mathrm{kg}$ (rabbit) 
Reviewed on 5/30/2015

Trade name: ELECTRON Aerosol

- Primary irritant effect:

(Contd. of page 6)

on the skin: Irnitant to skin and mucous membranes.

on the eye: No irritating effect.

Sensitization: Sensitization possible through skin contact.

Additional toxicological information:

The product shows the following dangers according to internally approved calculation methods for preparations:

Irritant

Carcinogenic categories

IARC (International Agency for Research on Cancer)

None of the ingredients is listed.

NTP (National Toxicology Program)

None of the ingredients is listed.

\section{Ecological information}

- Toxicity

- Aquatic toxicity: No further relevant information available.

Persistence and degradability No further relevant information available.

Behavior in environmental systems:

Bioaccumulative potential No further relevant information available.

Mobility in soil No further relevant information available.

Ecotoxical effects:

Remark: Very toxic for fish

Additional ecological information:

General notes:

Water hazard class 3 (Self-assessment): extremely hazardous for water

Do not allow product to reach ground water, water course or sewage system, even in small quantities.

Danger to drinking water if even extremely small quantities leak into the ground.

Also poisonous for fish and plankton in water bodies.

Very toxic for aquatic organisms

Results of PBT and $v P v B$ assessment

PBT: Not applicable.

vPvB: Not applicable.

Other adverse effects No further relevant information available.

\section{Disposal considerations}

Waste treatment methods

Recommendation:

Must not be disposed of together with household garbage. Do not allow product to reach sewage system. 


\section{ECOELININK.}

\section{Satety Data Sheet (SDS)}

Page 8

OSHA Hazard Communication Standard 29 CFR 1910.1200. Prepared to GHS

Rev03.

Reviewed on 5/30/2015

Trade name: ELECTRON Aerosol

(Contd. of page 7)

Uncleaned packagings:

- Recommendation: Disposal must be made according to official regulations.

\section{Transport intormation}

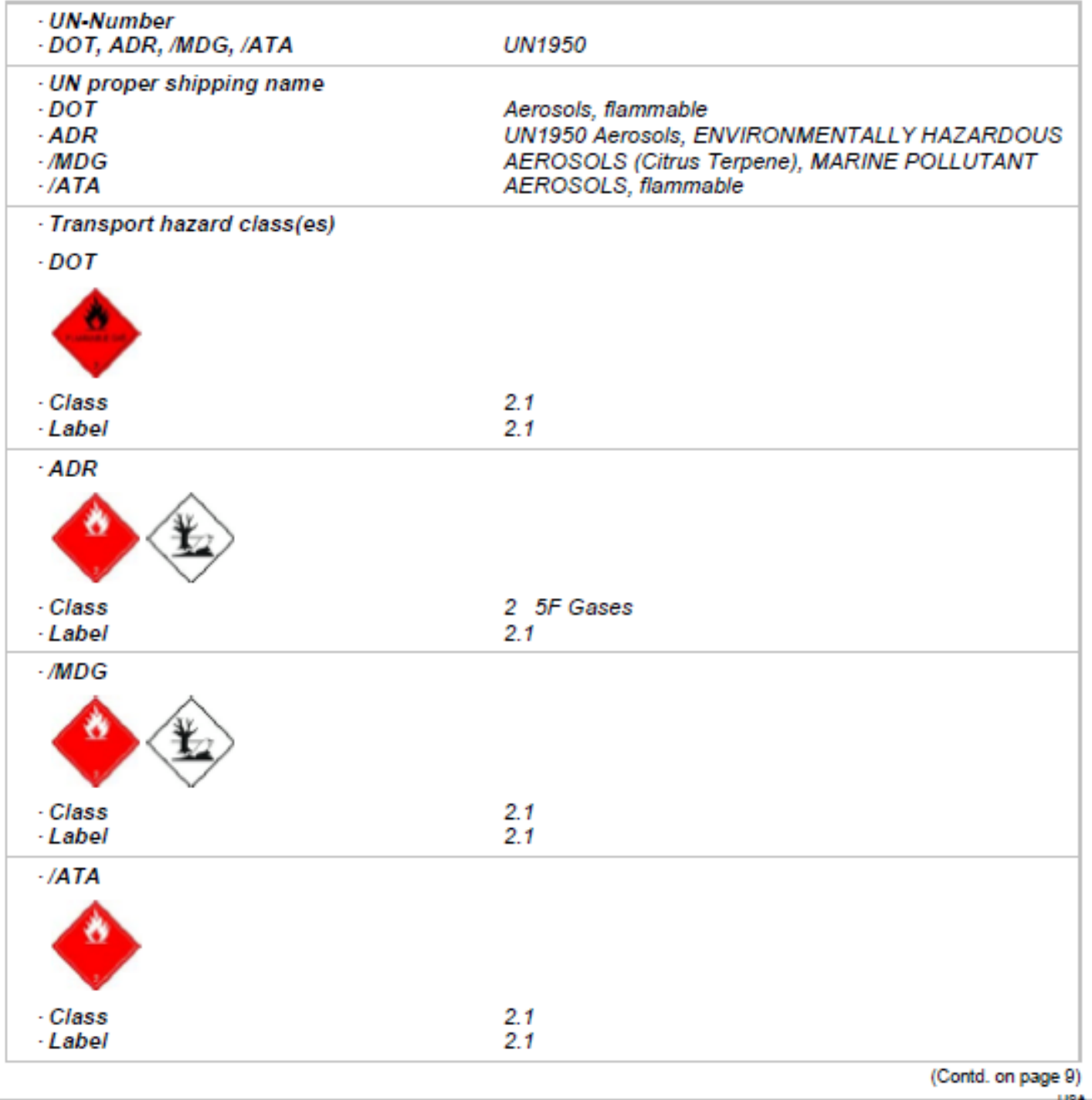


Trade name: ELECTRON Aerosol

\begin{tabular}{|c|c|}
\hline & (Contd. of page 8) \\
\hline $\begin{array}{l}\text { - Packing group } \\
\text {-DOT, ADR, IMDG, IATA }\end{array}$ & Non-Regulated Material \\
\hline $\begin{array}{l}\text { - Environmental hazards: } \\
\text { - Marine pollutant: } \\
\text {-Special marking (ADR): }\end{array}$ & $\begin{array}{l}\text { Product contains environmentally hazardous } \\
\text { substances: Citrus Terpene } \\
\text { Yes } \\
\text { Symbol (fish and tree) } \\
\text { Symbol (fish and tree) }\end{array}$ \\
\hline $\begin{array}{l}\text { - Special precautions tor user } \\
\text { - Danger code (Kemler): } \\
\text { - EMS Number: }\end{array}$ & $\begin{array}{l}\text { Warning: Gases } \\
- \\
F-D, S-U\end{array}$ \\
\hline $\begin{array}{l}\text { Transport in bulk according to Annex // ot } \\
\text { MARPOL } 73 / 78 \text { and the IBC Code }\end{array}$ & Not applicable. \\
\hline - Transport/Additional intormation: & \\
\hline $\begin{array}{l}\text { DOT } \\
\text {-Remarks: }\end{array}$ & ORM-D Limited QTY Item \\
\hline - UN "Model Regulation": & $\begin{array}{l}\text { UN1950, Aerosols, ENVIRONMENTALLY } \\
\text { HAZARDOUS, } 2.1\end{array}$ \\
\hline
\end{tabular}

\section{Regulatory intormation}

Safety, health and environmental regulations/legislation specific tor the substance or mixture

\section{- Sara}

- Section 355 (extremely hazardous substances):

None of the ingredients is listed.

- Section 313 (Specific toxic chemical listings):

None of the ingredients is listed.

- TSCA (Toxic Substances Control Act):

All ingredients are listed.

- Proposition 65

- Chemicals known to cause cancer:

None of the ingredients is listed.

- Chemicals known to cause reproductive toxicity tor females:

None of the ingredients is listed.

- Chemicals known to cause reproductive toxicity tor males:

None of the ingredients is listed.

- Chemicals known to cause developmental toxicity:

None of the ingredients is listed. 


\section{IDENTIFICATION}

Product identifier

Product Name $\quad$ Dripstop 927

Other means of identification

Product Code

UN/ID no.

MS- 927

Synonyms

None

Recommended use of the chemical and restrictions on use

Recommended Use Anaerobic Sealant.

Uses advised against None known

Details of the supplier of the safety data sheet

Manufacturer Address

Hernon Manufacturing Inc.

121 Tech Drive

Sanford, FL 32771

800-527-0004

Emergency telephone number

Company Phone Number

407-322-4000

Emergency Telephone

Chemtel 800-255-3924

\section{HAZARDS IDENTIFICATION}

\section{Classification}

OSHA Regulatory Status

This chemical is considered hazardous by the 2012 OSHA Hazard Communication Standard (29 CFR 1910.1200)

\begin{tabular}{|l|l|}
\hline Acute toxicity - Dermal & Category 4 \\
\hline Acute toxicity - Inhalation (Dusts/Mists) & Category 3 \\
\hline Skin corrosion/imitation & Category 2 \\
\hline Serious eye damage/eye irritation & Category 2A \\
\hline Skin sensitization & Category 1 \\
\hline Carcinogenicity & Category 2 \\
\hline Specific target organ toxicity (single exposure) & Category 3 \\
\hline Specific target organ toxicity (repeated exposure) & Category 2 \\
\hline
\end{tabular}

Label elements

Emergency Overview

Danger

Hazard statements

Harmful in contact with skin

Toxic if inhaled

Causes skin irritation

Causes serious eye irritation

May cause an allergic skin reaction

Suspected of causing cancer 


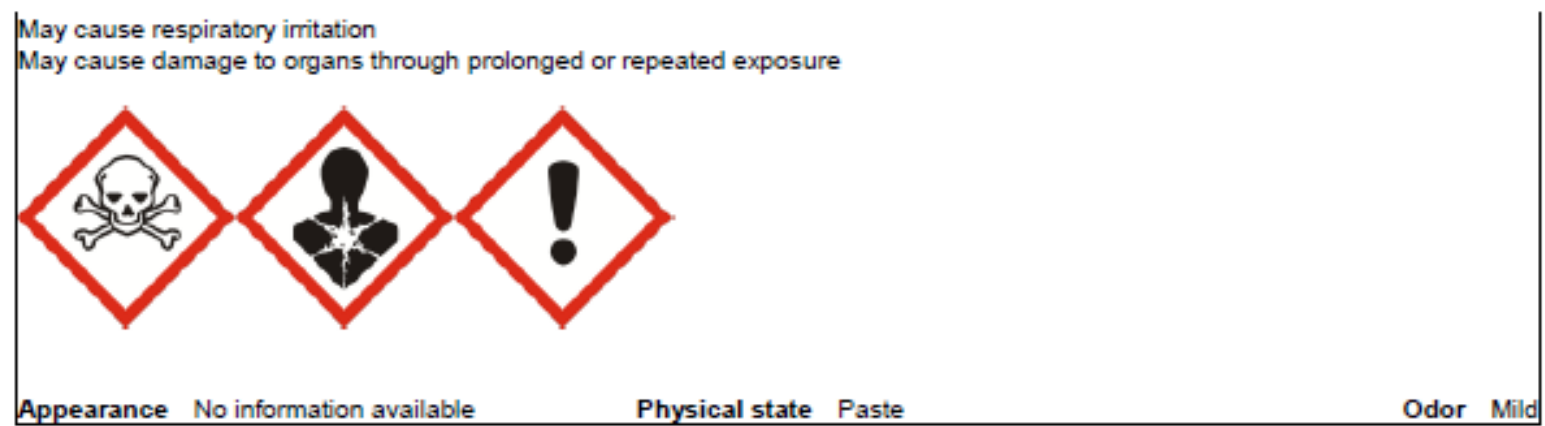

Precautionary Statements - Prevention

Obtain special instructions before use

Do not handle until all safety precautions have been read and understood

Wear protective gloves/protective clothing/eye protection/face protection

Use only outdoors or in a well-ventilated area

Wash face, hands and any exposed skin thoroughly after handling

Contaminated work clothing must not be allowed out of the workplace

Do not breathe dust/fume/gas/mist/vapors/spray

Precautionary Statements - Response

IF exposed or concemed: Get medical advice/attention

Specific treatment (see supplemental first aid instructions on this label)

IF IN EYES: Rinse cautiously with water for several minutes. Remove contact lenses, if present and easy to do. Continue rinsing

If eye irritation persists: Get medical advice/attention

IF ON SKIN: Wash with plenty of water and soap

Call a POISON CENTER or doctor if you feel unwell

Take off contaminated clothing and wash it before reuse

If skin irritation or rash occurs: Get medical advice/attention

IF INHALED: Remove person to fresh air and keep comfortable for breathing

Call a POISON CENTER or doctor

Precautionary Statements - Storage

Store locked up

Store in a well-ventilated place. Keep container tightly closed

Precautionary Statements - Disposal

Dispose of contents/container to an approved waste disposal plant

Hazards not otherwise classified (HNOC)

Not applicable

Other Information

May be harmful if swallowed

Toxic to aquatic life with long lasting effects

Toxic to aquatic life

\section{COMPOSITION/INFORMATION ON INGREDIENTS}

Substance

\begin{tabular}{|c|c|c|c|}
\hline Chemical Name & CAS No. & Weight- $\%$ & Trade Secret \\
\hline POLYETHYLENE GLYCOL DIMETHACRYLATE & $25852-47-5$ & $10-30$ & $\times$ \\
\hline TITANIUM DIOXIDE & $13463-67-7$ & $1-5$ & $\times$ \\
\hline Cumene Hydroperoxide & $80-15-9$ & $1-5$ & $\times$ \\
\hline Epoxy Resin/Bisphenyl A epoxy resin & $25068-38-6$ & $0.1-1$ & $\times$ \\
\hline METHANOL & $67-56-1$ & $0.1-1$ & $\times$ \\
\hline
\end{tabular}

Page 2/9 
"The exact percentage (concentration) of composition has been withheld as a trade secret.

\section{FIRST AID MEASURES}

\section{Description of first aid measures}

Eye contact

Skin contact

Inhalation

Ingestion
Rinse thoroughly with plenty of water for at least 15 minutes, lifting lower and upper eyelids. Consult a physician.

Wash with soap and water. Flush skin with water for several minutes. Remove contaminated clothing and shoes. If irritation develops, seek medical attention. Wash clothing before reuse.

Remove to fresh air. If breathing is difficult, give oxygen. If breathing has stopped, give artificial respiration. Get medical attention immediately.

Do NOT induce vomiting. Never give anything by mouth to an unconscious person. Call a POISON CENTER or doctor/physician if you feel unwell.

\section{Most important symptoms and effects, both acute and delaved}

Symptoms

None known.

Indication of any immediate medical attention and special treatment needed

Note to physicians Treat symptomatically.

\section{FIRE-FIGHTING MEASURES}

Suitable extinguishing media

Carbon dioxide (CO2). Foam. Dry chemical.

Unsuitable extinguishing media None.

Specific hazards arising from the chemical

No information available.

Hazardous combustion products Carbon oxides. Irritating organic vapors.

Explosion data

Sensitivity to Mechanical Impact None.

Sensitivity to Static Discharge None.

Protective equipment and precautions for firefighters

As in any fire, wear self-contained breathing apparatus pressure-demand, MSHA/NIOSH (approved or equivalent) and full protective gear.

\section{ACCIDENTAL RELEASE MEASURES}

Personal precautions, protective equipment and emergency procedures

Personal precautions

For emergency responders

Environmental precautions

Environmental precautions
Use personal protective equipment as required. Ensure adequate ventilation, especially in confined areas.

Use personal protection recommended in Section 8.

Do not allow into any sewer, on the ground or into any body of water. See Section 12 for 
additional ecological information.

Methods and material for containment and cleaning up

Methods for containment

Methods for cleaning up
Prevent further leakage or spillage if safe to do so.

Soak up with inert absorbent material. Store in a closed container until ready for disposal.

\section{HANDLING AND STORAGE}

Precautions for safe handling

Advice on safe handling

Avoid contact with skin, eyes or clothing. Avoid breathing vapors or mists. Wash thoroughly after handling. Ensure adequate ventilation, especially in confined areas.

\section{Conditions for safe storage, including any incompatibilities}

Storage Conditions

Keep at temperatures between 7 and $29^{\circ} \mathrm{C}$.

Incompatible materials

Strong oxidizers.

\section{EXPOSURE CONTROLS/PERSONAL PROTECTION}

\section{Control parameters}

Exposure Guidelines

\begin{tabular}{|c|c|c|c|}
\hline Chemical Name & ACGIH TLV & OSHAPEL & NIOSH IDLH \\
\hline $\begin{array}{c}\text { TITANIUM DIOXIDE } \\
13463-67-7\end{array}$ & TWA: $10 \mathrm{mg}^{3} \mathrm{~m}^{3}$ & $\begin{array}{l}\text { TWA: } 15 \mathrm{mg}^{3} \mathrm{~m}^{3} \text { total dust } \\
\text { (vacated) TWA: } 10 \mathrm{mg}^{3} \mathrm{~m}^{3} \text { total } \\
\text { dust }\end{array}$ & IDLH: $5000 \mathrm{mg}^{3} \mathrm{~m}^{3}$ \\
\hline $\begin{array}{c}\text { METHANOL } \\
67-56-1\end{array}$ & $\begin{array}{l}\text { STEL: } 250 \mathrm{ppm} \\
\text { TWA: } 200 \mathrm{ppm} \\
\mathrm{S}^{x}\end{array}$ & $\begin{array}{c}\text { TWA: } 200 \mathrm{ppm} \\
\text { TWA: } 260 \mathrm{mg} \mathrm{m}^{3} \\
\text { (vacated) TWA: } 200 \mathrm{ppm} \\
\text { (vacated) TWA: } 260 \mathrm{mg}^{3} \mathrm{~m}^{3} \\
\text { (vacated) STEL: } 250 \mathrm{ppm} \\
\text { (vacated) STEL: } 325 \mathrm{mg}^{3} \mathrm{~m}^{3} \\
\text { (vacated) } \mathrm{S}^{\star}\end{array}$ & $\begin{array}{l}\text { IDLH: } 6000 \mathrm{ppm} \\
\text { TWA: } 200 \mathrm{ppm} \\
\text { TWA: } 260 \mathrm{mg} / \mathrm{m}^{3} \\
\text { STEL: } 250 \mathrm{ppm} \\
\text { STEL: } 325 \mathrm{mg}^{3} \mathrm{~m}^{3}\end{array}$ \\
\hline
\end{tabular}

\section{Appropriate engineering controls}

$\begin{array}{ll}\text { Engineering Controls } & \text { Showers } \\ & \text { Eyewash stations } \\ & \text { Ventilation systems. }\end{array}$

Individual protection measures, such as personal protective equipment

Eye/face protection

Skin and body protection

Respiratory protection

General Hygiene Considerations
Wear safety glasses with side shields (or goggles).

Wear protective gloves and protective clothing. Use rubber or plastic gloves.

If exposure limits are exceeded or irritation is experienced, NIOSH/MSHA approved respiratory protection should be worn. Positive-pressure supplied air respirators may be required for high airborne contaminant concentrations. Respiratory protection must be provided in accordance with current local regulations.

Handle in accordance with good industrial hygiene and safety practice. 


\section{PHYSICAL AND CHEMICAL PROPERTIES}

Information on basic physical and chemical properties

\begin{tabular}{|c|c|}
\hline $\begin{array}{l}\text { Physical state } \\
\text { Appearance } \\
\text { Color }\end{array}$ & $\begin{array}{l}\text { Paste } \\
\text { No information available } \\
\text { White }\end{array}$ \\
\hline Property & Values \\
\hline $\begin{array}{l}\mathrm{pH} \\
\text { Melting point / freezing point }\end{array}$ & $\begin{array}{l}\text { Does not apply } \\
\text { No information available }\end{array}$ \\
\hline Boiling point $/$ boiling range & $>149{ }^{\circ} \mathrm{C} / 300^{\circ} \mathrm{F}$ \\
\hline $\begin{array}{l}\text { Flash point } \\
\text { Evaporation rate }\end{array}$ & $\begin{array}{l}>93{ }^{\circ} \mathrm{C} / 200{ }^{\circ} \mathrm{F} \\
\text { No information available }\end{array}$ \\
\hline $\begin{array}{l}\text { Flammability (solid, gas) } \\
\text { Flammability Limit in Air }\end{array}$ & No information available \\
\hline Upper flammability limit: & No information available \\
\hline Lower flammability limit: & No information available \\
\hline $\begin{array}{l}\text { Vapor pressure } \\
\text { Vapor density }\end{array}$ & $\begin{array}{l}\text { No information available } \\
\text { No information available }\end{array}$ \\
\hline Relative density & 1.15 \\
\hline Water solubility & Slightly soluble \\
\hline Solubility in other solvents & No information available \\
\hline $\begin{array}{l}\text { Partition coefficient } \\
\text { Autoignition temperature }\end{array}$ & $\begin{array}{l}\text { No information available } \\
\text { No information available }\end{array}$ \\
\hline Decomposition temperature & No information available \\
\hline $\begin{array}{l}\text { Kinematic viscosity } \\
\text { Dynamic viscosity }\end{array}$ & $\begin{array}{l}\text { No information available } \\
\text { No information available }\end{array}$ \\
\hline Explosive properties & No information availabl \\
\hline Oxidizing properties & No information availab \\
\hline
\end{tabular}

\section{Other Information}

$\begin{array}{ll}\text { Softening point } & \text { No information available } \\ \text { Molecular weight } & \text { No information available } \\ \text { VOC Content (\%) } & \text { No information available } \\ \text { Density } & \text { No information available } \\ \text { Bulk density } & \text { No information available }\end{array}$

\section{STABILITY AND REACTIVITY}

Reactivity

No data available

Chemical stability

Stable under recommended storage conditions.

Possibility of Hazardous Reactions

None under normal processing.

Conditions to avoid

Incompatible materials.

Incompatible materials

Strong oxidizers.

Hazardous Decomposition Products

Carbon oxides. Imitating organic vapors. 


\section{TOXICOLOGICAL INFORMATION}

Information on likely routes of exposure

$\begin{array}{ll}\text { Product Information } & \text { No data available } \\ \text { Inhalation } & \text { No data available. } \\ \text { Eye contact } & \text { No data available. } \\ \text { Skin contact } & \text { No data available. } \\ \text { Ingestion } & \text { No data available. }\end{array}$

\begin{tabular}{|l|c|c|c|}
\hline Chemical Name & Oral LD50 & Dermal LD50 & Inhalation LC50 \\
\hline $\begin{array}{l}\text { TITANIUM DIOXIDE } \\
13463-67-7\end{array}$ & $>10000 \mathrm{mg} / \mathrm{kg}$ (Rat) & - & - \\
\hline $\begin{array}{l}\text { Cumene Hydroperoxide } \\
80-15-9\end{array}$ & $=382 \mathrm{mg} / \mathrm{kg}$ (Rat) & $=0.126 \mathrm{~mL} / \mathrm{kg}$ (Rabbit) & $=220 \mathrm{ppm}$ (Rat) $4 \mathrm{~h}$ \\
\hline $\begin{array}{l}\text { Epoxy Resin/Bisphenyl A epoxy } \\
\text { resin } \\
25068-38-6\end{array}$ & $=11400 \mathrm{mg} / \mathrm{kg}$ (Rat) & & \\
\hline $\begin{array}{l}\text { METHANOL } \\
\text { 67-56-1 }\end{array}$ & $=6200 \mathrm{mg} / \mathrm{kg}$ (Rat) & $=15800 \mathrm{mg} / \mathrm{kg}$ (Rabbit) & $\begin{array}{c}=22500 \mathrm{ppm} \text { (Rat) } 8 \mathrm{~h}=64000 \\
\text { ppm (Rat) } 4 \mathrm{~h}\end{array}$ \\
\hline
\end{tabular}

Information on toxicological effects

Symptoms No information available.

Delayed and immediate effects as well as chronic effects from short and long-term exposure

$\begin{array}{ll}\text { Sensitization } & \text { No information available. } \\ \text { Germ cell mutagenicity } & \text { No information available. }\end{array}$

Carcinogenicity

\begin{tabular}{|l|c|c|c|c|}
\hline Chemical Name & ACGंH & IARC & NTP & OSHA \\
\hline $\begin{array}{l}\text { TITANIUM DIOXIDE } \\
13463-67-7\end{array}$ & - & Group 2B & - & $X$ \\
\hline
\end{tabular}

13463-67-7

No information available.

$\begin{array}{ll}\text { Reproductive toxicity } & \text { No information available. } \\ \text { STOT - single exposure } & \text { No information available. } \\ \text { STOT - repeated exposure } & \text { No information available. } \\ \text { Aspiration hazard } & \text { No information available. }\end{array}$

Numerical measures of toxicity - Product Information

The following values are calculated based on chapter 3.1 of the GHS document.

ATEmix (oral) $2,328.00 \mathrm{mg} / \mathrm{kg}$

ATEmix (dermal) $\quad 1,955.00 \mathrm{mg} / \mathrm{kg}$

ATEmix (inhalation-dust/mist) $0.89 \mathrm{mg} / \mathrm{l}$

\section{ECOLOGICAL INFORMATION}

Ecotoxicity

Toxic to aquatic life with long lasting effects

\begin{tabular}{|c|c|c|c|}
\hline Chemical Name & Algae/aquatic plants & Fish & Crustacea \\
\hline $\begin{array}{c}\text { Insoluble Saccharin } \\
81-07-2\end{array}$ & - & $\begin{array}{c}18300: 96 \mathrm{~h} \text { Pimephales promelas } \\
\text { mg/L LC50 }\end{array}$ & \\
\hline
\end{tabular}




\begin{tabular}{|c|c|c|c|}
\hline $\begin{array}{l}\text { Cumene Hydroperoxide } \\
80-15-\theta\end{array}$ & - & $\begin{array}{c}\text { 3.9: } 96 \text { h Oncorhynchus mykiss } \\
\text { mg/L LC50 static }\end{array}$ & 7: 24 h Daphnia magna mg/L EC50 \\
\hline $\begin{array}{c}\text { METHANOL } \\
67-56-1\end{array}$ & - & $\begin{array}{c}\text { 13500 - } 17600: 96 \mathrm{~h} \text { Lepomis } \\
\text { macrochirus mg/L LC50 } \\
\text { flow-through } 18 \text { - 20: } 96 \mathrm{~h} \\
\text { Oncorhynchus mykiss mL/L LC50 } \\
\text { static } 19500 \text { - } 20700: 96 \mathrm{~h} \\
\text { Oncorhynchus mykiss mg/L LC50 } \\
\text { flow-through } 28200: 96 \mathrm{~h} \\
\text { Pimephales promelas mg/L LC50 } \\
\text { flow-through } 100: 96 \mathrm{~h} \text { Pimephales } \\
\text { promelas mg/L LC50 static }\end{array}$ & - \\
\hline
\end{tabular}

Persistence and degradability No information available.

Bioaccumulation

\begin{tabular}{|c|c|}
\hline Chemical Name & Partition coefficient \\
\hline METHANOL & -0.77 \\
$67-56-1$ & \\
\hline
\end{tabular}

Other adverse effects

No information available

\section{DISPOSAL CONSIDERATIONS}

\section{Waste treatment methods}

Disposal of wastes

Contaminated packaging

\begin{tabular}{|c|c|c|c|c|}
\hline Chemical Name & RCRA & RCRA - Basis for Listing & RCRA - D Series Wastes & RCRA - U Series Wastes \\
\hline $\begin{array}{c}\text { Cumene Hydroperoxide } \\
80-15-9\end{array}$ & - & - & - & U096 \\
\hline $\begin{array}{c}\text { METHANOL } \\
67-56-1\end{array}$ & - & $\begin{array}{c}\text { Included in waste stream: } \\
\text { F039 }\end{array}$ & - & U154 \\
\hline
\end{tabular}

\begin{tabular}{|c|c|}
\hline Chemical Name & California Hazardous Waste Status \\
\hline Cumene Hydroperoxide & Toxic \\
Ignitable \\
\hline METHANOL & Toxic \\
$67-56-1$ & Ignitable \\
\hline
\end{tabular}

\section{TRANSPORT INFORMATION}

\begin{tabular}{cl} 
DOT & Not regulated \\
\hline UN/ID no. & None \\
Proper shipping name & Not regulated \\
Hazard Class & None \\
Packing Group & None \\
Special Provisions & None \\
& \\
IATA & Not regulated \\
\hline UN/ID no. & None \\
Proper shipping name & Not regulated \\
Hazard Class & None \\
Packing Group & None \\
Special Provisions & None
\end{tabular}




\begin{tabular}{ll} 
IMDG & Not regulated \\
\hline UN/ID no. & None \\
Proper shipping name & Not regulated \\
Hazard Class & None \\
Packing Group & None \\
Special Provisions & None
\end{tabular}

\section{REGULATORY INFORMATION}

International Inventories

\begin{tabular}{ll}
\hline TSCA & Complies \\
DSL/NDSL & Complies \\
EINECS/ELINCS & Complies \\
ENCS & Complies \\
IECSC & Complies \\
KECL & Complies \\
PICCS & Complies \\
AICS & Complies
\end{tabular}

All ingredients are on the inventory or are exempt from listing.

Legend:

TSCA - United States Toxic Substances Control Act Section 8(b) Inventory

DSL/NDSL - Canadian Domestic Substances List/Non-Domestic Substances List

EINECS/ELINCS - European Inventory of Existing Chemical Substances/European List of Notified Chemical Substances

ENCS - Japan Existing and New Chemical Substances

IECSC - China Inventory of Existing Chemical Substances

KECL - Korean Existing and Evaluated Chemical Substances

PICCS - Philippines Inventory of Chemicals and Chemical Substances

AICS - Australian Inventory of Chemical Substances

\section{US Federal Regulations}

SARA 313

Section 313 of Title III of the Superfund Amendments and Reauthorization Act of 1986 (SARA). This product contains a chemical or chemicals which are subject to the reporting requirements of the Act and Title 40 of the Code of Federal Regulations, Part 372

\begin{tabular}{|l|c|}
\hline Chemical Name & SARA 313 - Threshold Values \% \\
\hline Cumene Hydroperoxide - 80-15-8 & 1.0 \\
\hline METHANOL - 67-58-1 & \\
\hline SARA 311/312 Hazard Categories & Yes \\
\hline \multicolumn{1}{|c|}{ Acute health hazard } & Yes \\
Chronic Health Hazard & Yes \\
Fire hazard & No \\
Sudden release of pressure hazard & Yes \\
Reactive Hazard &
\end{tabular}

CWA (Clean Water Act)

This product does not contain any substances regulated as pollutants pursuant to the Clean Water Act (40 CFR 122.21 and 40 CFR 122.42)

\section{CERCLA}

This material, as supplied, contains one or more substances regulated as a hazardous substance under the Comprehensive Environmental Response Compensation and Liability Act (CERCLA) (40 CFR 302)

\begin{tabular}{|c|c|c|c|}
\hline Chemical Name & Hazardous Substances RQs & CERCLASARA RQ & Reportable Quantity (RQ) \\
\hline Cumene Hydroperoxide & $10 \mathrm{lb}$ & & RQ $10 \mathrm{lb}$ final RQ \\
$80-15-9$ & & - & RQ 4.54 kg final RQ \\
\hline METHANOL & $5000 \mathrm{lb}$ & - & RQ $5000 \mathrm{lb}$ final RQ \\
$67-56-1$ & & & RQ 2270 kg final RQ \\
\hline
\end{tabular}




\section{US State Regulations}

California Proposition 65

This product contains the following Proposition 65 chemicals

\begin{tabular}{|c|c|}
\hline Chemical Name & California Proposition 65 \\
\hline TITANIUM DIOXIDE - 13463-67-7 & Carcinogen \\
\hline METHANOL - $67-56-1$ & Developmental \\
\hline
\end{tabular}

\section{U.S. State Right-to-Know Regulations}

\begin{tabular}{|c|c|c|c|}
\hline Chemical Name & New Jersey & Massachusetts & Pennsylvania \\
\hline $\begin{array}{c}\text { TITANIUM DIOXIDE } \\
13463-67-7\end{array}$ & $\mathrm{X}$ & $\mathrm{X}$ & $\mathrm{X}$ \\
\hline $\begin{array}{c}\text { Cumene Hydroperoxide } \\
80-15-9\end{array}$ & $\mathrm{X}$ & $\mathrm{X}$ & \\
\hline $\begin{array}{c}\text { METHANOL } \\
67-56-1\end{array}$ & $\mathrm{X}$ & $\mathrm{X}$ & \\
\hline
\end{tabular}

U.S. EPA Label Information

EPA Pesticide Registration Number Not applicable

\section{OTHER INFORMATION, INCLUDING DATE OF PREPARATION OF THE LAST REVISION}

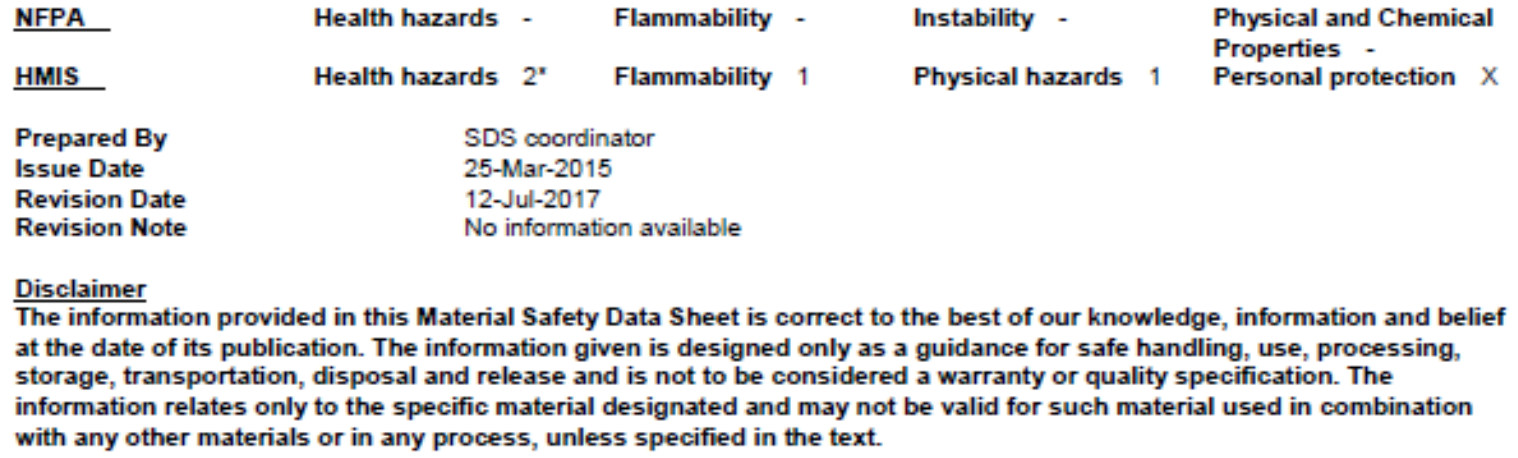

End of Safety Data Sheet 


\section{IDENTIFICATION}

Product Identifier

Product Name

Other means of identification

SDS \#

JNJ-0017

Product Code

HDD-C

Recommended use of the chemical and restrictions on use

Recommended Use

Cleaner for solder paste and flux.

Details of the supplier of the safety data sheet

Supplier Address

JNJ Industries

290 Beaver Street

Franklin, MA 02038

Emergency Telephone Number

Company Phone Number

Emergency Telephone (24 hr)

Phone: 800-554-9994 / 508-553-0529

Fax: 508-553-9973

INFOTRAC 1-352-323-3500 (International)

1-800-535-5053 (North America)

\section{HAZARDS IDENTIFICATION}

Appearance Dark amber liquid

Physical State Liquid

Odor Negligible

Classification

Serious eye damage/eye irritation

Category 2

\section{Signal Word}

Warning

Hazard Statements

Causes serious eye irritation

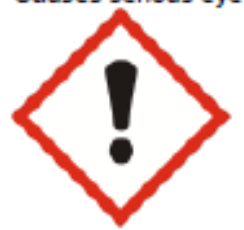

Precautionary Statements - Prevention

Wash face, hands and any exposed skin thoroughly after handling

Wear eye/face protection 
Precautionary Statements - Response

IF IN EYES: Rinse cautiously with water for several minutes. Remove contact lenses, if present and easy to do. Continue rinsing

If eye irritation persists: Get medical advice/attention

\section{COMPOSITION/INFORMATION ON INGREDIENTS}

\begin{tabular}{|c|c|c|}
\hline Chemical Name & CAS No & Weight-\% \\
\hline DI Water & $7732-18-5$ & $>85$ \\
\hline Oxygen and Phosphorous containing compound & Proprietary & Proprietary \\
\hline
\end{tabular}

"If Chemical Name/CAS No is "proprietary" and/or Weight- $\%$ is listed as a range, the specific chemical identity and/or percentage of composition has been withheld as a trade secret. ${ }^{x x}$

\section{FIRST-AID MEASURES}

\section{First Aid Measures}

Eye Contact

Flush eyes with water for 20 minutes. If eye irritation persists: Get medical advice/attention.

Skin Contact

Take off contaminated clothing. Wash contaminated clothing before reuse. Wash skin thoroughly with mild soap and water. Get medical attention if irritation develops or persists.

Inhalation

Remove to fresh air. If breathing is difficult, give oxygen. If not breathing. give artificial respiration. Get medical attention.

Ingestion

Do not induce vomiting. If drowsy or unconscious, do not give anything by mouth; place individual on the left side with head down. Dilute by giving a large amount of water.

Most important symptoms and effects

Symptoms

Exposed individuals may experience eye tearing, redness and discomfort. May include redness, drying and cracking of skin. Prolonged or repeated exposure to mists/vapor may damage peripheral nerves. May cause irritation to the mucous membranes and upper respiratory tract. Overexposure by inhalation may cause CNS depression- drowsiness, dizziness, confusion or loss of coordination. Nausea.

Indication of any immediate medical attention and special treatment needed

Notes to Physician

Epinephrine and other sympathomimetic drugs may potentiate arrhythmia in persons exposed to this substance. Such drugs should be used cautiously, if at all, and only with cardiac monitoring.

\section{FIRE-FIGHTING MEASURES}

Suitable Extinguishing Media

Dry chemical. Carbon dioxide (CO2). Foam.

Unsuitable Extinguishing Media Not determined.

Specific Hazards Arising from the Chemical

Vapors can combust and liquids can burn when temperatures reach or exceed the flashpoint.

Protective equipment and precautions for firefighters

As in any fire, wear self-contained breathing apparatus pressure-demand, MSHAJNIOSH (approved or equivalent) and full protective gear. Use water spray to keep fire-exposed containers cool.

\section{ACCIDENTAL RELEASE MEASURES}

Page $2 / 7$ 


\section{Personal precautions, protective equipment and emergency procedures}

Personal Precautions Stay upwind. Remove all sources of ignition. Ventilate affected area.

Environmental Precautions Keep out of waterways.

Methods and material for containment and cleaning up

Methods for Containment $\quad$ Prevent further leakage or spillage if safe to do so.

Methods for Clean-Up Contain and collect with an inert absorbent and place into an appropriate container for disposal.

\section{HANDLING AND STORAGE}

Precautions for safe handling

Advice on Safe Handling

Wash thoroughly after handling. Use personal protection recommended in Section 8. Keep away from heat/sparks/open flames/hot surfaces. - No smoking. Do not pressurize, cut, weld, braze, solder, drill, grind, or expose empty containers to heat, sparks or open flames.

Conditions for safe storage, including any incompatibilities

Storage Conditions Keep containers tightly closed in a dry, cool and well-ventilated place.

Incompatible Materials Strong acids. Strong bases. Strong oxidizers. Amines.

\section{EXPOSURE CONTROLS/PERSONAL PROTECTION}

Exposure Guidelines

\begin{tabular}{|c|c|c|c|}
\hline Chemical Name & ACGIH TLV & OSHA PEL & NIOSH IDLH \\
\hline $\begin{array}{c}\text { Oxygen and Phosphorous containing } \\
\text { compound }\end{array}$ & $\begin{array}{c}\text { STEL: } 3 \mathrm{mg}^{3} \mathrm{~m}^{3} \\
\text { TWA: } 1 \mathrm{mg}^{3} \mathrm{~m}^{3}\end{array}$ & $\begin{array}{c}\text { TWA: } 1 \mathrm{mg} / \mathrm{m}^{3} \\
\text { (vacated) TWA: } 1 \mathrm{mg}^{3} \\
\text { (vacated) STEL: } 3 \mathrm{mg}^{3} \mathrm{~m}^{3}\end{array}$ & $\begin{array}{c}\text { IDLH: } 1000 \mathrm{mg}^{3} / \mathrm{m}^{3} \\
\text { TWA: } 1 \mathrm{mg}^{3} \mathrm{~m}^{3}\end{array}$ \\
\hline
\end{tabular}

Appropriate engineering controls

Engineering Controls Apply technical measures to comply with the occupational exposure limits.

Individual protection measures, such as personal protective equipment

Eye/Face Protection Avoid contact with eyes.

Skin and Body Protection Wear suitable gloves.

Respiratory Protection If airborne concentrations exceed exposure limits, use a respirator or gas mask with appropriate cartridges and canisters (NIOSH approved), or a mask with an air supply.

General Hygiene Considerations Handle in accordance with good industrial hygiene and safety practice.

\section{PHYSICAL AND CHEMICAL PROPERTIES}

Page $3 / 7$ 
Information on basic physical and chemical properties

\begin{tabular}{|c|c|c|c|}
\hline $\begin{array}{l}\text { Physical State } \\
\text { Appearance } \\
\text { Color }\end{array}$ & $\begin{array}{l}\text { Liquid } \\
\text { Dark amber liquid } \\
\text { Dark amber }\end{array}$ & $\begin{array}{l}\text { Odor } \\
\text { Odor Threshold }\end{array}$ & $\begin{array}{l}\text { Negligible } \\
\text { Not determined }\end{array}$ \\
\hline Property & Values & Remarks - Method & \\
\hline$\overline{\mathrm{pH}}$ & $\sim 10$ & & \\
\hline $\begin{array}{l}\text { Melting Point/Freezing Point } \\
\text { Boiling Point/Boiling Range } \\
\text { Flash Point }\end{array}$ & $\begin{array}{l}\text { Not available } \\
>93^{\circ} \mathrm{C} />200{ }^{\circ} \mathrm{F} \\
>149^{\circ} \mathrm{C} />300^{\circ} \mathrm{F}\end{array}$ & & \\
\hline $\begin{array}{l}\text { Evaporation Rate } \\
\text { Flammability (Solid, Gas) } \\
\text { Upper Flammability Limits }\end{array}$ & $\begin{array}{l}<0.1 \\
\text { n/a-liquid } \\
\text { Not determined }\end{array}$ & (butyl acetate $=1$ ) & \\
\hline Lower Flammability Limit & Not determined & & \\
\hline $\begin{array}{l}\text { Vapor Pressure } \\
\text { Vapor Density }\end{array}$ & $\begin{array}{l}18.0 \mathrm{~mm} \mathrm{Hg} \\
\text { Not determined }\end{array}$ & & \\
\hline Specific Gravity & $1.06(8.82 \mathrm{lbs} / \mathrm{gal})$ & & \\
\hline Water Solubility & $>90 \%$ & & \\
\hline Solubility in other solvents & Not determined & & \\
\hline Partition Coefficient & Not determined & & \\
\hline Auto-ignition Temperature & Not determined & & \\
\hline Decomposition Temperature & Not determined & & \\
\hline Kinematic Viscosity & Not determined & & \\
\hline Dynamic Viscosity & Not determined & & \\
\hline Explosive Properties & Not determined & & \\
\hline Oxidizing Properties & Not determined & & \\
\hline VOC Content & $10.785 \mathrm{~g} / \mathrm{L}$ & & \\
\hline
\end{tabular}

\section{STABILITY AND REACTIVITY}

Reactivity

Not reactive under normal conditions.

Chemical Stability

Stable under recommended storage conditions.

Possibility of Hazardous Reactions

None under normal processing.

Hazardous Polymerization Hazardous polymerization does not occur.

Conditions to Avoid

Keep out of reach of children.

Incompatible Materials

Strong acids. Strong bases. Strong oxidizers. Amines.

Hazardous Decomposition Products

None known based on information supplied.

\section{TOXICOLOGICAL INFORMATION}

Information on likely routes of exposure

Product Information

Eye Contact Causes serious eye irritation.

Skin Contact Avoid contact with skin.

Page $4 / 7$ 


\begin{tabular}{|c|c|c|c|}
\hline $\begin{array}{l}\text { Inhalation } \\
\text { Ingestion }\end{array}$ & $\begin{array}{l}\text { Avoid breathing vap } \\
\text { Do not taste or swa }\end{array}$ & & \\
\hline \multicolumn{4}{|l|}{ Component Information } \\
\hline Chemical Name & Oral LD50 & Dermal LD50 & Inhalation LC50 \\
\hline $\begin{array}{c}\text { DI Water } \\
7732-18-5 \\
\end{array}$ & $>90 \mathrm{~mL} / \mathrm{kg}$ (Rat) & - & - \\
\hline $\begin{array}{l}\text { Oxygen and Phosphorous } \\
\text { containing compound }\end{array}$ & - & $>4640 \mathrm{mg} / \mathrm{kg}$ (Rabbit) & - \\
\hline Trade Secret & $=620 \mathrm{mg} / \mathrm{kg}$ (Rat) & $>10 \mathrm{~g} / \mathrm{kg}$ (Rat) & - \\
\hline $\begin{array}{l}\text { Oxygen and Phosphorous } \\
\text { containing compound }\end{array}$ & $=1530 \mathrm{mg} / \mathrm{kg}$ (Rat) & $=2730 \mathrm{mg} / \mathrm{kg}$ (Rabbit) & $>850 \mathrm{mg} / \mathrm{m}^{2}$ (Rat) $1 \mathrm{~h}$ \\
\hline
\end{tabular}

Information on physical, chemical and toxicological effects

Symptoms

Please see section 4 of this SDS for symptoms.

Delayed and immediate effects as well as chronic effects from short and long-term exposure

Carcinogenicity

Based on the information provided, this product does not contain any carcinogens or potential carcinogens as listed by OSHA, IARC or NTP.

Numerical measures of toxicity

Not determined

\section{ECOLOGICAL INFORMATION}

Ecotoxicity

An environmental hazard cannot be excluded in the event of unprofessional handling or disposal.

\begin{tabular}{|c|c|c|c|c|}
\hline Chemical Name & Algae/aquatic plants & Fish & $\begin{array}{c}\text { Toxicity to } \\
\text { microorganisms }\end{array}$ & \begin{tabular}{c} 
Crustacea \\
\hline $\begin{array}{c}\text { Oxygen and Phosphorous } \\
\text { containing compound }\end{array}$
\end{tabular} \\
\hline
\end{tabular}

Persistence/Degradability

Not determined.

Bioaccumulation

Not determined.

Mobility

Not determined

Other Adverse Effects

Not determined

\section{DISPOSAL CONSIDERATIONS}

Waste Treatment Methods

Page 5/7 


$\begin{array}{ll}\text { Disposal of Wastes } & \begin{array}{l}\text { Disposal should be in accordance with applicable regional, national and local laws and } \\ \text { regulations. }\end{array} \\ \text { Contaminated Packaging } & \begin{array}{l}\text { Disposal should be in accordance with applicable regional, national and local laws and } \\ \text { regulations. }\end{array}\end{array}$

California Hazardous Waste Status

\begin{tabular}{|c|c|}
\hline Chemical Name & California Hazardous Waste Status \\
\hline Oxygen and Phosphorous containing compound & Corrosive \\
\hline
\end{tabular}

\section{TRANSPORT INFORMATION}

$\underline{\text { Note }}$

Please see current shipping paper for most up to date shipping information, including exemptions and special circumstances.

DOT

Not regulated

IATA

Not regulated

IMDG

Not regulated

\section{REGULATORY INFORMATION}

International Inventories

\begin{tabular}{|c|c|c|c|c|c|c|c|c|c|c|}
\hline Chemical Name & TSCA & DSL & NDSL & EINECS & ELINCS & ENCS & IECSC & KECL & PICCS & AICS \\
\hline DI Water & Present & $\mathrm{X}$ & & Present & & & $\mathrm{X}$ & Present & $\mathrm{X}$ & $\mathrm{X}$ \\
\hline $\begin{array}{c}\text { Oxygen and Phosphorous } \\
\text { containing compound }\end{array}$ & Present & $\mathrm{X}$ & & Present & & Present & $\mathrm{X}$ & Present & $\mathrm{X}$ & $\mathrm{X}$ \\
\hline
\end{tabular}

Legend:

TSCA - Unted States Toxic Substances Control Act Section 8(b) Inventory

DSLNDSL - Canaclan Domesdic Substances L/st/Non-Domestic Substances L/st

EINECSIELINCS - European Inventory of Existing Chemical Substances European LIst of Nothed Chemlcal Substances

ENCS - Japan Existing and New Chemical Substances

IECSC - China inventory of Existing Chemical Substances

KECL - Korean Existing and Evaluated Chemical Substances

PICCS - Philippines inventory of Chemicals and Chemlcal Substances

AICS - Australlan inventory of Chemical Substances

\section{US Federal Regulations}

\begin{tabular}{|c|c|c|c|}
\hline Chemical Name & Hazardous Substances RQs & CERCLA/SARA RQ & Reportable Quantity (RQ) \\
\hline $\begin{array}{c}\text { Oxygen and Phosphorous } \\
\text { containing compound }\end{array}$ & $5000 \mathrm{lb}$ & & RQ $5000 \mathrm{lb}$ final RQ \\
& & & RQ 2270 kg final RQ \\
\hline
\end{tabular}

SARA 313

Not determined

\begin{tabular}{|c|c|c|c|c|}
\hline Chemical Name & $\begin{array}{c}\text { CWA - Reportable } \\
\text { Quantities }\end{array}$ & CWA - Toxic Pollutants & CWA - Priority Pollutants & $\begin{array}{c}\text { CWA - Hazardous } \\
\text { Substances }\end{array}$ \\
\hline $\begin{array}{c}\text { Oxygen and Phosphorous } \\
\text { containing compound }\end{array}$ & $5000 \mathrm{lb}$ & & & X \\
\hline
\end{tabular}

\section{US State Regulations}


U.S. State Right-to-Know Regulations

\begin{tabular}{|c|c|c|c|}
\hline Chemical Name & New Jersey & Massachusetts & Pennsylvania \\
\hline DI Water & & & $\mathrm{X}$ \\
\hline $7732-18-5$ & $\mathrm{X}$ & $\mathrm{X}$ & $\mathrm{X}$ \\
\hline $\begin{array}{c}\text { Oxygen and Phosphorous } \\
\text { containing compound }\end{array}$ & & & \\
\hline
\end{tabular}

\section{OTHER INFORMATION}

NFPA

HMIS

Health Hazards
1
Health Hazards
1

Flammability
0
Flammability
0

01-Jan-2012

15-Jan-2015

New format
Issue Date:

Revision Date:

Revision Note:

Instability
0
Physical Hazards
0

0

\author{
Special Hazards \\ Not determined \\ Personal Protection \\ B
}

Disclaimer

The information provided in this Safety Data Sheet is correct to the best of our knowledge, information and belief at the date of its publication. The information given is designed only as a guidance for safe handling, use, processing, storage, transportation, disposal and release and is not to be considered a warranty or quality specification. The information relates only to the specific material designated and may not be valid for such material used in combination with any other materials or in any process, unless specified in the text.

End of Safety Data Sheet 


\section{Section 2. Hazards identification}

Response

Storage

Disposal

Supplemental label elements
: Get medical attention if you feel unwell. IF SWALLOWED: Immediately call a POISON CENTER or physician. Do NOT induce vomiting.

: Store locked up. Protect from sunlight. Do not expose to temperatures exceeding 50 ${ }^{\circ} \mathrm{C} / 122{ }^{\circ} \mathrm{F}$. Store in a well-ventilated place.

: Dispose of contents and container in accordance with all local, regional, national and international regulations.

DELAYED EFFECTS FROM LONG TERM OVEREXPOSURE. Contains solvents which can cause permanent brain and nervous system damage. Intentional misuse by deliberately concentrating and inhaling the contents can be harmful or fatal. WARNING This product contains a chemical known to the State of California to cause cancer. FOR INDUSTRIAL USE ONLY.

Please refer to the SDS for additional information. Keep out of reach of children. Keep upright in a cool, dry place. Do not discard empty can in trash compactor.

Hazards not otherwise

: None known

classified

\section{Section 3. Composition/information on ingredients}

$\begin{array}{ll}\text { Substance/mixture } & \text { : Mixture } \\ \text { Other means of } & \text { : Not available. }\end{array}$

: Not available.

identification

CAS number/other identifiers

\begin{tabular}{|l|l|l|}
\hline Ingredient name & $\%$ by weight & CAS number \\
\hline Heavy Naphthenic Petroleum Oil & $\geq 25-\leq 50$ & $64742-52-5$ \\
Heavy Paraffinic Oil & $\geq 25-\leq 50$ & $64742-65-0$ \\
Propane & $\leq 10$ & $74-98-6$ \\
Butane & $\leq 5$ & $106-97-8$ \\
\hline
\end{tabular}

Any concentration shown as a range is to protect confidentiality or is due to batch variation.

There are no additional ingredients present which, within the current knowledge of the supplier and in the concentrations applicable, are classified as hazardous to health and hence require reporting in this section.

Occupational exposure limits, if available, are listed in Section 8.

\section{Section 4. First aid measures}

Description of necessary first aid measures

Eye contact

: Immediately flush eyes with plenty of water, occasionally lifting the upper and lower eyelids. Check for and remove any contact lenses. Continue to rinse for at least 10 minutes. Get medical attention following exposure or if feeling unwell.

Inhalation

: Remove victim to fresh air and keep at rest in a position comfortable for breathing. If not breathing, if breathing is irregular or if respiratory arrest occurs, provide artificial respiration or oxygen by trained personnel. It may be dangerous to the person providing aid to give mouth-to-mouth resuscitation. Get medical attention following exposure or if feeling unwell. If unconscious, place in recovery position and get medical attention immediately. Maintain an open airway. Loosen tight clothing such as a collar, tie, belt or waistband. In case of inhalation of decomposition products in a fire, symptoms may be delayed. The exposed person may need to be kept under medical surveillance for 48 hours.

Skin contact

: Flush contaminated skin with plenty of water. Remove contaminated clothing and shoes. Continue to rinse for at least 10 minutes. Get medical attention following exposure or if feeling unwell. Wash clothing before reuse. Clean shoes thoroughly before reuse.

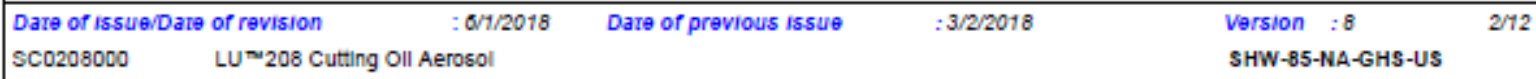




\title{
Section 4. First aid measures
}

Ingestion $\quad$ Get medical attention immediately. Call a poison center or physician. Wash out mouth
with water. Remove dentures if any. Remove victim to fresh air and keep at rest in a
position comfortable for breathing. If material has been swallowed and the exposed
person is conscious, give small quantities of water to drink. Stop if the exposed person
feels sick as vomiting may be dangerous. Aspiration hazard if swallowed. Can enter
lungs and cause damage. Do not induce vomiting. If vomiting occurs, the head should
be kept low so that vomit does not enter the lungs. Never give anything by mouth to an
unconscious person. If unconscious, place in recovery position and get medical
attention immediately. Maintain an open airway. Loosen tight clothing such as a collar,
tie, belt or waistband.

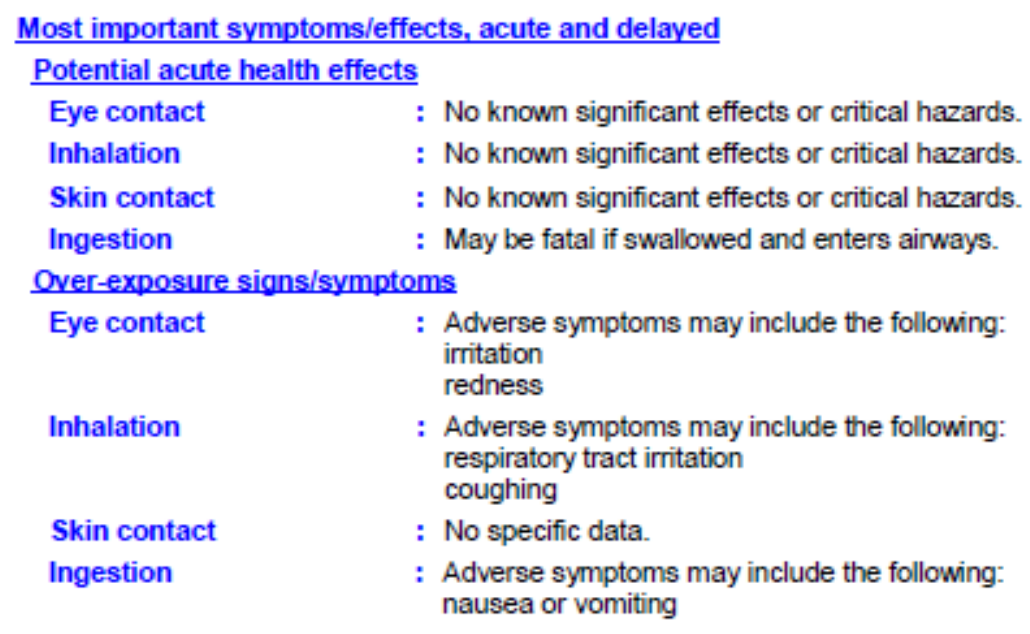

Indication of immediate medical attention and special treatment needed, if necessary
Notes to physician : : In case of inhalation of decomposition products in a fire, symptoms may be delayed. The exposed person may need to be kept under medical surveillance for 48 hours.
Specific treatments : No specific treatment.
Protection of first-aiders : No action shall be taken involving any personal risk or without suitable training. It may be dangerous to the person providing aid to give mouth-to-mouth resuscitation.

See toxicological information (Section 11)

\section{Section 5. Fire-fighting measures}

\author{
Extinguishing media \\ Suitable extinguishing \\ media \\ Unsuitable extinguishing \\ media \\ : Use an extinguishing agent suitable for the surrounding fire. \\ : None known.
}

Specific hazards arising from the chemical

Hazardous thermal decomposition products
: Extremely flammable aerosol. Runoff to sewer may create fire or explosion hazard. In a fire or if heated, a pressure increase will occur and the container may burst, with the risk of a subsequent explosion. Gas may accumulate in low or confined areas or travel a considerable distance to a source of ignition and flash back, causing fire or explosion. Bursting aerosol containers may be propelled from a fire at high speed.

: Decomposition products may include the following materials: carbon dioxide carbon monoxide carbonyl halides

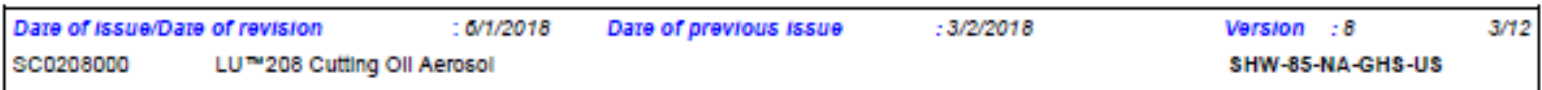




\title{
Section 5. Fire-fighting measures
}

$\begin{array}{ll}\begin{array}{l}\text { Special protective actions } \\ \text { for fire-fighters }\end{array} & \begin{array}{l}\text { : Promptly isolate the scene by removing all persons from the vicinity of the incident if } \\ \text { there is a fire. No action shall be taken involving any personal risk or without suitable } \\ \text { training. Move containers from fire area if this can be done without risk. Use water } \\ \text { spray to keep fire-exposed containers cool. }\end{array} \\ \begin{array}{ll}\text { Special protective } \\ \text { equipment for fire-fighters }\end{array} & \begin{array}{l}\text { : Fire-fighters should wear appropriate protective equipment and self-contained breathing } \\ \text { apparatus (SCBA) with a full face-piece operated in positive pressure mode. }\end{array}\end{array}$

\section{Section 6. Accidental release measures}

\begin{abstract}
Personal precautions, protective equipment and emergency procedures
For non-emergency : : No action shall be taken involving any personal risk or without suitable training. personnel Evacuate surrounding areas. Keep unnecessary and unprotected personnel from entering. In the case of aerosols being ruptured, care should be taken due to the rapid escape of the pressurized contents and propellant. If a large number of containers are ruptured, treat as a bulk material spillage according to the instructions in the clean-up section. Do not touch or walk through spilled material. Shut off all ignition sources. No flares, smoking or flames in hazard area. Avoid breathing vapor or mist. Provide adequate ventilation. Wear appropriate respirator when ventilation is inadequate. Put on appropriate personal protective equipment.
\end{abstract}

For emergency responders : If specialized clothing is required to deal with the spillage, take note of any information in Section 8 on suitable and unsuitable materials. See also the information in "For nonemergency personnel".

Environmental precautions : Avoid dispersal of spilled material and runoff and contact with soil, waterways, drains and sewers. Inform the relevant authorities if the product has caused environmental pollution (sewers, waterways, soil or air).

Methods and materials for containment and cleaning up

Small spill $\quad$ : Stop leak if without risk. Move containers from spill area. Use spark-proof tools and explosion-proof equipment. Dilute with water and mop up if water-soluble. Alternatively, or if water-insoluble, absorb with an inert dry material and place in an appropriate waste disposal container. Dispose of via a licensed waste disposal contractor.

Large spill

: Stop leak if without risk. Move containers from spill area. Use spark-proof tools and explosion-proof equipment. Approach release from upwind. Prevent entry into sewers, water courses, basements or confined areas. Wash spillages into an effluent treatment plant or proceed as follows. Contain and collect spillage with non-combustible, absorbent material e.g. sand, earth, vermiculite or diatomaceous earth and place in container for disposal according to local regulations (see Section 13). Dispose of via a licensed waste disposal contractor. Contaminated absorbent material may pose the same hazard as the spilled product. Note: see Section 1 for emergency contact information and Section 13 for waste disposal.

\section{Section 7. Handling and storage}

\section{Precautions for safe handling}

Protective measures

Advice on general occupational hygiene
: Put on appropriate personal protective equipment (see Section 8). Pressurized container: protect from sunlight and do not expose to temperatures exceeding $50^{\circ} \mathrm{C}$. Do not pierce or burn, even after use. Do not breathe vapor or mist. Do not swallow. Avoid contact with eyes, skin and clothing. Avoid breathing gas. Use only with adequate ventilation. Wear appropriate respirator when ventilation is inadequate. Store and use away from heat, sparks, open flame or any other ignition source. Use explosion-proof electrical (ventilating, lighting and material handling) equipment. Use only non-sparking tools. Empty containers retain product residue and can be hazardous.

: Eating, drinking and smoking should be prohibited in areas where this material is handled, stored and processed. Workers should wash hands and face before eating, drinking and smoking. Remove contaminated clothing and protective equipment before entering eating areas. See also Section 8 for additional information on hygiene measures.

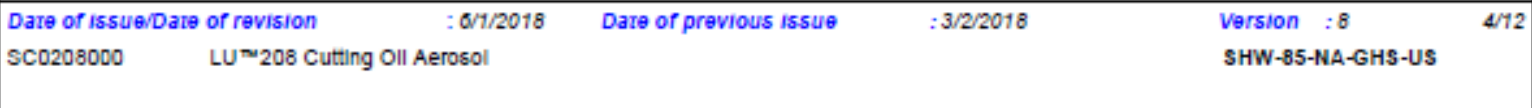




\section{Section 7. Handling and storage}

Conditions for safe storage, : Store in accordance with local regulations. Store away from direct sunlight in a dry, cool including any

incompatibilities and well-ventilated area, away from incompatible materials (see Section 10) and food and drink. Protect from sunlight. Store locked up. Eliminate all ignition sources. Use appropriate containment to avoid environmental contamination. See Section 10 for incompatible materials before handling or use.

\section{Section 8. Exposure controls/personal protection}

\section{Control parameters}

Occupational exposure limits (OSHA United States)

\begin{tabular}{|c|c|}
\hline Ingredient name & Exposure limits \\
\hline Heavy Naphthenic Petroleum Oil & $\begin{array}{l}\text { ACGIH TLV (United States, 3/2017). } \\
\text { TWA: } 5 \mathrm{mg} / \mathrm{m}^{3} 8 \text { hours. Form: Inhalable } \\
\text { fraction } \\
\text { OSHA PEL (United States, 6/2016). } \\
\text { TWA: } 5 \mathrm{mg} / \mathrm{m}^{3} 8 \text { hours. } \\
\text { NIOSH REL (United States, 10/2016). } \\
\text { TWA: } 5 \mathrm{mg} / \mathrm{m}^{3} 10 \text { hours. Form: Mist } \\
\text { STEL: } 10 \mathrm{mg} / \mathrm{m}^{3} 15 \text { minutes. Form: Mist }\end{array}$ \\
\hline Heavy Paraffinic Oil & $\begin{array}{l}\text { ACGIH TLV (United States, 3/2017). } \\
\text { TWA: } 5 \mathrm{mg} / \mathrm{m}^{3} 8 \text { hours. Form: Inhalable } \\
\text { fraction } \\
\text { OSHA PEL (United States, 6/2016). } \\
\text { TWA: } 5 \mathrm{mg} / \mathrm{m}^{3} 8 \text { hours. } \\
\text { NIOSH REL (United States, 10/2016). } \\
\text { TWA: } 5 \mathrm{mg} / \mathrm{m}^{3} 10 \text { hours. Form: Mist } \\
\text { STEL: } 10 \mathrm{mg} / \mathrm{m}^{3} 15 \text { minutes. Form: Mist }\end{array}$ \\
\hline Propane & $\begin{array}{l}\text { NIOSH REL (United States, 10/2016). } \\
\text { TWA: } 1000 \mathrm{ppm} 10 \text { hours. } \\
\text { TWA: } 1800 \mathrm{mg} / \mathrm{m}^{3} 10 \text { hours. } \\
\text { OSHA PEL (United States, 6/2016). } \\
\text { TWA: } 1000 \mathrm{ppm} 8 \text { hours. } \\
\text { TWA: } 1800 \mathrm{mg} / \mathrm{m}^{3} 8 \text { hours. } \\
\text { ACGIH TLV (United States, 3/2017). Oxygen } \\
\text { Depletion [Asphyxiant]. }\end{array}$ \\
\hline Butane & $\begin{array}{l}\text { NIOSH REL (United States, 10/2016). } \\
\text { TWA: } 800 \text { ppm } 10 \text { hours. } \\
\text { TWA: } 1900 \text { mg/m } 10 \text { hours. } \\
\text { ACGIH TLV (United States, 3/2017). } \\
\text { STEL: } 1000 \text { ppm } 15 \text { minutes. }\end{array}$ \\
\hline
\end{tabular}

Occupational exposure limits (Canada)

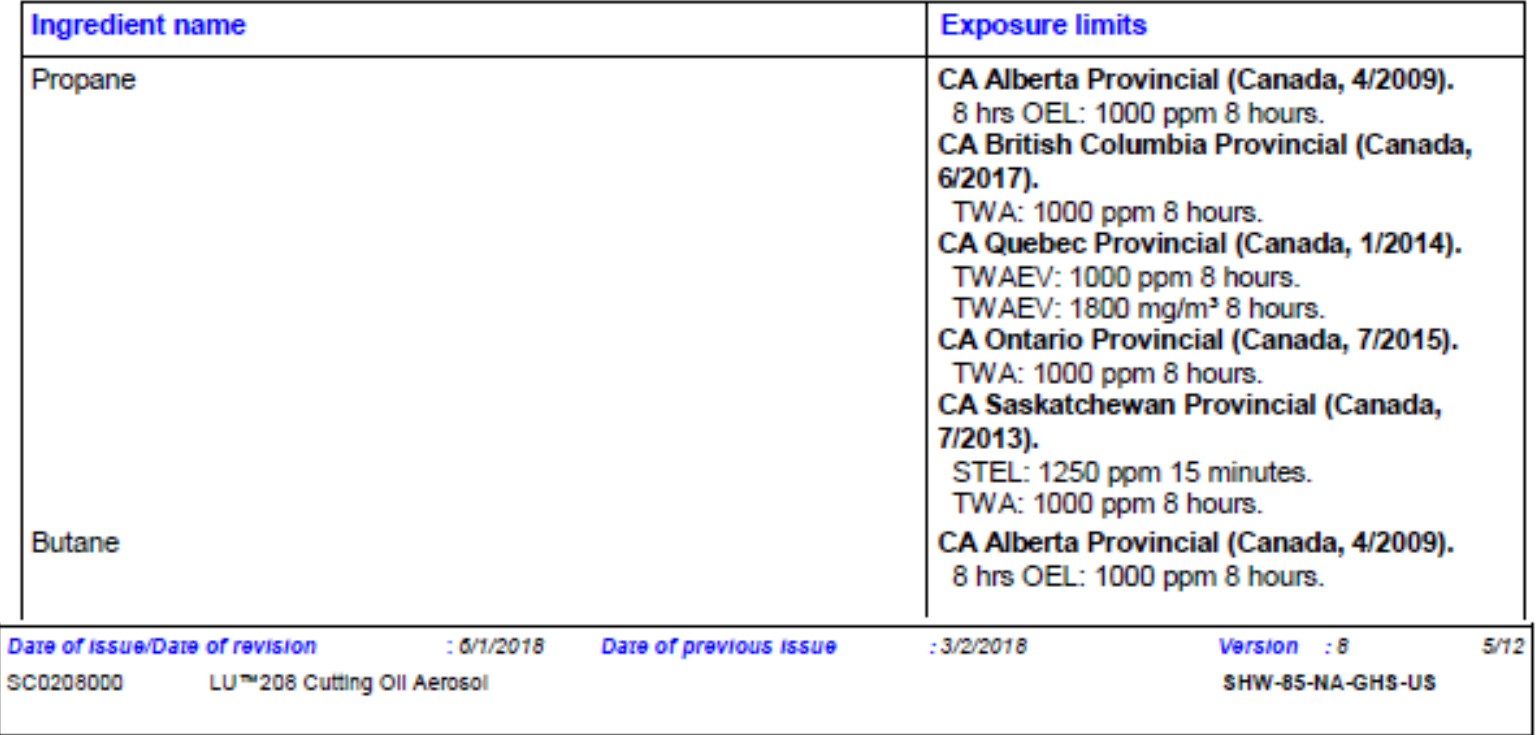




\section{Section 8. Exposure controls/personal protection}

\begin{tabular}{|c|c|}
\hline & $\begin{array}{l}\text { CA British Columbia Provincial (Canada, } \\
\text { 6/2017). } \\
\text { TWA: } 600 \text { ppm } 8 \text { hours. } \\
\text { STEL: } 750 \text { ppm } 15 \text { minutes. } \\
\text { CA Quebec Provincial (Canada, 1/2014). } \\
\text { TWAEV: } 800 \text { ppm } 8 \text { hours. } \\
\text { TWAEV: } 1900 \text { mg/m³ } 8 \text { hours. } \\
\text { CA Ontario Provincial (Canada, 7/2015). } \\
\text { TWA: } 800 \text { ppm } 8 \text { hours. } \\
\text { CA Saskatchewan Provincial (Canada, } \\
\text { 7/2013). } \\
\text { STEL: } 1250 \text { ppm } 15 \text { minutes. } \\
\text { TWA: } 1000 \text { ppm } 8 \text { hours. }\end{array}$ \\
\hline \multicolumn{2}{|c|}{ Occupational exposure limits (Mexico) } \\
\hline Ingredient name & Exposure limits \\
\hline $\begin{array}{l}\text { Propane } \\
\text { Butane }\end{array}$ & $\begin{array}{l}\text { NOM-010-STPS-2014 (Mexico, 4/2016). } \\
\text { TWA: } 1000 \text { ppm } 8 \text { hours. } \\
\text { NOM-010-STPS-2014 (Mexico, 4/2016). } \\
\text { TWA: } 1000 \text { ppm } 8 \text { hours. }\end{array}$ \\
\hline
\end{tabular}

Appropriate engineering controls

Environmental exposure controls
: Use only with adequate ventilation. If user operations generate dust, fumes, gas, vapor or mist, use process enclosures, local exhaust ventilation or other engineering controls to keep worker exposure to airborne contaminants below any recommended or statutory limits. The engineering controls also need to keep gas, vapor or dust concentrations below any lower explosive limits. Use explosion-proof ventilation equipment.

: Emissions from ventilation or work process equipment should be checked to ensure they comply with the requirements of environmental protection legislation. In some cases, fume scrubbers, filters or engineering modifications to the process equipment will be necessary to reduce emissions to acceptable levels.

\section{Individual protection measures}

Hygiene measures

: Wash hands, forearms and face thoroughly after handling chemical products, before eating, smoking and using the lavatory and at the end of the working period. Appropriate techniques should be used to remove potentially contaminated clothing. Wash contaminated clothing before reusing. Ensure that eyewash stations and safety showers are close to the workstation location.

Eye/face protection

: Safety eyewear complying with an approved standard should be used when a risk assessment indicates this is necessary to avoid exposure to liquid splashes, mists, gases or dusts. If contact is possible, the following protection should be wom, unless the assessment indicates a higher degree of protection: safety glasses with sideshields.

Skin protection

Hand protection

Body protection

Other skin protection
: Chemical-resistant, impervious gloves complying with an approved standard should be wom at all times when handling chemical products if a risk assessment indicates this is necessary. Considering the parameters specified by the glove manufacturer, check during use that the gloves are still retaining their protective properties. It should be noted that the time to breakthrough for any glove material may be different for different glove manufacturers. In the case of mixtures, consisting of several substances, the protection time of the gloves cannot be accurately estimated.

: Personal protective equipment for the body should be selected based on the task being performed and the risks involved and should be approved by a specialist before handling this product. When there is a risk of ignition from static electricity, wear antistatic protective clothing. For the greatest protection from static discharges, clothing should include anti-static overalls, boots and gloves.

: Appropriate footwear and any additional skin protection measures should be selected based on the task being performed and the risks involved and should be approved by a specialist before handling this product.

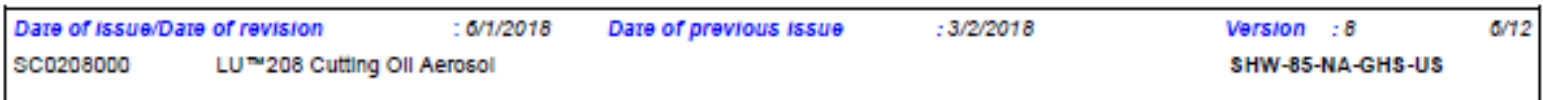




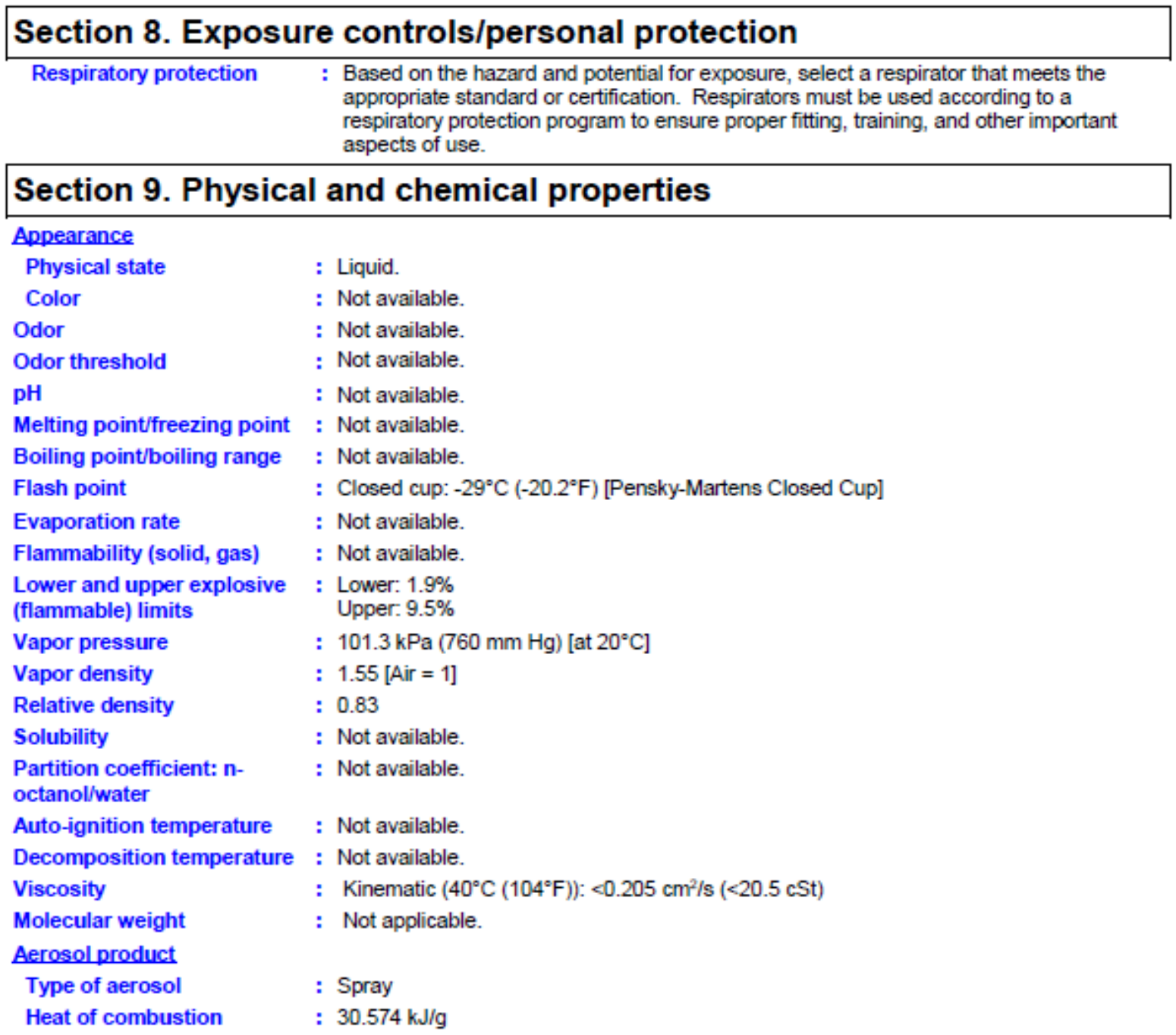

\section{Section 10. Stability and reactivity}

\begin{tabular}{|c|c|}
\hline Reactivity & : No specific test data related to reactivity available for this product or its ingredients. \\
\hline Chemical stability & : The product is stable. \\
\hline $\begin{array}{l}\text { Possibility of hazardous } \\
\text { reactions }\end{array}$ & : Under normal conditions of storage and use, hazardous reactions will not occur. \\
\hline Conditions to avoid & : Avoid all possible sources of ignition (spark or flame). \\
\hline Incompatible materials & : No specific data. \\
\hline $\begin{array}{l}\text { Hazardous decomposition } \\
\text { products }\end{array}$ & $\begin{array}{l}\text { : Under normal conditions of storage and use, hazardous decomposition products should } \\
\text { not be produced. }\end{array}$ \\
\hline
\end{tabular}

Under normal conditions of storage and use, hazardous decomposition products should

Date of issue/Date of revision $\quad:$ 6/1/2018 $\quad$ Date of previous issue $\quad: 3 / 2 / 2018$ Version : 8 SHW-85-NA-GHS-US

SC0208000 LU 208 Cutting Oll Aerosol SHW-85-NA-GHS-US




\section{Section 11. Toxicological information}

Information on toxicological effects

Acute toxicity

\begin{tabular}{|l|l|l|l|l|}
\hline Product/ingredient name & Result & Species & Dose & Exposure \\
\hline Heavy Naphthenic Petroleum & LD50 Oral & Rat & $>5000 \mathrm{mg} / \mathrm{kg}^{\prime}$ & - \\
Oil & LD50 Dermal & Rabbit & $>5000 \mathrm{mg} / \mathrm{kg}$ & - \\
Beavy Paraffinic Oil & LD50 Oral & Rat & $>5000 \mathrm{mg} / \mathrm{kg}^{3}$ & - \\
Butane & LC50 Inhalation Vapor & Rat & $658000 \mathrm{mg}^{3}$ & 4 hours \\
\hline
\end{tabular}

Irritation/Corrosion

\begin{tabular}{|l|l|l|l|l|l|}
\hline Product/ingredient name & Result & Species & Score & Exposure & Observation \\
\hline $\begin{array}{l}\text { Heavy Naphthenic Petroleum } \\
\text { Oil }\end{array}$ & Skin - Severe imitant & Rabbit & - & $\begin{array}{l}500 \\
\text { milligrams }\end{array}$ & - \\
\hline
\end{tabular}

Sensitization

Not available.

Mutagenicity

Not available.

Carcinogenicity

Not available.

Reproductive toxicity

Not available.

Teratogenicity

Not available.

Specific target organ toxicity (single exposure)

\begin{tabular}{|l|l|l|l|}
\hline Name & Category & $\begin{array}{l}\text { Route of } \\
\text { exposure }\end{array}$ & Target organs \\
\hline Propane & Category 3 & Not applicable. & $\begin{array}{l}\text { Respiratory tract } \\
\text { irritation and } \\
\text { Narcotic effects } \\
\text { Respiratory tract } \\
\text { irritation and } \\
\text { Narcotic effects }\end{array}$ \\
\hline
\end{tabular}

\section{Specific target organ toxicity (repeated exposure)}

\begin{tabular}{|l|l|l|l|}
\hline Name & Category & $\begin{array}{l}\text { Route of } \\
\text { exposure }\end{array}$ & Target organs \\
\hline $\begin{array}{l}\text { Propane } \\
\text { Butane }\end{array}$ & $\begin{array}{l}\text { Category 2 } \\
\text { Category 2 }\end{array}$ & $\begin{array}{l}\text { Not determined } \\
\text { Not determined }\end{array}$ & $\begin{array}{l}\text { Not determined } \\
\text { Not determined }\end{array}$ \\
\hline
\end{tabular}

Aspiration hazard

\begin{tabular}{|l|l|}
\hline Name & Result \\
\hline $\begin{array}{l}\text { Propane } \\
\text { Butane }\end{array}$ & ASPIRATION HAZARD - Category 1 \\
\hline
\end{tabular}

Information on the likely : Not available.

routes of exposure

Potential acute health effects

Eye contact $\quad$ : No known significant effects or critical hazards.

Inhalation : No known significant effects or critical hazards.

Skin contact : No known significant effects or critical hazards.

\begin{tabular}{|llllll}
\hline Date of issue/Date of revision & $: 0 / 1 / 2018$ & Date of previous issue & $: 3 / 2 / 2018$ & Version & $: 8$
\end{tabular}

SC0208000 LU 208 Cutting Oll Aerosol SHW-85-NA-GHS-US 
Ingestion : May be fatal if swallowed and enters airways.

Symptoms related to the physical, chemical and toxicological characteristics

$\begin{array}{ll}\text { Eye contact } & \begin{array}{l}\text { Adverse symptoms may include the following: } \\ \text { irritation } \\ \text { redness }\end{array} \\ \text { Inhalation } & \begin{array}{l}\text { Adverse symptoms may include the following: } \\ \text { respiratory tract irritation } \\ \text { coughing }\end{array} \\ \text { Skin contact } & : \begin{array}{l}\text { No specific data. } \\ \text { Ingestion }\end{array} \\ \text { : Adverse symptoms may include the following: } \\ \text { nausea or vomiting }\end{array}$

Delayed and immediate effects and alse chronic effects from short and long term exposure

Short term exposure

$\begin{array}{ll}\begin{array}{l}\text { Potential immediate } \\ \text { effects }\end{array} & \text { : Not available. } \\ \text { Potential delayed effects } & \text { : Not available. } \\ \text { Long term exposure } & \\ \begin{array}{l}\text { Potential immediate } \\ \text { effects }\end{array} & \text { : Not available. } \\ \text { Potential delayed effects } & \text { : Not available. }\end{array}$

Potential chronic health effects

Not available.

General : May cause damage to organs through prolonged or repeated exposure.

Carcinogenicity : No known significant effects or critical hazards.

Mutagenicity : No known significant effects or critical hazards.

Teratogenicity : No known significant effects or critical hazards.

Developmental effects : No known significant effects or critical hazards.

Fertility effects : No known significant effects or critical hazards.

Numerical measures of toxicity

Acute toxicity estimates

Not available.

\section{Section 12. Ecological information}

Toxicity

Not available.

Persistence and degradability

Not available.

Bioaccumulative potential

Not available.

Mobility in soil

Soil/water partition : Not available.

coefficient $\left(K_{\circ}\right)$

Other adverse effects

: No known significant effects or critical hazards.

Date of issuerDate of revision : 6/1/2018 Date of previous issue

SC0208000 LU 208 Cutting Oll Aerosol SHW-85-NA-GHS-US 


\section{Section 16. Other information}

referring to the supplier and obtaining written handling instructions. Due to the proliferation of sources for information such as manufacturer-specific SDS, the manufacturer cannot be responsible for SDSs obtained from any other source. 


\title{
SAFETY DATA SHEET
}

Biodegradable Penetrating Oil (Aerosol)

\section{Section 1. Identification}

\author{
GHS product identifier : Biodegradable Penetrating Oil (Aerosol) \\ Other means of : Not available. \\ identification \\ Product type : Aerosol. \\ Relevant identified uses of the substance or mixture and uses advised against \\ $\begin{array}{ll}\text { Product use } & \text { : Biodegradable lubricating oil. } \\ \text { Area of application } & \text { : Industrial applications. }\end{array}$ \\ Supplier/Manufacturer : LUBRIPLATE® Lubricants Co. \\ 129 Lockwood St. \\ Newark, NJ 07105 \\ Telephone no.: 1-973-589-9150 \\ e-mail address of person : SDS@lubriplate.com \\ responsible for this SDS \\ Emergency telephone \\ number (with hours of \\ : CHEM-TEL 1-800-255-3924 (24 hour) \\ operation)
}

\section{Section 2. Hazards identification}

\begin{tabular}{|c|c|}
\hline OSHA/HCS status & $\begin{array}{l}\text { : This material is considered hazardous by the OSHA Hazard Communication Standard } \\
\text { ( } 29 \text { CFR 1910.1200). }\end{array}$ \\
\hline \multirow[t]{2}{*}{$\begin{array}{l}\text { Classification of the } \\
\text { substance or mixture }\end{array}$} & $\begin{array}{l}\text { : H280 GASES UNDER PRESSURE - Compressed gas } \\
\text { H304 ASPIRATION HAZARD - Category } 1\end{array}$ \\
\hline & Percentage of the mixture consisting of ingredient(s) of unknown toxicity. $94.3 \%$ \\
\hline \multicolumn{2}{|l|}{ GHS label elements } \\
\hline \multicolumn{2}{|l|}{ Hazard pictograms } \\
\hline Signal word & : Danger \\
\hline Hazard statements & $\begin{array}{l}\text { : H280 - Contains gas under pressure; may explode if heated. } \\
\text { H304 - May be fatal if swallowed and enters airways. }\end{array}$ \\
\hline \multicolumn{2}{|c|}{ Precautionary statements } \\
\hline Prevention & : Not applicable. \\
\hline Response & $\begin{array}{l}\text { : P301 + P310 + P331 - IF SWALLOWED: Immediately call a POISON CENTER or } \\
\text { physician. Do NOT induce vomiting. }\end{array}$ \\
\hline Storage & $\begin{array}{l}\text { : P405 - Store locked up. } \\
\text { P410 - Protect from sunlight. } \\
\text { P403 - Store in a well-ventilated place. }\end{array}$ \\
\hline Disposal & $\begin{array}{l}\text { : P501 - Dispose of contents and container in accordance with all local, regional, national } \\
\text { and international regulations. }\end{array}$ \\
\hline $\begin{array}{l}\text { Hazards not otherwise } \\
\text { classified }\end{array}$ & : Defatting to the skin. \\
\hline
\end{tabular}

Date of issue/Date of revision

:07/03/2015 Date of previous issue

: No previous validation

Version : 1 


\section{Section 3. Composition/information on ingredients}

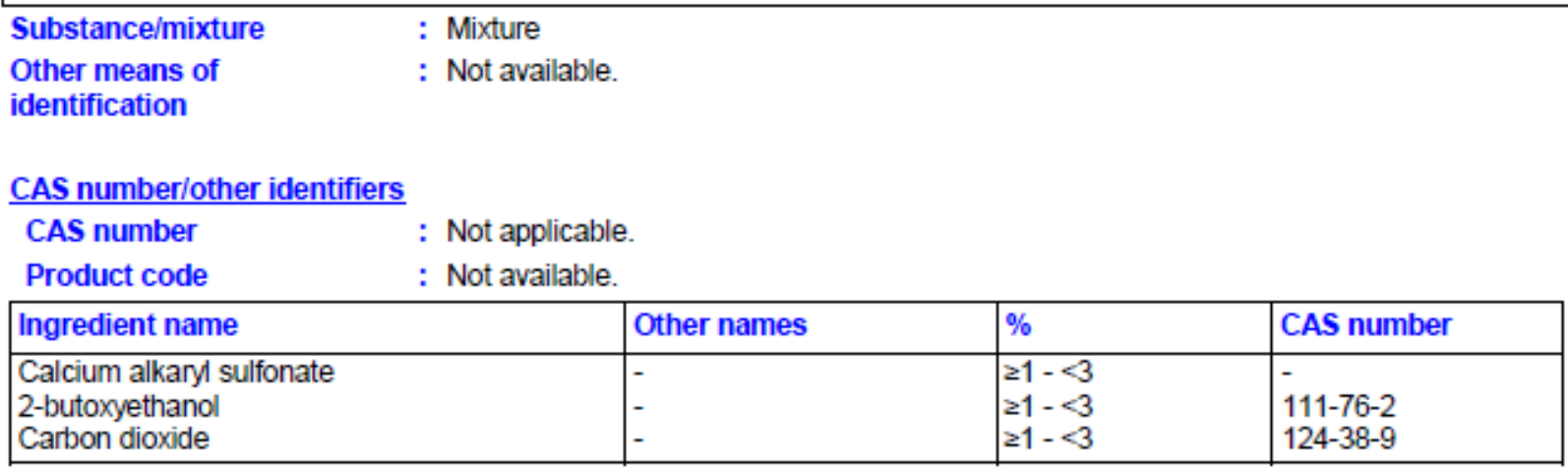

Any concentration shown as a range is to protect confidentiality or is due to batch variation.

There are no additional ingredients present which, within the current knowledge of the supplier and in the concentrations applicable, are classified as hazardous to health and hence require reporting in this section.

\section{Section 4. First aid measures}

\section{Description of necessary first aid measures}

Eye contact

Inhalation

Skin contact

Ingestion

: Immediately flush eyes with plenty of water, occasionally lifting the upper and lower eyelids. Check for and remove any contact lenses. Continue to rinse for at least 10 minutes. Get medical attention if irnitation occurs.

: Remove victim to fresh air and keep at rest in a position comfortable for breathing. If not breathing, if breathing is irregular or if respiratory arrest occurs, provide artificial respiration or oxygen by trained personnel. It may be dangerous to the person providing aid to give mouth-to-mouth resuscitation. Get medical attention if adverse health effects persist or are severe. If unconscious, place in recovery position and get medical attention immediately. Maintain an open airway. Loosen tight clothing such as a collar, tie, belt or waistband.

: Flush contaminated skin with plenty of water. Remove contaminated clothing and shoes. Get medical attention if symptoms occur. Wash clothing before reuse. Clean shoes thoroughly before reuse.

: Get medical attention immediately. Call a poison center or physician. Wash out mouth with water. Remove dentures if any. Remove victim to fresh air and keep at rest in a position comfortable for breathing. If material has been swallowed and the exposed person is conscious, give small quantities of water to drink. Stop if the exposed person feels sick as vomiting may be dangerous. Aspiration hazard if swallowed. Can enter lungs and cause damage. Do not induce vomiting. If vomiting occurs, the head should be kept low so that vomit does not enter the lungs. Never give anything by mouth to an unconscious person. If unconscious, place in recovery position and get medical attention immediately. Maintain an open airway. Loosen tight clothing such as a collar, tie, belt or waistband.

Most important symptoms/effects, acute and delayed

Potential acute health effects

Eye contact $\quad$ : No known significant effects or critical hazards.

Inhalation : No known significant effects or critical hazards.

Skin contact : No known significant effects or critical hazards.

Ingestion : May be fatal if swallowed and enters airways.

Over-exposure signs/symptoms

Eye contact

: Adverse symptoms may include the following: irritation

redness

Date of issue/Date of revision

: 07/03/2015 Date of previous issue

: No previous validation

Version : 
Biodegradable Penetrating Oil (Aerosol)

\section{Section 4. First aid measures}

$\begin{array}{ll}\text { Inhalation } & \begin{array}{l}: \text { Adverse symptoms may include the following: } \\ \text { respiratory tract irritation } \\ \text { coughing }\end{array} \\ \text { Skin contact } & : \begin{array}{l}\text { No specific data. } \\ \text { Ingestion }\end{array} \\ & \begin{array}{l}\text { Adverse symptoms may include the following: } \\ \text { nausea or vomiting }\end{array}\end{array}$

Indication of immediate medical attention and special treatment needed, if necessary
Notes to physician
: Treat symptomatically. Contact poison treatment specialist immediately if large quantities have been ingested or inhaled.
Specific treatments
: No specific treatment.
Protection of first-aiders : No action shall be taken involving any personal risk or without suitable training. It may be dangerous to the person providing aid to give mouth-to-mouth resuscitation.

\section{See toxicological information (Section 11)}

\section{Section 5. Fire-fighting measures}

\section{Extinguishing media \\ Suitable extinguishing media \\ Unsuitable extinguishing media \\ Specific hazards arising from the chemical \\ Hazardous thermal decomposition products}

Special protective actions for fire-fighters

Special protective equipment for fire-fighters

Remark
: Use an extinguishing agent suitable for the surrounding fire.

: Do not use water jet.

: In a fire or if heated, a pressure increase will occur and the container may burst. Bursting aerosol containers may be propelled from a fire at high speed.

: Decomposition products may include the following materials: carbon dioxide carbon monoxide sulfur oxides metal oxide/oxides

: Promptly isolate the scene by removing all persons from the vicinity of the incident if there is a fire. No action shall be taken involving any personal risk or without suitable training. Move containers from fire area if this can be done without risk. Use water spray to keep fire-exposed containers cool.

: Fire-fighters should wear appropriate protective equipment and self-contained breathing apparatus (SCBA) with a full face-piece operated in positive pressure mode.

: Pressurized container: may burst if heated.

\section{Section 6. Accidental release measures}

Personal precautions, protective equipment and emergency procedures

For non-emergency personnel

: No action shall be taken involving any personal risk or without suitable training. Evacuate surrounding areas. Keep unnecessary and unprotected personnel from entering. In the case of aerosols being ruptured, care should be taken due to the rapid escape of the pressurized contents and propellant. If a large number of containers are ruptured, treat as a bulk material spillage according to the instructions in the clean-up section. Do not touch or walk through spilled material. Avoid breathing vapor or mist. Provide adequate ventilation. Wear appropriate respirator when ventilation is inadequate. Put on appropriate personal protective equipment.

For emergency responders : If specialised clothing is required to deal with the spillage, take note of any information in Section 8 on suitable and unsuitable materials. See also the information in "For nonemergency personnel". 
Biodegradable Penetrating Oil (Aerosol)

\section{Section 6. Accidental release measures}

Environmental precautions : Avoid dispersal of spilled material and runoff and contact with soil, waterways, drains and sewers. Inform the relevant authorities if the product has caused environmental pollution (sewers, waterways, soil or air).

Methods and materials for containment and cleaning up

Small spill

: Stop leak if without risk. Move containers from spill area. Dilute with water and mop up if water-soluble. Altematively, or if water-insoluble, absorb with an inert dry material and place in an appropriate waste disposal container. Dispose of via a licensed waste disposal contractor.

Large spill

: Stop leak if without risk. Move containers from spill area. Approach release from upwind. Prevent entry into sewers, water courses, basements or confined areas. Wash spillages into an effluent treatment plant or proceed as follows. Contain and collect spillage with non-combustible, absorbent material e.g. sand, earth, vermiculite or diatomaceous earth and place in container for disposal according to local regulations (see Section 13). Dispose of via a licensed waste disposal contractor. Contaminated absorbent material may pose the same hazard as the spilled product. Note: see Section 1 for emergency contact information and Section 13 for waste disposal.

\section{Section 7. Handling and storage}

\section{Precautions for safe handling}

Protective measures

: Put on appropriate personal protective equipment (see Section 8). Pressurized container: protect from sunlight and do not expose to temperatures exceeding $50^{\circ} \mathrm{C}$. Do not pierce or burn, even after use. Do not swallow. Avoid contact with eyes, skin and clothing. Avoid breathing gas. Avoid breathing vapor or mist. Use only with adequate ventilation. Wear appropriate respirator when ventilation is inadequate. Empty containers retain product residue and can be hazardous.

Advice on general occupational hygiene

: Eating, drinking and smoking should be prohibited in areas where this material is handled, stored and processed. Workers should wash hands and face before eating, drinking and smoking. Remove contaminated clothing and protective equipment before entering eating areas. See also Section 8 for additional information on hygiene measures.

Conditions for safe storage, : Store in accordance with local regulations. Store away from direct sunlight in a dry, cool including any

incompatibilities and well-ventilated area, away from incompatible materials (see Section 10) and food and drink. Protect from sunlight. Store locked up. Use appropriate containment to avoid environmental contamination.

\section{Section 8. Exposure controls/personal protection}

\section{Control parameters}

Occupational exposure limits

\begin{tabular}{|l|l|}
\hline Ingredient name & Exposure limits \\
\hline 2-butoxyethanol & OSHA PEL 1989 (United States, 3/1989). \\
& Absorbed through skin. \\
& TWA: $25 \mathrm{ppm} 8$ hours. \\
& TWA: $120 \mathrm{mg} / \mathrm{m}^{3} 8$ hours. \\
& NIOSH REL (United States, 10/2013). \\
& Absorbed through skin. \\
& TWA: $5 \mathrm{ppm} 10$ hours. \\
& TWA: $24 \mathrm{mg} / \mathrm{m}^{3} 10$ hours. \\
& ACGIH TLV (United States, 4/2014). \\
& TWA: $20 \mathrm{ppm} 8$ hours. \\
& OSHA PEL (United States, 2/2013). \\
& Absorbed through skin. \\
& TWA: $50 \mathrm{ppm} 8$ hours. \\
& TWA: $240 \mathrm{mg} / \mathrm{m}^{3} 8$ hours. \\
\hline
\end{tabular}

\begin{tabular}{|lllllll}
\hline Date of issue/Date of revision & $: 07 / 03 / 2015$ & Date of previous issue & :No previous validation & Version & $: 1$ & $4 / 12$ \\
\hline
\end{tabular}


Biodegradable Penetrating Oil (Aerosol)

\section{Section 8. Exposure controls/personal protection}

Appropriate engineering : Use only with adequate ventilation. If user operations generate dust, fumes, gas, vapor controls or mist, use process enclosures, local exhaust ventilation or other engineering controls to keep worker exposure to airborne contaminants below any recommended or statutory limits.

Environmental exposure controls

: Emissions from ventilation or work process equipment should be checked to ensure they comply with the requirements of environmental protection legislation. In some cases, fume scrubbers, filters or engineering modifications to the process equipment will be necessary to reduce emissions to acceptable levels.

Individual protection measures

Hygiene measures

: Wash hands, forearms and face thoroughly after handling chemical products, before eating, smoking and using the lavatory and at the end of the working period. Appropriate techniques should be used to remove potentially contaminated clothing. Wash contaminated clothing before reusing. Ensure that eyewash stations and safety showers are close to the workstation location.

Eye/face protection

: Safety eyewear complying with an approved standard should be used when a risk assessment indicates this is necessary to avoid exposure to liquid splashes, mists, gases or dusts. If contact is possible, the following protection should be worn, unless the assessment indicates a higher degree of protection: safety glasses with sideshields.

Skin protection Hand protection

Body protection

Other skin protection

Respiratory protection
: Chemical-resistant, impervious gloves complying with an approved standard should be wom at all times when handling chemical products if a risk assessment indicates this is necessary. Considering the parameters specified by the glove manufacturer, check during use that the gloves are still retaining their protective properties. It should be noted that the time to breakthrough for any glove material may be different for different glove manufacturers. In the case of mixtures, consisting of several substances, the protection time of the gloves cannot be accurately estimated.

: Personal protective equipment for the body should be selected based on the task being performed and the risks involved and should be approved by a specialist before handling this product.

: Appropriate footwear and any additional skin protection measures should be selected based on the task being performed and the risks involved and should be approved by a specialist before handling this product.

: Use a properly fitted, air-purifying or air-fed respirator complying with an approved standard if a risk assessment indicates this is necessary. Respirator selection must be based on known or anticipated exposure levels, the hazards of the product and the safe working limits of the selected respirator.

\section{Section 9. Physical and chemical properties}

Appearance
Physical state
Color
Odor
Odor threshold
pH
Melting point
Boiling point
Flash point
Evaporation rate
Flammability (solid, gas)
Lower and upper explosive
(flammable) limits
Vapor pressure

: Liquid. [Transparent (Aerosol.)]

: Yellow.

: Not available.

: Not available.

: Not available.

: Not available.

: $>288^{\circ} \mathrm{C}\left(>550.4^{\circ} \mathrm{F}\right)$

: Open cup: $204^{\circ} \mathrm{C}\left(399.2^{\circ} \mathrm{F}\right)$ (without propellant)

: >1 (butyl acetate $=1$ )

: Not applicable.

: Not available.

: $<0.0013 \mathrm{kPa}(<0.01 \mathrm{~mm} \mathrm{Hg}$ ) [room temperature] (without propellant) 


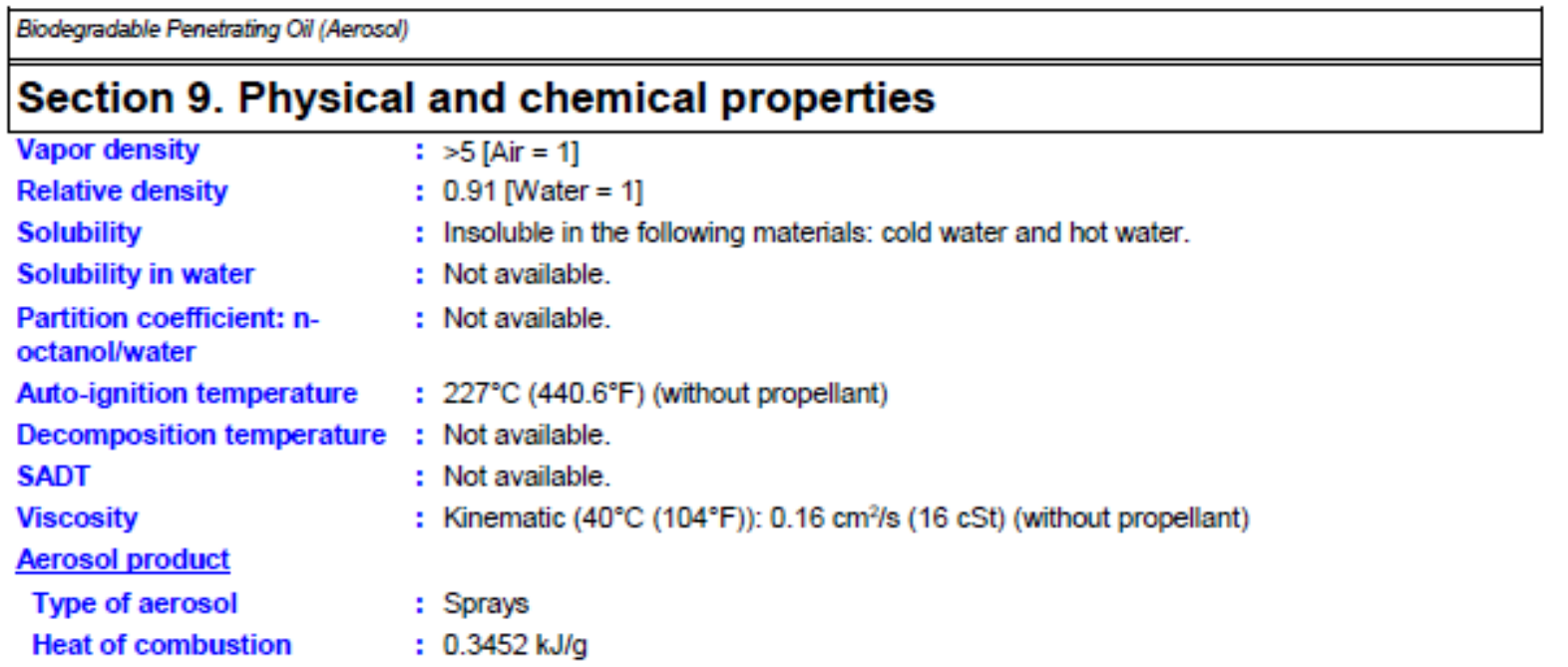

\section{Section 10. Stability and reactivity}
Reactivity
: No specific test data related to reactivity available for this product or its ingredients.
Chemical stability
: The product is stable. Possibility of hazardous
reactions
: Under normal conditions of storage and use, hazardous reactions will not occur.
Under normal conditions of storage and use, hazardous polymerization will not occur.
Conditions to avoid
: Keep away from heat, sparks and flame. Keep away from all sources of ignition.
Incompatible materials
: Reactive or incompatible with the following materials: oxidizing materials. Chlorine
Hazardous decomposition products
: Under normal conditions of storage and use, hazardous decomposition products should not be produced.

\section{Section 11. Toxicological information}

\section{Information on toxicological effects}

Acurte toxicity

\begin{tabular}{|l|l|l|l|l|}
\hline Product/ingredient name & Result & Species & Dose & Exposure \\
\hline 2-butoxyethanol & LC50 Inhalation Vapor & Rat & $450 \mathrm{ppm}$ & 4 hours \\
& LD50 Oral & Rat & $917 \mathrm{mg} / \mathrm{kg}$ & - \\
\hline
\end{tabular}

Irritation/Corrosion

\begin{tabular}{|c|c|c|c|c|c|}
\hline Product/ingredient name & Result & Species & Score & Exposure & Observation \\
\hline 2-butoxyethanol & $\begin{array}{l}\text { Eyes - Moderate irritant } \\
\text { Eyes - Severe imitant } \\
\text { Skin - Mild irritant }\end{array}$ & $\begin{array}{l}\text { Rabbit } \\
\text { Rabbit } \\
\text { Rabbit }\end{array}$ & - & $\begin{array}{l}24 \text { hours } 100 \\
\text { milligrams } \\
100 \\
\text { milligrams } \\
500 \\
\text { milligrams }\end{array}$ & - \\
\hline
\end{tabular}

Sensitization

Not available.

Mutagenicity

Conclusion/Summary : Not available.

\begin{tabular}{|lllllll}
\hline Date of issue/Date of revision & $: 07 / 03 / 2015$ & Date of previous issue & $:$ No previous validation & Version & $: 1$ & $6 / 2$
\end{tabular}


Biodegradable Penetrating Oil (Aerosol)

\section{Section 11. Toxicological information}

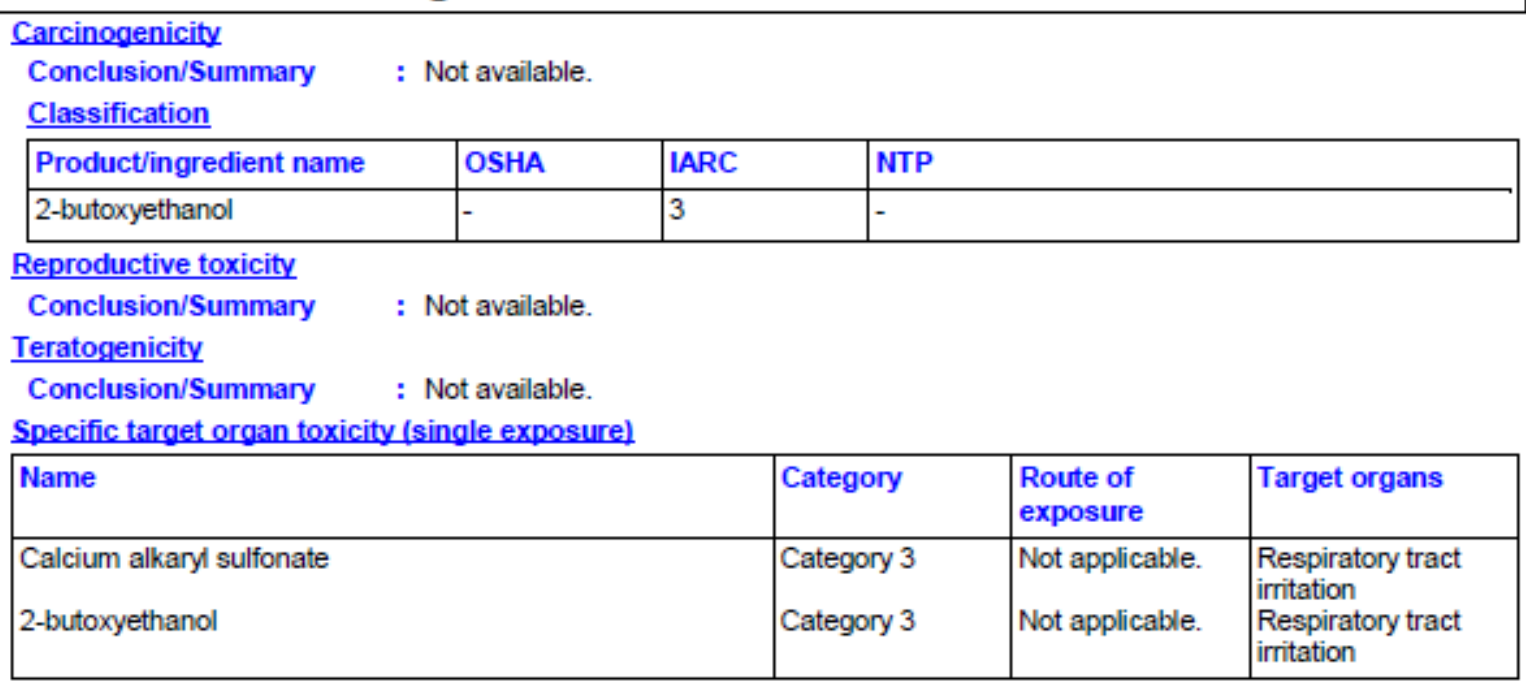

Specific target organ toxicity (repeated exposure)

Not available.

Aspiration hazard

Not available.

Information on the likely $\quad$ : Routes of entry anticipated: Oral, Dermal, Inhalation.

routes of exposure

Potential acute health effects
Eye contact
: No known significant effects or critical hazards.
Inhalation
: No known significant effects or critical hazards.
Skin contact
: No known significant effects or critical hazards.
Ingestion
: May be fatal if swallowed and enters airways.

Symptoms related to the physical, chemical and toxicological characteristics

Eye contact

: Adverse symptoms may include the following: irritation redness

Inhalation

: Adverse symptoms may include the following: respiratory tract irritation coughing

Skin contact

: No specific data.

Ingestion

: Adverse symptoms may include the following: nausea or vomiting

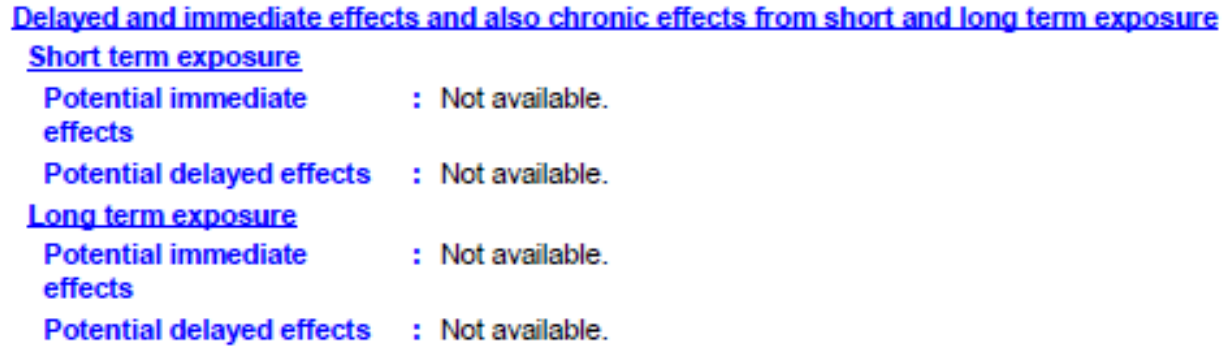

\begin{tabular}{|lllllll}
\hline Date of issue/Date of revision & $: 07 / 03 / 2015$ & Date of previous issue & $:$ No previous validation & Version & $: 1$ & $7 / 42$
\end{tabular}


Biodegradable Penetrating Oil (Aerosol)

\section{Section 11. Toxicological information}

Potential chronic health effects

Not available.

General : No known significant effects or critical hazards.

Carcinogenicity : No known significant effects or critical hazards.

Mutagenicity : No known significant effects or critical hazards.

Teratogenicity : No known significant effects or critical hazards.

Developmental effects : No known significant effects or critical hazards.

Fertility effects $\quad$ : No known significant effects or critical hazards.

Numerical measures of toxicity

Acute toxicity estimates

Not available.

\section{Section 12. Ecological information}

Toxicity

\begin{tabular}{|l|l|l|l|}
\hline Product/ingredient name & Result & Species & Exposure \\
\hline 2-butoxyethanol & Acute EC50 >1000 mg/l Fresh water & Daphnia - Daphnia magna & 48 hours \\
& Acute LC50 $800000 \mu \mathrm{g} /$ Marine water & Crustaceans - Crangon crangon & 48 hours \\
& Acute LC50 $1250000 \mu \mathrm{g} /$ Marine water & Fish - Menidia beryllina & 96 hours \\
\hline
\end{tabular}

Persistence and degradability

\begin{tabular}{|l|l|l|l|l|}
\hline Product/ingredient name & Test & Result & Dose & Inoculum \\
\hline 2-butoxyethanol & $\begin{array}{l}301 \mathrm{E} \text { Ready } \\
\text { Biodegradability - } \\
\text { Modified OECD } \\
\text { Screening Test }\end{array}$ & $95 \%-28$ days & - & - \\
\hline \hline Product/ingredient name & Aquatic half-life & Photolysis & Biodegradability \\
\hline 2-butoxyethanol & - & - & Readily \\
\hline
\end{tabular}

Bioaccumulative potential

\begin{tabular}{|l|l|l|l|}
\hline Product/ingredient name & LogP & BCF & Potential \\
\hline 2-butoxyethanol & 0.81 & $<100$ & low \\
\hline
\end{tabular}

Mobility in soil

Soil/water partition : Not available.

coefficient (Koc)

Other adverse effects

: No known significant effects or critical hazards.

\begin{tabular}{|lllllll|}
\hline Date of issue/Date of revision & $: 07 / 03 / 2015$ & Date of previous issue & :No previous validation & Version & $: 1$ & $8 / 12$ \\
\hline
\end{tabular}




\section{Section 13. Disposal considerations}

Disposal methods

: The generation of waste should be avoided or minimized wherever possible. Disposal of this product, solutions and any by-products should at all times comply with the requirements of environmental protection and waste disposal legislation and any regional local authority requirements. Dispose of surplus and non-recyclable products via a licensed waste disposal contractor. Waste should not be disposed of untreated to the sewer unless fully compliant with the requirements of all authorities with jurisdiction. Waste packaging should be recycled. Incineration or landfill should only be considered when recycling is not feasible. This material and its container must be disposed of in a safe way. Empty containers or liners may retain some product residues. Do not puncture or incinerate container.

\section{Section 14. Transport information}

\begin{tabular}{|c|c|c|c|}
\hline & DOT Classification & IMDG & IATA \\
\hline UN number & - & UN1950 & ID8000 \\
\hline $\begin{array}{l}\text { UN proper } \\
\text { shipping name }\end{array}$ & Consumer commodity & AEROSOLS & Consumer commodity \\
\hline $\begin{array}{l}\text { Transport } \\
\text { hazard class(es) }\end{array}$ & ORM-D & 2.2 & 9 \\
\hline Packing group & - & - & - \\
\hline $\begin{array}{l}\text { Environmental } \\
\text { hazards }\end{array}$ & No. & No. & No. \\
\hline $\begin{array}{l}\text { Additional } \\
\text { information }\end{array}$ & $\begin{array}{l}\text { Limited quantity } \\
\text { Yes. } \\
\text { Packaging instruction } \\
\text { Passenger aircraft } \\
\text { Quantity limitation: } 30 \mathrm{~kg} \\
\text { Cargo aircraft } \\
\text { Quantity limitation: Forbidden. } \\
\frac{\text { Special provisions }}{222} \\
\text { Remarks } \\
\text { Packaging: Limited quantity }\end{array}$ & $\begin{array}{l}\text { Emergency schedules (EmS) } \\
\text { F-D, S-U } \\
\frac{\text { Special provisions }}{63,190,277,327,344,959}\end{array}$ & $\begin{array}{l}\text { Passenger and Cargo Aircraft } \\
\text { Quantity limitation: } 30 \mathrm{~kg} \\
\text { Packaging instructions: Y963 } \\
\text { Cargo Aircraft OnlyQuantity } \\
\text { limitation: } 30 \mathrm{~kg} \\
\text { Packaging instructions: Y963 } \\
\text { Limited Quantities - } \\
\text { Passenger AircraftQuantity } \\
\text { limitation: } 30 \mathrm{~kg} \\
\text { Packaging instructions: Y963 } \\
\text { Special provisions } \\
\text { A112 }\end{array}$ \\
\hline
\end{tabular}

Special precautions for user : Transport within user's premises: always transport in closed containers that are upright and secure. Ensure that persons transporting the product know what to do in the event of an accident or spillage.

Transport in bulk according : Not available.

to Annex II of MARPOL

$73 / 78$ and the IBC Code 


\section{Section 15. Regulatory information}

\begin{tabular}{|c|c|c|c|c|c|c|c|c|}
\hline U.S. Federal regulations & \multirow{2}{*}{\multicolumn{8}{|c|}{$\begin{array}{l}\text { : United States inventory (TSCA 8b): All components are listed or exempted. } \\
\text { : Not listed }\end{array}$}} \\
\hline $\begin{array}{l}\text { Clean Air Act Section } 112 \\
\text { (b) Hazardous Air } \\
\text { Pollutants (HAPs) }\end{array}$ & & & & & & & & \\
\hline $\begin{array}{l}\text { Clean Air Act Section } 602 \\
\text { Class I Substances }\end{array}$ & \multicolumn{8}{|c|}{ : Not listed } \\
\hline $\begin{array}{l}\text { Clean Air Act Section } 602 \\
\text { Class II Substances }\end{array}$ & \multicolumn{8}{|c|}{ : Not listed } \\
\hline $\begin{array}{l}\text { DEA List I Chemicals } \\
\text { (Precursor Chemicals) }\end{array}$ & \multicolumn{8}{|c|}{ : Not listed } \\
\hline $\begin{array}{l}\text { DEA List II Chemicals } \\
\text { (Essential Chemicals) }\end{array}$ & \multicolumn{8}{|c|}{ : Not listed } \\
\hline \multicolumn{9}{|l|}{ SARA 302/304 } \\
\hline \multicolumn{9}{|c|}{$\underline{\text { Composition/information on ingredients }}$} \\
\hline \multicolumn{9}{|l|}{ No products were found. } \\
\hline SARA 304 RQ & \multicolumn{8}{|c|}{ : Not applicable. } \\
\hline \multicolumn{9}{|l|}{ SARA $311 / 312$} \\
\hline Classification & \multicolumn{8}{|c|}{ : Sudden release of pressure } \\
\hline \multicolumn{9}{|c|}{ Composition/information on ingredients } \\
\hline Name & & & $\%$ & \begin{tabular}{|l|} 
Fire \\
hazard
\end{tabular} & $\begin{array}{l}\text { Sudden } \\
\text { release of } \\
\text { pressure }\end{array}$ & Reactive & $\begin{array}{l}\text { Immediate } \\
\text { (acute) } \\
\text { health } \\
\text { hazard }\end{array}$ & $\begin{array}{l}\text { Delayed } \\
\text { (chronic) } \\
\text { health } \\
\text { hazard }\end{array}$ \\
\hline $\begin{array}{l}\text { Calcium alkaryl sulfonate } \\
\text { 2-butoxyethanol }\end{array}$ & & & $\begin{array}{l}\geq 1-<3 \\
\geq 1-<3\end{array}$ & $\begin{array}{l}\text { No. } \\
\text { Yes. }\end{array}$ & $\begin{array}{l}\text { No. } \\
\text { No. }\end{array}$ & $\begin{array}{l}\text { No. } \\
\text { No. }\end{array}$ & $\begin{array}{l}\text { Yes. } \\
\text { Yes. }\end{array}$ & $\begin{array}{l}\text { No. } \\
\text { No. }\end{array}$ \\
\hline
\end{tabular}

\section{SARA 313}

\begin{tabular}{|l|l|l|l|}
\hline & Product name & CAS number & $\%$ \\
\hline $\begin{array}{l}\text { Form R - Reporting } \\
\text { requirements }\end{array}$ & 2-butoxyethanol & $111-76-2$ & $\geq 1-<3$ \\
\hline Supplier notification & 2-butoxyethanol & $111-76-2$ & $\geq 1-<3$ \\
\hline
\end{tabular}

SARA 313 notifications must not be detached from the SDS and any copying and redistribution of the SDS shall include copying and redistribution of the notice attached to copies of the SDS subsequently redistributed.

\section{State regulations}

Massachusetts

New York

: The following components are listed: 2-BUTOXYETHANOL; CARBON DIOXIDE

New Jersey

: None of the components are listed.

: The following components are listed: 2-BUTOXY ETHANOL; BUTYL CELLOSOLVE; CARBON DIOXIDE; CARBONIC ACID GAS

Pennsylvania

: The following components are listed: ETHANOL, 2-BUTOXY-; CARBON DIOXIDE

California Prop. 65

None of the components are listed.

Chemical Weapon Convention List Schedules I, II \& III Chemicals

Not listed.

Montreal Protocol (Annexes A, B, C, E)

Not listed.

Stockholm Convention on Persistent Organic Pollutants

Not listed. 


\title{
Section 15. Regulatory information
}

\author{
Rotterdam Convention on Prior Inform Consent (PIC) \\ Not listed.
}

UNECE Aarhus Protocol on POPS and Heavy Metals

Not listed.

\section{Section 16. Other information}

Hazardous Material Information System (U.S.A.)

\begin{tabular}{|c|c|c|}
\hline Health & * & 1 \\
\hline Flammability & & 2 \\
\hline Physical hazards & & 0 \\
\hline
\end{tabular}

Caution: HMIS $\otimes$ ratings are based on a $0-4$ rating scale, with 0 representing minimal hazards or risks, and 4 representing significant hazards or risks Although HMIS $\otimes$ ratings are not required on SDSs under 29 CFR 1910. 1200 , the preparer may choose to provide them. HMIS 2 ratings are to be used with a fully implemented HMIS 2 program. HMIS $\otimes$ is a registered mark of the National Paint \& Coatings Association (NPCA). HMIS $\otimes$ materials may be purchased exclusively from J. J. Keller (800) 327-6868.

The customer is responsible for determining the PPE code for this material.

National Fire Protection Association (U.S.A.)

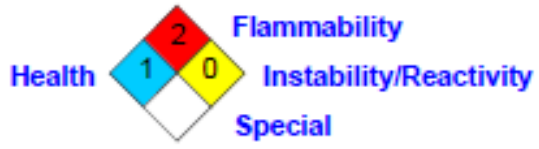

Reprinted with permission from NFPA 704-2001, Identification of the Hazards of Materials for Emergency Response Copyright (91997, National Fire Protection Association, Quincy, MA 02269. This reprinted material is not the complete and official position of the National Fire Protection Association, on the referenced subject which is represented only by the standard in its entirety.

Copyright (92001, National Fire Protection Association, Quincy, MA 02269. This warning system is intended to be interpreted and applied only by properly trained individuals to identify fire, health and reactivity hazards of chemicals. The user is referred to certain limited number of chemicals with recommended classifications in NFPA 49 and NFPA 325, which would be used as a guideline only. Whether the chemicals are classified by NFPA or not, anyone using the 704 systems to classify chemicals does so at their own risk.

Procedure used to derive the classification

\begin{tabular}{|l|l|}
\hline \multicolumn{1}{|c|}{ Classification } & \multicolumn{1}{|c|}{ Justification } \\
\hline $\begin{array}{l}\text { Press. Gas Comp. Gas, H280 } \\
\text { Asp. Tox. 1, H304 }\end{array}$ & $\begin{array}{l}\text { Expert judgment } \\
\text { Expert judgment }\end{array}$ \\
\hline
\end{tabular}

History

Date of issue/Date of revision

Date of previous issue

Version

Prepared by

Key to abbreviations

\section{: 07/03/2015}

: No previous validation

$: 1$

: IHS

: $\mathrm{ATE}=$ Acute Toxicity Estimate $\mathrm{BCF}=$ Bioconcentration Factor GHS = Globally Harmonized System of Classification and Labelling of Chemicals IATA = International Air Transport Association IBC = Intermediate Bulk Container

IMDG = International Maritime Dangerous Goods LogPow = logarithm of the octanol/water partition coefficient MARPOL 73/78 = International Convention for the Prevention of Pollution From Ships, 1973 as modified by the Protocol of 1978. ("Marpol" = marine pollution) 
Biodegradable Penetrating Oil (Aerosol)

\section{Section 16. Other information}

UN = United Nations

References $\quad$ : HCS (U.S.A.)- Hazard Communication Standard

International transport regulations

DIndicates information that has changed from previously issued version.

Notice to reader

To the best of our knowledge, the information contained herein is accurate. However, neither the above-named supplier, nor any of its subsidiaries, assumes any liability whatsoever for the accuracy or completeness of the information contained herein.

Final determination of suitability of any material is the sole responsibility of the user. All materials may present unknown hazards and should be used with caution. Although certain hazards are described herein, we cannot guarantee that these are the only hazards that exist. 


\section{Identification}

Product identifier

Trade name: Positron Aerosol

Product description

Ultra High Purity Dielectric Solvent

$\begin{array}{llll}\text { Product Name } & \text { Part No. } & \text { Packaging } & \text { National Stock No. } \\ \text { Positron (A) } & 696-1 & 12 \times 16 \text { oz net Aerosol } & 6850-01-445-3545\end{array}$

Details of the supplier of the safety data sheet

Manufacturer/Supplier:

Ecolink

2177 Flintstone Dr, Ste. A, Tucker, GA 30085

www.ecolink.com

800-886-8240 or 770-621-8240 (8-5 EST)

Emergency telephone number: Infotrac: 1-800-535-5053, 1-352-326-2510

\section{Hazard(s) identification}

- Classification of the substance or mixture

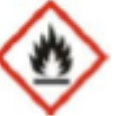

GHSO2 Flame

Flam. Aerosol 2 H223 Flammable aerosol.

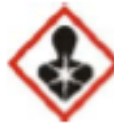
GHSO8 Health hazard

Asp. Tox. 1 H304 May be fatal if swallowed and enters airways.

\section{GHSO7}

Skin Irnit. 2

H315 Causes skin irritation.

Skin Sens. 1

STOT SE 3

H317 May cause an allergic skin reaction.

H335 May cause respiratory irritation.

Eye Irrit. $2 B$

H320 Causes eye irnitation.

Aquatic Chronic 3 H412 Harmful to aquatic life with long lasting effects.

- Label elements

- GHS label elements

The product is classified and labeled according to the Globally Harmonized System (GHS).

Hazard pictograms

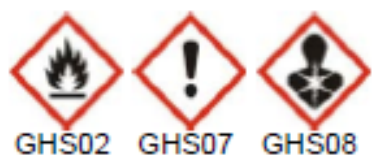




\title{
ECOELININ.
}

\section{Safety Data Sheet (SDS)}

\author{
OSHA Hazard Communication Standard 29 CFR 1910.1200. Prepared to GHS
}

Rev03.

Reviewed on 11/11/2014

Trade name: Positron Aerosol

- Signal word Danger

(Contd. of page 1)

- Hazard-determining components of labeling:

Distillates (petroleum), hydrotreated light

(R)-p-mentha-1,8-diene

- Hazard statements

H223 Flammable aerosol.

H315 Causes skin irritation.

H320 Causes eye irritation.

H317 May cause an allergic skin reaction.

H335 May cause respiratory irritation.

H304 May be fatal if swallowed and enters airways.

H412 Harmful to aquatic life with long lasting effects.

Precautionary statements

P251 Pressurized container: Do not pierce or burn, even after use.

P210 Keep away from heat1sparks1open flames1 hot surfaces. - No smoking.

P211 Do not spray on an open flame or other ignition source.

P261 Avoid breathing dust1fume1gas1mist1vapors1spray.

P271 Use only outdoors or in a well-ventilated area.

P280 Wear protective gloves1protective clothing1eye protection 1face protection. P301+P310 IF SWALLOWED: Immediately call a POISON CENTER or doctor1physician.

P305+P351+P338 IF IN EYES: Rinse cautiously with water for several minutes. Remove contact

P321 Specific treatment (see on this label).

P362 Take off contaminated clothing and wash before reuse.

P304+P340 IF INHALED: Remove victim to fresh air and keep at rest in a position comfortable

Call a POISON CENTER or doctor1physician if you feel unwell.

P405 Store locked up.

$P 410+P 412 \quad$ Protect from sunlight. Do not expose to temperatures exceeding $50^{\circ} \mathrm{C} 112{ }^{\circ} \mathrm{F}$.

P501 Dispose of contents1container in accordance with localfregionalinational1

Classification system: international regulations.

-NFPA ratings (scale 0 - 4)

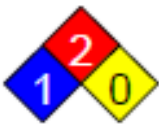

Health $=1$

Fire $=2$

Reactivity $=0$

- HMIS-ratings (scale 0 - 4)

\begin{tabular}{|c|c|}
\hline HEALTH & 1 \\
\hline FIRE & \\
\hline REACTIVITY [ & Reactivity $=0$ \\
\hline
\end{tabular}

- Other hazards

- Results of PBT and $v P v B$ assessment

-PBT: Not applicable.

- vPvB: Not applicable.

(Contd. on page 3) 


\section{Safety Data Sheet (SDS)}

Trade name: Positron Aerosol

(Contd. of page 2)

\section{Composition/information on ingredients}

- Chemical characterization: Mixtures

Description: Mixture of the substances listed below with nonhazardous additions.

Dangerous components:

64742-47-8 Distillates (petroleum), hydrotreated light

Asp. Tox. 1, H304; Aquatic Chronic 2, H411; Skin Imrit. 2, H315;

STOT SE 3, H336; H227

5989-27-5 (R)-p-mentha-1,8-diene

Flam. Liq. 3, H226; Aquatic Acute 1, H400; Aquatic Chronic 1, H410;

Skin Irrit. 2, H315; Skin Sens. 1, H317

124-38-9 Carbon dioxide

Press. Gas, H280

\section{First-aid measures}

- Description of first aid measures

- After inhalation:

Supply fresh air and to be sure call for a doctor.

In case of unconsciousness, place patient securely in side position for transportation.

- After skin contact: Immediately wash with water and soap and rinse thoroughly.

- After eye contact:

Rinse opened eye for several minutes under running water. If symptoms persist, consult a doctor.

- After swallowing: Give large amounts of water. If symptoms persist consult doctor.

- Information for doctor:

- Most important symptoms and effects, both acute and delayed

No further relevant information available.

- Indication of any immediate medical attention and special treatment needed

No further relevant information available.

\section{Fire-fighting measures}

Extinguishing media

- Suitable extinguishing agents:

$\mathrm{CO} 2$, extinguishing powder or water spray. Fight larger fires with water spray or alcohol resistant foam.

For safety reasons unsuitable extinguishing agents: Water with full jet

Special hazards arising from the substance or mixture No further relevant information available.

- Advice for firefighters

- Protective equipment: No special measures required.

\section{Accidental release measures}

- Personal precautions, protective equipment and emergency procedures

Wear protective equipment. Keep unprotected persons away. 


\section{Safety Data Sheet (SDS)}

Trade name: Positron Aerosol

\section{- Environmental precautions:}

Inform respective authorities in case of seepage into water course or sewage system.

Do not allow to enter sewers1 surface or ground water.

- Methods and material for containment and cleaning up: Ensure adequate ventilation.

Reference to other sections

See Section 7 for information on safe handling.

See Section 8 for information on personal protection equipment.

See Section 13 for disposal information.

\section{Handling and storage}

- Handling:

- Precautions for safe handling

Ensure good ventilation1exhaustion at the workplace.

Open and handle receptacle with care.

- Information about protection against exp/osions and fires:

Do not spray on a naked flame or any incandescent material.

Keep ignition sources away - Do not smoke.

Protect from heat.

Protect against electrostatic charges.

Pressurized container: protect from sunlight and do not expose to temperatures exceeding $50^{\circ} \mathrm{C}$, i.e. electric lights. Do not pierce or burn, even after use.

- Conditions for safe storage, including any incompatibilities

- Storage:

- Requirements to be met by storerooms and receptacles:

Store in a cool location.

Observe official regulations on storing packagings with pressurized containers.

- Information about storage in one common storage facility: Not required.

- Further information about storage conditions:

Keep receptacle tightly sealed.

Do not gas tight seal receptacle.

Store in cool, dry conditions in well sealed receptacles.

Protect from heat and direct sunlight.

- Specific end use(s) No further relevant information available.

\section{Exposure controls/personal protection}

- Additional information about design of technical systems: No further data; see section 7.

- Control parameters

- Components with limit values that require monitoring at the workp/ace:

124-38-9 Carbon dioxide

PEL Long-term value: $9000 \mathrm{mg} / \mathrm{m} 3,5,000 \mathrm{ppm}$

REL Short-term value: $54.000 \mathrm{mg} / \mathrm{m} 3,30,000 \mathrm{ppm}$

Long-term value: $9000 \mathrm{mg} / \mathrm{m} 3,5,000 \mathrm{ppm}$ 
TLV Short-term value: $54,000 \mathrm{mg} / \mathrm{m} 3,30,000 \mathrm{ppm}$ Long-term value: $9,000 \mathrm{mg} / \mathrm{m} 3,5,000 \mathrm{ppm}$

Additional information: The lists that were valid during the creation were used as basis.

\section{Exposure controls}

Personal protective equipment:

- General protective and hygienic measures: Keep

away from foodstuffs, beverages and feed. Immediately

remove all soiled and contaminated clothing. Wash hands

before breaks and at the end of work.

Avoid contact with the eyes and skin.

Breathing equipment:

In case of brief exposure or low pollution use respiratory filter device. In case of intensive or longer exposure, use respiratory protective device that is independent of circulating air.

Protection of hands:

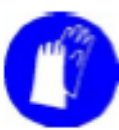

Protective gloves

The glove material has to be impermeable and resistant to the product1 the substance1 the preparation. Due to missing tests no recommendation to the glove material can be given for the product 1 the preparation 1 the chemical mixture.

Select glove material based on penetration times, rates of diffusion and degradation.

Material of gloves

The selection of the suitable gloves does not only depend on the material, but also on further marks of quality and varies from manufacturer to manufacturer. As the product is a preparation of several substances, the resistance of the glove material can not be calculated in advance and has therefore to be checked prior to the application.

- Penetration time of glove material

The exact break-through time has to be determined and observed by the manufacturer of the protective gloves.

Eye protection: Tightly sealed goggles or safety glasses with side shields

\section{Physical and chemical properties}

- Information on basic physical and chemical properties

- General Information

- Appearance:

Form:

Color:

- Odor:

- Odour threshold:

Aerosol

Colorless

Citrus

- $\mathrm{pH}$-value:

Not determined.

- Change in condition

Melting point/Melting range:

Boiling point/Boiling range:

Not determined.

Not determined.

$176-212^{\circ} \mathrm{C}\left(349-414^{\circ} \mathrm{F}\right)$ 


\section{Safety Data Sheet (SDS)}

OSHA Hazard Communication Standard 29 CFR 1910.1200. Prepared to GHS Rev03.

Reviewed on 11/11/2014

Trade name: Positron Aerosol

\begin{tabular}{|c|c|c|}
\hline & & (Contd. of page 5) \\
\hline Flash point: & $61^{\circ} \mathrm{C}\left(142^{\circ} \mathrm{F}\right)$ & \\
\hline Flammability (solid, gaseous): & Not applicable. & \\
\hline Ignition temperature: & $231^{\circ} \mathrm{C}\left(448^{\circ} \mathrm{F}\right)\left(448^{\circ} \mathrm{F}\right)$ & \\
\hline - Decomposition temperature: & Not determined. & \\
\hline Auto igniting: & Product is not selfigniting. & \\
\hline Danger of explosion: & Not determined. & \\
\hline $\begin{array}{l}\text { Explosion limits: } \\
\text { Lower: } \\
\text { Upper: }\end{array}$ & $\begin{array}{l}0.7 \mathrm{Vol} \% \\
7.0 \mathrm{Vol} \%\end{array}$ & \\
\hline -Vapor pressure @ $20^{\circ} \mathrm{C}\left(68^{\circ} \mathrm{F}\right):$ & $0.52 \mathrm{~mm} \mathrm{Hg}$ & \\
\hline $\begin{array}{l}\text { - Density @ } 20^{\circ} \mathrm{C}\left(68^{\circ} \mathrm{F}\right): \\
\text { - Relative density } \\
\text { - Vapor density } \\
\text { - Evaporation rate }\end{array}$ & $\begin{array}{l}0.807 \mathrm{~g} / \mathrm{cm} 3(6.73 \mathrm{lbs} / \mathrm{gal}) \\
\text { Not determined. } \\
\text { Not determined. } \\
\text { Not applicable. }\end{array}$ & \\
\hline $\begin{array}{l}\text { Solubility in I Miscibility with } \\
\text { Water: }\end{array}$ & Not miscible or difficult to mix. & \\
\hline - Partition coefficient ( $n$-octanol/w & : Not determined. & \\
\hline $\begin{array}{l}\text { Viscosity: } \\
\text { Dynamic: } \\
\text { Kinematic: }\end{array}$ & $\begin{array}{l}\text { Not determined. } \\
\text { Not determined. }\end{array}$ & \\
\hline $\begin{array}{l}\text { Solvent content: } \\
\text { Organic solvents: } \\
\text { VOC content: } \\
\text { - Other information }\end{array}$ & $\begin{array}{l}\sim 95 \% \\
807 \mathrm{gl} \\
\text { No further relevant information available. }\end{array}$ & \\
\hline
\end{tabular}

\section{Stability and reactivity}

Reactivity No further relevant information available.

Chemical stability Product is stable under normal conditions.

Thermal decomposition I conditions to be avoided:

No decomposition if used according to specifications.

- Possibility of hazardous reactions No dangerous reactions known.

Conditions to avoid High temperatures.

Incompatible materials:

Strong acids, strong bases, strong oxidizing agents and strong reducing agents.

- Hazardous decomposition products: No dangerous decomposition products known. 


\section{Toxicological information}

- Information on toxicological effects

Acute toxicity:

- LDILC50 values that are relevant for classification:

64742-47-8 Distillates (petroleum), hydrotreated light

Oral LD50 $>5,000 \mathrm{mg} / \mathrm{kg}$ (rat) Dermal

LD50 >2,000 $\mathrm{mg} / \mathrm{kg}$ (rabbit)

5989-27-5 (R)-p-mentha-1,8-diene

Oral LD50 $4,400 \mathrm{mg} / \mathrm{kg}$ (rat)

- Primary irritant effect:

on the skin: Irritant to skin and mucous membranes.

on the eye: Irritating effect.

- Sensitization: Sensitization possible through skin contact.

- Additional toxicological information:

The product shows the following dangers according to internally approved calculation methods for preparations:

Irritant

Carcinogenic categories

- IARC (International Agency for Research on Cancer)

5989-27-5 (R)-p-mentha-1,8-diene

NTP (National Toxicology Program)

None of the ingredients is listed.

\section{Ecological information}

\section{Toxicity}

Aquatic toxicity: No further relevant information available.

- Persistence and degradability No further relevant information available.

Behavior in environmental systems:

- Bioaccumulative potential No further relevant information available.

Mobility in soil No further relevant information available.

Ecotoxical effects:

Remark: Toxic for fish

Additional ecological information:

General notes:

Water hazard class 2 (Self-assessment): hazardous for water

Do not allow product to reach ground water, water course or sewage system.

Danger to drinking water if even small quantities leak into the ground.

Also poisonous for fish and plankton in water bodies.

Toxic for aquatic organisms

Results of PBT and $v P v B$ assessment

-PBT: Not applicable.

- vPvB: Not applicable. 
Trade name: Positron Aerosol

Other adverse effects No further relevant information available.

(Contd. of page 7)

\section{Disposal considerations}

Waste treatment methods

Recommendation:

Must not be disposed of together with household garbage. Do not allow product to reach sewage system.

Uncleaned packagings:

Recommendation: Disposal must be made according to official regulations.

\section{Transport information}

UN-Number

DOT, ADR, IMDG, IATA

UN1950

UN proper shipping name

DOT

$A D R$

IMDG

- IATA

Aerosols, flammable

UN1950 Aerosols

AEROSOLS

Transport hazard class(es)

AEROSOLS, flammable

DOT

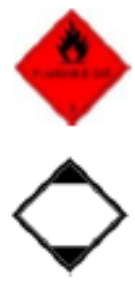

Limited Quantity

Class

2.1

- Label

$A D R$

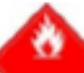

\section{.}

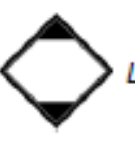

Limited Quantity

Class

2 5F Gases 
Trade name: Positron Aerosol

\begin{tabular}{|c|c|c|}
\hline & & (Contd. of page 8) \\
\hline - Label & 2.1 & \\
\hline \multicolumn{3}{|l|}{ IMDG, IATA } \\
\hline - Class & 2.1 & \\
\hline - Label & 2.1 & \\
\hline $\begin{array}{l}\text { - Packing group } \\
\text { - DOT, ADR, IMDG, IATA }\end{array}$ & Non-Regulated Material & \\
\hline $\begin{array}{l}\text { Environmental hazards: } \\
\text { Marine pollutant: }\end{array}$ & Yes & \\
\hline $\begin{array}{l}\text {-Special precautions for user } \\
\text { - Danger code (Kem/er): } \\
\text { - EMS Number: }\end{array}$ & $\begin{array}{l}\text { Warning: Gases } \\
- \\
F-D, S-U\end{array}$ & \\
\hline \multicolumn{3}{|c|}{$\begin{array}{l}\text { Transport in bulk according to Annex II of } \\
\text { MARPOL73/78 and the IBC Code Not applicable. }\end{array}$} \\
\hline \multicolumn{3}{|l|}{-Transport/Additional information: } \\
\hline$D O T$ & ORM-D consumer commodity & \\
\hline - UN "Model Regulation": & UN1950, Aerosols, 2.1 & \\
\hline
\end{tabular}

\section{Regulatory information}

Safety, health and environmental regulations/legis/ation specific for the substance or mixture Sara

Section 355 (extremely hazardous substances):

None of the ingredients is listed.

Section 313 (Specific toxic chemical listings):

None of the ingredients is listed.

- TSCA (Toxic Substances Control Act):

All ingredients are listed.

- Proposition 65

Chemicals known to cause cancer:

None of the ingredients is listed. 
Trade name: Positron Aerosol

Chemicals known to cause reproductive toxicity for females:

(Contd. of page 9)

None of the ingredients is listed.

Chemicals known to cause reproductive toxicity for males:

None of the ingredients is listed.

Chemicals known to cause developmental toxicity:

None of the ingredients is listed.

- Carcinogenic categories

EPA (Environmental Protection Agency)

None of the ingredients is listed.

- TLV (Threshold Limit Value established by ACGIH)

None of the ingredients is listed.

NIOSH-Ca (National Institute for Occupational Safety and Health)

None of the ingredients is listed.

OSHA-Ca (Occupational Safety \& Health Administration)

Corrosive to eyes

GHS label elements

The product is classified and labeled according to the Globally Harmonized System (GHS).

Hazard pictograms

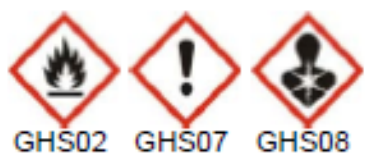

Signal word Danger

Hazard-determining components of labeling:

Distillates (petroleum), hydrotreated light

(R)-p-mentha-1,8-diene

Hazard statements

H223 Flammable aerosol.

H315 Causes skin irritation.

H320 Causes eye irritation.

H317 May cause an allergic skin reaction.

H335 May cause respiratory irritation.

H304 May be fatal if swallowed and enters airways.

H412 Harmful to aquatic life with long lasting effects.

Precautionary statements

P251 Pressurized container: Do not pierce or burn, even after use.

P210 Keep away from heat1sparks1open flames1 hot surfaces. - No smoking.

P211 Do not spray on an open flame or other ignition source.

P261 Avoid breathing dust1fume1gas1mist1vapors1spray.

P271 Use only outdoors or in a well-ventilated area.

P280 Wear protective gloves1protective clothing1eye protection1face protection.

P301+P310 IF SWALLOWED: Immediately call a POISON CENTER or doctor1 physician. 
Trade name: Positron Aerosol

P305+P351+P338 IF IN EYES: Rinse cautiously with water for several minutes. Remove contact

P321

P362

$P 304+P 340$ lenses, if present and easy to do. Continue rinsing. Specific treatment (see on this label).

Take off contaminated clothing and wash before reuse.

P312 Call a POISON CENTER or doctor1physician if you feel unwell.

P405 Store locked up.

$P 410+P 412 \quad$ Protect from sunlight. Do not expose to temperatures exceeding $50^{\circ} \mathrm{C} 1122^{\circ} \mathrm{F}$. P501 Dispose of contents1container in accordance with localiregionalinational1
international regulations.

- National regulations:

The product is subject to be labeled according with the prevailing version of the regulations on hazardous substances.

- State Right to Know

64742-47-8 Distillates (petroleum), hydrotreated light

Asp. Tox. 1, H304; Aquatic Chronic 2, H411; Skin Imit. 2, H315; STOT SE $3, H 336 ;$ H227

5989-27-5 (R)-p-mentha-1,8-diene

Flam. Liq. 3, H226; Aquatic Acute 1, H400; Aquatic Chronic 1, H410;

Skin Irrit. 2, H315; Skin Sens. 1, H317

124-38-9 Carbon dioxide

Press. Gas, H280

$80-90 \%$

$2-12 \%$

$2-12 \%$

None of the ingredients is listed.

- Chemical safety assessment: A Chemical Safety Assessment has not been carried out.

16 Other information

This information is based on our present knowledge. However, this shall not constitute a guarantee for any specific product features and shall not establish a legally valid contractual relationship.

- Date of preparation I last revision 11/11/2014

- Abbreviations and acronyms:

ADR: Accord europeen sur le transport des marchandises dangereuses par Route (European Agreement concerning the Intemational Carriage of Dangerous Goods by Road)

IMDG: International Maritime Code for Dangerous Goods

DOT: US Department of Transportation

IATA: International Air Transport Association

ACGIH: American Conference of Governmental Industrial Hygienists

EINECS: European Inventory of Existing Commercial Chemical Substances

ELINCS: European List of Notified Chemical Substances

CAS: Chemical Abstracts Service (division of the American Chemical Society)

NFPA: National Fire Protection Association (USA)

HMIS: Hazardous Materials Identification System (USA)

VOC: Volatile Organic Compounds (USA, EU)

LC50: Lethal concentration, 50 percent

LD50: Lethal dose, 50 percent

SDS / MSDS Created by MSDS Authoring Services (www.MSDSAuthoring.com) 
Safety Data Sheet

According to OSHA Hazard Communication Standard, 29 CFR 1910.1200

Initial preparation date: 01.26 .2017

Tap Magic Eco-Oil (Aerosol)

\section{SECTION 1: Identification}

Material name: Tap Magic Eco-Oil (Aerosol)

Product code: $60012 \mathrm{CL}$

Additional information: After use of this product, clean and lubricate metal

surfaces to avoid staining and/or corrosion.

Recommended use of the product and restriction on use:

Machining, Cutting, Tapping, and Metal Processing.

Manufacturer or supplier details

Manufacturer:

The Steco Corporation

2330 Cantrell Road

Little Rock, AR 72202

1-501-375-5644

steco@tapmagic.com

Emergency telephone number:

ChemTel Inc.

(800)255-3924

$+1(813) 248-0585$

\section{SECTION 2: Hazard(s) identification}

GHS classification:

Compressed gases.

\section{Label elements}

Hazard pictograms:

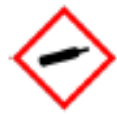

Signal word: Warning

Hazard statements:

H280 Contains gas under pressure; may explode if heated

Precautionary statements:

P410+P403 Protect from sunlight. Store in a well ventilated place.

Hazards not otherwise classified: None

\section{SECTION 3: Composition/information on ingredients}

\begin{tabular}{|l|l|l|}
\hline Identification & Name & Wt. $\%$ \\
\hline $\begin{array}{l}\text { CAS number: } \\
124-38-9\end{array}$ & Carbon dioxide & $<100$ \\
\hline
\end{tabular}




\section{Safety Data Sheet}

According to OSHA Hazard Communication Standard, 29 CFR 1910.1200

Initial preparation date: 01.26 .2017

Tap Magic Eco-Oil (Aerosol)

\section{SECTION 4: First-aid measures \\ Description of first aid measures \\ After inhalation: \\ Loosen clothing as necessary and position individual in a comfortable position. \\ Maintain an unobstructed airway. \\ Get medical advice/attention if you feel unwell. \\ After skin contact: \\ Rinse affected area with soap and water. \\ If symptoms develop or persist, seek medical attention. \\ After eye contact: \\ Rinse/flush exposed eye(s) gently using water for 15-20 minutes. \\ If symptoms develop or persist, seek medical attention. \\ After swallowing: \\ Rinse mouth thoroughly. \\ Seek medical attention if irritation, discomfort, or vomiting persists. \\ Most important symptoms and effects, both acute and delayed \\ Acute symptoms: \\ No information available. \\ Delayed symptoms: \\ No information available. \\ Immediate medical attention and special treatment: \\ No information available.}

\section{SECTION 5: Fire-fighting measures}

Extinguishing media

Suitable extinguishing media:

Use appropriate fire suppression agents for adjacent combustible materials or sources of ignition.

Unsuitable extinguishing media:

No information available.

\section{Specific hazards during fire-fighting:}

Thermal decomposition can lead to release of irritating gases and vapors.

Contents under pressure.

In a fire or if heated, a pressure increase will occur and the container may burst or explode.

\section{Special protective equipment for firefighters:}

Use typical firefighting equipment, self-contained breathing apparatus, special tightly sealed suit.

\section{Additional information:}

Shut off sources of ignition.

Carbon monoxide and carbon dioxide may form upon combustion.

Heating causes a rise in pressure, risk of bursting and combustion. 


\section{Safety Data Sheet}

According to OSHA Hazard Communication Standard, 29 CFR 1910.1200

Initial preparation date: 01.26 .2017

Tap Magic Eco-Oil (Aerosol)

SECTION 6: Accidental release measures

Personal precautions, protective equipment and emergency procedures:

Wear protective eye wear, gloves and clothing.

\section{Environmental precautions:}

Should not be released into the environment.

Prevent from reaching drains, sewer or waterway.

\section{Methods and material for containment and cleaning up:}

Wear protective eye wear, gloves and clothing.

Absorb with non-combustible liquid-binding material (sand, diatomaceus earth (clay), acid binders, universal binders).

Dispose of contents / container in accordance with local regulations.

\section{Reference to other sections:}

None

\section{SECTION 7: Handling and storage}

\section{Precautions for safe handling:}

Use only with adequate ventilation.

Avoid breathing mist or vapor.

Do not eat, drink, smoke or use personal products when handling chemical substances.

Do not puncture, crush, or incinerate containers, even when empty.

Protect cylinders from physical damage.

\section{Conditions for safe storage, including any incompatibilities:}

Protect from freezing and physical damage.

Protect from direct sunlight.

Store in a cool, well-ventilated area.

Store cylinders upright.

Store away from all ignition sources (open flames, hot surfaces, direct sunlight, spark sources).

\section{SECTION 8: Exposure controls/personal protection}

Components with workplace control parameters:

\begin{tabular}{|l|l|l|}
\hline \multicolumn{1}{|c|}{ Component name } & \multicolumn{1}{|c|}{ Identifier } & \multicolumn{1}{c|}{ Permissible concentration } \\
\hline Carbon dioxide & $124-38-9$ & ACGIH TWA 5,000 ppm \\
\hline Carbon dioxide & $124-38-9$ & ACGIH STEL $30,000 \mathrm{ppm}$ \\
\hline Carbon dioxide & $124-38-9$ & OSHA TWA $5,000 \mathrm{ppm} 9,000 \mathrm{mg} / \mathrm{m} 3$ \\
\hline Carbon dioxide & $124-38-9$ & NIOSH ST $30,000 \mathrm{ppm} 54,000 \mathrm{mg} / \mathrm{m} 3$ \\
\hline
\end{tabular}

\section{Appropriate engineering controls:}

Emergency eye wash fountains and safety showers should be available in the immediate vicinity of use or handling.

Provide exhaust ventilation or other engineering controls to keep the airborne concentrations of vapor and 
Safety Data Sheet

According to OSHA Hazard Communication Standard, 29 CFR 1910.1200

Initial preparation date: 01.26 .2017

Tap Magic Eco-Oil (Aerosol)

mists below the applicable workplace exposure limits (Occupational Exposure Limits-OELs) indicated above.

Respiratory protection:

If engineering controls do not maintain airborne concentrations below recommended exposure limits (where applicable) or to an acceptable level (in countries where exposure limits have not been established), an approved respirator must be worn.

\section{Eye protection:}

Safety goggles or glasses, or appropriate eye protection.

\section{Skin and body protection:}

Select glove material impermeable and resistant to the substance.

Wear appropriate clothing to prevent any possibility of skin contact.

\section{General hygienic measures:}

Avoid contact with skin, eyes and clothing.

Wash hands before breaks and at the end of work.

Wash contaminated clothing before reuse.

SECTION 9: Physical and chemical properties
\begin{tabular}{|l|l|l|l|}
\hline $\begin{array}{l}\text { Appearance (physical } \\
\text { state, color): }\end{array}$ & $\begin{array}{l}\text { Amber colored pressurized liquid } \\
\text { with propellant }\end{array}$ & $\begin{array}{l}\text { Explosion limit lower: } \\
\text { Explosion limit upper: }\end{array}$ & $\begin{array}{l}\text { Not available } \\
\text { Not available }\end{array}$ \\
\hline Odor: & Mild & Vapor pressure: & Not available \\
\hline Odor threshold: & Not available & Vapor density: & Not available \\
\hline pH-value: & Not available & Relative density: & $0.92 \mathrm{~g} / \mathrm{ml}$ \\
\hline Melting/Freezing point: & Not available & Solubilities: & Insoluble in water. \\
\hline Boiling point/range: & Not available & $\begin{array}{l}\text { Partition coefficient }(\mathrm{n} \text { - } \\
\text { octanol/water): }\end{array}$ & Not available \\
\hline $\begin{array}{l}\text { Flash point (closed } \\
\text { cup): }\end{array}$ & $>100{ }^{\circ} \mathrm{C}$ & $\begin{array}{l}\text { Auto/Self-ignition } \\
\text { temperature: }\end{array}$ & Not available \\
\hline Evaporation rate: & Not available & $\begin{array}{l}\text { Decomposition } \\
\text { temperature: }\end{array}$ & Not available \\
\hline $\begin{array}{l}\text { Flammability (solid, } \\
\text { gaseous): }\end{array}$ & Not available & Dynamic viscosity: & Not available \\
\hline Density: & Not available & Kinematic viscosity: & 34 cSt at 100 of \\
\hline
\end{tabular}

SECTION 10: Stability and reactivity

Reactivity:

Does not react under normal conditions of use and storage.

Chemical stability:

Stable under normal conditions of use and storage.

Possibility of hazardous reactions:

None under normal conditions of use and storage.

Conditions to avoid: 
Safety Data Sheet

According to OSHA Hazard Communication Standard, 29 CFR 1910.1200

Initial preparation date: 01.26 .2017

Tap Magic Eco-Oil (Aerosol)

None known.

Incompatible materials:

None known.

Hazardous decomposition products:

None known.

SECTION 11: Toxicological information

Exposure routes:

No information available.

Acute toxicity:

No information available.

Skin corrosion/irritation:

No information available.

Serious eye damage/irritation:

No information available.

Respiratory or skin sensitization:

No information available.

Carcinogenicity:

IARC (International Agency for Research on Cancer):

None of the ingredients are listed.

NTP (National Toxicology Program):

None of the ingredients are listed.

Germ cell mutagenicity:

No information available.

Reproductive toxicity:

No information available.

STOT-single and repeated exposure:

No information available.

Aspiration toxicity:

No information available.

Additional toxicological information

No information available. 


\section{SECTION 12: Ecological information}

\section{Ecotoxicity:}

No information available.

Persistence and degradability: No information available.

Bioaccumulative potential: No information available.

Mobility in soil:

No information available.

Other adverse effects:

No information available.

\section{SECTION 13: Disposal considerations}

Disposal methods:

It is the responsibility of the waste generator to properly characterize all waste materials according to applicable regulatory entities.

\section{SECTION 14: Transportation information}

Land transport:

DOT (49 CFR) transport

\begin{tabular}{|c|c|}
\hline UN Number: & UN 1950 \\
\hline UN Proper shipping name: & Aerosol, non-flammable \\
\hline UN Transport hazard classes: & 2 \\
\hline Packing group: & $\mathrm{N} / \mathrm{A}$ \\
\hline Danger label: & 2.2 Non-flammable non-toxic gases \\
\hline Environmental hazards: & No \\
\hline Special precautions for user: & None \\
\hline \multicolumn{2}{|l|}{ transport: } \\
\hline \multicolumn{2}{|l|}{ IATA-DGR } \\
\hline UN Number: & UN 1950 \\
\hline
\end{tabular}


Safety Data Sheet

According to OSHA Hazard Communication Standard, 29 CFR 1910.1200

Initial preparation date: 01.26 .2017

Tap Magic Eco-Oil (Aerosol)

\begin{tabular}{|l|c|}
\hline UN Proper shipping name: & Aerosol, non-flammable \\
\hline UN Transport hazard classes: & 2 \\
\hline Packing group: & N/A \\
Danger label: & No \\
\hline Environmental hazards: & None \\
\hline Special precautions for user: & \\
\hline
\end{tabular}

Sea transport:

IMDG

UN Number: $\quad$ UN 1950

UN Proper shipping name: Aerosol, non-flammable

UN Transport hazard classes: 2

Packing group: $\quad$ N/A

Danger label: $\quad 2.2$ Non-flammable non-toxic gases

EMS code: $\quad$ None

Environmental hazards: No

Special precautions for user: None

Transport in bulk according to Annex II of MARPOL73/78 and the IBC Code: Not applicable

\section{SECTION 15: Regulatory information}

\section{North American}

SARA Section 311/312 (Specific toxic chemical listings):

Not classified.

SARA Section 302 (Extremely hazardous substances): None of the ingredients are listed.

SARA Section 313 (Specific toxic chemical listings): None of the ingredients are listed.

TSCA (Toxic Substances Control Act):

124-38-9 Carbon dioxide: listed. 
Safety Data Sheet

According to OSHA Hazard Communication Standard, 29 CFR 1910.1200

Initial preparation date: 01.26 .2017

Tap Magic Eco-Oil (Aerosol)

TSCA Rules and Orders:

Not applicable.

Proposition 65 (California):

Chemicals known to cause cancer:

None of the ingredients are listed.

Chemicals known to cause reproductive toxicity for females:

None of the ingredients are listed.

Chemicals known to cause reproductive toxicity for males: None of the ingredients are listed.

Chemicals known to cause developmental toxicity:

None of the ingredients are listed.

\section{Canada}

DSL (Canadian Domestic Substances List):

124-38-9 Carbon dioxide: listed.

\section{SECTION 16: Other information}

Abbreviations and Acronyms: None

This product has been classified in accordance with OSHA HCS 2012 guidelines. The information provided in this SDS is correct, to the best of our knowledge, based on information available. The information given is designed only as a guidance for safe handling, use, storage, transportation and disposal and is not to be considered a warranty or quality specification. The information relates only to the specific material designated and may not be valid for such material used in combination with any other materials, unless specified in the text. The responsibility to provide a safe workplace remains with the user.

NFPA: $1-1-0$

HMIS: $1-1-0$

Initial preparation date: 01.26 .2017 
SAFETY DATA SHEET

\section{ZERO VOC BRAKE \& PARTS CLEANER}

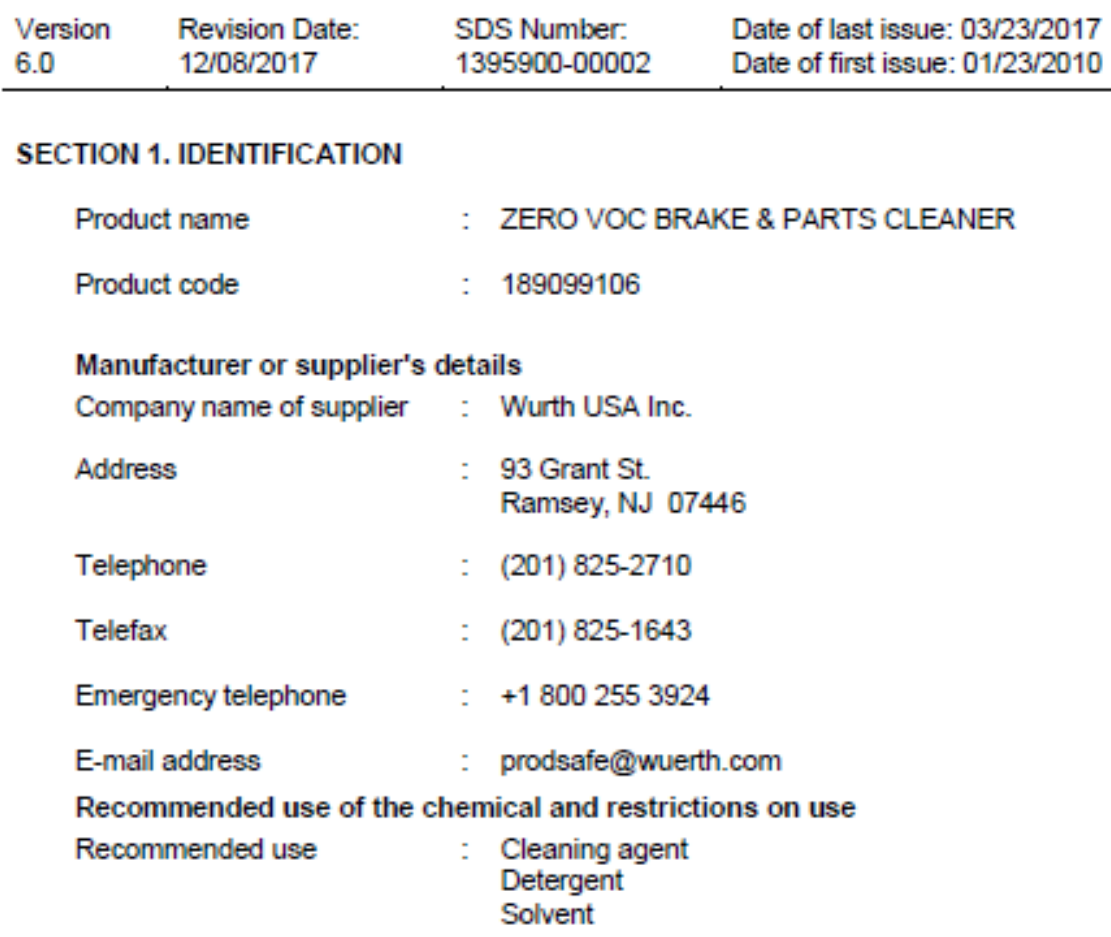

Product name

Product code

: 189099106

Manufacturer or supplier's details

Company name of supplier : Wurth USA Inc.

Address $\quad$ : 93 Grant St. Ramsey, NJ 07446

Telephone : (201) $825-2710$

Telefax

: (201) $825-1643$

Emergency telephone

: +18002553924

E-mail address

: prodsafe@wuerth.com

Recommended use of the chemical and restrictions on use

Recommended use

: Cleaning agent

Detergent

Solvent

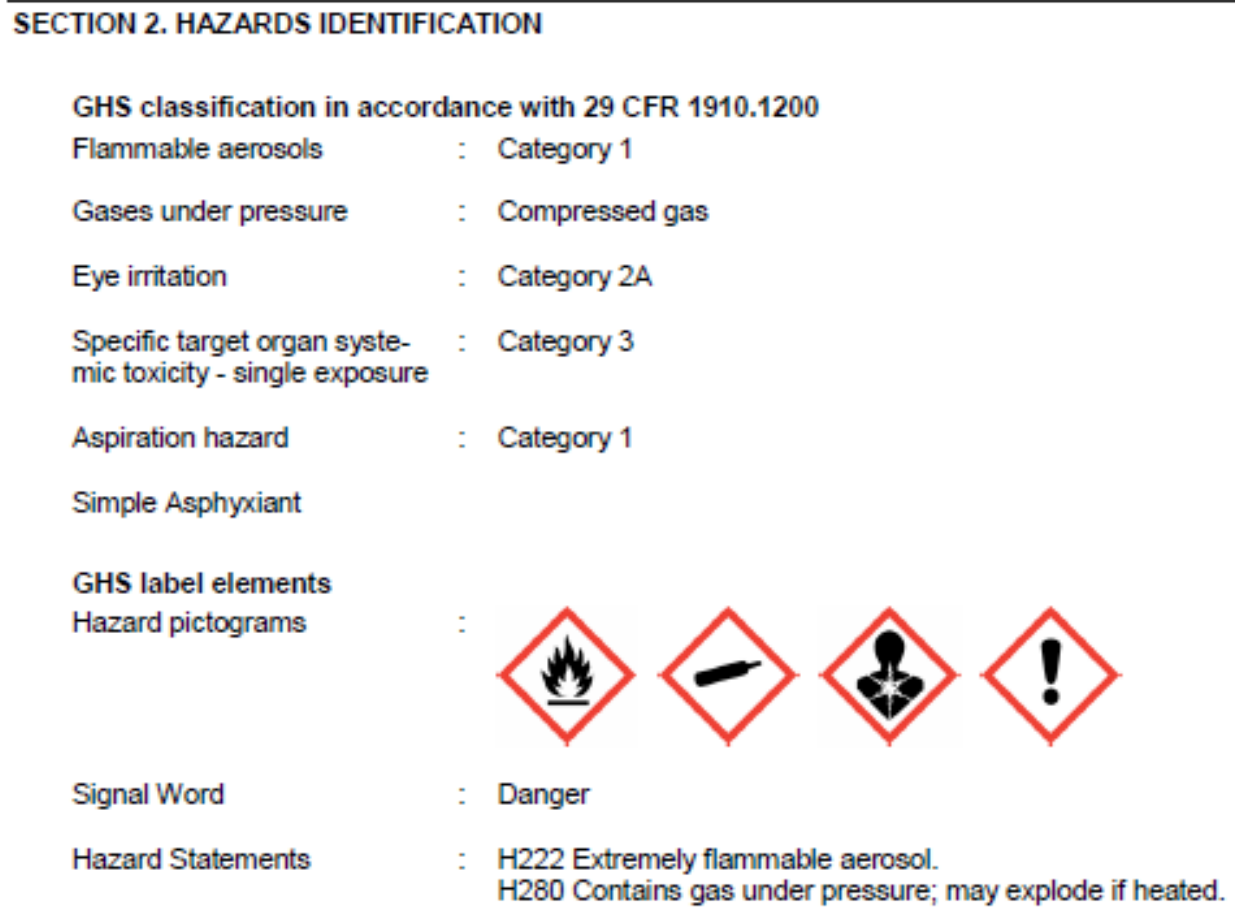

Signal Word

: Danger

Hazard Statements

H222 Extremely flammable aerosol. H280 Contains gas under pressure; may explode if heated. 
SAFETY DATA SHEET

ZERO VOC BRAKE \& PARTS CLEANER

\begin{tabular}{|c|c|c|c|}
\hline $\begin{array}{l}\text { Version } \\
6.0\end{array}$ & $\begin{array}{l}\text { Revision Date: } \\
12 / 08 / 2017\end{array}$ & $\begin{array}{l}\text { SDS Number: } \\
1395900-00002\end{array}$ & $\begin{array}{l}\text { Date of last issue: } 03 / 23 / 2017 \\
\text { Date of first issue: } 01 / 23 / 2010\end{array}$ \\
\hline \multirow{9}{*}{\multicolumn{2}{|c|}{ Precautionary Statements }} & \multicolumn{2}{|c|}{$\begin{array}{l}\text { H304 May be fatal if swallowed and enters airways. } \\
\text { H319 Causes serious eye irritation. } \\
\text { H336 May cause drowsiness or dizziness. } \\
\text { May displace oxygen and cause rapid suffocation. }\end{array}$} \\
\hline & & \multicolumn{2}{|l|}{ : Prevention: } \\
\hline & & \multicolumn{2}{|c|}{$\begin{array}{l}\text { P210 Keep away from heat/sparks/open flames/hot surfaces. } \\
\text { No smoking. } \\
\text { P211 Do not spray on an open flame or other ignition source. } \\
\text { P251 Pressurized container: Do not pierce or burn, even after } \\
\text { use. } \\
\text { P261 Avoid breathing spray. } \\
\text { P264 Wash skin thoroughly after handling. } \\
\text { P271 Use only outdoors or in a well-ventilated area. } \\
\text { P280 Wear eye protection/ face protection. }\end{array}$} \\
\hline & & \multicolumn{2}{|l|}{ Response: } \\
\hline & & \multicolumn{2}{|c|}{$\begin{array}{l}\text { P301 + P310 IF SWALLOWED: Immediately call a POISON } \\
\text { CENTER/doctor. } \\
\text { P304 + P340 + P312 IF INHALED: Remove person to fresh air } \\
\text { and keep comfortable for breathing. Call a POISON } \\
\text { CENTER/doctor if you feel unwell. } \\
\text { P305 + P351 + P338 IF IN EYES: Rinse cautiously with water } \\
\text { for several minutes. Remove contact lenses, if present and easy } \\
\text { to do. Continue rinsing. } \\
\text { P331 Do NOT induce vomiting. } \\
\text { P337 + P313 If eye irritation persists: Get medical advice/ atten- } \\
\text { tion. }\end{array}$} \\
\hline & & \multicolumn{2}{|l|}{ Storage: } \\
\hline & & \multicolumn{2}{|c|}{$\begin{array}{l}\text { P405 Store locked up. } \\
\text { P4 } 10+\text { P412 Protect from sunlight. Do not expose to tempera- } \\
\text { tures exceeding } 50^{\circ} \mathrm{C} / 122^{\circ} \mathrm{F} \text {. }\end{array}$} \\
\hline & & \multicolumn{2}{|l|}{ Disposal: } \\
\hline & & \multicolumn{2}{|c|}{$\begin{array}{l}\text { P501 Dispose of contents/ container to an approved waste dis- } \\
\text { posal plant. }\end{array}$} \\
\hline
\end{tabular}

Other hazards

Repeated exposure may cause skin dryness or cracking.

\begin{tabular}{l}
\hline SECTION 3. COMPOSITION/INFORMATION ON INGREDIENTS \\
Substance / Mixture : Mixture \\
Hazardous ingredients \\
\begin{tabular}{|l|l|c|}
\hline Chemical name & CAS-No. & Concentration $(\%$ w/w $)$ \\
\hline Acetone & $67-64-1$ & $>=90-<100$ \\
\hline Carbon dioxide & $124-38-9$ & $>=5-<10$ \\
\hline
\end{tabular}
\end{tabular}

SECTION 4. FIRST AID MEASURES 
SAFETY DATA SHEET

\section{ZERO VOC BRAKE \& PARTS CLEANER}

\begin{tabular}{|c|c|c|c|}
\hline $\begin{array}{l}\text { Version } \\
6.0\end{array}$ & $\begin{array}{l}\text { Revision Date: } \\
12 / 08 / 2017\end{array}$ & $\begin{array}{l}\text { SDS Number: } \\
1395900-00002\end{array}$ & $\begin{array}{l}\text { Date of last issue: } 03 / 23 / 2017 \\
\text { Date of first issue: } 01 / 23 / 2010\end{array}$ \\
\hline \multicolumn{2}{|c|}{ General advice } & $\begin{array}{l}\text { In the case o } \\
\text { vice immedia } \\
\text { When sympt } \\
\text { advice. }\end{array}$ & $\begin{array}{l}\text { cident or if you feel unwell, seek medical ad- } \\
\text { persist or in all cases of doubt seek medical }\end{array}$ \\
\hline \multicolumn{2}{|c|}{ If inhaled } & $\begin{array}{l}\text { If inhaled, rer } \\
\text { Get medical }\end{array}$ & $\begin{array}{l}\text { to fresh air. } \\
\text { tion if symptoms occur. }\end{array}$ \\
\hline \multicolumn{2}{|c|}{ In case of skin contact } & $\begin{array}{l}\text { In case of co } \\
\text { Get medical }\end{array}$ & $\begin{array}{l}\text { t, immediately flush skin with plenty of water. } \\
\text { tion if symptoms occur. }\end{array}$ \\
\hline \multicolumn{2}{|c|}{ In case of eye contact } & $\begin{array}{l}\text { In case of co } \\
\text { for at least } 1 \\
\text { If easy to do, } \\
\text { Get medical }\end{array}$ & $\begin{array}{l}\text { t, immediately flush eyes with plenty of water } \\
\text { nutes. } \\
\text { ove contact lens, if worn. } \\
\text { tion. }\end{array}$ \\
\hline \multicolumn{2}{|c|}{ If swallowed } & $\begin{array}{l}\text { If swallowed, } \\
\text { If vomiting oc } \\
\text { Call a physic } \\
\text { Rinse mouth } \\
\text { Never give a }\end{array}$ & $\begin{array}{l}\text { NOT induce vomiting. } \\
\text { have person lean forward. } \\
\text { r poison control center immediately. } \\
\text { oughly with water. } \\
\text { ing by mouth to an unconscious person. }\end{array}$ \\
\hline \multicolumn{2}{|c|}{$\begin{array}{l}\text { Most important symptoms } \\
\text { and effects, both acute and } \\
\text { delayed }\end{array}$} & $\begin{array}{l}\text { May be fatal } \\
\text { Causes serio } \\
\text { May cause d } \\
\text { Prolonged or } \\
\text { tion. }\end{array}$ & $\begin{array}{l}\text { llowed and enters airways. } \\
\text { ye irritation. } \\
\text { iness or dizziness. } \\
\text { eated contact may dry skin and cause irrita- }\end{array}$ \\
\hline \multicolumn{2}{|c|}{ Protection of first-aiders } & $\begin{array}{l}\text { First Aid resp } \\
\text { and use the } \\
\text { when the pot }\end{array}$ & $\begin{array}{l}\text { ers should pay attention to self-protection, } \\
\text { mmended personal protective equipment } \\
\text { al for exposure exists. }\end{array}$ \\
\hline \multicolumn{2}{|c|}{ Notes to physician } & : Treat sympto & ically and supportively. \\
\hline
\end{tabular}

SECTION 5. FIRE-FIGHTING MEASURES

Suitable extinguishing media

Unsuitable extinguishing media

Specific hazards during fire fighting

Hazardous combustion prod- : Carbon oxides

ucts

Specific extinguishing meth- : Use extinguishing measures that are appropriate to local cir-

\section{Water spray}

Alcohol-resistant foam

Carbon dioxide (CO2)

Dry chemical

None known.

Flash back possible over considerable distance. Vapors may form explosive mixtures with air. Exposure to combustion products may be a hazard to health. If the temperature rises there is danger of the vessels bursting due to the high vapor pressure. 
SAFETY DATA SHEET

WiRTH

\section{ZERO VOC BRAKE \& PARTS CLEANER}

\begin{tabular}{llll}
$\begin{array}{l}\text { Version } \\
6.0\end{array}$ & $\begin{array}{l}\text { Revision Date: } \\
12 / 08 / 2017\end{array}$ & $\begin{array}{l}\text { SDS Number: } \\
1395900-00002\end{array}$ & $\begin{array}{l}\text { Date of last issue: } 03 / 23 / 2017 \\
\text { Date of first issue: } 01 / 23 / 2010\end{array}$ \\
\hline \multirow{2}{*}{ ods } & $\begin{array}{l}\text { cumstances and the surrounding environment. } \\
\text { Use water spray to cool unopened containers. } \\
\text { Remove undamaged containers from fire area if it is safe to } \\
\text { so. } \\
\text { Evacuate area. }\end{array}$ \\
& $\begin{array}{l}\text { Special protective equipment } \\
\text { for fire-fighters }\end{array}$ & $\begin{array}{l}\text { In the event of fire, wear self-contained breathing apparatus. } \\
\text { Use personal protective equipment. }\end{array}$
\end{tabular}

SECTION 6. ACCIDENTAL RELEASE MEASURES

Personal precautions, protec- : Evacuate personnel to safe areas.

tive equipment and emer- Remove all sources of ignition.

gency procedures Ventilate the area.

Use personal protective equipment.

Follow safe handling advice and personal protective equipment recommendations.

Environmental precautions

Discharge into the environment must be avoided.

Prevent further leakage or spillage if safe to do so.

Prevent spreading over a wide area (e.g., by containment or

oil barriers).

Retain and dispose of contaminated wash water.

Local authorities should be advised if significant spillages

cannot be contained.

Methods and materials for

Non-sparking tools should be used.

containment and cleaning up

Soak up with inert absorbent material.

Suppress (knock down) gases/vapors/mists with a water spray jet.

For large spills, provide diking or other appropriate containment to keep material from spreading. If diked material can be pumped, store recovered material in appropriate container. Clean up remaining materials from spill with suitable absorbent.

Local or national regulations may apply to releases and disposal of this material, as well as those materials and items employed in the cleanup of releases. You will need to determine which regulations are applicable.

Sections 13 and 15 of this SDS provide information regarding certain local or national requirements.

\section{SECTION 7. HANDLING AND STORAGE}

Technical measures

Local/Total ventilation

Advice on safe handling
: See Engineering measures under EXPOSURE CONTROLSIPERSONAL PROTECTION section.

: Use with local exhaust ventilation. Use only in an area equipped with explosion-proof exhaust ventilation if advised by assessment of the local exposure potential

: Do not spray on an open flame or other ignition source. 
SAFETY DATA SHEET

\section{ZERO VOC BRAKE \& PARTS CLEANER}

\begin{tabular}{|c|c|c|c|}
\hline $\begin{array}{l}\text { Version } \\
6.0 \\
\end{array}$ & $\begin{array}{l}\text { Revision Date: } \\
12 / 08 / 2017\end{array}$ & $\begin{array}{l}\text { SDS Number: } \\
1395900-00002\end{array}$ & $\begin{array}{l}\text { Date of last issue: } 03 / 23 / 2017 \\
\text { Date of first issue: } 01 / 23 / 2010\end{array}$ \\
\hline & & \multicolumn{2}{|c|}{$\begin{array}{l}\text { Do not get on skin or clothing. } \\
\text { Do not breathe vapors or spray mist. } \\
\text { Do not swallow. } \\
\text { Do not get in eyes. } \\
\text { Handle in accordance with good industrial hygiene and safety } \\
\text { practice, based on the results of the workplace exposure as- } \\
\text { sessment } \\
\text { Keep container tightly closed. } \\
\text { Keep away from heat and sources of ignition. } \\
\text { Take precautionary measures against static discharges. } \\
\text { Take care to prevent spills, waste and minimize release to the } \\
\text { environment. }\end{array}$} \\
\hline \multicolumn{2}{|c|}{ Conditions for safe storage } & \multicolumn{2}{|c|}{$\begin{array}{l}\text { Store locked up. } \\
\text { Keep tightly closed. } \\
\text { Keep in a cool, well-ventilated place. } \\
\text { Store in accordance with the particular national regulations. } \\
\text { Do not pierce or burn, even after use. } \\
\text { Keep cool. Protect from sunlight. }\end{array}$} \\
\hline \multicolumn{2}{|c|}{ Materials to avoid } & \multicolumn{2}{|c|}{$\begin{array}{l}\text { Do not store with the following product types: } \\
\text { Self-reactive substances and mixtures } \\
\text { Organic peroxides } \\
\text { Oxidizing agents } \\
\text { Flammable solids } \\
\text { Pyrophoric liquids } \\
\text { Pyrophoric solids } \\
\text { Self-heating substances and mixtures } \\
\text { Substances and mixtures which in contact with water emit } \\
\text { flammable gases } \\
\text { Explosives }\end{array}$} \\
\hline \multicolumn{2}{|c|}{$\begin{array}{l}\text { Recommended storage tem- } \\
\text { perature }\end{array}$} & $: \quad<35^{\circ} \mathrm{C}$ & \\
\hline
\end{tabular}

\section{SECTION 8. EXPOSURE CONTROLS/PERSONAL PROTECTION}

Ingredients with workplace control parameters

\begin{tabular}{|l|l|l|l|l|}
\hline Ingredients & CAS-No. & $\begin{array}{l}\text { Value type } \\
\text { (Form of } \\
\text { exposure) }\end{array}$ & $\begin{array}{l}\text { Control parame- } \\
\text { ters / Permissible } \\
\text { concentration }\end{array}$ & Basis \\
\hline Acetone & $67-64-1$ & TWA & $250 \mathrm{ppm}$ & ACGIH \\
\hline & & STEL & $500 \mathrm{ppm}$ & ACGIH \\
\hline & & TWA & $\begin{array}{l}1,000 \mathrm{ppm} \\
2,400 \mathrm{mg}^{3}\end{array}$ & OSHA Z-1 \\
\hline & & TWA & $\begin{array}{l}250 \mathrm{ppm} \\
590 \mathrm{mg} / \mathrm{m}^{3}\end{array}$ & NIOSH REL \\
\hline Carbon dioxide & & TWA & $5,000 \mathrm{ppm}$ & ACGIH \\
\hline & $124-38-9$ & STEL & $30,000 \mathrm{ppm}$ & ACGIH \\
\hline & & TWA & $\begin{array}{l}5,000 \mathrm{ppm} \\
9,000 \mathrm{mg} / \mathrm{m}^{3}\end{array}$ & OSHA Z-1 \\
\hline & & TWA & $5,000 \mathrm{ppm}$ & NIOSH REL \\
\hline
\end{tabular}


SAFETY DATA SHEET

\section{ZERO VOC BRAKE \& PARTS CLEANER}

\begin{tabular}{|c|c|c|c|c|c|}
\hline $\begin{array}{l}\text { Version } \\
6.0\end{array}$ & $\begin{array}{l}\text { Revision Date: } \\
12 / 08 / 2017\end{array}$ & $\begin{array}{l}\text { SDS Number: } \\
1395900-00002\end{array}$ & \multicolumn{3}{|c|}{$\begin{array}{l}\text { Date of last issue: } 03 / 23 / 2017 \\
\text { Date of first issue: } 01 / 23 / 2010\end{array}$} \\
\hline & & & & $9,000 \mathrm{mg} / \mathrm{m}^{3}$ & \\
\hline & & & ST & $\begin{array}{l}30,000 \mathrm{ppm} \\
54,000 \mathrm{mg} / \mathrm{m}^{3}\end{array}$ & NIOSH REL \\
\hline
\end{tabular}

Biological occupational exposure limits

\begin{tabular}{|c|c|c|c|c|c|c|}
\hline Ingredients & CAS-No. & $\begin{array}{l}\text { Control } \\
\text { parameters }\end{array}$ & $\begin{array}{l}\text { Biological } \\
\text { specimen }\end{array}$ & $\begin{array}{l}\text { Sam- } \\
\text { pling } \\
\text { time }\end{array}$ & $\begin{array}{l}\text { Permissible } \\
\text { concentra- } \\
\text { tion }\end{array}$ & Basis \\
\hline Acetone & $67-64-1$ & Acetone & Urine & $\begin{array}{l}\text { End of } \\
\text { shift (As } \\
\text { soon as } \\
\text { possible } \\
\text { after } \\
\text { exposure } \\
\text { ceases) }\end{array}$ & $25 \mathrm{mg} /$ & $\begin{array}{l}\text { ACGIH } \\
\text { BEl }\end{array}$ \\
\hline
\end{tabular}

Engineering measures

- Minimize workplace exposure concentrations.

Use only in an area equipped with explosion-proof exhaust ventilation if advised by assessment of the local exposure potential

Use with local exhaust ventilation.

Personal protective equipment

Respiratory protection

: General and local exhaust ventilation is recommended to maintain vapor exposures below recommended limits. Where concentrations are above recommended limits or are unknown, appropriate respiratory protection should be worn. Follow OSHA respirator regulations (29 CFR 1910.134) and use NIOSH/MSHA approved respirators. Protection provided by air purifying respirators against exposure to any hazardous chemical is limited. Use a positive pressure air supplied respirator if there is any potential for uncontrolled release, exposure levels are unknown, or any other circumstance where air purifying respirators may not provide adequate protection.

Hand protection Material

butyl-rubber

Remarks

: Choose gloves to protect hands against chemicals depending on the concentration specific to place of work. For special applications, we recommend clarifying the resistance to chemicals of the aforementioned protective gloves with the glove manufacturer. Wash hands before breaks and at the end of workday. Breakthrough time is not determined for the product. Change gloves often!

Eye protection $\quad$ : Wear the following personal protective equipment: Safety goggles

Skin and body protection

: Select appropriate protective clothing based on chemical resistance data and an assessment of the local exposure 
SAFETY DATA SHEET

ZERO VOC BRAKE \& PARTS CLEANER

\begin{tabular}{|c|c|c|c|}
\hline $\begin{array}{l}\text { Version } \\
6.0\end{array}$ & $\begin{array}{l}\text { Revision Date: } \\
12 / 08 / 2017\end{array}$ & $\begin{array}{l}\text { SDS Number: } \\
1395900-00002\end{array}$ & $\begin{array}{l}\text { Date of last issue: } 03 / 23 / 2017 \\
\text { Date of first issue: } 01 / 23 / 2010\end{array}$ \\
\hline & & \multicolumn{2}{|c|}{$\begin{array}{l}\text { potential. } \\
\text { Wear the following personal protective equipment: } \\
\text { Flame retardant antistatic protective clothing, unless asses- } \\
\text { sment demonstrates that the risk of explosive atmospheres } \\
\text { or flash fires is low } \\
\text { Skin contact must be avoided by using impervious protective } \\
\text { clothing (gloves, aprons, boots, etc). }\end{array}$} \\
\hline \multicolumn{2}{|c|}{ Hygiene measures } & \multicolumn{2}{|c|}{$\begin{array}{l}\text { Ensure that eye flushing systems and safety showers are } \\
\text { located close to the working place. } \\
\text { When using do not eat, drink or smoke. } \\
\text { Wash contaminated clothing before re-use. }\end{array}$} \\
\hline
\end{tabular}

SECTION 9. PHYSICAL AND CHEMICAL PROPERTIES

$\begin{array}{ll}\text { Appearance } & : \text { Aerosol containing a compressed gas } \\ \text { Color } & : \text { No data available } \\ \text { Odor } & : \text { No data available } \\ \text { Odor Threshold } & : \text { No data available } \\ \text { pH } & : \text { No data available } \\ \text { Melting point/freezing point } & : \text { No data available } \\ \text { Initial boiling point and boiling } & : \text { Not applicable } \\ \text { range } & : \text {-18 }{ }^{\circ} \mathrm{C} \\ \text { Flash point } & : \text { Not applicable } \\ \text { Evaporation rate } & : \text { Extremely flammable aerosol. } \\ \text { Flammability (solid, gas) } & : \text { No data available } \\ \text { Upper explosion limit / Upper } \\ \text { flammability limit }\end{array}$


SAFETY DATA SHEET

\section{ZERO VOC BRAKE \& PARTS CLEANER}

\begin{tabular}{|c|c|c|c|}
\hline $\begin{array}{l}\text { Version } \\
6.0\end{array}$ & $\begin{array}{l}\text { Revision Date: } \\
12 / 08 / 2017\end{array}$ & $\begin{array}{l}\text { SDS Number: } \\
1395900-00002\end{array}$ & $\begin{array}{l}\text { Date of last issue: } 03 / 23 / 2017 \\
\text { Date of first issue: } 01 / 23 / 2010\end{array}$ \\
\hline \multicolumn{4}{|c|}{ octanol/water } \\
\hline Autc & nition temperature & : No data ava & \\
\hline Dec & nposition temperature & : No data ava & \\
\hline \multicolumn{4}{|c|}{ Viscosity } \\
\hline & cosity, kinematic & : Not applical & \\
\hline Expl & ive properties & : Not explosiv & \\
\hline Oxid & ing properties & : The substar & or mixture is not classified as oxidizing. \\
\hline Parti & e size & : Not applical & \\
\hline \multicolumn{4}{|c|}{ SECTION 10. STABILITY AND REACTIVITY } \\
\hline Rea & vity & : Not classifie & s a reactivity hazard. \\
\hline Che & cal stability & : Stable unde & ormal conditions. \\
\hline $\begin{array}{l}\text { Poss } \\
\text { tions }\end{array}$ & ility of hazardous reac- & $\begin{array}{l}\text { Extremely fl } \\
\text { Vapors may } \\
\text { If the tempe } \\
\text { due to the } h \\
\text { Can react wi }\end{array}$ & $\begin{array}{l}\text { mable aerosol. } \\
\text { m explosive mixture with air. } \\
\text { Ire rises there is danger of the vessels bursting } \\
\text { vapor pressure. } \\
\text { strong oxidizing agents. }\end{array}$ \\
\hline Con & ions to avoid & : Heat, flames & d sparks. \\
\hline Incol & patible materials & : Oxidizing ag & \\
\hline $\begin{array}{l}\text { Haz: } \\
\text { prod }\end{array}$ & $\begin{array}{l}\text { dous decomposition } \\
\text { ts }\end{array}$ & : No hazardou & lecomposition products are known. \\
\hline
\end{tabular}

SECTION 11. TOXICOLOGICAL INFORMATION

Information on likely routes of exposure

Inhalation

Skin contact

Ingestion

Eye contact

Acute toxicity

Not classified based on available information.

Ingredients:

Acetone:

Acute oral toxicity

LD50 (Rat): > 5,000 mg/kg

Acute inhalation toxicity

$$
\begin{aligned}
& \text { LC50 (Rat): > } 40 \mathrm{mg} / 1 \\
& \text { Exposure time: } 4 \mathrm{~h} \\
& \text { Test atmosphere: vapor }
\end{aligned}
$$


SAFETY DATA SHEET

\section{ZERO VOC BRAKE \& PARTS CLEANER}

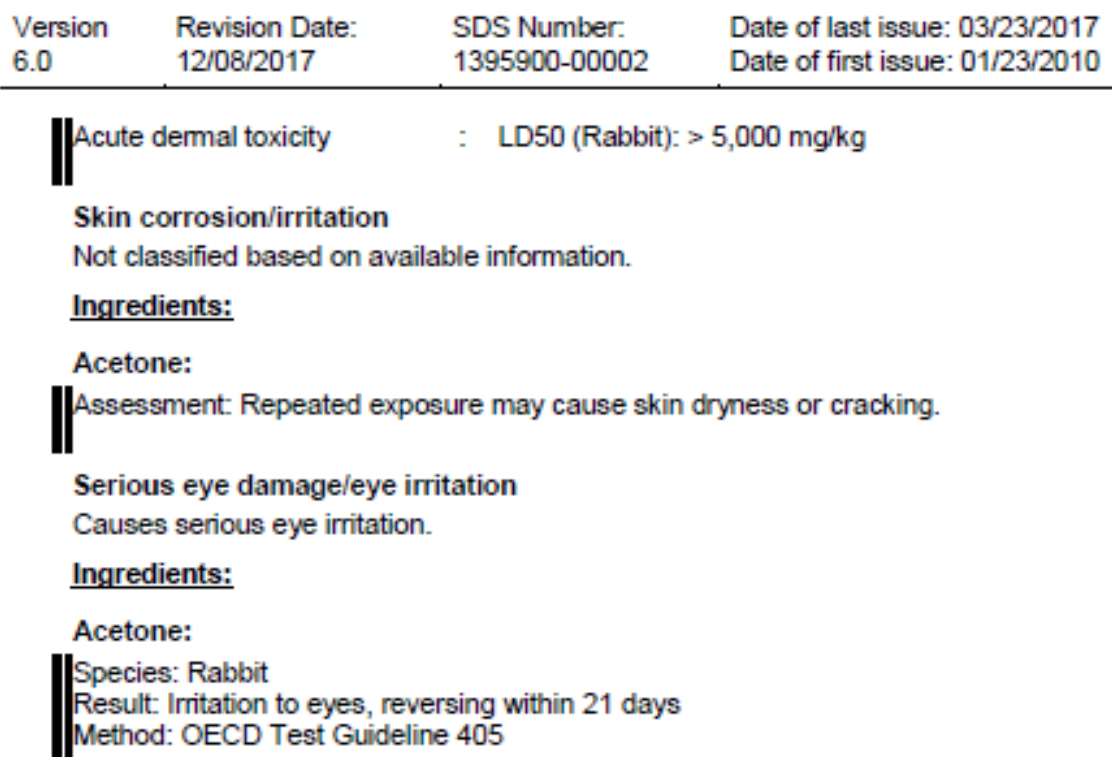

Respiratory or skin sensitization

\section{Skin sensitization}

Not classified based on available information.

Respiratory sensitization

Not classified based on available information.

Ingredients:

\section{Acetone:}

Test Type: Maximization Test

Routes of exposure: Skin contact

Species: Guinea pig

Result: negative

\section{Germ cell mutagenicity}

Not classified based on available information.

\section{Ingredients:}

Acetone:

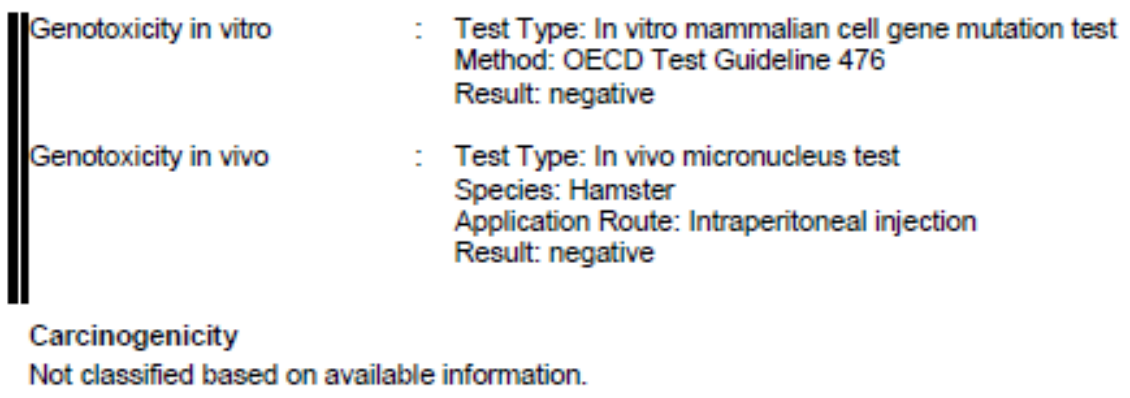


SAFETY DATA SHEET

\title{
ZERO VOC BRAKE \& PARTS CLEANER
}

\author{
Version Revision Date: $\quad$ SDS Number: Date of last issue: 03/23/2017

$6.012 / 08 / 2017 \quad 1395900-00002 \quad$ Date of first issue: $01 / 23 / 2010$ \\ Ingredients: \\ Acetone: \\ Species: Mouse \\ Application Route: Skin contact \\ Exposure time: 1 Years \\ Result: negative \\ IARC \\ No ingredient of this product present at levels greater than or \\ equal to $0.1 \%$ is identified as probable, possible or confirmed \\ human carcinogen by IARC. \\ OSHA No component of this product present at levels greater than or \\ equal to $0.1 \%$ is on OSHA's list of regulated carcinogens. \\ NTP No ingredient of this product present at levels greater than or \\ equal to $0.1 \%$ is identified as a known or anticipated carcinogen \\ by NTP.
}

Reproductive toxicity

Not classified based on available information.

Ingredients:

Acetone:

\begin{tabular}{|c|c|}
\hline Effects on fertility & $\begin{array}{l}\text { Test Type: One-generation reproduction toxicity study } \\
\text { Species: Rat } \\
\text { Application Route: Ingestion } \\
\text { Result: negative }\end{array}$ \\
\hline Effects on fetal development & $\begin{array}{l}\text { Test Type: Embryo-fetal development } \\
\text { Species: Mouse } \\
\text { Result: negative }\end{array}$ \\
\hline
\end{tabular}

STOT-single exposure

May cause drowsiness or dizziness.

Ingredients:

Acetone:

Assessment: May cause drowsiness or dizziness.

STOT-repeated exposure

Not classified based on available information.

Repeated dose toxicity

Ingredients:

Acetone:

Species: Rat

LOAEL: $1,700 \mathrm{mg} / \mathrm{kg}$

Application Route: Ingestion

Exposure time: 90 Days 
SAFETY DATA SHEET

\title{
ZERO VOC BRAKE \& PARTS CLEANER
}

\author{
Version Revision Date: $\quad$ SDS Number: Date of last issue: $03 / 23 / 2017$ \\ $6.012 / 08 / 2017 \quad 1395900-00002 \quad$ Date of first issue: $01 / 23 / 2010$ \\ II \\ Aspiration toxicity \\ May be fatal if swallowed and enters airways. \\ Product: \\ The substance or mixture is known to cause human aspiration toxicity hazards or has to be re- \\ garded as if it causes a human aspiration toxicity hazard.
}

SECTION 12. ECOLOGICAL INFORMATION

Ecotoxicity

Ingredients:

Acetone:

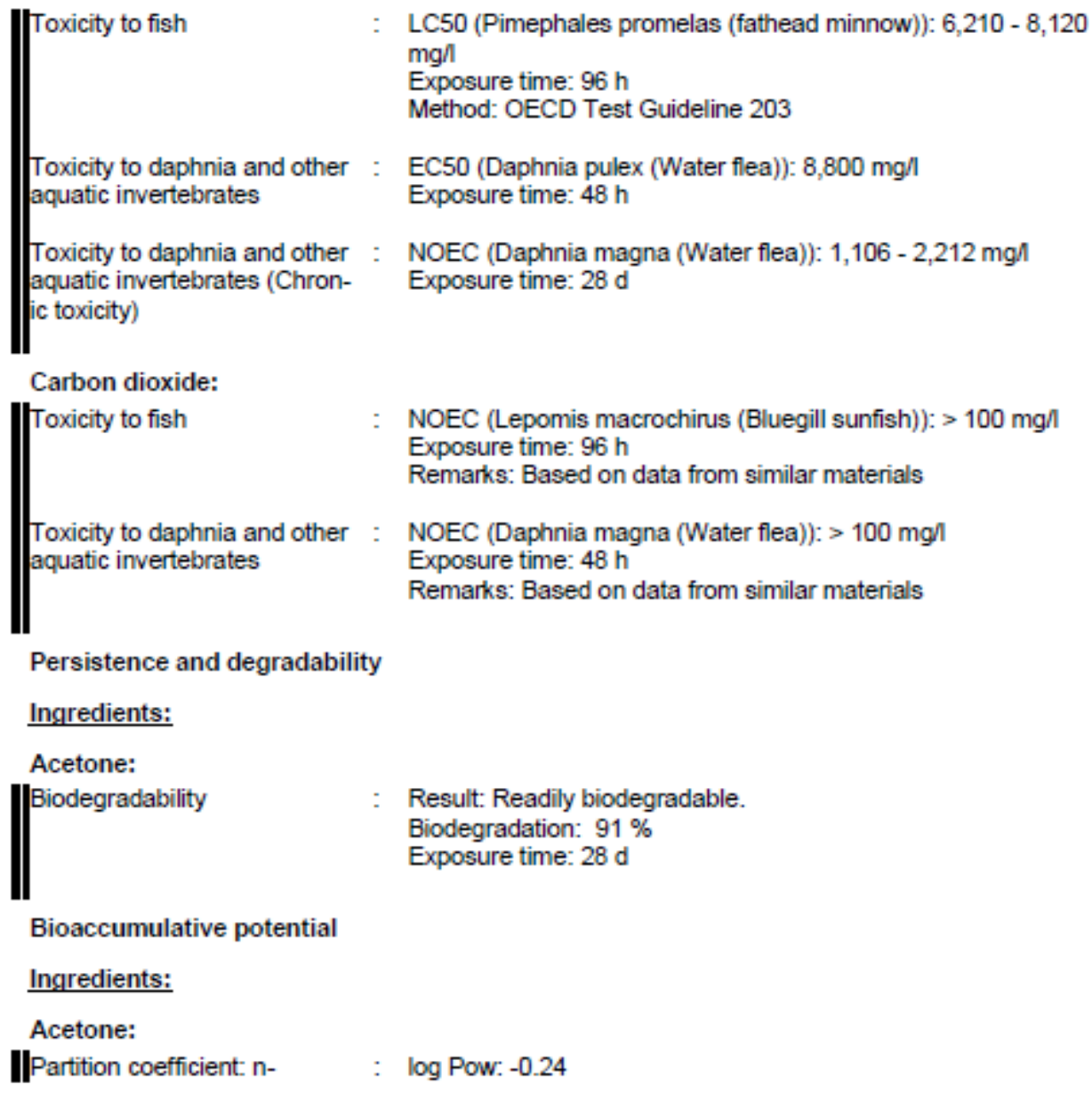

Carbon dioxide:

Toxicity to fish

NOEC (Lepomis macrochirus (Bluegill sunfish)): > $100 \mathrm{mg} /$

Exposure time: $96 \mathrm{~h}$

Remarks: Based on data from similar materials

Toxicity to daphnia and other

NOEC (Daphnia magna (Water flea)): > $100 \mathrm{mg} /$

aquatic invertebrates

Exposure time: $48 \mathrm{~h}$

Remarks: Based on data from similar materials

Persistence and degradability

Ingredients:

Acetone:

|Biodegradability

Result: Readily biodegradable.

Biodegradation: $91 \%$

Exposure time: $28 \mathrm{~d}$

Bioaccumulative potential

Ingredients:

Acetone:

|lPartition coefficient: $n-\quad$ : $\quad \log$ Pow: -0.24 
SAFETY DATA SHEET

불 WURTH

\section{ZERO VOC BRAKE \& PARTS CLEANER}

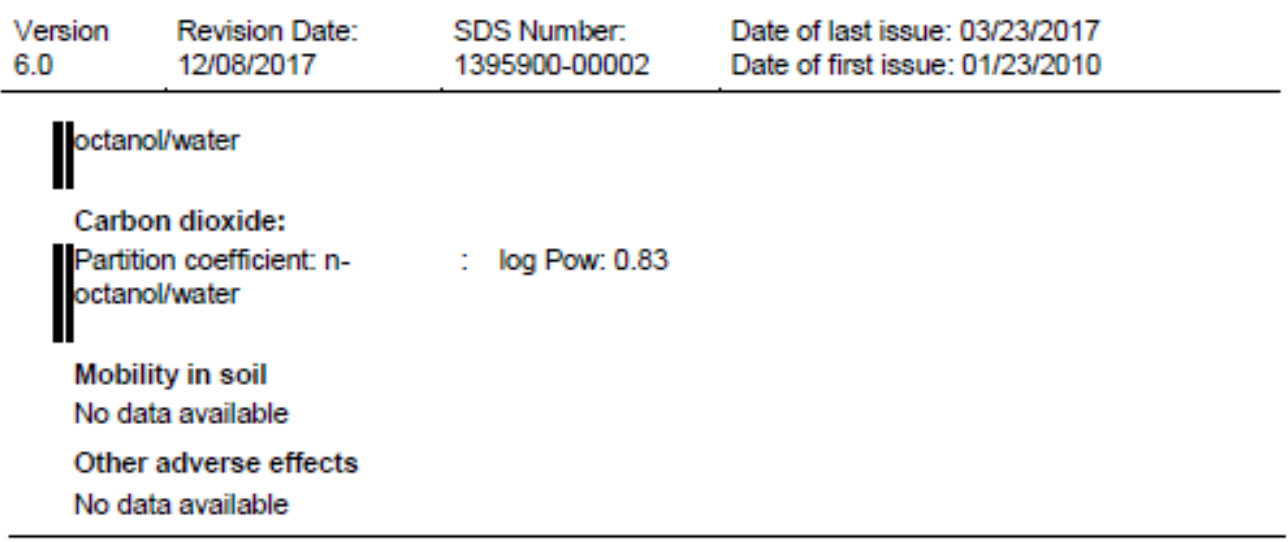

SECTION 13. DISPOSAL CONSIDERATIONS

Disposal methods

Waste from residues

: Dispose of in accordance with local regulations.

Contaminated packaging
: Empty containers should be taken to an approved waste handling site for recycling or disposal.
Empty containers retain residue and can be dangerous. Do not pressurize, cut, weld, braze, solder, drill, grind, or ex- pose such containers to heat, flame, sparks, or other sources of ignition. They may explode and cause injury and/or death. If not otherwise specified: Dispose of as unused product. Please ensure aerosol cans are sprayed completely empty (including propellant)

\begin{tabular}{|c|c|}
\hline \\
\hline \multicolumn{2}{|c|}{$\begin{array}{l}\text { SECTION 14. TRANSPORT INFORMATION } \\
\text { International Regulations }\end{array}$} \\
\hline \multicolumn{2}{|l|}{$\begin{array}{l}\text { UNRTDG } \\
\text { UN number } \\
\text { Proper shipping name } \\
\text { |l|class } \\
\text { Packing group } \\
\text { ||lLabels }\end{array}$} \\
\hline $\begin{array}{l}\text { IATA-DGR } \\
\text { UN/ID No. } \\
\text { Proper shipping name } \\
\text { |lClass } \\
\text { Packing group } \\
\text { |labels } \\
\text { Packing instruction (cargo } \\
\text { aircraft) } \\
\text { Packing instruction (passen- } \\
\text { ger aircraft) }\end{array}$ & $\begin{array}{ll}: & \text { UN } 1950 \\
\vdots & \text { Aerosols, flammable } \\
\vdots & 2.1 \\
\vdots & \text { Not assigned by regulation } \\
\vdots & \text { Flammable Gas } \\
& 203 \\
: & 203\end{array}$ \\
\hline $\begin{array}{l}\text { IMDG-Code } \\
\text { UN number } \\
\text { Proper shipping name }\end{array}$ & $\begin{array}{ll}: & \text { UN } 1950 \\
: & \text { AEROSOLS }\end{array}$ \\
\hline
\end{tabular}


SAFETY DATA SHEET

\section{ZERO VOC BRAKE \& PARTS CLEANER}

\begin{tabular}{|c|c|c|c|}
\hline $\begin{array}{l}\text { Version } \\
6.0\end{array}$ & $\begin{array}{l}\text { Revision Date: } \\
12 / 08 / 2017\end{array}$ & $\begin{array}{l}\text { SDS Number: } \\
1395900-00002\end{array}$ & $\begin{array}{l}\text { Date of last issue: } 03 / 23 / 2017 \\
\text { Date of first issue: } 01 / 23 / 2010\end{array}$ \\
\hline $\begin{array}{l}\mid \text { |llas } \\
\text { Pac } \\
\mid \begin{array}{ll}\text { Lab } \\
\text { Em } \\
\text { Mar }\end{array}\end{array}$ & $\begin{array}{l}\text { g group } \\
\text { pode } \\
\text { pollutant }\end{array}$ & $\begin{array}{ll}\vdots & 2.1 \\
\vdots & \text { Not assigned } \\
\vdots & 2.1 \\
\vdots & \text { F-D, S-U } \\
\vdots & \text { no }\end{array}$ & egulation \\
\hline \multicolumn{4}{|c|}{$\begin{array}{l}\text { Transport in bulk according to Annex II of MARPOL } 73 / 78 \text { and the IBC Code } \\
\text { Not applicable for product as supplied. }\end{array}$} \\
\hline \multicolumn{4}{|c|}{ Domestic regulation } \\
\hline $\begin{array}{l}490 \\
\text { UN/ } \\
\text { Prop }\end{array}$ & $\begin{array}{l}\text { NA number } \\
\text { shipping name }\end{array}$ & $\begin{array}{l}\text { : UN } 1950 \\
: \text { Aerosols }\end{array}$ & \\
\hline 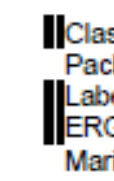 & $\begin{array}{l}\text { g group } \\
\text { ode } \\
\text { pollutant }\end{array}$ & $\begin{array}{ll}\vdots & 2.1 \\
\vdots & \text { Not assigned } \\
\vdots & \text { FLAMMABLE } \\
\vdots & 126 \\
\vdots & \text { no }\end{array}$ & $\begin{array}{l}\text { egulation } \\
\mathrm{S}\end{array}$ \\
\hline
\end{tabular}

SECTION 15. REGULATORY INFORMATION

EPCRA - Emergency Planning and Community Right-to-Know

CERCLA Reportable Quantity

\begin{tabular}{|l|l|c|c|}
\hline Ingredients & CAS-No. & $\begin{array}{c}\text { Component RQ } \\
\text { (lbs) }\end{array}$ & $\begin{array}{c}\text { Calculated product RQ } \\
\text { (lbs) }\end{array}$ \\
\hline Acetone & $67-64-1$ & 5000 & 5399 \\
\hline
\end{tabular}

SARA 304 Extremely Hazardous Substances Reportable Quantity

This material does not contain any components with a section 304 EHS RQ.

SARA 302 Extremely Hazardous Substances Threshold Planning Quantity

This material does not contain any components with a section 302 EHS TPQ.

SARA 311/312 Hazards

Flammable (gases, aerosols, liquids, or solids)

Gases under pressure

Simple Asphyxiant

Serious eye damage or eye irritation

Aspiration hazard

Specific target organ toxicity (single or repeated exposure)

SARA 313

This material does not contain any chemical components with known CAS numbers that exceed the threshold (De Minimis) reporting levels established by SARA Title III, Section 313.

Volatile organic compounds (VOC) content

40 CFR Part 59 National VOC Emission Standard For Consumer Products, Subpart C: VOC content: $0 \% / 0 \mathrm{~g} / \mathrm{l}$

US State Regulations

Pennsylvania Right To Know

Acetone

67-64-1

Carbon dioxide

124-38-9 
SAFETY DATA SHEET

\section{ZERO VOC BRAKE \& PARTS CLEANER}

$\begin{array}{llll}\text { Version } & \text { Revision Date: } & \text { SDS Number: } & \text { Date of last issue: } 03 / 23 / 2017 \\ 6.0 & 12 / 08 / 2017 & 1395900-00002 & \text { Date of first issue: } 01 / 23 / 2010\end{array}$

California Prop. 65

This product does not contain any chemicals known to the State of California to cause cancer, birth, or any other reproductive defects.

California List of Hazardous Substances

$\begin{array}{ll}\text { Acetone } & 67-64-1 \\ \text { Carbon dioxide } & 124-38-9\end{array}$

California Permissible Exposure Limits for Chemical Contaminants

$\begin{array}{ll}\text { Acetone } & 67-64-1 \\ \text { Carbon dioxide } & 124-38-9\end{array}$

The ingredients of this product are reported in the following inventories:

TSCA : All chemical substances in this product are either listed on the TSCA Inventory or are in compliance with a TSCA Inventory exemption.

SECTION 16. OTHER INFORMATION

Further information

NFPA:

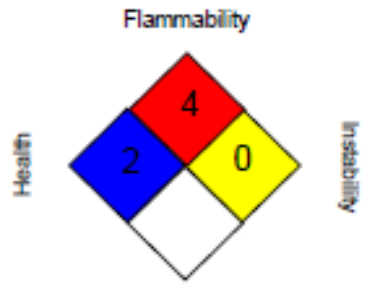

Special hazard.
HMIS\& IV:

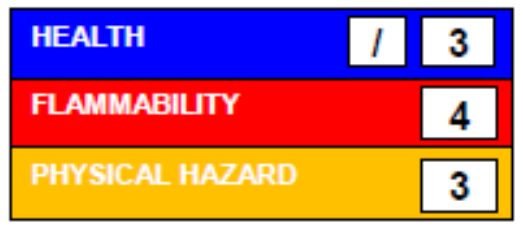

HMIS(2) ratings are based on a $0-4$ rating scale, with 0 representing minimal hazards or risks, and 4 representing significant hazards or risks. The "*" represents a chronic hazard, while the " $/ "$ represents the absence of a chronic hazard.

Full text of other abbreviations

ACGIH

ACGIH BEI

NIOSH REL

OSHA Z-1

ACGIH / TWA

$\mathrm{ACGIH} / \mathrm{STEL}$

NIOSH REL / TWA

NIOSH REL / ST

OSHA Z-1 / TWA
USA. ACGIH Threshold Limit Values (TLV)

ACGIH - Biological Exposure Indices (BEI)

USA. NIOSH Recommended Exposure Limits

USA. Occupational Exposure Limits (OSHA) - Table Z-1 Limits for Air Contaminants

8-hour, time-weighted average

Short-term exposure limit

Time-weighted average concentration for up to a 10 -hour workday during a 40-hour workweek

: STEL - 15-minute TWA exposure that should not be exceeded at any time during a workday

8-hour time weighted average 
SAFETY DATA SHEET

\section{ZERO VOC BRAKE \& PARTS CLEANER}

$\begin{array}{llll}\text { Version } & \text { Revision Date: } & \text { SDS Number: } & \text { Date of last issue: 03/23/2017 } \\ 6.0 & 12 / 08 / 2017 & 1395900-00002 & \text { Date of first issue: 01/23/2010 }\end{array}$

AICS - Australian Inventory of Chemical Substances; ASTM - American Society for the Testing of Materials; bw - Body weight; CERCLA - Comprehensive Environmental Response, Compensation, and Liability Act; CMR - Carcinogen, Mutagen or Reproductive Toxicant, DIN - Standard of the German Institute for Standardisation; DOT - Department of Transportation; DSL - Domestic Substances List (Canada); ECX - Concentration associated with $\mathrm{x} \%$ response; EHS - Extremely Hazardous Substance; ELx - Loading rate associated with $x \%$ response; EmS - Emergency Schedule; ENCS - Existing and New Chemical Substances (Japan); ErCX - Concentration associated with x\% growth rate response; ERG - Emergency Response Guide; GHS - Globally Harmonized System; GLP - Good Laboratory Practice; HMIS - Hazardous Materials Identification System; IARC International Agency for Research on Cancer, IATA - International Air Transport Association; IBC - Intemational Code for the Construction and Equipment of Ships carrying Dangerous Chemicals in Bulk; IC50 - Half maximal inhibitory concentration; ICAO - Intemational Civil Aviation Organization; IECSC - Inventory of Existing Chemical Substances in China; IMDG - International Maritime Dangerous Goods; IMO - International Maritime Organization; ISHL - Industrial Safety and Health Law (Japan); ISO - International Organisation for Standardization; $\mathrm{KECl}$ - Korea Existing Chemicals Inventory; LC50 - Lethal Concentration to $50 \%$ of a test population; LD50 - Lethal Dose to $50 \%$ of a test population (Median Lethal Dose); MARPOL - International Convention for the Prevention of Pollution from Ships; MSHA - Mine Safety and Health Administration; n.o.s. - Not Otherwise Specified; NFPA - National Fire Protection Association; NO(A)EC - No Observed (Adverse) Effect Concentration; NO(A)EL - No Observed (Adverse) Effect Level; NOELR - No Observable Effect Loading Rate; NTP - National Toxicology Program; NZloC - New Zealand Inventory of Chemicals; OECD - Organization for Economic Co-operation and Development; OPPTS - Office of Chemical Safety and Pollution Prevention; PBT - Persistent, Bioaccumulative and Toxic substance; PICCS - Philippines Inventory of Chemicals and Chemical Substances; (Q)SAR - (Quantitative) Structure Activity Relationship; RCRA - Resource Conservation and Recovery Act; REACH - Regulation (EC) No 1907/2006 of the European Parliament and of the Council conceming the Registration, Evaluation, Authorisation and Restriction of Chemicals; RQ - Reportable Quantity; SADT - Self-Accelerating Decomposition Temperature; SARA - Superfund Amendments and Reauthorization Act; SDS - Safety Data Sheet; TCSI - Taiwan Chemical Substance Inventory; TSCA - Toxic Substances Control Act (United States); UN - United Nations; UNRTDG United Nations Recommendations on the Transport of Dangerous Goods; vPvB - Very Persistent and Very Bioaccumulative

Sources of key data used to compile the Material Safety Data Sheet

Revision Date

Items where changes have been made to the previous version are highlighted in the body of this document by two vertical lines.

The information provided in this Safety Data Sheet is correct to the best of our knowledge, information and belief at the date of its publication. The information is designed only as a guidance for safe handling, use, processing, storage, transportation, disposal and release and shall not be considered a warranty or quality specification of any type. The information provided relates only to the specific material identified at the top of this SDS and may not be valid when the SDS material is used in combination with any other materials or in any process, unless specified in the text. Material users should review the information and recommendations in the specific context of their intended manner of handling, use, processing and storage, including an assessment of the appropriateness of the SDS material in the user's end product, if applicable.

US / Z8 

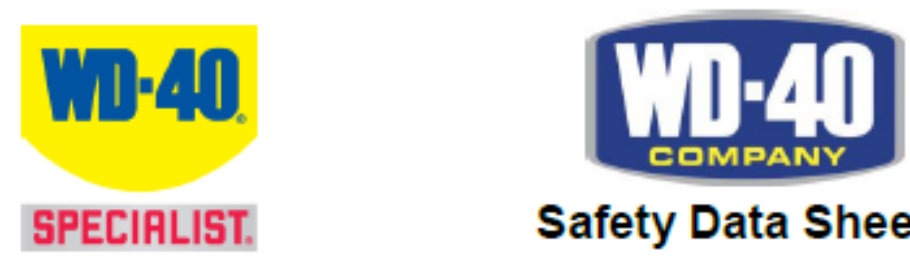

\section{Safety Data Sheet}

1 - Identification

Trade Name: WD-40 Specialist Industrial-Strength Cleaner \& Degreaser

Product Use: Degreaser

Restrictions on Use: None identified

SDS Date Of Preparation: 4/6/16

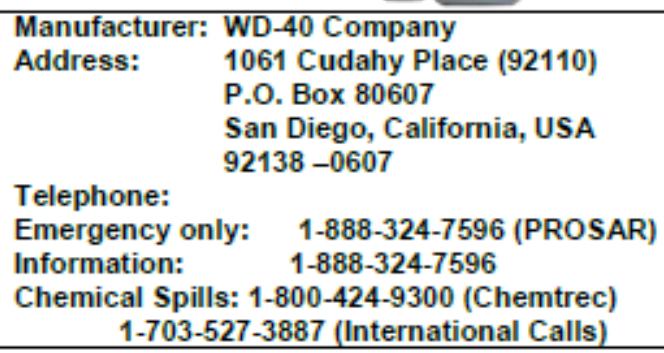
1-703-527-3887 (International Calls)

2 - Hazards Identification

Hazcom 2012/GHS Classification:

Not hazardous

Note: This product is a consumer product and is labeled in accordance with the US Consumer Product Safety Commission regulations which take precedence over OSHA Hazard Communication labeling.

Label Elements:

Not Required

3 - Composition/Information on Ingredients

\begin{tabular}{|l|c|c|c|}
\hline \multicolumn{1}{|c|}{ Ingredient } & CAS \# & Weight Percent & $\begin{array}{c}\text { US Hazcom 2012/ GHS } \\
\text { Classification }\end{array}$ \\
\hline $\begin{array}{l}\text { Water and Non-Hazardous } \\
\text { Ingredients }\end{array}$ & Mixture & $100 \%$ & Not Hazardous \\
\hline
\end{tabular}

Note: The exact percentages are a trade secret.

\section{4 - First Aid Measures}

Ingestion (Swallowed): Not toxic. Rinse out mouth and give sips of water. Do not induce vomiting. Call physician, poison control center or the WD-40 Safety Hotline at 1-888-324-7596.

Eye Contact: Flush thoroughly with water for 5 minutes then remove contact lenses if present. Continue flushing eyes for several minutes. Get medical attention if irritation persists.

Skin Contact: No first aid should be required. If irritation develops, rinse thoroughly with water. If irritation persists, get medical attention.

Inhalation (Breathing): Not toxic. If irritation develops, discontinue use and move to fresh air. Get medical attention if irritation persists.

Signs and Symptoms of Exposure: May cause mild eye irritation. May cause skin mild irritation and dryness on prolonged contact.

Indication of Immediate Medical Attention/Special Treatment Needed: Immediate medical attention is not required.

\section{5 - Fire Fighting Measures}

Suitable (and unsuitable) Extinguishing Media: This product is not flammable or combustible. Use any media that is appropriate for the surrounding fire.

Specific Hazards Arising from the Chemical: Thermal decomposition will release oxides of carbon and nitrogen.

Special Protective Equipment and Precautions for Fire-Fighters: No special precautions needed. 
6 - Accidental Release Measures

Personal Precautions, Protective Equipment and Emergency Procedures: Wear suitable protective clothing if large amounts are involved.

Methods and Materials for Containment/Cleanup: Wipe or soak up contents in an inert material. Pick up spill for recovery or disposal and place in a closed container.

7 - Handling and Storage

Precautions for Safe Handling: This product is not toxic and is not expected to cause irritation when used as directed. Avoid eye contact. Avoid prolonged contact with skin. Avoid breathing mists. Use with adequate ventilation. Keep container closed when not in use. Keep out of the reach of children

Conditions for Safe Storage: Store in a cool, dry area, away from incompatible materials.

8 - Exposure Controls/Personal Protection

\begin{tabular}{|l|l|}
\hline Chemical & Occupational Exposure Limits
\end{tabular}

Water and Non-Hazardous $\quad$ None Established

Ingredients

The Following Controls are Recommended for Normal Consumer Use of this Product Appropriate Engineering Controls: Use in a well-ventilated area.

Engineering Controls: No special controls needed.

Personal Protection:

Eye Protection: Avoid eye contact. No special protection is required for normal use.

Skin Protection: No special protection is required for normal use. For sensitive skin or prolonged use, wear rubber gloves.

Respiratory Protection: None required.

For Bulk Processing or Workplace Use the Following Controls are Recommended Engineering Controls: Use with adequate general ventilation or local exhaust to minimize exposure levels. Personal Protection:

Eye Protection: Safety glasses or goggles recommended if splashing or exposure to spray mists is possible. Skin Protection: Wear rubber gloves and protective clothing if needed to avoid prolonged skin contact. Respiratory Protection: None normally required. If exposure levels are excessive and irritation is experienced, wear an approved respirator. Selection of respiratory protection depends on the contaminant type, form and concentration. Select in accordance with OSHA 1910.134 and good Industrial Hygiene practice.

Work/Hygiene Practices: Avoid contact with the eyes. Wash hands thoroughly after use.

9 - Physical and Chemical Properties

\begin{tabular}{|l|l|l|l|}
\hline Appearance: & Clear, colorless liquid & $\begin{array}{l}\text { Flammable Limits: } \\
\text { (Solvent Portion) }\end{array}$ & None \\
\hline Odor: & Pleasant & Vapor Pressure: & Same as water \\
\hline Odor Threshold: & Not established & Vapor Density: & Same as water \\
\hline $\mathrm{pH}:$ & $\sim 11.2$ & Relative Density: & $\sim 1.0$ \\
\hline Melting/Freezing Point: & Not established & Solubilities: & $100 \%$ in water \\
\hline Boiling Point/Range: & Not determined & $\begin{array}{l}\text { Partition Coefficient; } n- \\
\text { octanol/water: }\end{array}$ & Not established \\
\hline Flash Point: & None & $\begin{array}{l}\text { Autoignition } \\
\text { Temperature: }\end{array}$ & None \\
\hline Evaporation Rate: & Not established & $\begin{array}{l}\text { Decomposition } \\
\text { Temperature: }\end{array}$ & None \\
\hline Flammability (solid, gas): & Not applicable & Viscosity: & Not determined \\
\hline VOC: & Not established & Pour Point: & Not applicable \\
\hline
\end{tabular}

Page 2 of 4 
10 - Stability and Reactivity

Reactivity: Not reactive under normal conditions

Chemical Stability: Stable

Possibility of Hazardous Reactions: None known.

Conditions to Avoid: None known.

Incompatible Materials: Strong oxidizing agents.

Hazardous Decomposition Products: Thermal decomposition may yield oxides of carbon and nitrogen.

11 - Toxicological Information

Symptoms of Overexposure:

Inhalation: No adverse effects expected from normal use. Breathing of high concentrations of spray mists may cause minor irritation to the eyes, mucous membranes of the throat and nose and upper respiratory tract.

Skin Contact: May cause mild irritation or dryness of skin on prolonged contact. No significant irnitation is expected.

Eye Contact: May cause mild irritation.

Ingestion: Not orally toxic. May cause upset stomach, nausea and diarrhea if large amount is swallowed.

Carcinogen Status: None of the components are listed as a carcinogen or suspect carcinogen by IARC,

NTP, ACGIH or OSHA.

Reproductive Toxicity: None of the components is considered a reproductive hazard.

Numerical Measures of Toxicity:

No animal testing was conducted on this product. The following data is based on assessment of the ingredients.

Product: Oral LD50 $>5000 \mathrm{mg} / \mathrm{kg}$; Dermal LD50 $>2000 \mathrm{mg} / \mathrm{kg}$ - Classification: Non-Toxic

This product was found to be non-irritating to skin and only minimally irritating to the eyes in in-vitro studies.

12 - Ecological Information

Ecotoxicity: No specific aquatic toxicity data is currently available; however components of this product are not expected to be harmful to aquatic organisms

Persistence and Degradability: This product was readily biodegradable according to OECD $301 \mathrm{~B}$.

Bioaccumulative Potential: Bioaccumulation is not expected based on an assessment of the ingredients.

Mobility in Soil: No data available.

Other Adverse Effects: None known.

13 - Disposal Considerations

Dispose in accordance with local, state and federal regulations.

14 - Transportation Information

DOT Classification: Not Regulated

IMDG Shipping Description: Not Regulated

ICAO Shipping Description: Not Regulated

NOTE: WD-40 Company does not test containers to assure that they can withstand the pressure change without leakage when transported by air. We do not recommend that our products be transported by air unless a specific review is conducted.

15 - Regulatory Information

U.S. Federal Regulations:

CERCLA 103 Reportable Quantity: This product is not subject to CERCLA reporting requirements. Many states have more stringent reporting requirements. Report spills and other releases as required under federal, state and local regulations.

SARA TITLE III:

Hazard Category For Section 311/312: Not Hazardous

Page 3 of 4 
Section 313 Toxic Chemicals: This product contains the following chemicals subject to SARA Title III Section 313 Reporting requirements: None

Section 302 Extremely Hazardous Substances (TPQ): None

EPA Toxic Substances Control Act (TSCA) Status: All of the components of this product are listed on the

TSCA inventory.

VOC Regulations: This product complies with the consumer product VOC limits of CARB, the US EPA and states adopting the OTC VOC rules.

California Safe Drinking Water and Toxic Enforcement Act (Proposition 65): This product does not contain chemicals regulated under California Proposition 65.

Canadian Environmental Protection Act: All of the ingredients are listed on the Canadian Domestic

Substances List or exempt from notification.

16 - Other Information

HMIS Hazard Rating:

Health -0 (minimal hazard), Fire Hazard -0 (minimal hazard), Physical Hazard - 0 (minimal hazard)

Revision Date: April 6, 2016

Supersedes: New SDS

Revision Summary: New SDS

Prepared by: Industrial Health \& Safety Consultants, Inc. Shelton, CT, USA

Reviewed By: I. Kowalski

Regulatory Affairs Dept.

$1031300 /$ No. 0125001

Page 4 of 4 